\title{
Journeys toward Reflective Practice: How Engaging in National Board Certification Influences Teacher Identities and Practices
}

\author{
MaryLu Hutchins
}

Follow this and additional works at: https://researchrepository.wvu.edu/etd

\section{Recommended Citation}

Hutchins, MaryLu, "Journeys toward Reflective Practice: How Engaging in National Board Certification Influences Teacher Identities and Practices" (2016). Graduate Theses, Dissertations, and Problem Reports. 5847.

https://researchrepository.wvu.edu/etd/5847

This Dissertation is protected by copyright and/or related rights. It has been brought to you by the The Research Repository @ WVU with permission from the rights-holder(s). You are free to use this Dissertation in any way that is permitted by the copyright and related rights legislation that applies to your use. For other uses you must obtain permission from the rights-holder(s) directly, unless additional rights are indicated by a Creative Commons license in the record and/ or on the work itself. This Dissertation has been accepted for inclusion in WVU Graduate Theses, Dissertations, and Problem Reports collection by an authorized administrator of The Research Repository @ WVU.

For more information, please contact researchrepository@mail.wvu.edu. 
Journeys toward Reflective Practice: How Engaging in National Board

Certification Influences Teacher Identities and Practices

\author{
MaryLu Hutchins
}

\author{
Dissertation submitted \\ to The College of Education and Human Services at \\ West Virginia University \\ in partial fulfillment of the requirements for the degree of
}

Doctor of Education in

Educational Leadership Studies

\author{
Sharon B. Hayes, Ph.D., Chair \\ Allison Swan Dagen, Ph.D. \\ Ugur Kale, Ph.D. \\ Neal Shambaugh, Ph.D. \\ Melissa Sherfinski, Ph.D. \\ Department of Education Leadership Studies \\ Morgantown, West Virginia \\ 2016
}

Key words: Reflection, Education, Standards, Teacher, Identity, Professional Learning Copyright 2016 MaryLu Hutchins 


\section{Abstract \\ Journeys toward Reflection Practice: How National Board Certification Influences Teacher Identities and Practices}

\section{MaryLu Hutchins}

The purpose of this study was to explore the lived experiences of accomplished teaching practitioners by tracing the development of the teaching expertise of participants using a narrative inquiry frame. This allowed time and space for participants to engage in making meaning of the memories of lived teaching experiences. This perspective took into account the influence of the cultures and contexts in which the teacher was situated prior to, during, and after engaging in the National Board process. The implications of the study indicated engaging in continuous reflection enabled teachers to mitigate problems by framing and reframing practices. Educators at all levels may do well to pause, reflect, and reconsider the how the structures of public school might be altered so that teachers have the spaces they need to learn to teach in ways that ensure all students, particularly those with a support system that is significantly different from the backgrounds of their teachers, are provided with an equitable education. School leaders might choose to consider how the disparate cultural history of teachers and students influences the teaching practices in their school and community context, which may diminish the likelihood of equity, access, and fairness for learning by all students. Emphasis on creating pathways for culturally diverse future educators will continue to be of concern as our knowledge of the growing diversity of our students depends on constructing understandings of their actual, not perceived, educational needs. 
Journeys toward Reflective Practice: How Engaging in National Board Certification Influences Teacher Identities and Practices

\section{Acknowledgements}

"It doesn't happen all at once...you become. It takes a long time," By Margery Williams, in The Velveteen Rabbit

It is important to thank the people who believed in you. Supportive relationships created my opportunity for genuine education and growth. I will always be deeply indebted to the time and experience of Dr. Sharon B. Hayes, whose level of expertise and responsiveness guided each moment of composing coherent thought and writing. She has been a blessing to me in this process and more importantly, to my life. Dr. Sherfinski reminded me to consider the level of access to learning we, as educators, provide to our students. Dr. Swan-Dagen moved the National Board process forward in West Virginia so that we might provide more opportunity for our students with her tireless work. Dr. Neal Shambaugh analyzed my research documentation and his insights improved my work. Dr. Kale reminded me that videotaping and subsequent "reflection on action" are potent forces for improving educational practices at every level. My committee discussed, questioned, and guided my dissertation process, and made his work possible.

Thank you to Karrie, Aaron, Lauren, John, and Lucia, my motivation for all time. Success is a journey and the next level is always possible. Your expectations kept me on track. Most importantly, Russell, thank you for being my greatest teacher. It truly has been our parents who enabled the strength we possess and which remains unwavering for the journey. 


\section{Table of Contents}

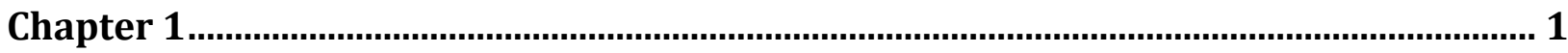

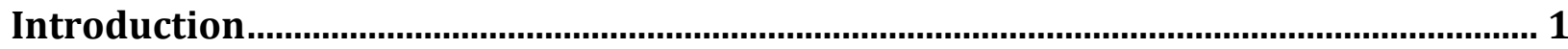

Background

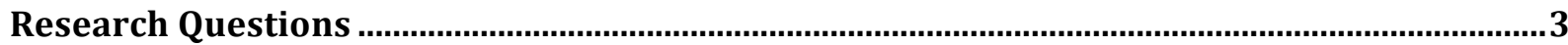

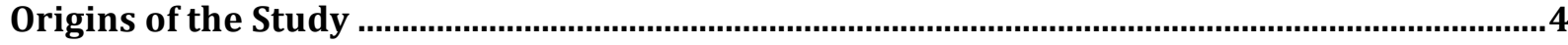

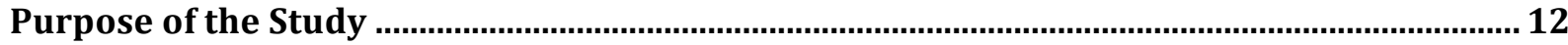

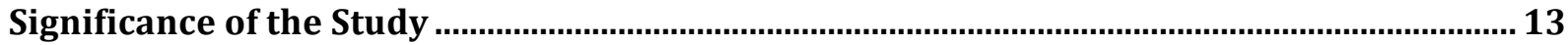

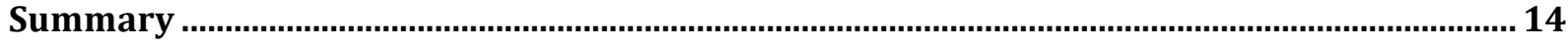

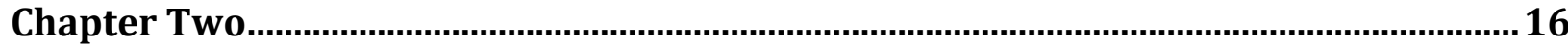

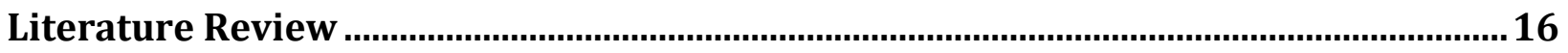

Foundations for Examination of Reflective Teaching as Practice.......................................... 16

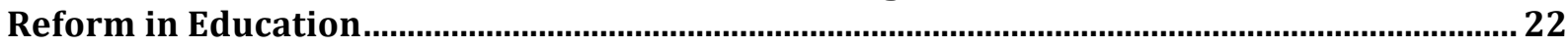

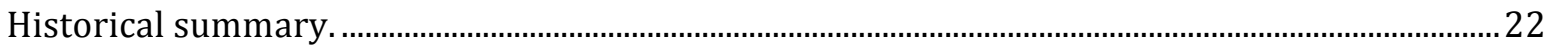

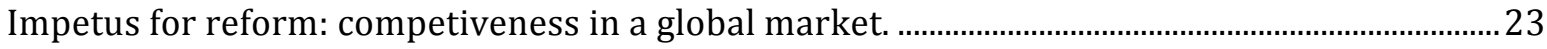

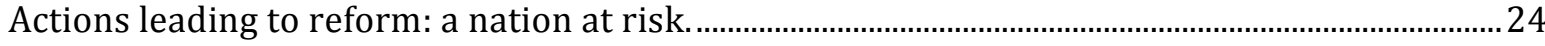

National Board for Professional Teaching Standards........................................................ 27

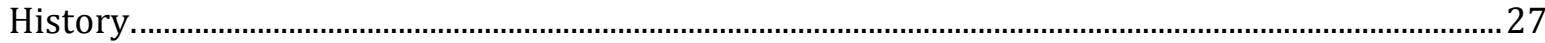

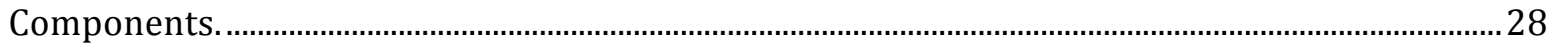

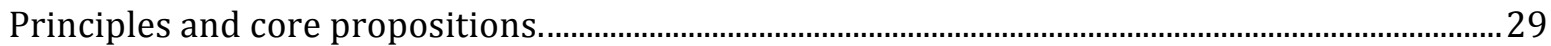

Standings of accomplished practice.

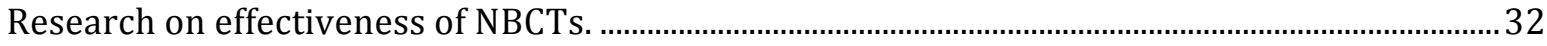

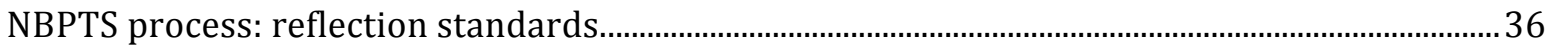

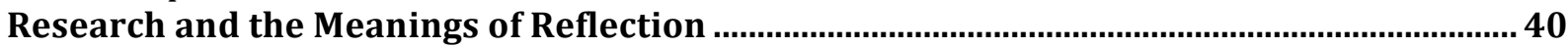

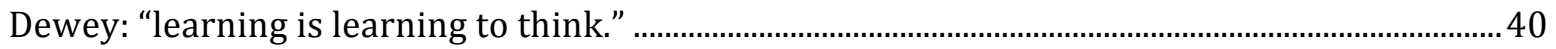

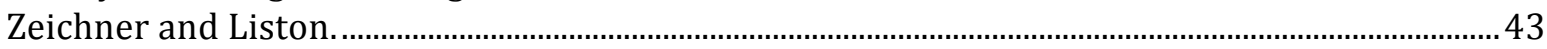

Schön: reflection on action and in action......................................................................................... 45

Etscheidt, Curran, and Sawyer: models of reflection..........................................................................50

Zeichner and Liston: five key features of reflection.

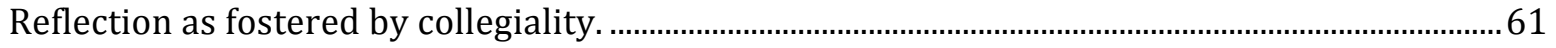

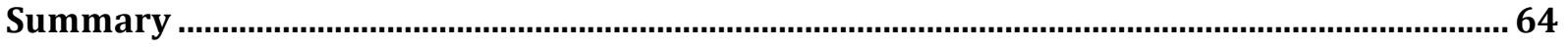

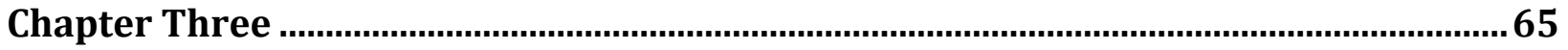

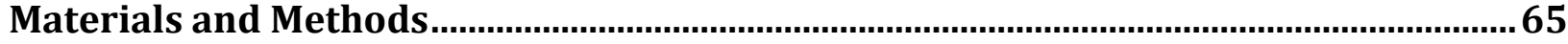

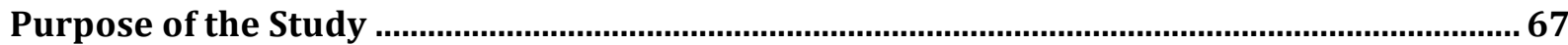

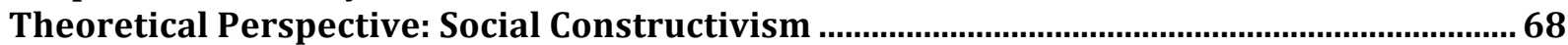

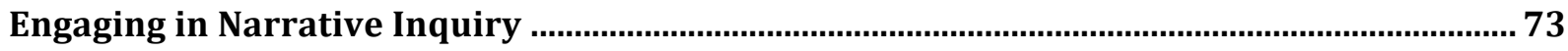

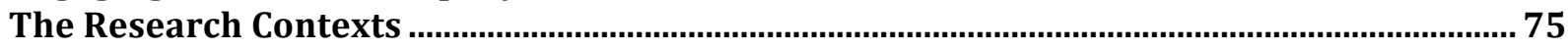

National board certification process.............................................................................................. 76

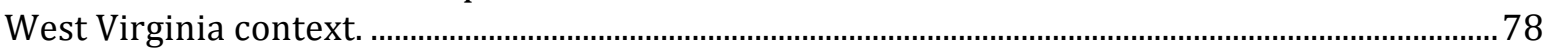

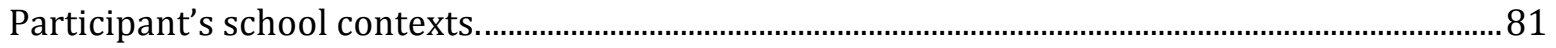


Journeys toward Reflective Practice: How Engaging in National Board Certification Influences Teacher Identities and Practices

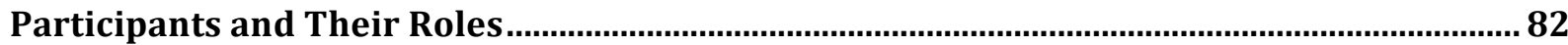

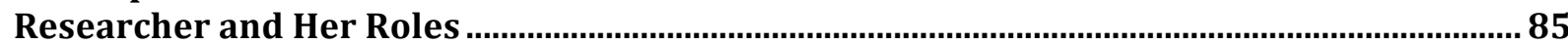



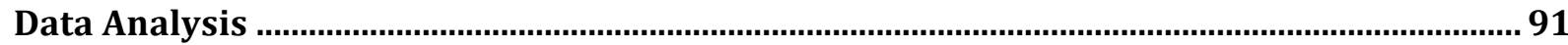

Thematic analysis.

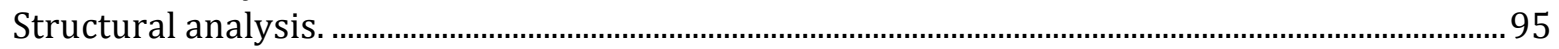



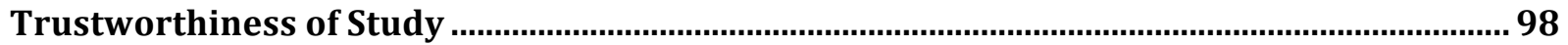

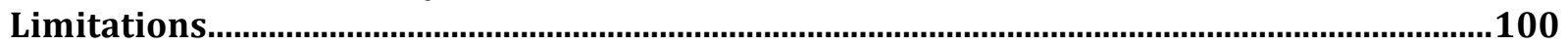

Subjectivity and positioning of principle researcher....................................................................... 101

Quality and authenticity of interactions between participants and researcher.......................... 102

The challenges of constructivist research in a constructionist environment. ............................... 103

Limitations of methods of data collection. ..................................................................................... 103

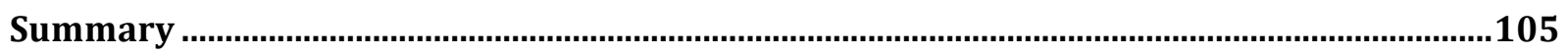

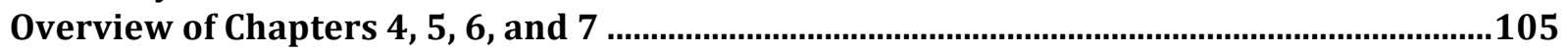

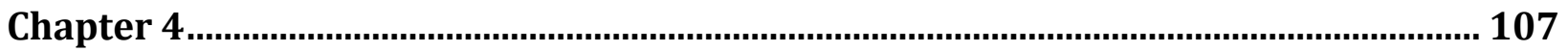

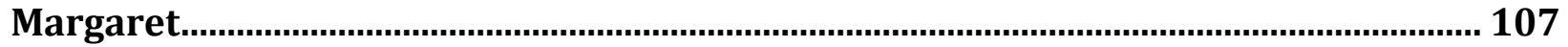

Margaret's Reflective Practices prior to National Board Work ................................................108

The influence of autobiography on reflection and the development of reflective practices.... 112

The influence of sacred stories on reflection and the development of reflective practices...... 116

The influence of isolation and collegiality on reflection and the development of reflective

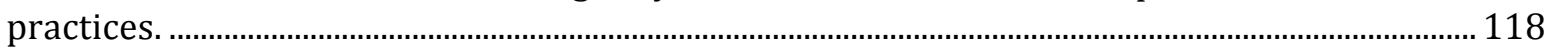

The development of independent reflective practices...................................................................... 121

The influence of context and independent reflection on the development of pedagogy content

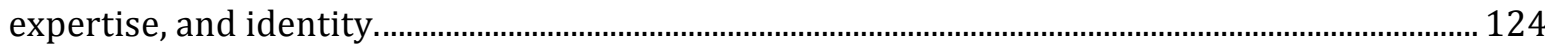

Margaret's Reflective Practices during National Board Work .................................................129

The influence of the NB process on the development of reflective practice. ...............................129

The influence of critical reflection on the development of identity and practice. .......................132

Margaret's Reflective Practices after National Board Certification .......................................141

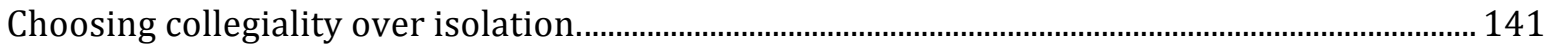

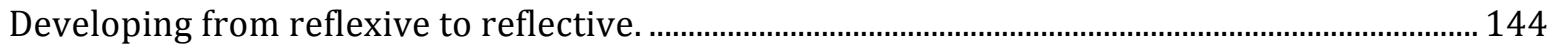

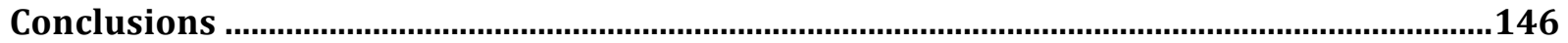

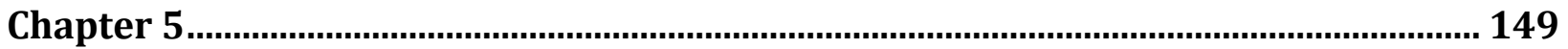

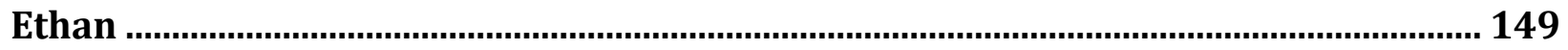

Ethan's Reflective Practices prior to National Board Work.................................................150

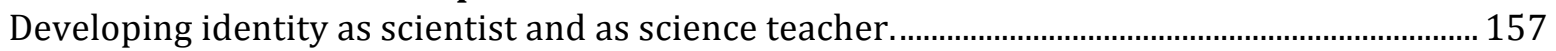

Indications of Ethan's development as a reflective practitioner. ....................................................... 165

Ethan's Reflective Practices during National Board Work

Ethan's Reflective Practices after National Board Certification ............................................181

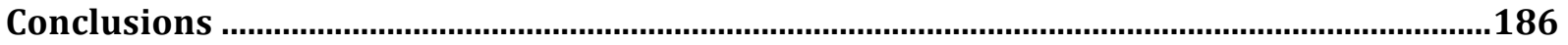

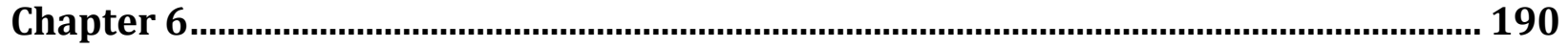



Gretchen's Reflective Practices prior to National Board Work ..............................................191

Influence of sacred stories on reflection and the development of reflective practices. .............193

The influence of isolation and collegiality on reflection and the development of reflective

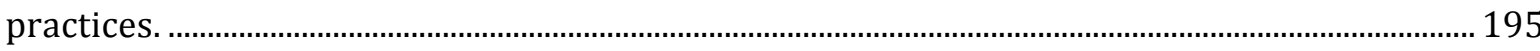


Journeys toward Reflective Practice: How Engaging in National Board Certification

Influences Teacher Identities and Practices

The development of independent reflective practices................................................................... 199

Gretchen's Reflective Practices during National Board Work .................................................202

The influence of context and independent reflection on the development of pedagogy, content

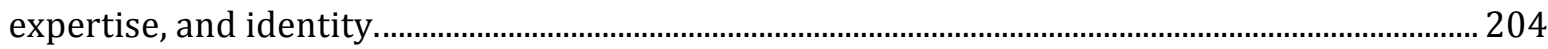

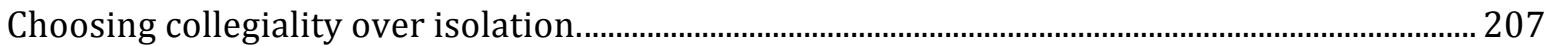

The influence of the NB process on the development of reflective practice. ................................ 209

Gretchen's Reflective Practices after National Board Certification ........................................211

Developing from reflexive to reflective. ……........................................................................... 215

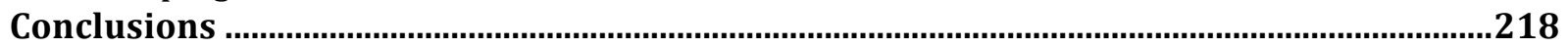

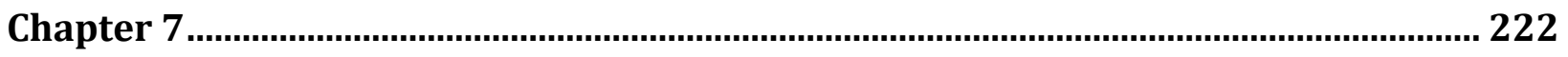

Reflections of NBCTs Initiated Via Video Experiences, Journals,............................... 222

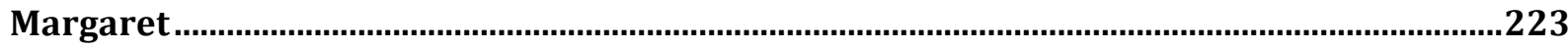

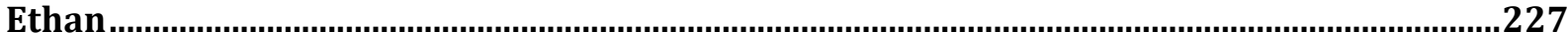

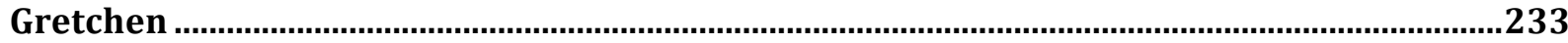

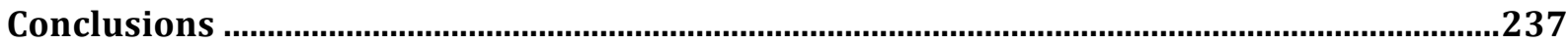

Chapter 8...................................................................................................................................... 240

Reflection on Practices and Identities prior to National Board Work .................................242

Development of Reflective Practice during the National Board Process ..............................246

The Development of Reflective Practices after the National Board Process .......................249

Present Influences of the National Board Process on the Continuous Learning Cycle.......256

Implications for School Leadership and Future Research ...................................................259

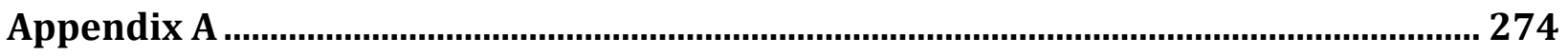

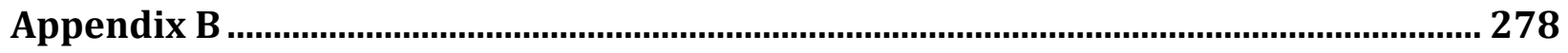

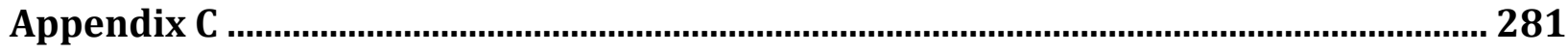

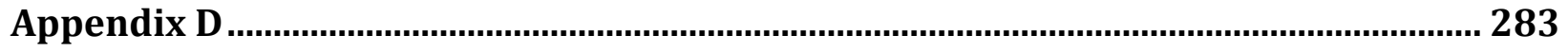



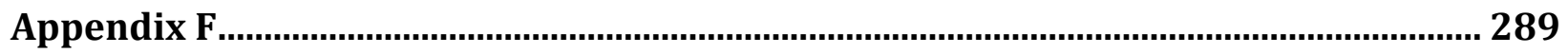

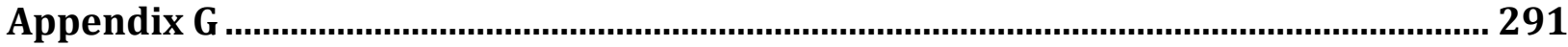


Journeys toward Reflective Practice: How Engaging in National Board Certification Influences Teacher Identities and Practices

\section{Tables}

Figure 2-1 Educator Career Continuum................................... 37

Table 2-1 Models of Reflection.............................................. 52

Table 3-1 Participant Information......................................... 88

Table 3-2 Dialogical Markings...........................................9 
Journeys toward Reflective Practice: How Engaging in National Board Certification Influences Teacher Identities and Practices

\section{Chapter 1}

\section{Introduction}

\section{Background}

This study was informed by the robust transformation of educational practice taking place across West Virginia in our classrooms, schools, administrative offices, boardrooms, and the homes of our children. Current thinking across the nation was most clearly expressed in a press release issued by Lowell Milken in 2014, "If we are to achieve the promise of education for all young people, we must focus reform efforts on the predominant human capital component in the system--talented teachers--people who are the heart and soul of education, the inspiration for the young people they teach." Therefore, if education was dependent on the professional acumen of our teachers, how do teachers learn to teach over the course of their teaching careers? The purpose of my study was to draw upon the growth mindset of teachers who engaged in professional reflective thinking as they completed the National Board Certification process. In West Virginia and across the nation, action steps for rebuilding and monitoring effective educational practices were based on renewal of the United States Department of Education Elementary and Secondary Act (ESEA). The state prepared for this mandate in 2013 with its adoption of Standards for High Quality Schools established by WVBE Policy 2322.

The American educational system, when established, held very different expectations for teaching and learning outcomes than those required and presumably measured under the former No Child Left Behind (NCLB) mandates now known as the ESEA waiver process. 
Journeys toward Reflective Practice: How Engaging in National Board Certification Influences Teacher Identities and Practices

\section{Sec.1001 Statement of Purpose}

The purpose of this title is to ensure that all children have a fair, equal, and significant opportunity to obtain a high-quality education and reach, at a minimum, proficiency on challenging State academic achievement and state academic assignments. This purpose can be accomplished by:

(1) ensuring that high-quality academic assessments, accountability systems, teacher preparation and training, curriculum, and instructional materials are aligned with challenging State academic standards so the teachers, parents, and administrators can measure progress against common expectations for student academic achievement;

This amendment excerpt presents a series of factors (assessment, accountability, teacher learning, curriculum, instruction, standards) that may have influenced how children learn. Inclusion of teachers and parents was critical because these were the social elements exerting the greatest influence and well-defined expectations on what, when and how effectively children achieved mastery of subject matter in and beyond our school walls. Education in a school setting was an intensely human interactive experience. Teachers who provided the instructional design and learning supports within our school environments shouldered the brunt of our collective enormously compelling burden in stimulating student achievement. Many of these teachers chose to share the task by engaging support from the parents of the children served in their classrooms. Shared support of student learning was integral to NCLB, however in the language of this policy, the efforts of teachers and parents occupied less stature than accountability factors measured by 
Journeys toward Reflective Practice: How Engaging in National Board Certification Influences Teacher Identities and Practices

assessment of curriculum, materials, and standards. Indeed a highly controversial outcome of NCLB led to teacher evaluations that were based, in part, on student assessment.

This overarching emphasis of NCLB on student achievement was to be measured by externally normed assessments, which were then used to scrutinize/evaluate effectiveness of teaching and learning in particular classrooms. This analysis of student data and control of the curriculum was generally completed by education personnel who had not taught in any classroom for a decade or longer. At the school and district level, responsibility for teacher professional development fell to the same administrators who handle to student data.

\section{Research Questions}

My thinking has been guided through my doctoral readings by an assembly of concerns embodied by, but not limited to: How has the American educational system, in its evolving state, served its instructional leaders by providing professional development, supports, and opportunities for teacher learning and leading? Can schools be conceptualized to maximize potential for accomplished teaching practices? Did the research about teaching and learning influence the actual design and delivery of instruction? How did teachers recognize and understand the influences of mentors, research, mandates, administrators and personal choices in the development of their professional lives? How does an educator understand and manifest the characteristics of effective teaching and learning in the instructional decision making process? Does the process of teaching help teachers learn to teach more effectively? How do teachers learn to teach in the course of their teaching careers? These questions refined my inquiry to a manageable level by taking time to research the bureaucratic structures of schools, educational leadership, and teachers as evolving reflective practitioners. The National Board for Professional 
Journeys toward Reflective Practice: How Engaging in National Board Certification Influences Teacher Identities and Practices

Teaching Standards process was considered as a strong venue for professional improvement within WVDE, so applying this template to my research was reasonable and justified.

The origins of my study were entrenched in practice, guided by the underpinnings of theory about reflection, and sought to answer purposeful research questions. These factors guided the methods used in my study as I sought to explore the lived experiences of practicing NBCTs and the following questions guided my research. My research questions both broadened and narrowed as I reached the narrative inquiry stage with teaching professionals, but throughout I asked myself these questions as I listened to each participant:

- How do teachers learn to teach over the course of their teaching careers?

- How do the contexts in which teachers are situated influence their professional development?

- How does the process of engaging in National Board Certification influence a teacher's development as a reflective practitioner?

\section{Origins of the Study}

This study explored the strategies teachers used when they engaged in reflective thinking to submit a successful National Board portfolio and if these strategies persist beyond the NB process. My thinking about teacher reflection began when I became a teacher and has continued for my 37 years as an educator, both in the classroom and currently as a countywide administrator. My first hand experiences broadened my perspective and intensified my observations of the practices evident in effective teaching. During my final 20 years in the classroom, I taught in a highly successful school designated by the United States Department of Education as a 2003 Blue Ribbon School of Excellence. When I read about the introduction of 
Journeys toward Reflective Practice: How Engaging in National Board Certification Influences Teacher Identities and Practices

NCLB in 2000, I raised the topic during a school level staff meeting and my colleagues professed no knowledge of NCLB's content or ultimate meaning to students, families, and school personnel. I later acted as instructional coach with staff in the same school and $40 \%$ of the original staff members were still teaching in the same building. When I contrasted this 2000 conversation to one held in 2014, the environment of this school as a whole and its classroom teachers' perception of teaching and of accountability had radically changed. Historically a high performing school, this site faced the changing demographic of the neighborhood over time, teacher turnover, lessening efficacy in leadership, and the pressure of extremely high expectations. Due to the requirements (mandated by the language of NCLB) that every child be measured "on grade level," focus on student achievement as measured by summative testing presented unique challenges for each teacher present in the 2014 conversation. The conversational tone vacillated between frustration with the intense level of pressure to perform and genuine interest in the information the student data provided. I too felt the angst created when students feel stressed by chronic data measures and intuit a personal need to perform at a very high standard. Induced or perceived stress over teaching and learning performance created an inability for both teachers and students to perform at their best. These teachers and students were all too aware of the penalties for failure on these assessments and they collectively spent enormous amounts of time preparing for and being assessed. Most notably, a little more than a decade earlier conversation during staff gatherings focused on student enrichment opportunities that the school might have shared across grade levels to build a cohesive school family dynamic. This type of conversation was intended to build the type of classroom environment that led to students who developed self-efficacy and possessed a willingness to take the risks necessary in inquiry based curriculum. When teachers and students conducted actual inquiry in prior years, 
Journeys toward Reflective Practice: How Engaging in National Board Certification Influences Teacher Identities and Practices

the outcomes achieved through a genuine discovery process often led to deep and sustained knowledge and skills for both teachers and their students. Currently, the conversation at my former school, was much more likely to focus on yearly learning outcomes for individual students and declining performance rates. These conversations led to decisions about interventions for certain students, which focused on short-term measures and, while admirable, were not examples of forward thinking.

Conversing with others in the educational field was an effective source for expansion of ideas and secondary knowledge as we learned from the primary experiences and the tacit knowledge base of other educators. The intellectual coaching I experienced was largely dialogue based and varied from engaging with professional liaisons in public meetings to strong personal connections with guides, coaches, mentors, and relatives. Tracing these conversations allowed me to examine the evolution of my viewpoint and the questions I pondered when considering effective teaching and expectations for outcomes with students and teachers involved.

In 1910 my grandfather began his professional life's work in his one-room school at Bald Knob when he reached age 18 in July of that year. His sole credential was successful completion of Ohio Normal School, the historically accepted mode of teacher preparation for classroom instruction. He ultimately became superintendent of schools before his retirement in 1954. According to my grandfather, the educational process was based on dissemination of information that was static in nature. Teaching and testing were delivered in a rote manner and student success or failure was determined based on the memorization effort of the student. In our conversations, there was no evidence of teacher insight that suggested individualized instructional design was a method to meet student learning preferences and abilities. In his notion of education, the teacher taught and the student learned or failed. There appeared to be a 
Journeys toward Reflective Practice: How Engaging in National Board Certification Influences Teacher Identities and Practices

stark contrast between the pedagogical practices of the one room school and the student centered learning espoused as the preferred model in the classrooms of the $21^{\text {st }}$ century. Nevertheless the one-room schools and classes of the $20^{\text {th }}$ century may have effectively prepared students for the industrial age and its demands on the American work force.

My subsequent undergraduate and graduate level class work, reading of documents, and teaching and learning experiences continually influenced my personal perception of the evolution of the work of teachers in our present public school system. My personal belief in inquiry based teaching strategies stimulated my quest for deeper knowledge of the culture of teaching as related to teacher mindset. As a graduate student, I studied the effects of education history, changes in legislation, education leadership theory and its practice, and the way these factors influenced the progression of the American education system. These combined reasons lent insights into the nature of my educational philosophy and how my thinking about teacher mindset was nurtured over time.

In August of 1979, I was situated in my first classroom and as a member of a small school community, my principal, colleagues, and the families of my students were highly focused on support of each student as a learner. While our meetings, collaboration, and conversations were effective in support of me as a fledgling teacher, the guidance provided by my principal and the time she invested in my learning about teaching had the greatest positive impact. In the instructional decision making process, I continued to reflect on and mimic the calmly perceptive influential stance she modeled, which I would now term as cyclic investigation which was entrenched in the processes of learning to observe objectively and to record evidence (not perception), attempting to reach logical conclusion, and finally questioning the same 
Journeys toward Reflective Practice: How Engaging in National Board Certification Influences Teacher Identities and Practices

conclusions with reflective thinking over time. These were the precepts that are entrenched in the National Board process.

There were many education practices I used in my classroom that I knew worked with students, yet I was unable to articulate these findings when I began the National Board process. I thought I understood how students learn under my tutelage from my experience but when I put my pen to paper to record my thinking, I grappled with its complexity. Truly I was re-engaged in inquiry learning that was personal. This struggle to communicate my thoughts gave urgency to my sense of inquiry learning and reinforced inquiry learning as a permanent, positive strategy to embed knowledge and skills. Inquiry learning based on knowledge of students and knowledge of content became my gold standard as an educator. I achieved NB certification in 2004. The same year I earned the distinction of West Virginia Science Teacher of the Year and also was named West Virginia Presidential Awardee for Excellence in Math and Science Teaching the following year. As an NBCT, I was also chosen from a pool of NBCTs and was trained for a statewide project that began in 2005 that led to my current role as West Virginia's lead facilitator for the West Virginia Center for Professional Development (CPD) Candidate Support Providers (CSP). In West Virginia, the initial phases of NB process support was largely funded by independent grantors. This led to a wide range of flexibility in program development that was not necessarily in place nationally. In 2006, I was tapped by a different local university and served as Teacher in Residence. I worked directly with pre-service candidates from freshman introductory courses through senior methods coursework and also supervised a select group of student teaching candidates. I was also selected as one of two classroom level educators to serve on former Governor Manchin's Jobs Cabinet. This commenced in 2006 and I fulfilled the NBCT advisory role until he became West Virginia State Senator in 2010. In 2007, I began my coursework in the 
Journeys toward Reflective Practice: How Engaging in National Board Certification Influences Teacher Identities and Practices

Educational Leadership program for public schools at West Virginia University. In 2008, Dr. Steven Paine requested that I serve on the newly organized West Virginia Teacher Evaluation System (WVTES) Task Force as the NBCT advisor. These learning opportunities led to a great deal of self-examination, strengthened my resolve to use inquiry based learning in my personal studies and in my classroom with my students. My voice as a classroom practitioner enabled me to promote educational best practices on many levels within West Virginia and at a national level when I was named West Virginia Teacher of the Year (WVTOY) 2009.

As a result of these opportunities and challenges, I had a voice in vital conversations, both in West Virginia and nationally, about America's future in an ever-changing technology driven world. Many of these conversations were based in redesigning educational preparation for pre-service and professional development for in-service teachers as their work assured our students' future success in the global economy. This future success was dependent on improved instructional design and required that student tasks must evolve toward much higher levels of critical thinking, communication, and proficiency in both content knowledge and skills. This profound emphasis on student mastery learning included student self-directed learning and a multi-faceted approach to the development of the child's intellectual, social, emotional, and physical wellbeing as a norm in West Virginia. Change may often be best accomplished when embraced by the local community. Local NBCTs, generally well respected in the educational community, provided teacher leadership to develop and sustain these recognized best practices at the school and system level.

Compliance with United States Department of Education initiatives led to the establishment of an entirely new and innovative system of teacher and school counselor performance in the state. These West Virginia proficiency standards were based in large part on 
Journeys toward Reflective Practice: How Engaging in National Board Certification Influences Teacher Identities and Practices

improved teacher preparedness focused on providing teachers with the knowledge and skills needed to design instruction that consistently developed student capacity and empowered participation in the global marketplace. NBPTS stated an intention for improving education outcomes through specific teacher professional development designed to develop reflection practitioners in each classroom. The West Virginia Teacher Evaluation System (WVTES) was aligned with the principles established by National Board for Professional Teaching Standards (NBPTS).

While multiple teachers served on sub-committees developed to meet the need for a broad base on influence, I served as the sole NBCT on the initial and lead body of the WVDE Task Force (approximately 40 persons) to design the revised West Virginia Teacher Evaluation System (WVTES). The language and intent of WVTES is to assist educators in developing effective practices and included implementation of formative assessment aligned with constant re-design of student learning strategies as developmentally appropriate practices. The WVTES prototype was based on teacher knowledge of content intertwined with knowledge of students. This combination led to more effective instructional design, delivery, and ongoing practical assessment of and for learning. The WVTES team was composed of representatives of West Virginia Institutions of Higher Education (IHE), WVDE Office of Professional Preparation and Office of Certification, West Virginia School Principals, the Marzano Institute, and Stanford University as we crafted and parsed the teaching standards documents. Therefore, I had first hand knowledge of the intention for defining high-level teacher competencies and a leadership mindset of those involved in this process. The final document created a process for teacher growth and describes standards for novice, emerging, accomplished and distinguished levels of 
Journeys toward Reflective Practice: How Engaging in National Board Certification Influences Teacher Identities and Practices

professional practice. In effect a teacher at the highest level in WVTES was capable of or had achieved National Board Certification.

As I began work at West Virginia University to earn my terminal degree, one of the works I studied in 2009 included The National Research Council's How People Learn, Brain, Mind, Experience, and School (Bransford et al., 2000). This thinking led me to study of National Academy of Education works by Bransford and Darling-Hammond. On a subsequent Stanford campus visit, I arranged to meet with Linda Darling-Hammond to gain first hand experience of her insights on the National Board process. Darling-Hammond asserted that reflective examination of one's practice was salient in the development of effective educational leadership in the classroom and beyond (Darling-Hammond, personal conversation, February 2010). She also stated that a piece of research as yet unstudied was "How do teachers reflect? Specifically what strategies are used by teachers to reflect?" This line of questioning continued with my doctoral chair and other professors as I completed the coursework required as a student. My study in relationship with Darling-Hammond continued and she influenced and reinforced the thinking of the WVTES Task Force as she subsequently traveled to West Virginia and led a significant body of this work as contracted by WVDE.

The thread of family encouragement cannot be overstated in my life and their collective and individual influences led to the origin of this study. In fact, in my acceptance speech as Ohio County Schools Teacher of the Year, I was well aware that recognition of a series of professional mentors seemed verbose so with care I chose to state, "I want to thank every person present here for the role each played in helping me learn in the past and your continued assistance as I learn to serve as your representative. However, if I could thank only four people, it would be my mother and my father and the parents of my husband because of their deep abiding belief that education 
Journeys toward Reflective Practice: How Engaging in National Board Certification Influences Teacher Identities and Practices

is the pathway that best serves us all." The educational support of parents was a luxury that not all students possessed. My husband held an advanced degree and currently teaches. I always considered him to be by greatest mentor. Early in his career, my husband was selected to take part as a lead facilitator in a national initiative. As lead facilitator, he shared his learning with all of the teachers in our district, and I had time to probe his thinking, strategies, and deeply specialized knowledge over many years. Furthermore, I taught two of our three now adult children in my classroom. Our parenting lives were always focused on assuring that our children were members of our local learning community and involved in the total school experience. My NB experience demonstrated for our children the utmost importance of continuing to learn over the course of one's entire life.

The fiber of mentoring and collegial relationships either reinforced my beliefs or challenged me to grow to new levels of understanding. Similar to the dilemma presented when making the acceptance speech with multiple mentors present, it was not possible to return to every conversation and acknowledge each mentor. The thread of these conversations was deeply entrenched in the questions I posed and the cognitive coaching based thinking I attempted to offer in conversation with others. I struggled with my thinking about the culture of teaching as related to teacher mindset. I sought answers that were entrenched in teacher practice and the underlying reasons that good teachers learned to effectively meet student needs in progressive learner centered classrooms, while others used less effective techniques such as reliance on tradition and textbooks to satisfy curriculum requirements rather than focusing on student needs.

\section{Purpose of the Study}


Journeys toward Reflective Practice: How Engaging in National Board Certification Influences Teacher Identities and Practices

The purpose of my study evolved based on my reading, the mentoring I received, and my collegial explorations in school system settings. The study design encouraged participating educators to ponder who they were before, during, and after the National Board process. The purpose of my study was to draw upon the growth mindset of teachers who engaged in professional reflective thinking as they engaged in and completed the National Board Certification process. As I explored the narratives constructed during the interviews with my NBC teacher participants, the specific prompts were designed to elicit reconstructive thinking related to: How do teachers learn to teach over the course of their teaching careers? How do the contexts in which teachers are situated influence their professional development? How does the process of engaging in National Board Certification influence a teacher's development as a reflective practitioner?

This study presented conclusions about how a teacher's mindset enabled professional transformation or reinforced one's original thinking about teaching. Due to the influence of my parents, my experiences with the parents of my students, and the conversations with teachers I mentored through the process, I was interested in reflection on learning in action though communications with others. Many teachers entered the process with no systematic design for their practices. For these practitioners, reflection on learning in action though communication presented a marked challenge. My questions, while initiated on a personal level, led me to think more globally.

\section{Significance of the Study}

The significance of this study was situated in how people learn, not just the teacher leaders, but also the school administration, families, and students themselves. As an educator 
Journeys toward Reflective Practice: How Engaging in National Board Certification Influences Teacher Identities and Practices

achieved advanced certification by providing evidence and documentation of the respective and potentially improved practices, the teacher's communication and interactions with the school community had the potential to positively influence the entire learning community. While this study was narrowed to the personal perspectives of its participants, reflection in action (Schön, 1983) was widely accepted as a powerful tool for improving teacher and therefore student learning. The more we knew about helping teachers master the knowledge and skills necessary for their work, the more effectively we provided appropriate supports in a meaningful process. The continuous improvement process enabled teachers to work effectively as adaptive learners using metacognitive knowledge and self-regulation (Pintrich \& de Groot, 1990). Educational decision-making involved forethought in instructional design, deep knowledge of subject matter and accurate knowledge of what one's students currently know, understand, and are able to do according to Bransford, Brown, Cocking, Donovan, \& Pellegrino (2000). These factors were then brought into play on a microscopic level during every single teacher student interaction. Teachers used all of the information available and made instructional decisions in the moment. These interactive decisions emerged in the context of teaching practice and were affected by the teacher student relationship. Additionally, the teacher student relationship was necessarily influenced by the climate of the classroom and the culture of the school as a learning community.

\section{Summary}

In summary, my life experiences as a learner, child, teacher, parent, spouse, mentor, mentee, friend, acquaintance, colleague and employee were inextricably intertwined. In the aforementioned series, learner preceded all of my other defined or undefined roles as I was highly cognizant of the learning that took place during every interaction I experienced. These 
Journeys toward Reflective Practice: How Engaging in National Board Certification Influences Teacher Identities and Practices

interactions were colored by my knowledge base and the skills I acquired within and beyond the educational frame of West Virginia and Ohio, and in our current national and international forum. I completed the NB process successfully without the benefit of a cohort and subsequently began facilitation of multiple cohorts. I developed continuing connections with many of the teachers who opted to engage in this reflective work about their own professional practice.

Research presented in Chapter 2 demonstrated findings in literature that supported the belief that the American education system evolved into a learner centered environment with support for the notion that both teachers and students were the learners. Chapter 3 described the use of a narrative methodology, a theoretical frame based on Dewey's theory of "reflection in action," and the data collection and analysis methods used in this study and the ways in which trustworthiness of the findings were established. In the closing chapter(s) I reported my findings related to inferences and patterns that emerged from the study and how these factors implied a need for further action and/or research on my part. The process of mentoring teacher professional development, especially within the NB process, offered implications in the movement toward learner centered teaching strategies.

This study was rooted in my acknowledgement that what I understand about teaching and learning has been stimulated by the students I had the privilege of serving. My curiosity about the learning processes involved was nurtured, guided, and encouraged by my mentors.

The intensive nature of reflection itself, explicitly and systematically developed during the onset of field experiences, may lead to a habit of thoughtful contemplation about teaching practices if the reflection was thoroughly reinforced by mentors who also modeled the practice. 
Journeys toward Reflective Practice: How Engaging in National Board Certification Influences Teacher Identities and Practices

\section{Chapter Two}

\section{Literature Review}

In this chapter a review of research related to the process of reflective practice combined with theory in practice in the classroom was presented. Research emphasized that reflective practice in action and on action combined with dialogue based framing of teaching contexts may be the potential triumvirate force poised to transfigure education reform (Zeichner \& Liston, 2014) at its grass roots level. Furthermore, the American movement toward building the stature of teaching to a professional standing (Schösn, 1983) was important as political and institutional voices (Carnegie Forum on Education and the Economy's Task Force on Teaching as a Profession, 1986) led to initiation of the National Board for Professional Teaching Standards (NBPTS). Political factions, institutional needs and assessments, and research findings played a role in the evolving notion of teaching and learning. In this chapter, I will map the foundations of theory and current research based teaching practices.

\section{Foundations for Examination of Reflective Teaching as Practice}

John Dewey was known for applying theory to educational practice (Zeichner \& Liston, 2014). In fact, he continued to build his theories while a teaching practitioner in the laboratory school of the University of Chicago. According to Dewey, education in the early $20^{\text {th }}$ century was in the process of evolving from traditional methodology, notions that use of subject matter and cultural heritage for content was sufficient, to progressive practices, which "exalted the learner's interest and impulse" (Dewey, 1938). This progressive learner-centered philosophy ultimately sought to balance the human-interest element against the former singular focus on content to improve the students' educational experience. Neither the traditional nor the 
Journeys toward Reflective Practice: How Engaging in National Board Certification Influences Teacher Identities and Practices

progressive approach, as a stand-alone method, was sufficient in Dewey's view. Near the close

of Dewey’s Kappa Delta Pi lecture series appears his guiding statement:

The old phrase stop and think is sound psychology. For thinking is a stoppage of the immediate manifestation of impulse until that impulse has been brought into connection with other possible tendencies of action so that a more comprehensive and coherent plan of activity is formed. Some of the other tendencies to action lend to use of eye, ear, and hand to observe objective conditions; others result in recall of what has happened in the past. Thinking is thus a postponement of immediate action, while it effects internal control of impulse through a union of observation and memory, this union being the heart of reflection. (Dewey, 1938, p. 64)

Dewey espoused that close observation was a first step in the exercise of thoughtfulness with routines and reflective action in teaching and learning and went on to posit "components" of reflection:

But observation alone is not enough. We have to understand the significance of what we see, hear, and touch. This significance consists of the consequences that will result when what is seen is acted upon...we cannot tell just what the consequences of observed conditions will be unless we go over past experiences in our mind, unless we reflect upon them by seeing what is similar in them to those now present, go on to form a judgment of what may be expected in a similar situation. The formation of purpose is then a rather complex intellectual operation. It involves (1) observation of surrounding conditions; (2) knowledge of what has happened in the past, a knowledge obtained partly by recollection and partly from the information, advice, and warning of those who have had a wider experience; and (3) judgment which puts together what is observed and recalled to see what they signify. (Dewey, 1938, pp. 68-69)

Therefore teaching, and learning about teaching, matured as the teacher as learner's capacity to recognize the historical context of personal reaction to an event improved and noted the context's influence on the interpretation of that singular personal experience. This enabled the teacher as learner to develop contemplation skills and thereby promoted the teacher's intellectual capacity in reflective discernment to transcend reactive intuition. According to Dewey, for the teacher as learner, possession of expert contemplative skills yielded the ability to improve critical thinking 
Journeys toward Reflective Practice: How Engaging in National Board Certification Influences Teacher Identities and Practices

and decision-making skills based on prior knowledge, context of learning for one's students, and the conscious use of meaningful educational practices.

According to Oner and Adadan (2011), “...reflection is ubiquitous in teacher education, literature, yet its meanings differ- which perhaps signifies the difficulties of making the construct operational" (p.148). Reflection permeated the teaching literature; therefore examination of the manner and scope of reflection manifested in practice was relevant study. Oner and Adadan examined use of Dewey's reflective foundation cited in variant resources examining effective educational practice. A summary of their findings stated the need for intertwining Dewey's precept of learner centered teaching in further research.

Zeichner and Liston (2014) defined the movement toward reflection as "embraced by teachers, teacher educators, and educational researchers all over the world" as a relatively recent movement, presented and debated as the means of effective teaching practice for no more than twenty years both in literature and in use. They go on to share five key features emphasized in reflective teaching, stating that a reflective teacher:

1. examines, frames, and attempts to solve the dilemmas of classroom practice;

2. is aware of and questions the assumptions and values he or she brings to teaching;

3. is attentive to the institutional and cultural contexts in which he or she teaches;

4. takes part in curriculum development and is involved in school change efforts; and

5. takes responsibility for his or her professional development.

Although, we think these are integral features of what it means to be a reflective teacher, not everyone agrees with us nor do all understand the implications of this view. (Zeichner \& Liston, 2014, pp. 6-7)

The significance of this viewpoint was concisely brought forth when this set of attributes is followed by “....reflection does not consist of a series of steps or procedures to be used by teachers. Rather it is a holistic way of meeting and responding to problems, a way of being a teacher" (Zeichner \& Liston 2014, p.10). This connected with, and elaborated upon, Dewey’s understandings. 
Journeys toward Reflective Practice: How Engaging in National Board Certification Influences Teacher Identities and Practices

Furthering this reasoning, Danielson (2009) stated, "Because of their ability to reflect, great teachers know not only what to do, but also why” (p. 1). Danielson cited Dewey’s assertion that effective teachers made decisions by recognizing the dilemmas inherent in teaching practice and suspended judgment on the course of action to resolve the dilemma until after a period of study of the problem itself, of potential solutions, of potential outcomes based on actions contemplated, and finally commencing action (that may continue to be adapted while taking place) as new teacher knowledge emerged. She asserted that a failure to reflect often led to imitation of the teaching practice of others, and Danielson recognized that rote observation of one's own teachers throughout the preschool to college/university experience led to a sense of "what teachers do" (p. 3) recognized as novice teaching notions and these observers had no usable knowledge of "why they do it" (p. 4) known as accomplished teaching practices. If the traditional methods comprised of novice notions of subject based learning were sufficiently effective, this continued practice would present few concerns for educators. However, it was problematic, so Danielson responded to the challenge of improving learning in school settings and proposed that teachers must develop a "disposition for reflection" (p. 7) by adopting four modes of thinking. Each mode was successively tiered; technological (pragmatic and planned based only on the curriculum needs), became situational (integrating student needs into the design of learning), advanced to deliberate (planned and executed with both pragmatic and learner needs), and finally to dialectical (discussion based with ongoing adjustments to instructional delivery based on what was revealed during instruction).

Danielson contended that educators should develop thinking patterns that lead to understanding of one's own intention based on all known information while engaged in teaching practice. This informed work of the teacher and resulted in continually improving personal 
Journeys toward Reflective Practice: How Engaging in National Board Certification Influences Teacher Identities and Practices

teaching practice culminating in the high standard of intentional teaching competence levels.

Danielson ultimately recognized that effective teachers knew which decisions should be reflexive (technological, situational) due to the lack of complexity and which decisions should be reflective (deliberate, dialectical) due to the nature of the learning dilemma. In this model, reflexive decision-making operated with a separation of curriculum demands and student needs. Reflective decision-making involved thoughtful fine tunings to delivery of content and learner skill tasks based on what the teachers perceives as important to student learning and these decisions were based on the interaction between student and teacher. Danielson went on to state that all teachers had the potential to improve reflective thinking skills and that this progress was best accomplished when "fostered with colleagues" (p.11). Her observations reinforced Dewey's notion that responding to the problems of learning were inherent to growth as a reflective teaching practitioner and interaction with colleagues fostered this development.

In How People Learn: Brain, Mind, Experience, and School, Bransford and colleagues (2000) focused on human learning embedded in neuroscience, on research about learning as affected by environmental design, and on the nurture of human potential in school environments. Critical information in How People Learn included the role of preconceptions in developing significant understanding levels, the role of inquiry to develop learning expertise, and the use of metacognitive strategies taught by teachers to students and then practiced with their students in the context of subject learning. Their research questioned traditional methods of subject-based education and concluded that implementation of innovative, research based teaching practices made it possible for the majority of public school enrollees to develop deep understanding of mathematics, science, history, and literature. 
Journeys toward Reflective Practice: How Engaging in National Board Certification Influences Teacher Identities and Practices

The study was significantly situated in how people learn through reflection in practice, marked by meta-cognitive strategies focused on the problems of professional teaching performance, therefore my research was dominated by the theme: teachers as learners (FeimanNemser, 2001). According to the Harvard Strategic Data Project, 2012, when a teacher earned accomplished status as a National Board Certified Teacher (NBCT) the documented existence of that person's reflective practice had the potential to positively influence the entire learning community. Reflection on action (Schön, 1983) was widely accepted as a powerful tool for improving teacher performance and therefore student learning. The more that was known about helping teachers with mastery of knowledge and skill with instructional design, delivery, and assessment of student learning inherent in their work, the more effectively appropriate supports were provided in a meaningful process. This was the intent of the revised West Virginia Teacher Evaluation System. Teachers, who worked effectively as adaptive learners, used metacognitive knowledge and self-regulation, and were engaged in the continuous improvement process at a personal level. Educational decision-making involved forethought in instructional design, deep knowledge of subject matter and accurate knowledge of what one's students currently know, understand, and are able to do (National Board for Professional Teaching Standards, 2000). Acumen in educational decision-making traits formed a significant portion of the basis for advanced certification and research documented teacher forethought, content knowledge, and knowledge of students as positive effects on student learning. These factors were then brought into play on a microscopic level during every single classroom teacher-student interaction. Teachers were wise to use all of the information available as they made both reflexive and reflective instructional decisions, each having a role in the classroom environment (FeimanNemser, 2001). Furthermore, Feiman-Nemser contended that these interactive decisions that 
Journeys toward Reflective Practice: How Engaging in National Board Certification Influences Teacher Identities and Practices

emerged in the context of teaching practice were deeply affected by quality of the teacherstudent relationship.

\section{Reform in Education}

\section{Historical summary.}

In the United States, teaching contexts were influenced by multiple factors, with most of these early factors noted at the local level. The high value on education as an integral element of a democratic society positioned public educators in high profile roles that evolved as educational processes faced changes over decades. The traced outline of legislation, practice and theory that influenced the progression of American education from stand alone buildings and teachers into a burgeoning bureaucracy allowed for a working understanding of the functioning of the state based educational system. In 1826, Massachusetts established a school 'committee' separate from government for service to children at a time that education was determined only a very local level. Schools were widely established to provide for basic subject instruction. The emphasis on educational outcomes was less important than the function of schools as designed to meet the needs of families, so schools were open only during non-cultivation and harvesting periods to provide families with the labor services of their children for the families' agrarian livelihood.

Instruction centered on basic skills known as the three "r" s- reading, writing, and arithmetic. Teachers were expected to assure student memorization to demonstrate their subject understandings as recitation of basic skills were accepted as evidence of learning. Students were to demonstrate subject abilities to the eighth grade level as the norm. Public schools were promulgated to "protect and improve...the republic...by molding morals, fostering 
Journeys toward Reflective Practice: How Engaging in National Board Certification Influences Teacher Identities and Practices

responsibility...teaching citizenship, spreading prosperity and ending poverty" (Wirt \& Kirst, 2005, p.32). The mission of schools was ostensibly to educate and inculcate youth with civic values to form a more capable citizenry (Kowalski, 2006). By the early 1900s, agrarian pursuits of American economy gave way to production factories, whose managers sought unquestioning American workers. Students who would eventually be employed in those positions were expected to master subject matter via rote methods and this enabled highly functional performance by workers in the single outcome narrow task production industries of the era (Hoy \& Miskel, 2005). Therefore the minimal progression of school design and moderate expectancies for teacher performance continued to serve American society in that era.

In 1947, Max Weber contributed an Open Systems theory defined as "a social system dependent on and influenced by its environment" (Hoy \& Miskel, 2005, p. 19). This merged philosophy led to the bureaucratic management structures that formed the backbone of present day schooling systems. These schooling structures were serviceable to the populace, business, and trade during the American Industrial Age when mass production, mining of American resources, and distribution of products were crucial to the United States economy. The status quo included the continuation of traditional pragmatic teacher practices until, as a nation, America became concerned about its position in what is now termed the global marketplace. This shift, brought about by a change in perspective of economic emphasis, led to a de-emphasis on the management of education at the system level and the subsequent scrutiny of the quality of the education delivery at the teacher level.

\section{Impetus for reform: competiveness in a global market.}

During and after the space race of the 1950s, the perception of American competition with Russian technology became a focal point (Garber, 2007) and consequently it was assumed 
Journeys toward Reflective Practice: How Engaging in National Board Certification Influences Teacher Identities and Practices

that the American education bureaucracy was at fault for the discrepancy. For the first time, research on the impact of teachers and their abilities as practitioners (Bybee, 1997) developed on several fronts and ultimately assumed a forefront role in American culture. According to Schön (1983):

Sputnik shocked America into increased support for science, especially basic science, and created a new sense of urgency about the building of a society based on science.

Suddenly we became aware of a national shortage of professionals - scientists and engineers, but also physicians and teachers - who were seen as necessary to the development and application of scientific knowledge. (p. 39)

As a result of studies on the economic competiveness, or lack thereof, of the students graduating from the American system of education, the National Commission on Excellence in Education was commissioned by the Carnegie Foundation to conduct research on the state of education in America.Actions leading to reform: a nation at risk.

A Nation at Risk, published in 1983 conceived the phrase "rising tide of mediocrity" referring to teacher and student educational performance that imperiled America's economic future and the standing of America in the global economy. Publication of A Nation at Risk alerted multiple stakeholders to these risks and subsequently attention was placed on development of a restructured American education system from the former rational systems top down management model (traditional) to an exemplary practice based on teacher expertise (student centered) in the classroom model.

A task force (Carnegie Forum on Education and the Economy) comprised of policy makers, educators, teachers' union leaders and business leaders convened. After three years of intensive study, this group produced a document titled $A$ Nation Prepared: Teachers for the 21st Century. The task force argued that our nation's teachers must be more highly trained, deeply 
Journeys toward Reflective Practice: How Engaging in National Board Certification Influences Teacher Identities and Practices

specialized, and supported in multiple ways in our schools to prepare students for the rigors of the 21st century. A Nation Prepared provided specific suggestions for professionalizing the teaching workforce by creating standards in teaching, which in turn would lead to measurably improved student learning outcomes. Following task force recommendations, in 1987 the National Board for Professional Teaching Standards (NBPTS) was formed.

"Common practices among highly effective teachers" (Darling-Hammond \& Bransford, 2005, p.6) were cited in Preparing Teachers for a Changing World. Gleaned from the Public Education Foundation study of 92 teachers who were identified as highly effective by virtue of three consecutive years with documented high levels of student learning gains in Hamilton County, Tennessee (Carter, 2003). While these teachers varied in many demographic and personal attributes, Darling-Hammond \& Bransford (2005) noted their exemplary seven common traits in teaching practices were:

High expectations for students were clearly stated...exemplars of previous year's work were shown to students as models of what to produce...complex and varied student work could be found (on display) everywhere...the teachers did not stand still and lecture: they covered every part of the room and monitored...multiple small group activities were found...traditional desk arrangement was virtually non-existent...students were encouraged to ask questions, discuss ideas, and comment on statements...organization and preparation of rooms was clearly evident. (p. 6)

These attributes were further explored in their findings based on the one succinct idea that prevailed in their research, "a central part of being a professional teacher is a commitment to help all students succeed" (Darling-Hammond \& Bransford, 2005, p. 6). They characterized the realization of this commitment as dependent on teacher knowledge, skills, and access to other professionals. They went on to state that their research pointed to defined conclusions about "what teachers need to know and why" (p.6). Darling-Hammond \& Bransford contended that the defined teacher traits noted in Tennessee were the similar to the traits ensconced in the National 
Journeys toward Reflective Practice: How Engaging in National Board Certification Influences Teacher Identities and Practices

Board for Professional Teaching Standards (NBPTS). NBPTS held that these principles were aligned with professional teaching associations, which included, but not limited to, the national councils/associations of teachers of English, science, social studies, technologies, and mathematics.

Key to the Darling-Hammond \& Bransford premise was the idea of professional teacher commitment that guaranteed the academic success of each and every student. This student success was enabled by the teacher's ability to analyze a single student's work and evaluate the student's unique learning progression based on the instruction designed by the teacher to meet that child's learning needs. This skill was subsequently generalized and applied to the full panoply of instructional design for every student. Darling-Hammond \& Bransford stated that accomplished professional teaching practice was characterized by reflection on the nature of individualized instruction combined with retrospective analysis of the student's learning response. Embedded standards included expectations for student performance, exemplars as models, use of student work displays that created student ownership of the environment, regular teacher-student interaction in conjunction with multiple interactive student groupings. All of these traits were orchestrated by the teacher and combined with retrospective analysis of the student's learning response. This model of reflection enabled the teacher to ensure, rather than assume, student proficiency and was the norm for every student in the professional teacher's care and service. This level of student-centered educational professionalism was considered as a direct contrast to the traditional practice of presenting information and testing the student solely to obtain grades (Darling-Hammond \& Bransford, 2005).

Schools functioning as service agencies persisted in importance in the modern era as according to Darling-Hammond and Bransford, 2005, “ ....in the United States, education must 
Journeys toward Reflective Practice: How Engaging in National Board Certification Influences Teacher Identities and Practices

continue to serve the purposes of democracy" (p. 31). In discussing these ideals for the foundations and evolution of the American public schooling systems, in Preparing Teachers for a Changing World (2005) they state:

In a democratic society, teachers must also evaluate their teaching decisions against the goals of preparing students to be equitable participants in a society that relies on interdependence. An important component of preparing students to participate in democracy is to allow them to experience democratic classroom and schools. This includes a commitment to eliminate disparities in educational opportunities among students...It also includes ambitious learning opportunities, and in today's society, equitable access to the...tools that citizens need to succeed. (p. 35)

Therefore, they maintain that teachers must think of the content taught in a context that included the social purposes of education and the function of schools.

\section{National Board for Professional Teaching Standards}

\section{History.}

Historically state level legislation outlined minimum qualifications for teacher licensure. No profession-driven standards were formerly established in education, yet these common practice professional standards were established in medicine and law. Under legislation, the state enabled the novice or continuing teaching practitioner to obtain a license to practice when each successfully followed procedures tat included a college/university degree and satisfactory completion of an examination that met minimum teaching standards for initial/continuing licensure. In contrast to novice or emergent teaching status, the concept of professional standards was developed to delineate what an accomplished teaching practitioner knows and should be able to do. However, following the recommendations set forth in A Nation At Risk, the National Board, was commissioned to define key terms outlining the quality of teacher knowledge, skills, performance, and of classroom practices. Led by strong champions including the Carnegie 
Journeys toward Reflective Practice: How Engaging in National Board Certification Influences Teacher Identities and Practices

Foundation of New York, two national teacher unions (AFT and NEA), Governor George B. Hunt of North Carolina, and the Ford Foundation, the work of initiating and building a coherent and encompassing plan for professional stature in education commenced. "The main purpose of the NBPTS is maintaining high and rigorous standards for what accomplished teachers should know and be able to do by providing a national voluntary system certifying teachers who meet these standards" (Kleinhenz \& Ingvarson, 2007, p.69).

The original 63-member National Board of Directors was formed in 1983 and its by-laws provide that it be composed of practicing teachers (66\%), legislators, governors, administrators, representatives of the major teacher unions, and teacher educators. As a governing board, NBPTS had consistent support from the highest levels of state and national government, business, teacher professional organizations, foundations and parents of students enrolled in public schools. Current teaching practitioners held a primary role in determining standards of entry and these processes were devised and specifically equated to the professions of law and medicine. In 1987, after four years of intensive work, the National Board of Directors finalized standards based definitions of accomplished teaching that were to be proven by the practitioner through reliable performance-based processes. The National Board for Professional Teaching Standards continued its work with political, institutional, business and research partners and inspired support at state and local levels in the educational system.

\section{Components.}

The certificate area principles of practice that comprise the NBPTS were developed and written by content based committees and designed to be age appropriate for students. The age distinctions included instruction specific to learner traits developmentally appropriate to students 
Journeys toward Reflective Practice: How Engaging in National Board Certification Influences Teacher Identities and Practices

sub-grouped by age as 3-8 years, 7-12 years, 11-15 years, and 14-18 years. These content committees were composed mainly of teachers who were recognized as practicing experts in their fields. They worked collaboratively with teacher educators, experts in child development, and other established professionals from the relevant certification areas. Teachers were required to submit portfolios of work in which the focus of the tasks differed from one certification field to another while the type and underlying structure of the tasks were, by metric measurement, equivalent. For example an early childhood teacher's documented evidence of practice supported student learning in all curriculum areas, while an early adolescence/English language arts teacher's portfolio specifically demonstrated pedagogical expertise with literacy skills appropriate for students aged 11-15. Crucial to the candidate's success was a demonstrated commitment to eliminate disparities in educational opportunities among students and documented evidence that supported this self-reported practice in equity, fairness, and access to learning by all students served.

\section{Principles and core propositions.}

In this evidence-based system, teacher candidates were required to provide detailed information about:

- student school and community context,

- classroom context,

- instructional design based on fairness, equity, and access to high level learning for students,

- continual efficient instructional decision making,

- redesign of planned learning sequences based on short term and long term student 
Journeys toward Reflective Practice: How Engaging in National Board Certification Influences Teacher Identities and Practices

learning outcomes in a highly iterative process.

Teacher portfolio work also involved descriptive writing about student actions, analytic writing about the processes of student learning, and ongoing reflective practice which documented the teacher's impact on student learning based on each student's actions and learning processes. The National Board candidate portfolio presented student tasks embedded in the teacher's instructional design that demonstrated evidence defined by what the students knew, understood, and were able to do. These know, understand, do student evidences must have directly resulted from opportunities for learning the teacher organized in a safe supportive culture that emphasized collaborative inquiry learning practices by students in the classroom.

While the National Board for Professional Teaching Standards (NBPTS) were written as tailored to each of the qualifying certificate areas, the underlying tenet to the distinction of holding national level certification by a teacher was based in the five core propositions published in 1989, in the document, What Teachers Should Know and Be Able to Do. These precepts formed the foundation as a fusion of commitment, knowledge, skills, dispositions, and beliefs that characterized accomplished National Board Certified Teachers (NBCTs).

- Proposition 1: Teachers are committed to students and their learning.

- Proposition 2: Teachers know the subjects they teach and how to teach those subjects to students.

- Proposition 3: Teachers are responsible for managing and monitoring student learning.

- Proposition 4: Teachers think systematically about their practice and learn from experience.

- Proposition 5: Teachers are members of learning communities. 
Journeys toward Reflective Practice: How Engaging in National Board Certification Influences Teacher Identities and Practices

The five core propositions (Retrieved April 2, 2014 from NBPTS.org) were tailored to individual content certification areas with age commensurate standards of practice. Therefore each certification area was held to standards that included knowledge of students and the candidate's ability to assure student learning based on knowledge of content, strong communication with families of students, collaboration with colleagues, instructional behaviors that reached out to the larger community and most importantly, reflective practices. The reflective practice standard was embedded into every characteristic of the portfolio design and, when the portfolio was assessed, carried the greatest point value.

This intentional collaborative effort was instrumental in building common language (emphasis added) for "state of the art practice reflected in professional standards" (DarlingHammond \& Bransford, 2005) in education and was accomplished by connecting the use of teaching standards to common performance-based assessments and resources. This connectivity was designed to build educator effectiveness and resulted in potential career ladders across the span of a teacher's career, from pre-service teachers to accomplished teacher leaders. Educators moved into the realm of professionalism due to the development of career pathways of accomplishment with meaningful teacher leadership roles both in the classroom and beyond. 
Journeys toward Reflective Practice: How Engaging in National Board Certification Influences Teacher Identities and Practices

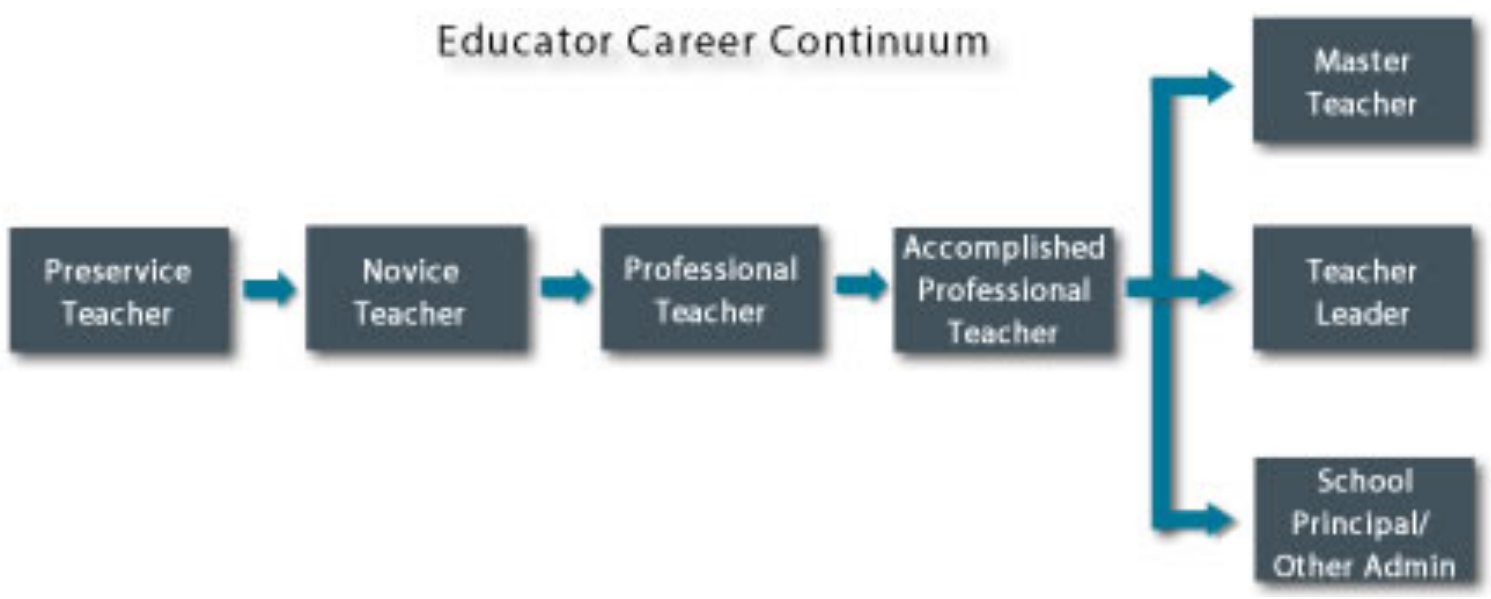

Figure 1, Retrieved April 2, 2014 from NBPTS.org

\section{Standings of accomplished practice.}

By November 2004, the NBPTS had certified approximately 40,000 teachers by assessing the portfolios of approximately 100,000 applicants (Kleinhenz \& Ingvarson, 2007). Continuing growth ensued so that by 2014 , more than 100,000 teachers earned the distinction of National Board Certified Teachers (NBCTs), as educators who taught pre-kindergarten through $12^{\text {th }}$ grade. The rate of achievement showed an approximate $40 \%$ certification rate for first year candidates and for those continuing into year two and three, just over $60 \%$ become NBCTs (National Board for Professional Teaching Standards, 2014). According to Hunzicker (2006, p.48), "The relatively low achievement rate is a stark indicator of the rigor required in order to earn National Board certification.”

\section{Research on effectiveness of NBCTs.}

Documents demonstrate the positive impact of National Board Certification on student achievement in the United States. According to Kleinhenz \& Ingvarson (2007), the NBPTS 
Journeys toward Reflective Practice: How Engaging in National Board Certification Influences Teacher Identities and Practices

certification system generated highly effective forms of school-based and collaborative professional learning and the development of a new infrastructure to support that professional learning. In West Virginia, teacher grade level collaborative team networks or professional learning communities (PLCs) were instituted in 2009 as a direct result of former State Superintendent Dr. Paine's knowledge of and belief in the power of teacher's collegial studies in support of student learning and achievement.

Darling-Hammond, Wei, Andree, Richardson, and Orphanos (2009) cited recent research that showed teachers "undertaking certification by the National Board for Professional Teaching Standards found that the experience can lead teachers to change how they teach, increase their knowledge of various approaches, and enable them to engage in more effective teaching practices" (p. 22). Research suggests that National Board Certified Teachers (NBCTs) have more positive effects on student learning than non-certified, licensed teachers. Research in North Carolina by Goldhaber \& Anthony (2004) on NBCTs presented a strong correlation between strong teacher performance on content-based initial state licensure exams and, after a minimum of three years of teaching experience, the achievement of National Board Certification. Studies noted a positive correlation between teachers' performance on content assessments and student learning outcomes (Ferguson \& Ladd, 1996; Greenwald, Hedges, \& Laine, 1996). This was not to be interpreted as a direct causal relationship between certification processes and improved student achievement as many highly qualified and effective teachers had not (yet) engaged in the process. It was a potential indicator that the skill required to achieve National Board Certification may have had the desired positive impact on student learning and achievement. This was born out by research that indicated that teacher quality had a greater impact on poor students than on high-income students (Coleman, 1990; Goldhaber \& Anthony, 2004). In a another North 
Journeys toward Reflective Practice: How Engaging in National Board Certification Influences Teacher Identities and Practices

Carolina based study, Salvador and Baxter (2010), found that NBCTs were significantly more effective than their non-National Board Certified peers in teaching Algebra II, Biology, Civics and Economics, Chemistry, and Geometry. This data was collected by measured student performance on end-of-course tests in Charlotte-Mecklenburg Schools.

In Arizona, Vandervoort, Beardsley and Berliner (2004) compared the academic performance of students in the classrooms of NBCTs with that of the students of their noncertified peers in multiple school districts. After academic gain scores were adjusted for students' documented ability, $75 \%$ of the students taught by an NBCT surpassed the performance of those in non-National Board Certified teacher classrooms by $36 \%$. Further documentation revealed that these Arizona learning gains by students were equivalent to an extra month in school.

The Harvard University Strategic Data Project (2012) noted that students of NBCTs in the Los Angeles Unified School District gained roughly the equivalent of two months of additional instruction in math and one month in English Language Arts, compared with students taught by non-National Board Certified teachers. Further studies by the same Harvard University Strategic Data Project indicated students of NBCTs outperformed students of non-National Board Certified peers with the same levels of experience in Gwinnett County, Georgia.

Students of NBCTs outperform students of non-NBCTs on specific subject area achievement tests (Clotfelter, Ladd \& Vigdor, 2007; National Research Council, 2008; Chingos \& Peterson, 2011). In terms of the democratic and equitable intentions of American public schools, this statistic should be more fully explored because according to Cavalluzzo (2004), and Goldhaber and Anthony (2007), the positive impact of having a National Board Certified Teacher was even greater for minority and low-income students.

Thirunarayanan (2004) contended that the NBPTS supported certification processes for 
Journeys toward Reflective Practice: How Engaging in National Board Certification Influences Teacher Identities and Practices

teachers are closer to entry level standards and cited that NBCTs "need only have as much content knowledge as some of the more advanced students they teach...such advanced knowledge can be obtained by achieving a doctorate in the subject area or by publishing scholarly peer reviewed articles." Thirunarayanan believed that to attain NB Certification candidates should have met and proven certain standards including: an earned doctorate, five years of teaching experience, rigorous performance on exams in their content field, and publications in scholarly journals.

Margolis (2004) issued an immediate rebuttal and cited a lack of evidence to back the claims made by Thirunarayanan. Margolis also refuted those unsupported assertions as being grounded in "culturally embedded stereotypes of teachers," were threaded with "bias," and demonstrated "elitism and condescension" (p..33). Margolis claimed that to the contrary, NB processes are one "excellent way to celebrate the hard work of accomplished teachers" and he averred that NBCTs "persevere through multiple obstacles and constraints to make their classrooms better places for students" (p. 33). Margolis had concerns with the NB process including the assessor-bias training, the assessor understandings of evidence (submitted as videotaped teaching, student work samples, teaching artifacts, correspondence with parents, and administrator verifications) and its outcomes, as well as a low initial year certification rate. Margolis contended that the "benefits of the National Board process far outweigh the drawbacks" (p. 34). The benefits resulted in better teacher practices and a higher level of “dispositions towards students" and their learning (Margolis, 2004, p. 34).

Following the theme of assessor bias, Szpara and Wylie (2005) investigated the bias reduction training provided to 42 potential NB assessors and approached this study by working with these groups at five NBPTS assessment sites. Our students are increasingly culturally 
Journeys toward Reflective Practice: How Engaging in National Board Certification Influences Teacher Identities and Practices

diverse, while our teaching force is not growing in diversity at the same rate (Howard, 2006).

Bias toward both students and teacher populations had the potential to influence scoring decisions. Additionally at its inception, NBPTS stated its fundamental purpose was achieving fairness, equity, and access in education for all students despite any disparity they faced beyond the school setting. Data was collected both before and after bias reduction training and included assessor constructed essays and trigger lists. These were coded using linguistic content analysis by two coders who worked separately. The validity of how the scoring of each candidate's submissions was completed in the NB process factored into the worthiness of certification. Szpara and Wylie concluded learning as an assessor was defined as:

Increasing awareness of bias... and of the potential effects of bias on the work of the assessors. Overall, the bias exercises appeared to produce the intended effect of increasing assessor's awareness of biases and the impact those biases could have on the scoring processes... This study provides valuable confirmation of the efficacy of the bias awareness exercises. The study also suggests...the importance of taking conscious action to minimize the impact of their biases during scoring.

The authors concluded societal bias and writing preference often exist at the sub-conscious level and recommended further NBPTS refinements in understanding how to deal with societal biases as they affect the task of scoring portfolio entries. Bias may have taken on many forms and this study sought information about the ways informed teachers used and valued knowledge of students, with regard to the prior experiences and attitudes toward learning they brought to the classroom.

\section{NBPTS process: reflection standards.}

According to Jolynn Tarwater, NBCT, and employee of the National Board as Teacher in Residence:

In the National Board process, teachers examine what is taking place in their own classrooms. The close examination and reflection are tailored to meet the learners' needs. 
Journeys toward Reflective Practice: How Engaging in National Board Certification Influences Teacher Identities and Practices

In the National Board classroom, both the teacher and the students are the learners. The compelling question is what does differentiated instruction look like at the accomplished level? This is the critical work of a candidate in a National Board Cohort (personal conversation, March 24, 2007).

Examination of reflection standards that were common to all certification areas revealed that accomplished teachers knew how to engage in systematic reflection on their teaching to develop their professional knowledge and skill while working with colleagues to benefit children's development and learning. Purposes that guided accomplished teachers' reflective routines were to improve teaching and promoted steady growth in professional knowledge and skill.

An assumption embedded in the process of creating and providing evidence of professional thinking was the practitioner's knowledge of how to engage in reflection. This repetitive query was often the obstacle that prospective candidates struggled with to gain National Board Certified Teacher designation. The opening passage of the National Board Certification Reflection Standards posed these concepts:

Accomplished teachers reflect in order to optimize the way in which their instruction supports student's development and learning, to critique the assumptions underlying their teaching practices, and to make the rationale for their teaching explicit. They also understand that reflection is a way to assess the strengths and weaknesses of their knowledge and skill. They take action in light of their reflection to improve their knowledge as well as their teaching, by delving into professional literature, engaging with colleagues, and perhaps designing classroom-based action research projects to change their teaching for the better (National Board for Professional Teaching Standards, retrieved December 3, 2014).

Following the precept that teachers must have had the tools to engage in reflective thinking are two foundational concepts. First, the teacher must have assumed personal responsibility to participate in the continuous improvement process and secondly professional collegiality was expected. Professional growth had to be personalized in much the same manner as student learning and achievement were personalized. The following National Board Reflection Standards elaborated on the continuous improvement thinking processes and type of evidence presumed to 
Journeys toward Reflective Practice: How Engaging in National Board Certification Influences Teacher Identities and Practices

be in the repertoire of the accomplished teacher, such as:

- Resist quick conclusions, choosing instead to carefully consider multiple possible interpretations

- Are willing to rethink, reinvent, and reinvestigate

- Use reflection to think through the obligations and complexities of teaching in order to gain deeper perspectives on their instruction

- Connect their observations with particular routes of action that are likely to improve opportunities for children to develop and learn

- Draw on substantial professional resources such as knowledge about students' development, pedagogical knowledge, and subject-matter knowledge

- Reflect for the purpose of improving instruction

- Have a deep appreciation of the intricacies of practice

- Know they can learn more and do more to improve components of their teaching

- Know each group of children presents unique challenges

- When successful, reflect on why it succeeded, how it might be enhanced, and determine how this knowledge can apply the lessons learned to other situations

- When less successful, reflect on ways to adjust instruction by abandoning less effective practices and seeking more promising approaches

- Use repeated and systematic engagement in reflection to hone selection and implementation of practices

- Become more skilled in the metacognitive process of reflecting

- Use reflection to develop knowledge that is deep, multifaceted, situation relevant, and connected to experience

(National Board for Professional Teaching Standards, retrieved December 3, 2014)

Learning from the working and teaching context and the beneficence of collegial

interaction was an important hallmark of reflective practitioners in every profession. Historically, the work of Dewey (1938) introduced the premise and Schön (1983) expanded on this tenet in his theories on the conflict between the continuous improvement process of education and the bureaucratization of schools when he asserted that "the teacher's isolation in her classroom works against reflection in action. She needs to communicate her private puzzles and insights, to test them against the views of her peers" (p. 333). Furthermore in support of the use of reflection to improve organizational outcomes, Schön stated, "Reflection in action is essential to the process by which individuals function as agents of significant organizational learning” (p. 338). 
Journeys toward Reflective Practice: How Engaging in National Board Certification Influences Teacher Identities and Practices

The National Board Professional Teaching Reflection Standards reiterated this thinking when combining standards of reflection, professional growth and development and collegial interaction. Accomplished teachers:

- Improve their professional knowledge by engaging with colleagues in reflection

- Ponder the obligations of teaching and seek greater access to theories, emerging practices, and promising research findings with colleagues that can help them develop their professional expertise

- Learn about new facets of familiar approaches and instructional strategies and seek approaches with which they may have limited expertise

- Know that systematic reflection not only improves their own work, but also serves as an example that can improve the work of colleagues and thus strengthen practice in the teaching profession

(National Board for Professional Teaching Standards, retrieved December 3, 2014)

In How People Learn (2000), Bransford and colleagues assured their audience that "developments in the science of learning also emphasize people taking control of their own learning. Since understanding is viewed as important, people must learn to recognize when they understand and when they needed more information" (p. 12). Nowhere was this more important than in the teaching practitioner's developing understanding of reflective processes.

In my experience as a mentor of National Board candidates, I used cognitive coaching strategies (Costa \& Garmston, 2002). Candidates, including those who planned instructional sequences and design learning environments meticulously, had difficulty remembering the approaches used during instruction. Teaching, and learning about teaching while teaching, was a true multi-tasking endeavor. Asking the right questions of candidates may have parted the pathway to reflective thinking, but it was work that the candidate must have embraced, struggled with, and eventually mastered in meta-cognitive effort. Bransford and colleagues (2000) elaborated on the concept with their assertion that the:

New science of learning is beginning to provide knowledge to significantly improve 
Journeys toward Reflective Practice: How Engaging in National Board Certification Influences Teacher Identities and Practices

people's abilities to become active learners who seek to understand complex subject matter and are better prepared to transfer what they have learned to new problems and settings. (p. 27)

Thus, the implied need for research with the concept of teacher as learner was both compelling and worthy of exploration. Therefore study of teachers in practice included their thinking about how they (the teachers) approached learning tasks, and was conducted in conjunction with how they analyzed their students' learning processes.

\section{Research and the Meanings of Reflection}

\section{Dewey: "learning is learning to think."}

The act of reflection may be regarded as consideration of ideas, subjects, and/or purposes with an emergent outcome that is a thought, idea, or opinion deeply rooted in recursive meditation. With its self-repeating function, the ideas and evolving conclusions were naturally steeped in self-questioning inquiry, testing of patterns, and redemption or renewal. Reflection, according to Dewey (1910), was a cornerstone of effective progressive teaching and educational practice.

Reflection is turning a topic over in various aspects and in various lights so that noting significant abut it shall be overlooked-almost as one might turn a stone over to see what its hidden side is like or what is covering it. Thoughtfulness means practically, the same thing as careful attention; to give our mind to a subject is to give heed to it, to take pains with it. (Dewey, 1910, p. 57)

Therefore in practice, the use of reflection did not become routinized, but continually sought deeper grasp of student learning realities as a means for improvement of teaching through adaptive knowledge, strategies, and design. Dewey returned to this dilemma of focused attention in subsequent research and continued to produce evidence that routinized tasks were less likely to influence student learning in the ways reflective practices exerted on teacher and student 
Journeys toward Reflective Practice: How Engaging in National Board Certification Influences Teacher Identities and Practices

progress.

Learning experience, according to Dewey, was an activity that meets five criteria.

Learning was based on children's interest and naturally emerges from their existing knowledge and life experiences. Learning, by necessity, supported the child's development. It helped the child develop new skills and competency. Learning built the child's understanding of the world. Ultimately, learning enriched and fulfilled existence (Mooney, 2000). Teachers made use of Dewey’s learning theory in daily teaching and learning practices.

Theory needs to be real to the developing teacher. It needs to be tested in practice and adapted to the realities of individual children in classrooms. This ongoing practice is what builds the bridge between theory and practice...practitioners want to better understand how children think and act and be more effective when working with them. (Mooney, 2000 , p. Xv)

Teaching planning and execution was based on the teacher's known or implied understanding of how children learn. Mooney (2000) reasoned that the differences between novice educators and experienced teachers in carrying out learning were often noted in the connection of the underlying theory that stimulated teacher decision-making about the instruction. John Dewey (1859-1952) was a principal spokesman of American practical thinking (Hickman \& Alexander, 1998). Dewey argued that true and valued education must "flow from the intelligent practice of teaching and learning” (Hickman \& Alexander, 1998, p.255) excerpted from Dewey’s Democracy and Education (1916). He went on and stated "there is perhaps no better definition of culture then that it is the capacity for consistently expanding the range and accuracy of one's perceptions and meanings" (Hickman \& Alexander, 1998, p. 264).

According to Darling-Hammond and colleagues (2009):

The intensity and duration of professional development offered to U.S. teachers is not at a level...necessary to have noticeable impacts on instruction and student learning....and 
Journeys toward Reflective Practice: How Engaging in National Board Certification Influences Teacher Identities and Practices

lags in providing teachers with participation in extended learning opportunities ...to guide professional learning decisions" (p. 27).

Mooney (2000) reminded educators that our current conversations about dispositions for learning, shaping experiences through well-planned environments, and many other practical conditions of teaching were issues that Dewey wrote about in his theories. Educators agreed with Dewey's theory that students "learn from doing and that education should involve real life materials and experiences and should encourage experimentation and independent thinking" (p. 4). NBPTS principles were united with Dewey's principles when teachers used reflective thoughts about their own actions. This unification forced thought concerned with the obligations and complexities of teaching and included creating environments that involved real life materials and experiences. These complexities encouraged (student) experimentation and independent thinking, and the teacher then assessed learning sequences and committed to instructional redesign as needed. The aforementioned tenets enabled teachers' work as they gained deeper perspectives on the effectiveness of their instruction. Mooney (2000) suggested that Dewey raised the expectation that "it is the teacher's job to determine the curriculum based on the knowledge of the learners and their abilities" (p. 6). He also expressed the idea that progressive education in its purest form was not in the best interest of the student. Dewey held that the path to quality education lies in knowing children well, building their school experiences on past learning, being very organized, and planning well based on documented observations of student abilities and challenges in learning. The resemblance of Dewey's theory, explained here in practice, to the standards set forth by the National Board were notable.

The one statement that all National Board candidates reiterated during the process was an expression of an uncomfortable, almost painful, sense of disequilibrium when the selfquestioning about decision-making in one's teaching practice process commenced. Dewey 
Journeys toward Reflective Practice: How Engaging in National Board Certification Influences Teacher Identities and Practices

qualified this sense in How We Think (1910), when he said, "reflective thinking is always more or less troublesome because it involves overcoming the inertia that inclines one to accept suggestions at their face value; it involves willingness to endure a condition of mental unrest or disturbance" (p. 13). The National Board process emulated this instability in practiced thought and enabled the candidate to strive for and master the elements of reflective practice. Dewey explained his view as he reminded humans to "maintain the state of doubt and carry on systematic thinking and protracted inquiry- these are the essentials of thinking” (p. 13). Furthermore, in his writing he described how thinking relied on training mental habit to "suspend conclusion" and master new methods to search for new evidence "to corroborate or refute the first suggestions that occur" (p. 13).

\section{Zeichner and Liston.}

Zeichner \& Liston (1987) explored how we learn to reflect and asserted that:

The experiences we have before we enter teaching education programs, those encountered within programs, and our subsequent work experiences as teachers provide a background of episodes and events that inform who we are and how we will think, feel, and plan as teachers. The degree to which we think about those experiences frame further events and enable us to continue to grow as thoughtful teachers constitutes, in part, our reflective understanding. (p.29)

Placed in the context of the works of Lev Vygotsky, the aforementioned Zeichner and Liston phrase (the degree to which we think about those experiences frame further events and enable us to continue to grow) referred to thought about former events that imparted a substantive background and absolutely and irrevocably influenced future thinking. Thusly, "Inner speech referred to a unique form of dialogue with oneself comprised of both speech and a distinct plane of verbal thought (which is) comprised of pure meaning" (Vygotsky, 1986, pp. 248-249). He went on to state that "inner speech" possessed characteristics such as being "subvocal and 
Journeys toward Reflective Practice: How Engaging in National Board Certification Influences Teacher Identities and Practices

generative" because it "contains thoughts in seed form", was incomplete, and highly egocentric (Vygotsky, 1986, p. 249). Inner speech did not communicate with an audience, yet when joined with efforts to communicate promoted and synthesized concept development. Knowledge that once was "felt" tacitly became explicit by established thought bonds joined to conceptual relationships. In fact, Vygotsky went on to declare, "concepts are formed through first-hand personal connections in creating meaning" (Lake, 2012, p. 90). Lake then connected this theory to Bruner's spiral notions of learning as, under perfect conditions, this spiraling growth metaphor described how the teacher/learner "will continue to move to higher levels of thought...moving upward in the developmental process of consciousness" (Lake, 2012, p. 91).

Vygotsky's theory (1986) had the effect of being manifest as habit for the reflective teaching practitioner as delineated in the following:

The relationship of thought to word is not a thing but a process, a movement from thought to word and from word to thought...Thought is not expressed but completed in the word. We can, therefore, speak of the establishment (i.e., the unity of being and nonbeing) of thought in the word... The structure of speech is not simply a mirror image of the structure of thought. It cannot, therefore, be placed on thought like clothes off a rack. Speech does not merely serve as an expression of developed thought. Thought is restructured as it is transformed into speech. It is not expressed but completed in the word. (pp. 250-251)

Successful completion of the rigor of the National Board process resulted when the candidate transformed his or her mindset from tacit knowledge, or inner speech, to explicit reflective communication via written expression of: the instructional design created, its implementation, and the subsequent active reframing of the problems inherent in serving the educational needs of their students. The candidate's teaching practices were subjected to intensive self-analysis and also presumably were analyzed when available ethical mentors served in the role of coach and sounding board. 
Journeys toward Reflective Practice: How Engaging in National Board Certification Influences Teacher Identities and Practices

Vygotsky (1986) maintains that "inner speech is the sum and substance of personal identity" (p. 252) and therefore with personal decision-making. Lake (2012) wrote about Vygotsky's formation of inner speech as he stated “...the process is summarized by social communication leading inner speech and concept formation, followed by external expression in shared meanings" (p. 78). Lake expanded on the notion when he said, "the heart of Vygotsky's emphasis on...inner speech leading to internalized connections that finds articulation (emphasis added) through...all forms of outward communication" (p.79). In theory, the mentor and NB candidate relationship instigated the articulation of the candidate's thought at the same time as the iterative NB writing process strengthened the ability to frame, reframe and reflect effectively. According to Whitaker (2012), the work of teachers was dependent on personal knowledge and philosophy and this was expressed through candidate writings, which in turn, guided thinking about teaching practice. Whitaker (2012) also said, "for great teachers...in the end, the difference lies in the core beliefs and understandings that guide their work" (p.78). Understanding as a teacher as learner appeared to develop during the process when the candidate successfully achieved the distinction of National Board Certification.

\section{Schön: reflection on action and in action.}

Schön (1983) stated at the outset, "I begin with the assumption that competent practitioners usually know more than they can say. They exhibit a kind of knowing-in-practice, most of which is tacit" (p. viii). Then he examined the process of knowledge acquisition and demonstrated construction of and tested "models of knowing." His research averred that practitioners “....reveal a capacity for reflection on their intuitive knowing in the midst of action and sometimes use this capacity to cope with the unique, uncertain, and conflicted situations of practice" (pp.viii, viiii). Schön noted that individuals in a bureaucratic system generally operated 
Journeys toward Reflective Practice: How Engaging in National Board Certification Influences Teacher Identities and Practices

within the accepted behavioral norms of the system. The organization systems tended to be social which in turn "determine(s) the boundaries and directions of organizational inquiry, they are learning systems... (and) may severely constrain organizational learning” (p. 328). This was highly relevant to the practice of education on both large and small scale as the educational organization itself resisted the advancing notions of improved teaching practice of the few, the innovators.

Schön described the school setting as an institution of "technical rationality" with "bureaucratic efficiency." He postulated that a single practitioner using "reflection in action poses a potential threat to the dynamically conservative system” (p. 332).

School is built, in a very special sense, around a theory of knowledge. There is a concept of privileged knowledge which is the business of teachers to teach, and students to learn...Teachers are seen as technical experts who impart privileged knowledge to students... The efficient transmission of knowledge requires a system of controls. The teacher is supposed to convey standard units of knowledge to large number of students and must employ measures, in the form of quizzes and examinations, in order to determine what students have learned or failed to learn ... Students are rewarded for their ability to digest the appropriate knowledge and skill, and they are punished for their failure to do so...Teachers are also subject to a similar system of controls...monitored, and rewarded or punished, according to the measures of their students' progress. (p. 330)

To the reflective practitioner, "each student makes up a universe of one" (p. 331) because each student presented a different set of life experiences, knowledge, and skills sets and was to be taught at his/her instructional level. Teacher reflection in action guarded intellectual freedom and had the potential, according to Schön to "disrupt the institutional order of space and time" (p.

333). When an organization:

Seeks to accommodate reflection in action of its professional members, it must...place a high priority on flexible procedures, differentiated responses, qualitative appreciation of complex processes, and decentralized responsibility for judgment and action. In contrast to the normal bureaucratic emphasis on technical rationality, a reflective institution must make a place for attention to conflicting value and purposes...extraordinary conditions are also necessary for organizational learning. (p. 338) 
Journeys toward Reflective Practice: How Engaging in National Board Certification Influences Teacher Identities and Practices

When an individual teacher undertook completion of the National Board process, a level of disruption to the school environment may have existed. At the micro level, the teacher questioned his or her teaching practices and this conversation may have extended to collegial partners, and the process required created documentation of working in collaboration with colleagues. Amelioration of this potential for discord by some degree, was undertaken when a National Board Cohort and its mentor(s) supported the teacher during the self-examination and encouraged professional response patterns during what may have been a cyclical periods of frustration experienced by the candidate.

The mentor assumed a very important role in the initial phases of developing the tool kit of the reflection practitioner. The use of Schön's model of reflection on action took place when the candidate and mentor focused on recent lessons taught and the difficulties encountered when the teacher made the attempt to engage students in learning. The difficulty was placed in a frame for dissection as the beginning of troublesome learning or non-learning behaviors were noted, characteristics of the difficulty were recorded, and possible solutions were discussed. During the NB process, the mentor and candidate explored and noted the contextual pieces of the setting and searched for the causes of single student's or the group's struggle with a concept, the candidate was encouraged to pose potential reteach variation strategies based on this increased depth of thought. The candidate then went back to the classroom with the same student(s) and taught once again. During the very next interaction with each student, the candidate was expected to implement the chosen solution(s) and reflect in action by providing just in time instruction that bridged the gap between student knowledge or skill level and the very next step required toward the developing concept and/or student aptitude being 
Journeys toward Reflective Practice: How Engaging in National Board Certification Influences Teacher Identities and Practices

approached. Key to reflection in action was being able to break down the learning sequence, a technical concept, and the knowingly chosen option of use of the most effective strategy known for the particular student in the situation, an accomplished teacher trait.

According to Zeichner and Liston (2014):

In addition to the knowledge-in-action that teachers accumulate over time, teachers also continually create knowledge as they think about their teaching and as they teach...(we) recognize that teachers continually theorize and reframe their work in an attempt to understand their students and their learning. (pp. 16-17)

Restructuring classroom experiences spiraled through various phases identified by Schön (1983) as "appreciation, action, and reappreciation" (p.132). Appreciation was evident when the practitioner recognized and attempted to isolate the unique factors in the dilemma faced. A question pertinent to the problem was posed in the attempt to lead the learner to explore the situation from a new perspective (frame). The practitioner had to appreciate the phenomena, then reframe it and take an action though interaction with the learner. In close observation of one's own action, and the reaction of the learner, the practitioner became expert in looking for the appropriate learning consequences as well as unintended consequences of the action. "The unique and uncertain situation comes to be understood through the attempt to change it, and changed (emphasis added) by the attempt to understand it" (p.132), asserted Schön (1983). He went on to question the rigor in "on the spot experiments" and convincingly suggested that trustworthy inquiry structures were developed "by reflection on the actual practice of experienced, competent practitioners who reflect-in-action" (p.133).

Schön explored the use of past experience in application to the new and unique situation extensively. "It is in relation to the unique features of his problematic situation that each practitioner undertakes the problem-setting experiment...this is puzzling...How can an inquirer use what he already knows in a situation which he takes to be unique?" (pp.132-133). The way 
Journeys toward Reflective Practice: How Engaging in National Board Certification Influences Teacher Identities and Practices

of knowing became a solution set, also known as the teacher's tool kit, of strategies for interventions tailored to the student's ability and/or capacity for intellectual growth at the specific moment in time.

Schön (1987) stated that learning to reframe teaching via reflective practice gave central importance to the work of teacher as learner, rather than that of privileged knowledge holder. This concurred with his perception "that the most important things cannot be taught but must be discovered and appropriated for oneself” (p.92). Schön outlined the following example as a model for practice of reflection in action:

The clarification of intended meanings and the discovery and resolution between the instructor's intentions and the student's understandings are best achieved through action...it is when students try to act on what they have seen or heard that they are likely to reveal, to themselves and to their coaches, both prior knowledge they bring... and the understandings of misunderstandings they have construed. (p.161)

Schön, a strong proponent of thinking deeply and constantly about the teaching learning process, was an influential primary source of professional philosophy and elaborated on the practice of reflection in action and reflection on action (Grushka, Hinde-McLoed, \& Reynolds, 2005; Pitsoe \& Maila, 2012; Scales, 2013; Seban, 2009; Zeichner \& Liston, 1987). Researchers elaborated on Schön's work and used his ideas as he "embraced the notion of reflective practice and have helped us see more clearly how it can operate in our daily work lives" (Zeichner and Liston, 2014, p.15).

Subsequent research furthered Schon's thinking and was expressed in the writings of

Reagan, Case, \& Brubacher (2000), as they noted:

The reflective educator is first and foremost a decision maker who must make decisions consciously and rationally. Further, the reflective teacher must base his or her decisions on a solid body of content, including both technical and content knowledge, which are organized and reinterpreted according to the teacher's unique experiences. The reflective teacher must also demonstrate both ethical behavior and sensitivity, as well as sociocultural awareness...Finally, it is important to note that reflective practice involves 
Journeys toward Reflective Practice: How Engaging in National Board Certification Influences Teacher Identities and Practices

what the teacher does before entering the classroom, while in the classroom, and retrospectively after leaving the classroom...Reflective practice allows teachers to act in a deliberate, intentional manner... distinguishes teachers as educated human beings because it is one hallmark of intelligent action. (pp. 25-26)

They elucidated their thinking further with the idea that teachers improved their practices and became "better, more proficient, and more thoughtful professionals" (p.26) with increased selfawareness cultivated with the process of becoming reflective practitioners who make mindful rational decisions based on a firm and justifiable educational knowledge base.

\section{Etscheidt, Curran, and Sawyer: models of reflection.}

Dewey's 1933 notion of reflective deliberation to hold thinking on course in continuous improvement influenced theorists and practitioners since its inception (Etschidt, Curran, \& Sawyer, 2011). They cited Shulman (1987), who advocated for use of reflective strategy at an introductory level in the education of pre-service teachers. A history of thinking by researchers about reflective practice exemplified the models used, principles of design, and processes of deliberation that withstood the tests of practice in various situations and for fluctuating teacheras-learner needs. Etschidt, Curran, and Sawyer (2011) contended that reflective opportunities must be promoted and provided early and continually in work with pre-service teachers as an ethical component of teacher preparation programs. The intensive nature of reflection itself, explicitly and systematically developed during the onset of field experiences, was expected to lead to a habit of thoughtful contemplation about teaching practices if the reflection was thoroughly reinforced by mentors who also modeled the practice. They continued this thinking as they examined multiple strategies used to inculcate reflective thinking with pre-service teachers as the trainees began fieldwork, including but not limited to, lesson study using video based lesson analysis and journal writing. Scripted interactions were viewed and recorded from the 
Journeys toward Reflective Practice: How Engaging in National Board Certification Influences Teacher Identities and Practices

video segment that led to recursive thinking about how each statement made by the student and the teacher in turn chose the next scaffold provided to deepen or enhance the learning process for the student.

Models of reflective thinking demonstrated both common qualities and divergent strengths. Many models of reflection were built on prior research presented and provided guidance for teacher preparation programs; teachers in practice, researchers, and school system based professional development models. Table 2.1. (Etscheidt, Curran, \& Sawyer, 2011, pp. 1011) yielded a common thread that, while not hierarchical, tended to demonstrate deepening of thought processes and greater complexity for teachers. 
Journeys toward Reflective Practice: How Engaging in National Board Certification Influences Teacher Identities and Practices

Table 2.1 Models of Reflection

Source

Description of reflective model, element, or process $\begin{array}{ll}\text { Van Manen (1977) } & \begin{array}{l}\text { Level 1 - Technical: Addressing the application of specific skills and } \\ \text { pedagogy in the classroom considering alternative actions and strategies }\end{array}\end{array}$ Level 2 - Practical: Interpreting the value of specific teaching practices for independent, individual teaching decisions Level 3 - Critical: Examining the influence of structural and societal constraints and how personal values may conflict with those constraints

Van Manen (1991)

Anticipatory reflection: Examining teaching actions through an organized and deliberate selection of teaching action Active or interactive reflection: Using reflection to support an informed on-the-spot decision

Recollective reflection: Using past experiences to gain insight into teaching Mindfulness: Engaging in continuous sensitivity to dynamic aspects of teaching

Schon $(1983,1987)$

Reflection in action: Developing an awareness of decisions in practice Reflection on action: Developing an interpretive critique of practice

Grimmet, Mackinnon, Erickson, \& Rieken (1990)

Technical mode: Enabling teachers to determine how to meet professional standards

Deliberative mode: Guiding teachers' consideration of competing or diverse views of teaching

Valli, (1990)

Technical reflection: Applying to reflection to specific teaching practices Reflection on action: Evaluating a teaching performance Deliberative reflection: Appraising individual development

Critical reflection: Considering social and political influences on teaching practice

Gore \& Zeichner (1991)

Academic: Focusing on subject matter knowledge to promote student understanding Social efficiency: Emphasizing application of evidence-based teaching strategies

Developmental: Prioritizing teaching practices sensitive to individual student interests and preferences

Social Reconstructionist: Stressing the social and political context of schooling 
Journeys toward Reflective Practice: How Engaging in National Board Certification Influences Teacher Identities and Practices

Table 2.1 Models of Reflection (continued)

Source

Description of reflective model, element, or process

Sparks-Langer

Colton (1991)

Pultorak (1996)

Wellington \&

Austin (1996)

Stanley (1998)
Cognitive element: Constructing knowledge to make effective decisions about classroom situations

Critical element: Addressing personal experiences, beliefs, sociopolitical values, and goals

Teacher narratives: Interpreting contexts and developing rationale for decision-making

Technical rationality: Focusing on teacher competency and effectiveness

Subjective reflection: Revealing personal bias and values based on personal perceptions

Critical reflection: Considering the values of knowledge and moral or ethical dimensions of schooling

Immediate orientation: Addressing the immediate, situational demands related to teaching and learning

Technical orientation: Developing and refining instructional methodologies

Deliberative orientation: Emphasizing discovery, assignment, and personal meaning of educational practices

Dialectic orientation: Questioning, revising, and validating educational practices and beliefs

Transpersonal orientation: Sustaining self-development, personal responsibility, experience, and decision-making

Engaging with reflection: Engaging a committed process of reflection with consideration of the personal and contextual factors influencing the process

Thinking reflectively: Learning to think reflectively through guided scaffolds and questions

Using reflection: Using reflection as a tool to examine actions and beliefs, which benefit professional and personal practices

Sustaining reflection: Maintaining committed reflection practice in workable formats for improved understanding Practicing reflection: Using reflection as an integral part of practice and developing an analytic personal framework of multiple lenses to examine classroom, school and societal practices, and influences 
Journeys toward Reflective Practice: How Engaging in National Board Certification Influences Teacher Identities and Practices

Table 2.1 Models of Reflection (continued)

Source

Description of reflective model, element, or process

$\begin{array}{ll}\text { Jay \& Johnson } & \text { Descriptive: Examining personal classroom actions } \\ \text { (2002) } & \text { Comparative: Inviting alternative views, perspectives, and research } \\ & \text { Critical: Posing questions pertaining to pubic democratic purposes of } \\ & \text { schooling and the moral and political dimensions of schooling }\end{array}$

Ward \& McCotter (2004)

Routine reflection: Investigating the impact of practice or experience on the pre-service teacher with little inquiry or persona response Technical reflection: Examining specific teaching tasks. Inquiry guided by questions about specific teaching situations

Dialogic reflection: Reflecting on student outcomes with consideration of divergent perspectives

Transformative reflection: Revealing fundamental pedagogical, ethical, moral, cultural, or historical concerns leading to changes in practice

From "Promoting Reflection in Teacher Preparation Programs: A Multi-Level Model" by S. Etscheidt, C. Curran, and C. Sawyer, 2011, Teacher Education and Special Education: The Journal of the Teacher Education Division of the Council for Exceptional Children Volume 35, pp. 10-11, Copyright (2012) Sage. Reprinted with permission.

As Darling-Hammond (personal conversation, February 2010), asserted, reflective examination of one's practice was an effective tool in establishment of educational leadership in the classroom and beyond. Her subsequent questions about research as yet unstudied included, "How do teachers reflect? Specifically what strategies are used by teachers to reflect?" The practices of reflection outlined from 1977 through 2004 on Table 1 (Etscheidt, Curran, \& Sawyer, 2011) were explicit expectations in the learner-centered classroom of the future shaped by the Stanford Teacher Education program at the Center for Educational Research at Stanford (CERAS).

Etscheidt, Curran, and Sawyer's article promoted videotaping and repeated viewing with journal analysis of the script gleaned from the video segment and this practice was a central component of portfolio work in the National Board process. These may be considered effective 
Journeys toward Reflective Practice: How Engaging in National Board Certification Influences Teacher Identities and Practices

tools of reflection. The National Board process maintained that study of teacher-student, studentstudent, and student-teacher discourse led to increased teacher knowledge about student thought processes and was simultaneous to the student acquiring deeper content knowledge and/or learning skills. By promulgating these practices with teachers, the connection of theory to practice was affirmed. Etscheidt, Curran, and Sawyer (2011) concluded as they stated, “As reflectivity is a cornerstone for effective instructional decision making and advocacy... teacher(s)...should deliberately incorporate these practices" (p. 21).

All of the models on Table 2.1 examined the upheld appropriate modes and levels of reflection ranging from routine in technical use with an content focus to significantly transformative in the self-sustaining models of examination based on values, sensitivity to student needs, and attention to the essential outcomes of education. Yet, the models of Schön (1983, 1987) and Gore and Zeichner (1991) were most closely aligned with the NBPTS reflective standards and were the subject of further examination in my research.

\section{Zeichner and Liston: five key features of reflection.}

Advancing the notion of reflection as critical to the education and to instructional practices as implemented, Zeichner and Liston (2014) posited that:

Reflection ... signifies a recognition that the generation of new knowledge about teaching is not the excusive property of colleges, universities and research and development centers...teachers have ideas, beliefs, and theories, too, that contribute to the betterment of teaching. (p. 5)

Their research indicates that effective teachers ask themselves how to solve problems that constantly arise in the classroom. According to Zeichner and Liston (2014):

During the last two decades, the slogan of reflective teaching has been embraced by teachers, teacher educators, and educational researchers all over the world. This international movement in teaching and teacher education has developed under the banner of reflection can be seen as a reaction against the view of teachers as technicians 
Journeys toward Reflective Practice: How Engaging in National Board Certification Influences Teacher Identities and Practices

who narrowly construe the nature of problems confronting them and merely carry out what others, removed from the classroom, want them to do. (p. 4)

Their theories continued in this vein as they recognized that wisdom was often derived from one's own teaching based in reflective practice; that was based on concurrently examining what was effective and less than effective and promoted and nourished student learning while performing the act of teaching. Therefore exemplary teacher expertise did not result solely from examining the research and experience of others.

An existing level of contrast was noted between the view that teachers may gain significant knowledge derived from the act of teaching and thinking deeply about the actions of the classroom as learning generative and the opposing view of reforming the teaching profession via “top down" professional development. Zeichner and Liston (2014) noted a "general lack of respect for the craft knowledge of teachers in the educational research establishment" (p.5). Professional development for educators was generally executed in the bureaucratic model and delivered by "experts" who were often supervisors, researchers, or businesses dedicated to the instruction of teachers and hired to deliver teacher trainings. They cited the research on school reform as connected to No Child Left Behind legislation and the subsequent teacher training as externally driven. In contrast to these professional development models, Zeichner and Liston gave credence to the notion that "teachers...bring a perspective to understanding the complexities of teaching that cannot be matched by external researchers" (p. 7). Zeichner \& Liston's studies were published in Reflective Teaching, An Introduction (2014, p. 6-7), based in five key concepts, as follows:

A reflective teacher:

1. examines, frames, and attempts to solve the dilemmas of classroom practice;

2. is aware of and questions the assumptions and values he or she brings to teaching;

3 . is attentive to the institutional and cultural contexts in which he or she teaches;

4. takes part in curriculum development and is involved in school change efforts; and 
Journeys toward Reflective Practice: How Engaging in National Board Certification Influences Teacher Identities and Practices

5. takes responsibility for his or her own professional development.

The National Board portfolio, separated into various component entries, encompassed each of these concepts. The teacher produced portfolio demonstrated content expertise aligned with knowledge of students while the teacher as learner simultaneously self- assessed: personal ability to examine and frame student learning difficulties, personal belief system, understanding of teaching context, personal ability to secure the advantages of school community support, and participation as a collegial professional to benefit students. These exemplars were all deeply embedded in continuous development of intentional professional expertise.

In developing one's skill with examining, framing, and attempting to solve the dilemmas of classroom practice, Zeichner and Liston cited the foundations of John Dewey and the conversion of his theory into the more contemporary writings of Donald Schön. The precepts of Dewey included openmindedness, responsibility, and wholeheartedness, and according to Zeichner and Liston were "key features of a reflective teacher" (p.15). Schön then furthered the use of theses attributes as he described the limitations of technical expertise and put forth the notion of effective teaching characteristics. Openmindedness, responsibility, and wholeheartedness yielded the ability to reflect prior to teaching and contributed significantly to the creation of the design of excellent instruction. These skills also enabled the practitioner to adjust lessons during their course by taking into account the classroom actions and reactions of students taught to enable deeper learning in a just in time manner. Many of these adjustments involved open-ended questioning (Walsh \& Sattes, 2011). Thus the anticipatory instructional design was framed, and then reframed, in the moment of instructional delivery due to the teacher's expertise as tailored instruction for each child was provided. 
Journeys toward Reflective Practice: How Engaging in National Board Certification Influences Teacher Identities and Practices

The second key component, awareness of and ability to acknowledge and question assumption/values, was impacted by the degree to which teachers' experiences as young students, as pre-service learners, and as practitioners, set the stage for the perception of future teaching sequences. Information, attached to memory during each classroom/learning experience, influenced and produced "who we are, how we will think, feel, and plan as teachers" (Zeichner \& Liston, 2014, p. 29).

Institutional and cultural contexts exerted a very real influence on practices in the classroom, so the third key concept was examined under the mantle of the "permeability" of classroom walls. Zeichner and Liston examined "issues of class, gender, and racial differences and how those differences affected students' education” (p. 87). They further asserted, "interconnection and interdependence... are dependent on many forces outside the classroom" (p. 92). While the neighborhood in which the school existed had a profound impact on classroom practice, the school culture itself and teacher working conditions created a palpable connection to, or disconnect from, learning and teaching and therefore impacted teacher efficacy. Accordingly, a basic tenet of the National Board for Professional Teaching Standards remained: no member of the school community was immune from the effects of context.

Furthering their position, Zeichner and Liston, moved on to the fourth key factor when they stated reflective teachers took part in curriculum development and were involved in school change efforts. This was expressed in the continuing discussion that challenged both the conservative and the progressive notions of teaching and learning. The tradition of emphasized content and its presentational delivery model in which content acquisition was primarily stressed was often juxtaposed against the focus on student background (understandings, cultural background, readiness for learning tasks). The notation and accounting of student prior 
Journeys toward Reflective Practice: How Engaging in National Board Certification Influences Teacher Identities and Practices

experience and learning disposition, as a precursor to development of teaching strategies, was known as the progressive approach. While learning outcomes within our schools remained a near constant, the strategies imposed to achieve these outcomes was a continued debate and reflective teachers were at the forefront of aligning content with student prior knowledge, interests, and learning needs resulting in more pronounced achievement. This notion referred back to the idea that reflective teachers lead staff development and learning as they fostered inquiry by all, rather than thoughtlessly following top down staff development programs.

Zeichner and Liston's fifth tenet, that explained how reflective teachers assumed responsibility for personal professional development, was explored by returning to the Schön's concepts of "reflection on action" and "reflection in action." The concepts highlighted an expanded view of the teacher's self-understanding and explored its impact on professional knowledge and learning. The key question was: "What is the role of the teacher's self in teaching?" There may have been no question more relevant to the teacher as a professional in service to others. If and when the teacher assumes the full responsibility for acknowledging and attending to students' real needs, the learning in the classroom community transcends content, and reaches to quality of life issues. This realization spurred the teacher to continued professional growth, as its impetus was to appropriately attack issues that impeded student learning and to acquire the ability to inspire student learning. Professional growth subsequently built teacher expertise in abilities to design instruction tailored to students, to use adaptive implementation skills, and to evaluate student learning outcomes accurately. Accomplished levels of professional practice was in direct contrast to the technical model of covering content and skills, which students may or may not have understood, absorbed, and used as a tool or stepping stone to acquire further learning. 
Journeys toward Reflective Practice: How Engaging in National Board Certification Influences Teacher Identities and Practices

Zeichner and Liston closed Reflective Teaching, An Introduction (2014) with resources for further exploration as they highlighted the need for teacher inquiry at many nuanced levels with enhanced capacity for decision-making and growth. Reflection was cited as a form of inquiry into one's personal skills, knowledge level, and disposition. This thinking aligned with the precepts of National Board for Professional Teaching candidacy which was aligned with exploration dependent on developing a level of systematic personal examination that spiraled into previously unknown territory, was recorded, and then developed the momentum for future thought, and hence personal and professional discovery. Thus the teacher, who perceived his or her role as sage, became a facilitator of learning. In the National Board tradition, as teachers became learners, the less they believed to be absolutes. Learning brought about new genuine questions about teaching and learning. This blend of uncertainty and discovery instigated true autonomous inquiry enmeshed in questioning and reviewing the reasoning behind one's teaching practices, thus the personalized continuous learning cycle was initiated.

However, reflective practices may be constrained in particular contexts by the "sacred stories" imposed upon teachers via the school, district office, or state and federal governments.

What teachers know depends on the school stories and stories of school that constitute their landscape..." how is teacher knowledge shaped by the professional knowledge landscape in which teachers work?' ...We believe we have shown that the professional landscape of schools is of such contextual complexity...that it is simply not possible to use this (research knowledge base)...to build with confidence, programs that lead to better teaching... We believe that teacher's practical knowledge, set in the context of teacher's professional knowledge landscapes...points in a different direction. (Clandinin \& Connelly, 2000, p. 29).

Teachers may have accepted their professional landscapes without question and acceded to the "sacred stories" of their apprenticeships of observation and larger school contexts, which had implications for teaching and learning. Traditional schools called for very traditional teacher and student behaviors. However, as Olson and Craig (2005) asserted: 
Journeys toward Reflective Practice: How Engaging in National Board Certification Influences Teacher Identities and Practices

Regardless of whether teachers personally approve of the communal story and whether it fits with the personal teaching narratives they are creating, compelling reasons exist to at least appear to be living the socially authorized story or stories (p. 163).

In this manner, the teaching context, particularly for novice teachers, may have caused these neophytes to embrace or, at some point, to reject the common teaching practices of their school context(s). In order to fit a context that embraced traditional teaching, teachers who chose student-centered practices over traditional methodology may have been in a circumstance where they constructed "secret stories" (Clandinin \& Connelly, 2000, p. 30). These secret stories, in turn, required "cover stories" (p.32) that an innovative teacher used to maintain harmonious relationships with colleagues. Thus, the knowledge teachers constructed as they engaged in reflection and other professional development activities within particular schools was influenced by the professional knowledge context(s) in which they were situated. This positioning may have contributed to the narratives teachers constructed of their practice and the teacher identities they created.

\section{Reflection as fostered by collegiality.}

The role of professional learning communities (PLCs) was reinforced by Zeichner and Liston (2014) as they posited:

The final narratives for...practicing teachers arise in response to such questions as Why teach? What do I expect to accomplish from working in public schools? What kind of relationships will I form with students? What does it mean to learn and what should I teach?...How we respond to these questions illuminates our deepest values; builds from our own experiences as children, students, teachers, and parents; and is shaped by the information we have about education and schooling. (p.47)

Mentoring relationships supported clarification of one's deepest values and this collegial work was often borne via dialog. According to Autumn Troullos, NBCT, (personal conversation, 
Journeys toward Reflective Practice: How Engaging in National Board Certification Influences Teacher Identities and Practices

December 7, 2014), “A good mentor doesn't give answers. A good mentor asks questions and helps people find their own way." Mentors once held traditionally defined roles as providers of short-term emotion and technical assistance or were focused on student thinking and developing justification for the mentees teaching habits. Conversely some mentors viewed the role as a process of constructed networks of collegiality that developed as a vehicle for educational change (Feiman-Nemser, 2001). This work was undertaken by accomplished teachers in efforts to provide quality opportunity for peers to shape the work of teaching, a complex, uncertain, dilemma filled profession.

Feiman-Nemser averred that every year teachers were expected to create and maintain a classroom learning community that was safe, respectful, and produced student learning. Creation of a learning community may have been the most important task that faced the teacher. PLC work was also developed as a safe learning community for teachers to gain "opportunities to talk with others about their teaching, to analyze students' work, to examine problems, and to consider alternative explanations and actions" (p. 103).

Improving Teaching through Continuous Learning (Ermeling, 2012) focused on established practice based inquiry teams who were assigned the arduous responsibility of advancing professional practice. School change efforts were dedicated to developing meaningful professional growth via facilitated teacher learning and were designed with a structured and systematic study of the practices in place across the school environment (Ermeling, 2012). Specific features involved included identification of "instructional problems specific to local context; preparing and implementing detailed instructional plans; utilizing evidence to drive reflection, analysis, next steps; and persistently working toward detectable improvements" (p.197). Recurring interactive teacher dialog involved: exploration of the acknowledged 
Journeys toward Reflective Practice: How Engaging in National Board Certification Influences Teacher Identities and Practices

dilemma, remedies, analysis of the remedies, and potential working solutions as noted during instruction. "This mindset, one of intellectual curiosity and a desire to continuously improve, is best supported by ongoing context-specific opportunities for professional growth" (Ermeling, p. 202).

Furthermore, according to Cochran-Smith and Lytle (1999):

Teachers, like all learners, bring prior knowledge and experience to all learning situations, which are social and specific...teacher learning takes place over time rather than in isolated moments in time and that active learning requires opportunities to link previous knowledge with new understandings. (p. 258)

Cochran-Smith and Lytle contended that the effectiveness of teaching was not in the methods employed, but in the "ideas and assumptions that animate them" (p. 270). Colleagues who worked together provided social contexts for the "kind of constructivist classroom practice that is the target" (p. 270). This shared thinking helped teaching practitioners as they explored "problems of practice that cannot be solved by straightforward application of theories and by reconsidering their own assumptions and reasoning processes...the role of facilitator, who... guides...the process of learning how to reflect and/or conduct inquiry, is central" (pp. 270-271). Schön (1987) focused on contexts for professional learning and asserted that the type of learning that took place in paired conversation or in groups of educators was distinct from introspective reflection. Articulated and shared thought allowed teacher to "consider and reconsider what it means to know or believe something, and then to examine and reinvent ways of teaching that are consistent with their knowledge and beliefs" (Cochran-Smith \& Lytle, 1999, p. 272).

In closure, Cochran-Smith and Lytle (1999) discussed educators' collective oral inquiry as based on "rich conversations about students' work, teachers' classroom observations and reflections, curriculum materials and practices, and classroom and school-related 
Journeys toward Reflective Practice: How Engaging in National Board Certification Influences Teacher Identities and Practices

artifacts... analyses of these data sources are primarily oral and constructed in social

interaction...primary outcomes are enriched understandings of the participants" (p.279-280).

Their question for teachers then became, how shall we advance professional learning, build

teacher capacity, and replicate the exemplary use of perceptions and meanings owned by

accomplished teachers?

The National Board process is based in Five Core Propositions, which conclude with

Teachers are Member of Learning Communities. To this outcome the fifth Core Proposition

(nbpts.org, retrieved April 14, 2014) stated:

Teachers work together to strengthen their teaching. Sometimes they observe each other; at other times they engage in discussions about teaching; and they collaborate to try out new instructional strategies. While the particulars of how teachers choose to improve their instruction will vary according to the structure of opportunity and a teacher's disposition and interests, the principle underlying such engagement is the continuous pursuit of teaching excellence in the company of peers (emphasis added). Strong schools emphasize a process of continuous improvement. Committed teachers... are team players willing to share their knowledge and skill with others... This participation may take on many forms, such as mentoring novices, serving on school and district policy councils, demonstrating new methodology, engaging in various forms of scholarly inquiry and artistic activity, or forming study groups. (p. 19)

Thus collegiality in its many forms was a requirement of completion of the National Board process.

\section{Summary}

With this study situated in how people learn through reflection in practice, with the overarching theme: teachers as learners (Feiman-Nemser, 2001). I examined possible outcomes for teachers, who had successfully completed the National Board process, were established as accomplished reflective teachers, and who continued to learn in the classroom and as members of the community of professional practice. 
Journeys toward Reflective Practice: How Engaging in National Board Certification Influences Teacher Identities and Practices

\section{Chapter Three}

\section{Materials and Methods}

In this chapter, qualitative methodology was used to build an examination of teacher inquiry, which was embedded as a strong feature of the National Board process. Therefore the qualitative methodology entailed examination of teacher student interaction using reconstructive narratives. Through this lens, thinking, formerly unspoken, may have been revealed (Vygotsky, 1962). Qualitative methods were appropriate for the study of reflective behaviors and strategies used by teachers who are in practice in educational settings. A study of reflective technique lent itself to narrative inquiry because according to Zeichner and Liston (2014), "Without these conversations among and dialog between practitioners...our reflection will be severely limited" (p. 20). Shavelson and Towne (2011) recognized "It's the question-not the method- that should drive the design of education research" (p. 2). This qualitative research design was based on questions that explored the teaching experience and traced the development of teaching expertise. The questions were designed to gain a deeper understanding of the participant's thinking about teaching and in practice behaviors. Mitra \& Halabi (2012) suggested a study composed of "a combination of semi-structured interviews and document collection to ascertain the visions, intentions, and implementation" and use of "interview protocols (that) explored the actors, problem definitions, collaborative patterns, and implementation" and yielded data to be coded and reduced and provided insights into lived experiences in various contexts (p. X). Layering of questioning from generalized to specific was based on the individual participant's response pattern and allowed for the possibility of delving into participant's lived experience, both in and beyond the classroom. Therefore using the reasoning of Shavelson and Towne 
Journeys toward Reflective Practice: How Engaging in National Board Certification Influences Teacher Identities and Practices

(2011), meaning making of the memories of lived teaching experience necessitated a research method entrenched in dialog between researcher and participants.

Denzin and Lincoln (2005) asserted that qualitative research "consists of a set of interpretive, material practices that make the world visible...(into) a series of representations" (p. 3). Thus, participants described decision-making and reflective process skills as a "series of representations" of their thinking during the interview process. As participants constructed their narratives during the interviews, their thinking was recorded and the written transcripts of the interviews allowed for open exploration of the meanings ascribed by both the teacher and the researcher. Furthermore, Denzin and Lincoln stated, "qualitative researchers...are always attempting to make sense of, or interpret, phenomena in terms of the meanings that people bring them" (p. 3). In these ways, my interviews placed me in the role of learner as I explored and studied the significance of the professional growth of each participant before, during, and after the National Board process.

Use of qualitative research was an appropriate means to examine my participants' responses about their own reflective strategies. According to Krathwohl (2009), "qualitative methods are especially useful for exploring a phenomenon, for understanding it and for translating that understanding into theory" (p. 255). In addition to understanding the phenomena of teacher as learner retrospectively, my qualitative design, specifically the interview series, provided me with an opportunity to engage with my participants in an exploration of their present selves as teacher-learners.

This chapter expands upon the purpose of my study, makes the questions explicit, describes the research frame, and included both the methods of data collection and analysis. The context of teaching for participants described was aligned with the circumstances that led each to 
Journeys toward Reflective Practice: How Engaging in National Board Certification Influences Teacher Identities and Practices

seek and complete National Board Certification. In chapter three, I close by contemplating the limitations of my research methods and consider the trustworthiness of potential findings.

\section{Purpose of the Study}

During the coursework required by my doctoral studies, I read the work of Bransford, et al. (2000) which asserted that the:

New science of learning is beginning to provide knowledge to significantly improve people's abilities to become active learners who seek to understand complex subject matter and are better prepared to transfer what they have learned to new problems and settings. (p. 27)

Linda Darling-Hammond (1998) also discussed teachers as learners, stating:

Acquiring this sophisticated knowledge and developing a practice...requires learning opportunities for teachers that are more powerful than simply reading and talking about new pedagogical ideas. Teachers learn best by studying, doing, and reflecting; by collaborating with other teachers; by looking closely at students and their work; and by sharing what they see. (p. 6)

She suggested that very little is known about how teachers reflect and consequently learning about this phenomenon has been a driving force in my thinking.

When I was a National Board candidate, I struggled with producing the narrative, analytic, and reflective writing required in constructing a NB portfolio. Candidates were expected to descriptively frame student based learning dilemmas and create prospective solutions, test the proposed solutions and analyze the results, and finally reflect on the effectiveness of those decisions. I realized via this process that my own formerly tacit knowledge was clearly, convincingly and consistently expressed as I justified and recorded my beliefs about effective practices and evidence of my work as a teacher and a learner. Prior to candidacy, my efforts as I designed and facilitated the learning of my elementary students caused me to seek current research, implement the strategies I read about, and became what I now recognize as an 
Journeys toward Reflective Practice: How Engaging in National Board Certification Influences Teacher Identities and Practices

action researcher as I experimented with multiple strategies of instructional delivery tailored to student strengths. The resulting instructional design, by current definition, included differentiated instruction (DI). The term DI had not been in general educational usage when I earned the distinction of NBCT, yet was expected in the documented classroom practices of an NBCT. As I struggled to grow professionally, engaged in the NB process, and developed as a mentor of candidates, I continuously framed and reframed problems in reflective thought. As a practicing NB mentor, I wished to discover how others experienced the reflective practice component of the National Board process and to access the ways in which teachers made sense of their role as learners. Therefore, the origins of my study were entrenched in practice, guided by the underpinnings of theory about reflection, and sought to answer purposeful research questions. All of these influences guided the methods used in my study as I sought to explore the lived experiences of practicing NBCTs; thus, the following questions guided my research:

- How do teachers learn to teach over the course of their teaching careers?

- How do the contexts in which teachers are situated influence their professional development?

- How does the process of engaging in National Board Certification influence a teacher's development as a reflective practitioner?

\section{Theoretical Perspective: Social Constructivism}

I framed my study within the epistemology of constructionism because, according to Crotty (2010), “constructionism is an epistemology embodied in many theoretical perspectives... a way of understanding and explaining how we know what we know" (p. 3). In the constructionist view, truth was known because human beings engaged with and developed a 
Journeys toward Reflective Practice: How Engaging in National Board Certification Influences Teacher Identities and Practices

view of existing realities of the world. The construction of meaning was dependent on the lens, experience, and abilities of the person. Therefore, constructionism was suited to developing an understanding of teachers as learners in progress as teachers explained how the chronology of reflecting on teaching experiences before, during, and after the NB process enabled their current teaching practices. Furthermore Crotty (2010) averred that constructionism was an approach that sought understanding and explanation of social interaction and the human world. The study of teacher reflection on interactions with students fit into the narrative inquiry frame as the researcher questioning led the teacher to (re)construction of meaning in an ongoing interview process.

Crotty then stressed applicability of the use of constructivist theory for internal thinking, or meta-cognitive work, by reserving "the term constructivist for epistemological considerations focusing exclusively on the meaning making of the individual mind” (p. 58). So while my communication with my participants had a limited social context as a dyad, other social contexts in which my participants were or had been situated, enabled them to reflect on multiple interactive settings and moments within the teacher as learner frame. Our interviews provided a space for personal examination of their lived experiences and illuminated the often tacit, internalized reflective thinking for each participant. This dyad was what Crotty termed "constructionism where the focus includes the collective generation [and transmission] of meaning” (p. 58) because "people develop meanings together and it is...interpreted" (p. 57). Thus the making of meaning and understanding the significance of teaching experience(s) was always evolving and ongoing.

The work of Freire (1972a) provided a foundation for the change process of every human's thought and action. Individuals may be viewed "as beings in the process of becoming- 
Journeys toward Reflective Practice: How Engaging in National Board Certification Influences Teacher Identities and Practices

as unfinished, uncompleted human beings in and with a likewise unfinished reality" (pp. 56-57).

This process of internal change, which often involved negotiating the tension between stasis and transformation, often became evidence as we worked with others. Thus, "to ask who human beings are or what it means to be human is to ask what human beings have made of themselves" (Crotty, 1998, p.150). Understanding who these NBCTs have become as teachers and are becoming as teachers was at the heart of this inquiry.

Further, Crotty (1998) shared that cultural context exerted an influence on personal constructions and therefore on the manner in which one viewed the world. Aligned with that theory, it may be assumed that a social constructivist perspective offered a more nuanced way to understand factors that may have contributed to teachers' decisions to develop reflective practices. Drago-Severson (2004) interposed her beliefs based on constructivist theory of Robert Kegan (1994) that "focuses on the person as the active meaning maker of experience, considering both interpersonal and internal experiences, particularly how they intersect in one's work" (p. 22). This perspective also took into account the influence of the cultures and contexts in which the teacher was situated prior to and during the National Board process. Additionally, the social constructivist perspective offered an opportunity for research participants to engage in deep thinking related to discovery of participants' understandings of their experiences and the influence of specific contexts on those experiences and understandings. This may have included, but was not limited to, influences of mentors, research, mandates, and administrators. However, while the construction of meaning was "liberating...it must also be called into question...constructivism tends to resist the critical spirit, while constructionism tends to foster it" (Crotty, 1998, p. 58). Therefore, this study also explored the decision to engage in effective 
Journeys toward Reflective Practice: How Engaging in National Board Certification Influences Teacher Identities and Practices

reflective practice in the role of teacher as learner as influenced by particular contextual and collegial relationships.

Citing Kegan (1982), "As important as it is to understand the way the person creates the world, we must also understand the way the world creates the person" (p. 114). He went on the label the context in which a person experiences the world as a "holding environment" (p. 114). This location, or position, called a:

Holding environment...provides both a welcoming acknowledgment to who the person is right now as he or she is, and fosters the person's psychological evolution. As such a holding environment is a truly transitional culture, an evolutionary bridge, a context for crossing over. It fosters developmental transformation, or the process by which the whole ("how I am") becomes gradually a part ("how I was") of the new whole ("how I am now”). (Kegan, 1994, p. 114)

Kegan defined ways of knowing as meaning making systems with differing qualitative characteristics and it seemed important to note that Love \& Guthrie (2002) elaborated on Kegan's work with reference to "not only...how one thinks but more generally to how one constructs experience, which includes thinking, feeling, and social relating...concern(s) the organization of one's thinking... rather than content" (p. 67).

The use of social constructivist theory framework for exploration of reflective practice in education, in which the school setting may have become the holding environment, had potential to illuminate how teachers "make sense of their internal and external experiences" (DragoSeverson, 2004, p. 23) and moved through the stages of practice to the achievement of accomplished teaching status. Drago-Severson furthered this thinking by describing two types of teacher learning experiences or outcomes, the informational and the transformational. Informational learning might have contributed to a teacher's improved skill base and knowledge of content: however, transformational learning altered "how a person knows... adults undergo a 
Journeys toward Reflective Practice: How Engaging in National Board Certification Influences Teacher Identities and Practices

development and profound change in the way they construct or make sense of experience. The kind of change was the very core of constructive-developmental theory" (p. 23).

Constancy of growth involved a gradual renegotiation of defining self within one's context, while the way the experience was filtered and understood was referenced as a "way of knowing" and "a person's ways of knowing dictates how learning experiences will be taken in, managed, handled, used, and understood" (Drago-Severson, 2004, p. 24).

Drago-Severson focused her theories about teacher learning in three sub-groups, "the instrumental way of knowing, the socializing way of knowing, and the self-authoring way of knowing” (p. 25). Instrumental knowing was concrete and was manifested with an exchange level perspective in interaction with others, basically defined as a position defined by expectations that when I helped you, then in turn, you helped me. The socializing way of knowing was dominated by more abstract thinking, the ability to generalize ideas, and the use of reflection on personal actions and the actions of others. Self-authoring involved capacity for heightened responsibility and a sense of internal authority. Combined with regulation of relationships, self-authoring had a tendency to limit perspective according to Drago-Severson. Limiting of perspective became an asset to a teacher to some extent when it enabled establishment of social parameters and reflection on relationships with others, but ruled out taking on their perspectives.

Jonas Soltis (1984) wrote that:

Educational research takes its work to be inquiry ... investigate(s) what is distinctly human...is pervasive in all societies...transmission and reception of human meaning is so central...(and) requires us to consider the nature of human meaning, interpretation, and understanding. (pp. 5-6)

The transmission of these meanings for this inquiry study created space for exploration of the lived experiences of teachers before, during, and after the NB process. While much research has 
Journeys toward Reflective Practice: How Engaging in National Board Certification Influences Teacher Identities and Practices

focused on the situated teacher-student interaction, this research focused on how the teacher thinks about these interactions. Thus, social constructivism provided a meaningful framework to examine the "ways of knowing" teachers used in reflecting on planning and executing interaction with students.

\section{Engaging in Narrative Inquiry}

The story of the teacher's progress from novice practitioner to accomplished practitioner is individual and tied to his/her teaching context. According to Clandinin (2013), "narrative inquiry is both a phenomenon under study and the methodology for its study. Narrative inquiry is how we understand human experience...Experience is fundamentally narrative" (p. 216).

Therefore a study of teachers looking back and vocalizing perceptions of their personal reflective practices tended to yield stories of their individual situated lived experiences. The teachers used stories not only to share their experiences, but also as they made sense of them. In fact, Seidman (2013) suggested, "telling stories is essentially a meaning-making process. When people tell stories, they select details from their stream of consciousness...in order to select the details...people must reflect on their experience" (p. 7). The language people use as they tell their stories "is a microcosm of their consciousness " (p. 7) and provides the medium through which they were able to symbolize their experiences.

Inside this puzzle as we attempted to build understanding of and between educators, it was deeply important to remember, “Their story, yours, mine- it's what we carry with us on this trip we take, and we owe (emphasis added) it to each other to respect our stories and learn from them" (Coles, 1989, p. 30). If the "trip" we took was a good faith attempt to offer a positive influence on the lives of the students we served, and in educational settings nothing resonates 
Journeys toward Reflective Practice: How Engaging in National Board Certification Influences Teacher Identities and Practices

more, then indeed we owed it to ourselves and our colleagues to have been open to the idea that the lived stories of ourselves and our students was a worthy study. As such we may have adopted and remained open to the narrative research experience with the words of Clandinin and Connelly (2000), "We see individuals as living storied lives on storied landscapes.

Understanding life, experience, narratively is our research and our life project” (p. 24).

As a researcher, I attempted to open a time frame and allow the intellectual space for each participant as they examined, or re-examined, their lived experience, in this case, the National Board experience. The examination of one's reflective practices was as important after one becomes an NBCT as it was before and during the process. Therefore, narrative inquiry was uniquely positioned to allow the richness of lived educational practice and accomplishment a space for expression. As Clandinin and Connelly (2000) suggested:

On reflection, we understand that relationship is at the heart of thinking narratively. Relationship is the key to what narrative thinkers do... Narrative inquiry is an experience of the experience. It is people in relation studying with people in relation. (p.189)

In working through narrative inquiry it may have been possible to discern how accomplished teachers recollected and viewed their experiences in becoming more progressive in the classroom. In the words of Sarah Lawrence-Lightfoot (2003),

I felt that it was important to describe the good but imperfect work of these teachers, because I think we...learn a lot more from examining examples of goodness than we can from dissecting weakness and pathology. We can also appreciate how incredibly complex and dynamic this work is by looking at people whose craft is well developed and whose self-reflective capacities are well honed. (p. xxvii)

Key words in her phrasing were describe the work because narrative inquiry proved to be a productive tool for a descriptive analysis of complex, dynamic, self-reflective, well honed pedagogical expertise that was present in effective classroom learning. The intellectual space was created before, during, and after the narrative inquiry interview sessions because both the 
Journeys toward Reflective Practice: How Engaging in National Board Certification Influences Teacher Identities and Practices

researcher and the participants, all NBCTs, may have been predisposed to adopting the reflective stance.

As a researcher entering into the lives of my participants, I considered how the time, place, and space continuum entrenched in narrative inquiry might have enabled the participants to devote significant recursive cognitive effort to the NB experience and how that effort contributed to their reflection on action. Clandinin (2013) suggested that it is in the nature of the researcher and participant relationship to become "nested" (p. 44) and this dual relationship was further enmeshed in the researcher's and participant's larger life narratives. The relationship was based on constructing and re-constructing the lived experience "even as they tell the experiences over time" (p. 44) and Clandinin posited that narrative inquiry always existed inside the entire life context. Of importance was the realization that, as inquirers, we may have concluded the research data- gathering phase but " exit was never a final exit. We continue to carry long-term relational responsibilities for participants, for ourselves, and for the work we have done together" (p.44). The researcher and participants in this study held commonality as successful completers of the NB process. Therefore while the time, place, and space may have been temporal, this temporality yielded genuine positive influences for us as reflective educators who revisited a threshold experience in our accomplished professional lives.

\section{The Research Contexts}

This study situated research in the lived experience of three NBCTs in West Virginia who practiced in various districts, schools, and disciplines. Their experiences held both similarities and separations as learning was strongly influenced by context, a primary precept of the National Board for Professional Teaching Standards. 
Journeys toward Reflective Practice: How Engaging in National Board Certification Influences Teacher Identities and Practices

\section{National board certification process.}

The process of becoming a National Board Certified Teacher required documentation of evidence that demonstrated positive impacts for student learning in multiple formats both in and beyond the classroom. Achieving NB Certification was time-intensive and was completed in up to three years. Candidates were required to submit a four-part portfolio and completed a series of written exercises at a licensed testing site. The first portfolio entry included written commentaries on multiple samples of the work of multiple students. Entries two and three were videotaped segments displaying authentic classroom sessions; employing both large group and small group design documented by the candidate's extensive narrative commentary. The fourth entry documented evidence of collaborative work inside the school community, during ongoing two-way communication with parents and families of students, and positive engagement in the wider community in which the school was situated. The assessment center exercises were timed essay questions designed to test the candidate's pedagogical content knowledge and verified the portfolio entries. The four portfolio entries and six assessment center essays carried varied weights for scoring purposes. Candidates who began their application process prior to 2002 completed six portfolio entries and four assessment center exercises. Current procedures, still in the revision stage, required that candidates submit three portfolio components over a three-year period with the fourth component completed in an online assessment center.

Written commentaries began with specific statements about current levels of student achievement at the onset of the learning sequence and goals were written for the entire class of students. Individualized goals were also written for the specific students under close analysis. Selected students were described by defined learning characteristics, level of skill mastery, and instructional challenges. Student work samples were presented and analyzed for evidence of 
Journeys toward Reflective Practice: How Engaging in National Board Certification Influences Teacher Identities and Practices

initial student knowledge and skill set(s). The candidate then used the points highlighted and illustrated in the first student work sample and created specific learning tasks, represented skills and knowledge sets the student must acquire within the student's zone of proximal development, that were then taught to that student. Student prescriptive assigned work was closely monitored and was expected to spiral to meet successively higher learning goals. After completion of the assigned prescriptive measure(s), a second work sample was displayed for analysis. This iterative process generally continued for up to three months. The candidate described and analyzed the student work pieces while reflecting on the intervention(s) employed and made instructional decisions based on why the interventions, individualized teaching strategies had, or had not, shown student gains. The running narrative was critical to the process with its descriptive, analytic and finally the most heavily weighted (when scoring is assigned by the NB evaluative team) reflective narrative component.

Baseline data was presented, learning goals ware written, and specific measurement points were chronicled in both entry two (whole group instructional design) and three (small group instructional design). The running narrative writing chronicled the work that preceded the videotaped segment and produced the student abilities used during the interaction seen in the tape as was designed by the candidate. The lesson documented by the taped segment was analyzed in narrative form and then the succeeding lesson intentions and ultimate outcomes of those succeeding lessons were documented via student created artifacts. This created documentation of lesson sequences designed to last from 3 to 6 or more weeks in length. The narrative written commentary created by the candidate was again, descriptive, analytical, and reflective throughout all passages. 
Journeys toward Reflective Practice: How Engaging in National Board Certification Influences Teacher Identities and Practices

The fourth entry documented evidence of collaborative work inside the school community via a variety of school teams that necessarily included the PLC format. Colleagues were expected to verify evidence of the contributions of the candidate to the work of the school team in precise and definitive reports. Documentation of ongoing two-way communication with parents and families of students was required to demonstrate positive impacts for student learning via documented evidence. Finally the candidate used multiple examples and demonstrated engagement strategies in formats that took students into the community and brought community members into school settings.

\section{West Virginia context.}

West Virginia statistically was a state with little racial/ethnic diversity according to Boser (2014), $98 \%$ of teachers in the state were white as were $95 \%$ of students, as posted in his data analysis of the 2010-2011 school year enrollment. NBPTS stated its fundamental purpose was achieving fairness, equity and access in education for all students despite any disparity they faced in and beyond the school setting. Particular challenges in West Virginia schools exist for students of color with the disproportionate lack of role models of color and the potential for societal preference of their non-similar teachers. While, this was not explored in my research, the degree of student diversity in the classrooms of these participants was discussed during our interviews. Furthermore, no non-white candidates have attended NB support cohorts in West Virginia since their inception in 2005, despite the 2008 meetings conducted by WVDE to support NB candidates of color in West Virginia. I was a presenter at this initial state level meeting attended by approximately 30 black educators.

Irvine (1998) addressed this inconsistency in racial equity and cited low non-white teacher certification rates in the NB process when she suggested African-American cultural 
Journeys toward Reflective Practice: How Engaging in National Board Certification Influences Teacher Identities and Practices

traditions emphasized "warm demanders" and this teaching style did not match the "substantially different pedagogical approaches described effective teaching research" (p. 1). However, this characteristic of African-American teachers "is correlated with achievement gains by black students" (p. 1). Irvine's research indicated that students of color are entering professional realms other than teaching, and becoming teachers at a lesser rate (based on percentage of total population) than their white peers. She also indicated that black teachers (11\%) achieve NBCT status at a much lower rate that white teachers (40\%) during the first year of NB candidacy. These statistics could not be verified in West Virginia due to the fact that African American teachers in West Virginia are not participating in the NB process. The low percentage of nonwhite teachers in West Virginia may contribute to a non-existent collegial support network for teachers of color, and this presents a paradox for contextual learning as the numbers of non-white students increase.

Since teachers were expected, as of WVDE policy built in 2009 , to engage in Professional Learning Communities (PLC), collaborative teacher planning was expected. This planning was organized for discussion of student growth and then teachers were expected to provide specific interventions that stimulated student growth as evidenced by student generated data. These PLC structures held the potential to yield time and space for reflective thinking when teachers narrated the events that caused concern when considering student growth. However, this time and space for thinking may well have been under utilized.

Beginning in 2005, regional level cohorts/PLCs were developed as a support vehicle and allowed for ethically trained NBCTs to provide cohort support to aspiring NB candidates. Officials in WVDE and the Governor's office valued the NB process, cited its positive impact on student learning, and provided support and incentives for teachers to engage in this professional 
Journeys toward Reflective Practice: How Engaging in National Board Certification Influences Teacher Identities and Practices

development. At present (April, 2016), 927 teachers in West Virginia have achieved NB Certification. NBCTs now interact with all professional and support staff in our 808 West Virginia schools and have the potential to be instrumental in changing grade level narrative at the PLC table, thereby building positive culture across schools and at the district level.

The updated language of collaboration between students, required by the recently adopted 2011West Virginia Next Generation Standards and the subsequent 2015 West Virginia College and Career Readiness Standards, emanated from NBPTS under Knowledge of Students Standards, Knowledge of Content Standards, and Designing Instructional Environment Standards. West Virginia Professional Teaching Standards and the West Virginia Teacher Evaluation System mirror expectations created by the original Carnegie Task Force and were imbued with both "Knowledge of the Practice of Teaching" and "Reflection and Professional Growth Standards" set forth by NBPTS.

Accordingly, West Virginia schools with National Board Certified Teachers tended to have more effective professional communities, were more likely to focus on teacher leadership, made time to support teacher learning, and strongly valued staff collaboration. School culture benefited from the shared teacher language drawn from known National Board Professional Teaching Standards. Conversation was much more likely to center on discussion about professional practice and its relationship to student learning according to Hunzicker (2008). Successful schools were often characterized by higher rates of increased community involvement, due to an emphasis on collaboration with the school community, a position adopted by teachers who were NBCTs.

While the mentoring of candidates took on varying forms, it was generally characterized as beginning when the prospective candidate sought support. The prevalent body offering 
Journeys toward Reflective Practice: How Engaging in National Board Certification Influences Teacher Identities and Practices

candidate support in West Virginia was the governor's office through the Center for Professional Development. Mentors for localized cohorts were trained via the yearly summer workshop and this annual event also introduced prospective candidates to the NB process. Cohorts operated locally and accepted every prospective candidate who participated in sessions designed to offer sustained mentoring in the form of cognitive coaching.

The NBCTs interviewed in this study may or may not have participated in varying forms of NB support systems within West Virginia. Key to participation was whether any NB support system was in place during the candidacy time frame. The location of an available NB cohort in proximity to a candidate's home was also a factor. West Virginia is divided into eight functioning Regional Educational Service Agencies, and these serve as hubs for NB support cohorts.

\section{Participants' school contexts.}

School One, where Margaret currently teaches, was a middle school in a suburban setting with 181 students and a professional staff of 26 , and provided a 1:7 teacher to student ratio. It was located in a small city with a population of 28,486 people, 12,816 households, and 6,949 family residents with a median family income of $\$ 38,708$. One hundred percent of students qualified for free meals and $25 \%$ of the student population was non-white. Twenty-one percent of students enrolled qualified for special education services. PLCs have been functioning in this school for four years. The school district employed approximately 500 professionals and $8.6 \%$ of all professional employees hold National Board Certification.

School Two, a high school in a suburban setting, is home to Ethan's practice. It was populated by approximately1,200 students and a professional staff of more than one hundred, creating a teacher to student ration of 1:12. This school was located in a town with a major 
Journeys toward Reflective Practice: How Engaging in National Board Certification Influences Teacher Identities and Practices

university and was home to approximately 29,660 people, with 11,701 households, and is the residence of 3,827 families with a median income of $\$ 44,622$. Thirty percent of students qualified for free meals and less than $10 \%$ of the student population was non-white. Twenty percent of students enrolled qualified for special education services. PLCs have been and are currently functional in this school.

Gretchen teaches in School Three, a high school in a suburban setting, with more than 1,600 students and a professional staff of more than 100, enabling a teacher to student ratio of $1: 16$. It is located in a small city with a population of 27,790 people, 12,318 households, and 6,557 family residents with a median family income of $\$ 42,350$. In school two, 38 percent of students enrolled qualified for free meals. Fifteen percent of the student population was nonwhite. Eleven percent of students enrolled qualified for special education services. PLCs have been functioning in this school for five years. The school district employed approximately 430 professionals and $9 \%$ hold National Board Certification.

\section{Participants and Their Roles}

Criterion sampling (Patton, 2001) was used to select the three participants with two required characteristics: 1.) the participant must hold National Board Certification and 2.) be currently employed as a teacher in a West Virginia public school. All participants have taught in a public school classroom setting for 12 years or more. One participant has a Bachelor's degree, one a Master', and one holds a Doctorate in Education. All serve in schools that have achieved recognition at some point on a state or national level. Two of the participants have experienced the NB re-certification process successfully, while one has been certified for five years. 
Journeys toward Reflective Practice: How Engaging in National Board Certification Influences Teacher Identities and Practices

Administrators, colleagues, students, and parents have recognized each as an exemplary teacher both through formal and informal means.

A fourth participant was interviewed, however during the early attempts to mine data for evidence of reflection, it became apparent that he, a high school social studies teacher, spoke only in generalities. Therefore, I sought another participant, a female high school English/Language Arts teacher, and this addition allowed me to continue the process using Seidman's (2006) narrative inquiry model consisting of three ninety minute reconstructive interviews.

Table 3.1, on the following page, provided a biographical summary for each participant with detailed teacher descriptors included within the findings chapters $(4,5,6,7,8)$ as was appropriate to the interview context. All participants were engaged in reflective practice to varying degrees before, during, and after certifying as an accomplished teacher through the external voluntary NB process. Revisiting this reflective work allowed space to work metacognitively and express that level of introspection explicitly with a specified audience. 
Journeys toward Reflective Practice: How Engaging in National Board Certification Influences Teacher Identities and Practices

Table 3.1

Participant Information

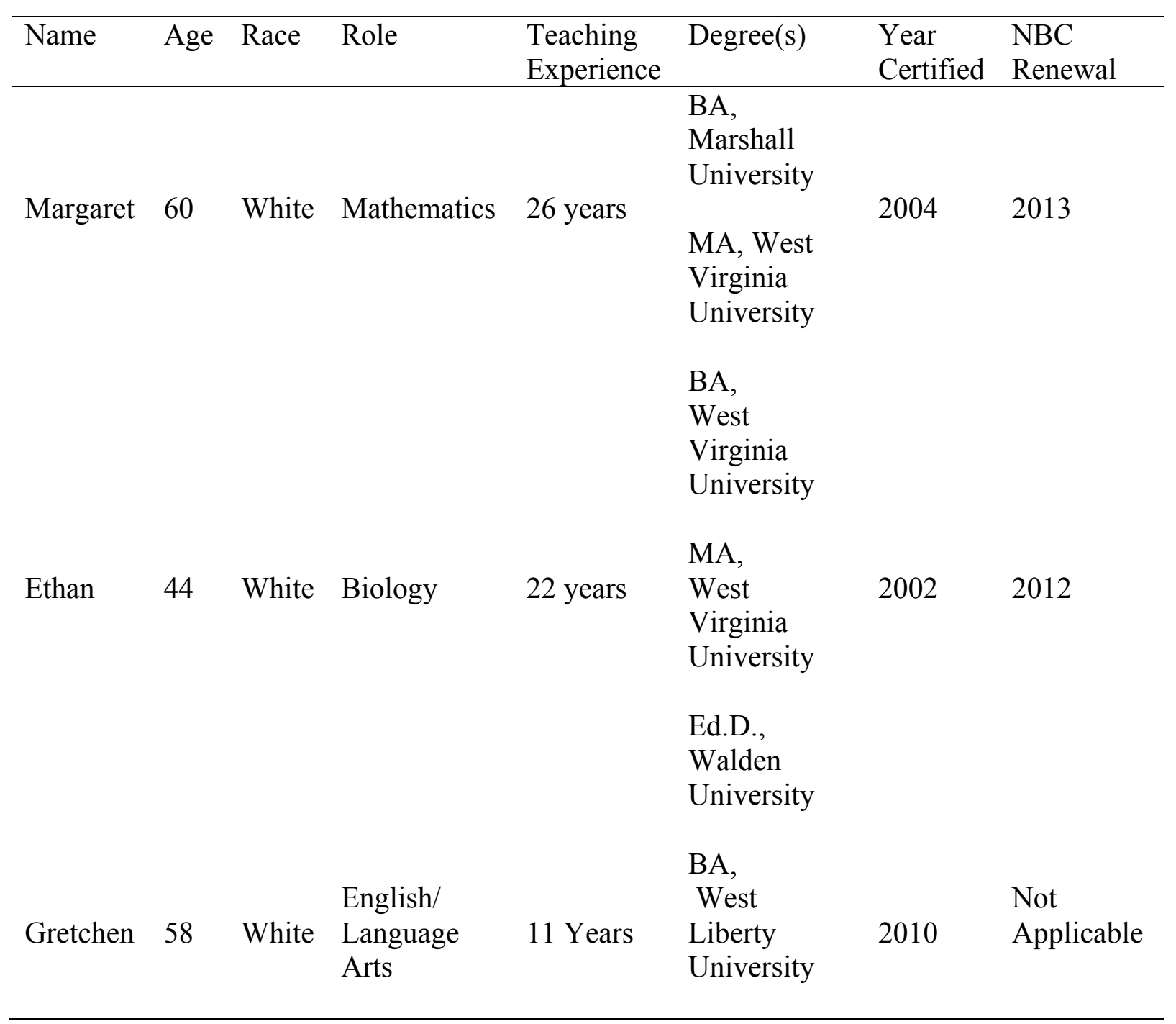


Journeys toward Reflective Practice: How Engaging in National Board Certification Influences Teacher Identities and Practices

\section{Researcher and Her Roles}

This study was rooted in my acknowledgement that what I understood about teaching and learning was nurtured and stimulated by the students I had the privilege of serving. My curiosity about the learning processes involved has been guided and encouraged by my mentors. The willingness to examine one's own educational practice in collaboration with a mentor was a brave and stimulating undertaking. I was encouraged to develop my thinking about my own educational practices by colleagues who were not NBCTs at that time and this reinforcement enabled the meaningful questioning that served me in professional growth.

I entered the NB Certification process as a veteran teacher with more than two decades of classroom experience. At that time, no candidate support networks existed in West Virginia. I established NB candidacy and spent weeks studying and working with the NB Standards for my certificate area. At that time, the introduction to candidacy on NBPTS.org recommended no less than forty hours of NB standards study prior to commencing work with the portfolio entries. Learning how to document my strategies for embedding these standards in my professional practice was challenging. While I believed that I was embracing the standards in my practice, production of clear, consistent, convincing evidence within the limited page allotment for submission was extremely demanding. My first written draft for presenting evidence that my practices were aligned with NBPTS standards (Entry One) was 27 pages in length. However according to portfolio instructions, I was required to submit no more than 12 pages total for Entry One. A process in which I narrowed my focus and culled examples as evidence took place without the benefit of a mentor or a relationship with any board certified teacher. My writing attempts were isolated, with no feedback available other than that of family, parents, colleagues, and community members who assured me that I had the "right stuff" to be an NBCT but they had 
Journeys toward Reflective Practice: How Engaging in National Board Certification Influences Teacher Identities and Practices

no knowledge of the demands of the process. I was forced to ask myself questions about the portfolio prompts to ascertain the evidence the assessors would deem acceptable as accomplished by design and implementation. While it was my nature to take time to review and re-organize my instructional design, interaction with students, and assessment of student learning in progress, the NB process provided me with the impetus to articulate my thoughts succinctly. My thinking about teaching and learning, formerly unspoken, was exposed, explicit, and no longer private. Interestingly, this exposure had the potential for my thinking to be criticized and since that time, I have learned this aspect of the NB process may dissuade potential candidates. It did not have this effect on me because I knew no NBCTs when I was a candidate. I sought these explicit conversations about how we teach because I wanted to learn how others think about teaching in order to increase my knowledge base.

Mentoring NB candidates has enlarged my territory and provided the opportunity to develop an unassuming stance that is both respectful and open-minded. In mentoring, I was not necessarily the leader of learning. I strived to serve as a stimulator of mentee's thinking about teaching practice. In mentoring others, I realized that I was afforded the same opportunity to learn about teaching and learning through a new lens, my students were no longer elementary age, but colleagues who were respected professionals. The strategies employed went from explicit technique designed to achieve set measurable learning outcomes to more open-ended facilitation of professional thought. As a researcher, what I understood about teaching and learning was nurtured and stimulated by coursework, planned and incidental dialog, work with professional development provided for colleagues, and opportunities to conduct narrative interview with accomplished teachers. It was important for me to remember that in my role as a 
Journeys toward Reflective Practice: How Engaging in National Board Certification Influences Teacher Identities and Practices

researcher I was serving as "a filter through which the information was gathered, processed, and organized" (Lichtman, 2010, p. 117).

Subjectivity was and always has been embedded in the research process (Glesne, 1999), and as a researcher I was highly aware of the fragility of a study of lived experience with persons I considered as colleagues. My life experiences as a learner, teacher, mentor, mentee, colleague and employee were entwined. I explicitly placed learner at the onset of the series of professional roles as I intended to prioritize learning during professional interactions experienced. As an interviewer, my narrative interpretations were influenced by my lived experience so I consciously sought to understand the word choice of participants as I described their meanings rather than assigning my reactions to their musings. While it may have felt natural to share my experience with colleagues, I have noticed that I learn more as a listener than I do as a speaker. I completed the NB process successfully without the benefit of a cohort and subsequently began facilitation of multiple cohorts; therefore I have been intentional in developing continuing connections with many of the teachers who opted to engage in this reflective work about their own professional practice.

Reflectivity as a trait served me well as an analyst of the narrative stories of reflective decision-making. When I took the time to listen only and respond with minimal judgmental feedback with participants, I took myself as a learner to an unexplored space. My identity has been formed by interactions such as these dyads, and growth had its challenges. I was continually guided to assess my role, moved (by the nature of the interview process) away from reflexive thinking, and worked to be a researcher versus holding to my former long term standing as a practitioner. According to Glesne (2003), "the research methods with which you feel most comfortable say something about your views of what qualifies as valuable knowledge and your 
Journeys toward Reflective Practice: How Engaging in National Board Certification Influences Teacher Identities and Practices

perspective on the nature of reality" (p. 5). Narrative inquiry required time to build trust with participants and space as we explored by studying, doing, and reflecting, collaborating, and by sharing meta-cognitive decision-making. The act of study allowed me to review and rationalize how my view of authentic distinguished practices of accomplished teachers is not a "simple reflection of what is there, but is a set of social artifacts of what we make of what is there" (Schwandt, 1997, p. 20).

\section{Data Sources and Collection}

"Naturalistic inquiry calls for ongoing openness to whatever emerges in the field and during interviews" (Patton, 2002, p. 402). Therefore, using interviewing technique as a data collection method was structured as four interviews separated by relatively short windows of time. This spacing was done on two levels. First, I spaced the interviews to open the conversation with participants related to their education and early professional development as teachers by exploring queries related to: How do the contexts in which teachers are situated influence their professional development? The spacing was also designed to allow sufficient time for participants and for me to reflect effectively on the nature of our interview(s) and conceptually prepare for phase two. Interview two was more focused on engagement in the stages of the NB portfolio writing: How does the process of engaging in National Board Certification influence a teacher's development as a reflective practitioner? Then the third interview explored: How do teachers learn to teach over the course of their teaching careers? However, the interview questions did not broach these central concerns directly. The central questions were explored using a professional timeline search including elements of pre-service and in-service work that led the teacher in seeking the validation offered by the achievement of 
Journeys toward Reflective Practice: How Engaging in National Board Certification Influences Teacher Identities and Practices

National Board Certification, the quality the teacher attached to student teacher interaction, and most importantly, the factors that were considered by the teacher in framing classroom dilemmas leading to reflection on action. Our fourth and final interview acted as a coda, with interview strategies focused on each participant's current practices related to videotaping and analyzing student work (NB Entry 2 and 3), teacher goal setting for student learning (NB Entry 1) as embedded in the West Virginia Teacher Evaluation System, and journaling practices that replicated the writing processes (NB Entry 1, 2, 3, and 4) required during the National Board process. This interview focused on the teacher's thinking with just in time problem solving, provided evidence of reflection on/in action as visible within the videotaped teaching segment, and elements of the reflective journaling reflection. All three components of interview four provided an opportunity for my participants and I to discuss and analyze their work with the students they were currently teaching.

Salient to this line of inquiry was my confidence in the use of story in understanding the development of teacher efficacy. According to Patton (2002), "Cognitive scientists have found that stories are more memorable and better support learning and understanding than non-story narratives" (p. 196). When teachers narrated their own stories, they were articulating personal thinking, much in the manner used to write responses to the portfolio prompts employed in the process of achieving National Board Certification and renewal of the same. Success in the NB process made these teachers excellent candidates to orally reiterate (both the seemingly vague and) the intentional habits of ongoing reflective thinking during data collection for this study.

Interview guides for each of the three interviews, included in Appendix A, utilized openended questions to generate the reconstruction of participant's stories about their developing 
Journeys toward Reflective Practice: How Engaging in National Board Certification Influences Teacher Identities and Practices

teaching practices. Webster and Mertova (2007) cited qualities of good questions that might be divided into the following groups:

- Sensitizing questions such as what was going on?

- Theoretical questions such as how did these events and actions change over time?

- Structural/practical questions such as which concepts were well developed and which were not?

Furthermore, they suggested that within a narrative inquiry, "questions should be structured in such a way that they encourage reflection and recall...time and experience are critical here, as narrative is essentially temporal" (p.86). Therefore my design sequence of questioning was structured to allow for reconstruction of teacher-student interactions along a timeline that reflected the continuum of accomplished practices developed within the participant's teaching repertoire. Use of sensitizing, theoretical, and structural/practical questions yielded participant response patterns that were thoughtfully responsive to the probes offered.

The primary source of information was interview data and face-to-face conversation, both verbal and non-verbal in nature. Participant observation enabled notation of the nuances of the interviewer and participant interaction and as stated by Patton (2002):

Qualitative data describe. They take us, as readers, into the time and place...so we will know what it is like to have been there. They capture and communicate someone else's experience of the world in his or her own words. (p.47)

An accurate snapshot of the interview process allowed me to reflect on the nature and meanings of our shared words. Together we sought to gain a better understanding of the nature of educational practice, particularly that of a National Board Certified Teacher serving in the same community context over time. The shared meaning flowed from rapport and common experience, however it was nuanced by the fact that I no longer serve in the classroom and spoke 
Journeys toward Reflective Practice: How Engaging in National Board Certification Influences Teacher Identities and Practices

as a researcher rather than a colleague. The non-verbal data was a secondary source of information that lent elaboration to the research based conversation.

Field notes (my actions, interviewee actions and re-actions) were expanded as recorded daily post interview. While recording these notes, I also inserted personal reflective additions in an attempt to clarify complexities noted and maintain external balance in my thinking (Marshall \& Rossman, 1995). Field notes ultimately became an excellent tool for the development of subsequent interview questions to explore areas of participant thinking that were not anticipated.

\section{Data Analysis}

According to Miles and Huberman, (1994), the assumed strength of qualitative research was positioned in the close examination of the text created by interviewing participants. The analysis of massive amounts of data collected via narrative interviews presented a challenge in organization and reduction of data to meaningful sets. My choice of analysis methods allowed me to step back from the text to assess narrative structure and note emergent patterns.

My study was designed to engage with teachers in reconstructing and exploring their perceptions about their reflective practices through interviews. These meetings provided a space for my participants to tell stories of their individual situated lived experiences relating to becoming NBCTs. The teachers may have used these stories not only to share their experiences, but also as they made sense of them as they articulated their experiences in retrospect through constructivist processes. Therefore narrative and discourse analysis was the most likely means for investigating and made the relived experience somewhat less transient and available for discussion and exploration. The transcription of the interviews which included prompts related to the National Board process, current videotaped sessions with students, discussions about the West Virginia Teacher Evaluation System, and participant journals allowed me to analyze our 
Journeys toward Reflective Practice: How Engaging in National Board Certification Influences Teacher Identities and Practices

shared discourse in a number of ways, which included not only the spoken and written words, but also the dialogical interactions comprised of pauses: to refine meanings, to collect more useful terms, and to reflect on the ideas shared. Dialogical interactions also included emphasis, elongation, repetitive mouthing, and events such as coughs, chuckles, and hand to face gestures.

Table 3.2 Dialogical Notes with Ascribed Markings

\begin{tabular}{ll}
\hline Conversation Interaction & Notation \\
\hline Pause, momentary & $\cdot$ \\
Pause, noticeable & $\ldots$ \\
Word & Emphasis on word(s), sound(s) \\
( ) & Speech recorded that could not be transcribed \\
$(())$ & Events as described, e.g., ((coughs)) \\
\hline
\end{tabular}

After the tapes were transcribed verbatim, the printed versions were available for recursive study in sequential order. The repeated readings allowed for time as I took notes and highlighted areas of story telling that were uniquely enlightening based on the overarching emphasis of my research questions. I used coding (Saldana, 2012) on the third round of reading to bring a semblance of order and as I began to identify the stories that were emerging within and among the series of interviews I conducted with each participant. The notes became less cumbersome as coding enabled identification of salient passages. I discerned salient passages and applied thematic, structural, and discourse analysis to these reduced sets of field notes that were available for interpretation. 
Journeys toward Reflective Practice: How Engaging in National Board Certification Influences Teacher Identities and Practices

\section{Thematic analysis.}

Crotty averred, "all human life and every human situation can be seen as text" (p. 182). Text recorded through interviews and analyzed in narrative form yielded an opportunity to begin with an idea, seek supporting information for that idea, and return to the original notion with a more developed understanding. In this manner, thematic analysis provided a lens for illumination of teacher as reflective practitioner. The construction of participant-generated vignettes provided a vehicle for my participants and for me and we took a step away from the personal lived experience and understood, deconstructed, and reconstructed the lived experiences. This analysis allowed us to locate refined vocabulary, note evolving self-reflective strategies, and recreate a quilt-like foundation to illustrate their narrative understandings of who they were/are as teachers and learners. Kvale (2009) further suggested that conversation allowed us to find and examine these substructures of effective teaching practices as we worked "with a social construction of reality (where) the emphasis is on the discourse of the community. Communication of knowledge becomes significant" (p. 247). The act of communicating our shared understandings allowed us to record and analyze their value.

Thematic analysis of the content of the narrative expressed by the participant meant that the narrator's recurring emphasis after multiple interviews or recurring responses with the same interview held some level of significance. As the participant's recounting of lived experiences was recorded, "primary interest is in generating thematic categories across individuals, even as individual stories are preserved and regrouped, and the work is located in the narrative research tradition" (Riessman, 2008, p. 62). Constructionist theory guided the interviews and allowed participants to reconstruct the daily classroom experience by recall of teacher-student interactions. These data segments were recorded verbatim, coded for emerging themes, and 
Journeys toward Reflective Practice: How Engaging in National Board Certification Influences Teacher Identities and Practices

named after repeated readings. Themes that emerged with all three participants were based on "what" (Riessman, 2008) was stated, not on how the ideas were shared.

Thematic analysis provided opportunities to interpret accrued data, attached significance to portions, and promoted the culling narrative sections that appeared to be unsubstantiated to “portray a holistic picture” (Patton, 2002, p. 480) of teacher as learner. The descriptions I built that reconstructed practice through narrative were not simplistic or linear. As a researcher, I sought possible explanations for evolving teacher decision-making before, during, and after the National Board experience. The relationships between vignettes offered and the development of reflective expertise, while time bound, were not ascribed to any one set of factors. According to Patton (2002), my strategy of reading, re-reading, and reading part to whole in seeking themes had the potential to create meaningful representations of the lived experiences of my participants. Moreover, my previously stated acknowledgement that teaching context played a major role in each teacher's evolving level of accomplishment allowed similar values and themes to emerge across participants' stories. One advantage to gaining an initial sense of the whole body of documents was that subsequent readings were more likely to take the form of a close read (Miles \& Huberman, 1994). During close reading, I highlighted elements of text I believed to be repeated elements. Next I developed a coding system which I perused for repetition and noted the frequency of repetition. Coding took place as I marked both repetitive and less frequent elements and enabled the labeling of subcategories, which included consequences of teacher actions and lessons learned by teachers (Webster \& Mertova, 2007). The condensed information then led to the discovery of related elements and regrouped sets with common emergent themes.

An analysis of each teacher's theoretical stance, expressed in themes and followed by teacher decision-making was a new way of knowing for me. In facilitating teacher portfolio 
Journeys toward Reflective Practice: How Engaging in National Board Certification Influences Teacher Identities and Practices

work, candidates and I explored decision-making skills while we co-viewed videotaped lessons or co-analyzed student work samples. As a mentor, I asked portfolio related problem-solving questions but did not venture deeply into the NB candidate's underlying philosophies or understanding of educational theory. The recording of each participant's teaching belief system as related to reconstruction of his/her developing reflective practices was crucial to efficient data reduction and these components were analyzed to provide research findings.

\section{Structural analysis.}

Labov (1997) cited that data gleaned from narrative inquiry traced transfer of information from speaker to listener and yielded a "profound concentration of attention" (p. 1) with immeasurable influence on the listener. As the focus of many academic disciplines, narrative recitations retold the stories of lived experience and were to be understood in an "amenable framework" by the researcher. "A narrative of personal experience is a report of ...events that have entered into the biography of the speaker by a sequence of clauses that correspond to the ...events" (p. 2).

Structural analysis of narratives offered insights based on the temporal organization of the narrative. According to Labov (1997), the narrative clauses that began and ended within a temporal juncture were a report of real events were the realis mood. The irrealis clause in a narrative served the function of self-evaluation events of the speaker's experience during the telling. Analysis of both realis and irrealis narrative reconstructions of the teachers' experiences held value for me, the researcher, because events (realis) in the participants teaching lives were the substances of their reflection and subsequent evaluative (irrealis) constructs. In addition, I identified additional elements of my participant's narratives including the abstract (summary point of the narrative), orientation (time, place, situation, and participants), complicating actions 
Journeys toward Reflective Practice: How Engaging in National Board Certification Influences Teacher Identities and Practices

(sequence of actions, turning point, crisis, problem), evaluation (narrator's comment on complicating action), resolution (resolves plot), and coda (ends narrative, returns narrator to the present). Identification of these narrative elements were intended to provide insight into how my participants used narrative to create representations of their lived experiences that positioned participants and the people with whom they interacted in particular ways.

Use of structural analysis of the participant-generated narratives explored the way participants reflected on student learning in the classroom and their further reflection on what they believed worked in stimulating student learning provided insights into how participants understood the influence of the NB experience on their identities and practices. This analysis also provided opportunities to explore the ways participants chose to structure their stories and how these stories influenced their understandings and the ways in which participants were able to reconcile their lived experiences with current circumstances.

\section{Discourse analysis.}

According to Gee (2005), tools of inquiry were "thinking devices" and guides in the process of discovery. He made a distinction between "Discourse" with a "big D" and "discourse with a "little d" that transferred to shared meanings and interpretations during our interview experiences. The interest lay in how "discourse" (little d) allowed us to reconstruct and share classroom based lived experiences as familiar. Then it transformed as our common value system of accomplished teachers emerged during richly meaningful discussion centered on classroom teaching experience, and allowed us to enter into interaction in "Discourse" (big D) with collective:

Ways of acting, interacting, feeling, believing, valuing, and using various sorts of objects, symbols, tools, and technologies - to recognize your self in meaning and meaningful in 
Journeys toward Reflective Practice: How Engaging in National Board Certification Influences Teacher Identities and Practices

certain ways. In turn, you produce, reproduce, sustain, and transform a given form of life or Discourse. (p. 7)

Discourse was one means to build and connect our shared reality as (relatively homogenous in terms of background) National Board Certified Teachers. Most salient was our shared mission in examining teaching practices and way this connection brought us back on topic as we explored the questions posed about teacher as learner. Gee's analysis tasks permitted deeper understanding of the discourse by an examination of the way each story generated a potential "depiction... of what was said, not actually what was said" (1999, p. 18). In other words, the meanings expressed were not necessarily literal, and the pattern and intent of communication, by commission or omission, emerged. Discourse, two-way idea sharing, was built according to Gee by seven characteristics, leading to seven questions. I sought answers to two of Gee's questions in my analysis of our interviews: 1.) How does our language connect or disconnect things, make one thing relevant or irrelevant to one another? In analysis, I also explored: 2.) How does this language privilege or dis-privilege ways of knowing and believing or claims to knowledge and belief?

According to Gee (1999), discourse analysis served as a tool to ask multiple questions about "language-in-use" (p. 11). He posited that language was designed to fit the situation and communicate in that context. At the same time, context prompted communication as it determined the type of word choice and meanings conferred. Communicators "continually and actively rebuild our worlds, not just through language but through language used in tandem with action, interactions, non-linguistic symbol systems, objects, technologies, and distinctive ways of valuing, thinking, and believing" (p. 10).

Connection was an important area of Gee's reality that was explored because the use of language to "render certain things connected or relevant to other things" (p. 12) prompted and 
Journeys toward Reflective Practice: How Engaging in National Board Certification Influences Teacher Identities and Practices

molded a significant interchange of ideas. In the conversation with teacher as learner, the analysis of connection and disconnection, relevance and irrelevance assumed an important role and allowed interviews to flow from one theme into another. The very nature of teacher as learner involved active connection of classroom dilemma to potential solution, to solution impracticality or failure, to reframed dilemma in a potentially cyclical manner as we explored becoming a reflective practitioner.

Sign systems and knowledge also fit into the teacher as learner frame for Gee's discourse analysis. Educators may have had tendencies to speak to one another in a language forms that held nuanced meanings and was highly specific in reference to the design for learning, tasks assigned to learners, and assessment at multiple levels where students tend to perform. This type of language was not always student friendly, nor was it parent friendly, and may have exhibited unintentional exclusionary practice. Examination of the forms of language we used revealed a tendency toward use of privileged meaning, technical terms, and beliefs and ways of knowing centered on standards based instructional design. In our interview dyads, this language form was important when it created positive and trusting bonds because it may have been intended to eliminate repetition or refine meanings in common academic tone and usage.

Data analysis through emergent themes, structure of communication, and discourse allowed me to explore how teachers remembered and perceived their personal reflective practices through interviews. Telling the stories of their individual situated lived experiences relating to becoming NBCTs created data that might be assessed using narrative structure to note emergent patterns.

\section{Trustworthiness of Study}


Journeys toward Reflective Practice: How Engaging in National Board Certification Influences Teacher Identities and Practices

I approached this study with a genuine inquiry motive, with no idea of how the conversation with teachers might evolve and where the interviews would ultimately lead us. My stance was aligned with the statement of Dewey (1925), “...if we once start thinking no one can guarantee where it might come out...” (p. 222). For eleven years, I have acted as a mentor/facilitator in this process, asking open-ended questions of National Board candidates about their practices. The shift to researcher and the responsibility of developing a line of questioning designed to develop a narrative on teacher reflectivity posed significant changes in my stance and perspective. Patton (2002) posited:

Perspective that the researcher brings to a qualitative inquiry is a part of the context of the findings. A human being is the instrument of qualitative methods...the findings are thus inevitably connected to the researcher's credibility, competence, thoroughness, and integrity. (p. 64)

To this end, I professed and exhibited an empathetic view that enabled participant trust and seemingly facilitated conversation that was authentic and stimulating.

Reconstruction of the stages before, during, and after becoming a NBCT was a highly important strategy in building trustworthiness in this study. Reconstruction relied on participant decision making about what each now sensed as vitally important about these past events. Seidman (2013) argued, "In interviewing, it is better to go for reconstruction as directly as possible" (p. 90). After reconstruction was analyzed and reduced, member checking was conducted to gain the further insights of participants as they read data, reviewed interpretations, and shared feedback on the credulity of the presentation based on our interviews that I created in my attempt to record their lived experiences (Creswell, 1998).

My doctoral committee provided impartial feedback on method rigor and facilitated my responsive interpretation to assure its trustworthiness. My biases were explicitly stated. In my researcher's notebook, I attempted to separate my observations from my impressions in my effort 
Journeys toward Reflective Practice: How Engaging in National Board Certification Influences Teacher Identities and Practices

to be candid about assumptions about teaching and learning that I brought to the study. The process was distinctly iterative, because I listened to our taped interviews multiple times, read and reread the transcripts, and was deliberate in trying to produce a transparent audit trail. My writing started with description, these passages were analyzed in conjunction with the transcripts, and through my spiraling reflective thought processes, and I sought connections but did not force insights. For example, use of similar language patterns, particularly when participants spoke of their struggles with administrators, were noted but did not become a focus during the research analysis process.

\section{Limitations}

Collection of data by interview method had both strengths and limitations. According to Seidman (2013), "Every research method has its limits and its strengths" (p. 143). Interview data had the strength of allowing participants to express voice as evidence of teacher as learner was produced and documented. Yet the accuracy of voice was related to the ability of the participant to speak in recall of the NB experience as well as discuss his/her current practices as an NBCT. Patton (2002) asserted, "Interview data limitations include possible distortions due to personal bias, anger, anxiety, politics, and a simple lack of awareness since interviews can be greatly affected by the emotional state of the interviewee at the time of the interview" (p. 306). Awareness of limitations served as a guide to the structure of questioning in seeking accuracy of participant voice.

Narrative interviewing technique relied on the researcher as the instrument for data collection. In the words of Patton (2002): 
Journeys toward Reflective Practice: How Engaging in National Board Certification Influences Teacher Identities and Practices

As an evaluator, I...approach my task with equal measures of chutzpah and humility so that I will not fail to challenge all of the assumptions, especially my own, nor ever assume that I have all the questions, much less the answers, right (p. 337).

Limitations withstanding, the parallel of a positive National Board experience in diverse content specialization allowed me to use common standards based vocabulary with the participants, which in turn enabled the narrative conversation to flow, and at times ebb, in waves.

Interviewing, was a mainstay in data collection and became a restriction when the conversation ebbed, however pauses led us to points when we stopped and reflected on the thought processes about teaching explored.

\section{Subjectivity and positioning of principle researcher.}

I, too, experienced the National Board process and worked in the field as a reflective practitioner. Though my experiences may have resembled those of participants, it only paralleled the lived experience of participants who continued to serve the educational needs of students while in the classroom while I became a researcher and an administrator. This original similarity was important in establishing the researcher and participant bond, however it also placed me as the instrument of research (Patton, 2002). Situated as such, I chose to be highly conscious of the similarity and potential for bias and deliberately attempted to negate any of my prior expectation of the paths our interviews might take. I was challenged by close listening and recording while interviewing which was paramount, and interpretation of data ensued. Bias was known to manifest in many forms and my close attention to context of participants was intentional. This provided limits on my NBCT lens, as I placed tighter focus on the participant's lived experience. According to Tallmadge (1997),

Qualitative inquiry offers opportunities not only to learn about the experiences of others but also to examine the experiences that the researcher brings to the inquiry, experiences 
Journeys toward Reflective Practice: How Engaging in National Board Certification Influences Teacher Identities and Practices

that will, to some extent, affect what is studied and help shape, for better or worse, what is discovered (p. ix).

Acknowledging this influence was very important to shaping the open-ended questions focused on context that provided a framework for this inquiry process.

\section{Quality and authenticity of interactions between participants and researcher.}

As a researcher, I had an obligation to examine how my presence as an interviewer held potential to taint results of these recurring interviews on multiple levels. Therefore, I discussed this concern with participants prior to completing the interviews and my candor assisted in the establishment of common objectives. While I sought the opportunity to observe, explore, and study the significance of the professional growth of each participant before, during, and after the National Board process, participants were afforded the opportunity to renew self-dedication to the reflective thinking each had examined before, during, and after NB candidacy. The audience of a researcher gave each a prior uncharted space to develop his/her "ways of knowing" (Patton, 2002, p. 6). Essentially, the struggle to move our common and diverse "ways of knowing" from tacit to expressed often provided an appropriate stimulus so we engaged in constructive and/or reconstructive work as we pieced together teacher as learner scenarios in the community, school, or classroom level context.

Using the framework of context, according to Lightfoot-Lawrence (1997) was critical to my capacity to develop outward understanding. Patton (2002) considered that "Naturalistic inquiry preserves natural context" (p. 62). This "elevation" of context was a predominant feature of the NB process, especially in the evidentiary pieces included in the written portfolio, therefore participants were conditioned to its influence and accepted its importance in the research realm. One of three overarching questions of this study was "How do the contexts in which teachers are 
Journeys toward Reflective Practice: How Engaging in National Board Certification Influences Teacher Identities and Practices

situated influence their professional development?" and this query resonated with participants, helped foster communication as we established common ground, and allowed me to maintain open-ended questioning strategies throughout our sessions.

\section{The challenges of constructivist research in a constructionist environment.}

Constructivism implied meta-cognitive work; in this study this was the work of teacher as learner. Crotty (2010) reserved "the term constructivism for epistemological considerations focused exclusively on the meaning making activity of the individual mind" (p. 58). This separated teacher and student interaction and the influence of external source(s) from the private musings of the teacher as learner. Furthermore, Crotty (2010) theorized, "the distinction itself is an important one. Constructivism taken in this sense points up to the unique experience of each of us" (p. 58). Constructivism therefore exists inside the mind of the teacher as he/she reflects and "makes sense of the world" (Crotty, 2002, p. 58), a world where the teacher co-existed with others. The influence of student led dialog directed toward the teacher lent research to a differently defined constructionist frame, somewhat removed from constructivist (internally generated) theory, because all human interactions held social value. According to Patton (2002), "the two terms are difficult to distinguish and easy to confuse" (p. 97). For the purposes of this study, constructivism referred to the meta-cognitive exploration of each teacher's individual instructional decision making that was situated inside the constructionist world where teachers and students were cohabitants. Constructivism guided questions that were designed to illuminate the principal precept, "How do teachers learn to teach over the course of their teaching careers?"

\section{Limitations of methods of data collection.}


Journeys toward Reflective Practice: How Engaging in National Board Certification Influences Teacher Identities and Practices

Narrative inquiry is the study of experience, and experience, as John Dewey taught, is a matter of people in relation contextually and temporally. Participants are in relation, and we as researchers are in relation to participants. Narrative inquiry is an experience of the experience. It is people in relation studying with people in relation. (Clandinin \& Connelly, 2000, p. 189)

Researchers struggled to convey the lived experience of participants accurately because these narratives were disparate, intimate, and influenced by memory colorization. As viable exploration, narrative study yielded responses that resemble a river delta, with information flowing in many diverse patterns and were limited only by the researcher's ability to discern meaning formed by the dialogue. This was complicated by the fact that the researcher was the primary instrument in data collection. According to Clandinin \& Connelly (2000) narrative inquiry takes place at the boundaries between researchers' own "narrative histories and the narrative research they undertake" (p. 46) in examining the lives of participants. Holding a stance of empathic neutrality (Patton, 2002) was one strategy that resonated and assisted in the process of data reduction and the development of findings generated by the interview process.

Furthermore, the nature of narrative was dependent upon the reconstruction of the teacher's professional history and willingness to share in this meta-cognitive work. While the rapport between participants and researcher contributed to the quality of data produced, there was no guarantee that the narrative interview would generate usable material for analysis. Seidman (2006) cited ambiguity in response as a confounding factor that may occur during narrative interview processes. It was also posited by Patton (2002) that participants might have unintentionally distorted their responses when certain conditions existed. Holstein and Gubrium (2012) shared a case during which the participant unconsciously blocked legitimate response patterns and the skill of the interviewer was able to overcome some barriers to the process. This dependence on participants had the potential to severely limit research findings. 
Journeys toward Reflective Practice: How Engaging in National Board Certification Influences Teacher Identities and Practices

\section{Summary}

In summary, my research study used constructivist theory in an exploration of reflective practice in education to investigate the lived experience of current National Board Certified Teachers. Close attention to the development of reflective technique throughout the teachers' years in the classroom was enabled by the use of narrative interview processes. Narrative data collected via interviews with open ended and structured questions was taped and transcribed verbatim from conversations with three NBCTs from various school settings. Analysis of the data began with thematic analysis using a part to whole approach. Open-ended inquiry prompts illuminated a path for Labov's (1997) structural analysis and Gee's (1999) discourse analysis framed by connection, relevance, and forms of language enabled further investigation of data. Rich descriptions of the research process, voice and style attributes of participants, and the character of mutual respect stimulated my findings, which were documented through our conversation, and illuminated how teachers made sense of their teaching experiences and became accomplished reflective practitioners. Member checking offered stabilizing feedback and the review of colleagues allowed for my work to demonstrate trustworthy findings. Each member of my research audience determined how reflective practice appeared in my work and made decisions about its rigor and usefulness in improving knowledge of educational practice.

\section{Overview of Chapters 4, 5, 6, and 7}

The next four chapters present my findings from inquiry in exploration of learning to teach over the course of one's teaching career. Each chapter began with a biographical outline of 
Journeys toward Reflective Practice: How Engaging in National Board Certification Influences Teacher Identities and Practices

Margaret, Ethan, and Gretchen and noted the correlated teaching context for each. The dialogue presented illuminated participants' meta-cognitive work as each one reconstructed their use of reflective strategies. I sought patterns or themes as emerging evidence that was drawn from excerpts of the texts generated. I elaborated upon these texts by rereading the recorded thickly descriptive passages in my attempt to share these findings. Chapter 7 detailed an interview dedicated exclusively to video review, the participant's journaling or note-taking practices, and experiences with the revised West Virginia Teacher Evaluation System. Each chapter concluded with a summary of the participants' toolkit for achieving accomplished practice. This toolkit became evidence that accomplished teaching strategies remained a part of the participants' repertoire of pedagogical practice. 
Journeys toward Reflective Practice: How Engaging in National Board Certification Influences Teacher Identities and Practices

\section{Chapter 4}

\section{Margaret}

Margaret's story of becoming a reflective practitioner demonstrated elements of consistency and change, traditional and progressive practices, reflexivity and reflection. Margaret began her teaching career during the mid-1970s in an elementary setting in West Virginia, and then moved and was employed as a teacher in Florida and Georgia. She returned to West Virginia and was employed in the field of social services for several years, eventually returning to teach in a middle school setting. The interview series focused mostly, but not exclusively, on her experiences while employed as a teacher in West Virginia. Margaret launched the interview series by stating that in her onset as a teacher, she was "more reactive than reflective. I would say that was the biggest difference." While her memories of colleagues, mentors, and administrators were vague, they were also revealing of her journey in becoming a reflective practitioner.

Margaret currently characterized herself to be a mathematics specialist and stated that (during her interview for rehire as a teacher in West Virginia) she overtly expressed she had been "born to teach." Now in her early $60 \mathrm{~s}$, she has no desire to retire in the near future and appears to be a highly energetic, focused instructor of both $6^{\text {th }}$ and $8^{\text {th }}$ grade mathematics in a high poverty Title 1 school. She also has no desire to move from this location to a more affluent neighborhood to teach, although I am aware she has been approached by principals at other locations and asked to consider a position in their schools.

Margaret was able to recall very specific information during our interviews; she thought through the prompts with care and appeared to exert concerted effort to provide thorough 
Journeys toward Reflective Practice: How Engaging in National Board Certification Influences Teacher Identities and Practices

answers. While she seldom overtly referred to teaching colleagues, administrators and mentors, there appeared to be evidence that interactions with trusted adults played an important role in her development as a teacher.

While these interviews were not fully reconstructive in nature because she often told stories about current events, there was an element of purposeful recall as she thought of her actions and decision-making during her previous school years. This deep thinking often created long pauses and a discernable level of deliberation as she constructed her responses. She openly talked about her current teaching practices and described how she arrived at these practices, which she believed to be successful with the students she currently teaches.

In her reconstruction of the period she has been an educator, three trends or themes emerged: elements of consistency and change; traditional teaching evolving into student centered progressive practice; and movement from reflexivity as an educator toward use of notable levels of reflection as are noted in this chapter. These themes are used throughout the chapter to document and discuss her development as a teacher and reflective practitioner.

\section{Margaret's Reflective Practices prior to National Board Work}

There was a sense during Margaret's first interview that reconsidering her early years in teaching as a fourth grade teacher was something she had not done with any depth since she attained National Board Certification. The accomplishment of NBCT status may be a major factor in her current professed belief when she said, "I am an accomplished professional teacher." At one point, she stated with apparent personal regret, "I wish I could go back and do those early years all over. I would be so much better." She was explicit in discussing her practices as "teaching the way I was taught, feeling frustration about not knowing how to reach 
Journeys toward Reflective Practice: How Engaging in National Board Certification Influences Teacher Identities and Practices

students, and being on my own." However, she eventually distanced herself from the desire to go back in time when she stated, "I mean, you learn from experience." Margaret seemed to resolve her early frustration with learning to teach by taking personal responsibility for student learning:

I think I was beginning to evolve. I was changing my mindset about how I had to approach teaching... because I wasn't there yet. I still wasn't ....reflective.... think that was the life changer for me. . .I thought about (my students)... all the time...but...there was something...I don't know... something not quite there yet. How many years do you have to teach before it gets there? ((Laughs)).

It may be that she needed the structure of the NB process to understand and engage in the reflective practices that would later inform her teacher identity.

Bransford \& Darling-Hammond (2005) seemed to capture what Margaret has realized about the influences of her experiences on her practice and teacher identity:

Experiences in and of themselves are not necessarily educative. What makes them so are the opportunities for...(people) to reflect on and challenge their initial assumptions they (teachers) carry with them into the field...guided reflection helps teachers make sense of what they have seen and heard and helps them learn how to use their emerging knowledge to design curriculum and assessment materials to help the students they teach. (pp. 265-266)

As a result of reflecting on her experiences, Margaret realized she needed to focus on her students and change her instructional approach. Rather than blaming outside forces or her students, Margaret accepted responsibility for what was occurring (or not) in her classroom and thus, her experiences became educative.

Listening to Margaret and providing her with a space to reconstruct her early experiences in the elementary classroom provided opportunities for Margaret discussing her first school context, a Title 1 school and its influence on her development as a reflective practitioner. She maintained that collegial rapport was non-existent in her evaluation of this context and ultimately 
Journeys toward Reflective Practice: How Engaging in National Board Certification Influences Teacher Identities and Practices

resolved, "I had to figure it out on my own" when she experienced dilemmas of practice. It was clear Margaret recognized the conversations with colleagues that did occur as storytelling and providing aid, rather than collaborative work that changed individuals and contexts. She shared, "There were several of us who taught $4^{\text {th }}$ grade together (orientation) and we would occasionally talk in the hall in passing, but to have official meetings to sit down and discuss students, that never happened." While Margaret believed the school had an "excellent staff” and everyone was "very involved with the students," she recognized that the lack of collegial communication about student needs, academic growth, or curriculum design was a major complicating factor in her early teaching years, which influenced not only how she engaged in reflection, but also who she sought as a source of counsel and professional expertise.

According to Bransford, et al., (2000), "Learning is influenced in fundamental ways by the context in which it takes place... teachers must be enabled and encouraged to establish a community of learners among themselves" (p. 22). While the teachers in Margaret's early context developed congenial relationships with each other, they did not create a community in which they engaged in collegial dialogues and made the dilemmas of their practice public. It was important to note that these experiences took place during the 1970s and school settings during this time did not often provide common planning time or encourage professional learning communities, nor did principals serve as facilitators of professional learning. Margaret's references to teachers "talking in the hall" were evaluated as superficial conversation with fellow grade level teachers, which, in retrospect she believed contributed to her frustration with her reflective practices and professional development.

Margaret described one specific training session for professional staff that took place after school hours and related the following: 
Journeys toward Reflective Practice: How Engaging in National Board Certification Influences Teacher Identities and Practices

Someone came in to talk with us about discipline in the classroom. And I had a particular student I struggled with and I can remember saying... here is what I have tried, and people would kind of go, would you just shut up, we want to go home (complicating action). They wanted their hours and they wanted to go home. And I seriously wanted a solution for this child (further complicating action)...eventually I went well okay...this is not what we are here for (evaluation), so I need to be quiet. That's the way I felt, you know, they didn't want to hear about him.

Her resolution indicated no positive outcome in terms of professional learning or in collegial support development.

Bransford and colleagues (2000) maintained that it was common for professional development for teachers to be "not learner centered." This appeared evident in Margaret's recollection, as a percentage of teachers in attendance at this professional development session remained unengaged during the time designed for collaboration. Margaret recognized that this type of professional development from an outside agency, where "someone who came in to talk to us about discipline," may have been ineffective as she was unable to determine how to make use of these strategies in her own classroom, with her own students. It seemed that Margaret looked to these outsides experts for answers to her dilemmas and did not, at this point in time, feel empowered to reflect on and discover her own "answers" to her problems of practice.

However, Margaret was interested in improving her practice and she embraced the opportunity to engage in discussion with these "experts," about the dilemmas she experienced in her classroom. Her peers did not share her perspective and because they did not appreciate the questions she posed, their disapproval served to silence Margaret. Ultimately, Margaret was unable, even retrospectively, to identify how taking responsibility for her own professional development or engaging in reflection on action might have been used to resolve these difficulties.

Principals, in their roles as school leaders, may have supported teachers' professional development and reflective practice. However, Margaret shared that her main interaction with 
Journeys toward Reflective Practice: How Engaging in National Board Certification Influences Teacher Identities and Practices

her principal seemed to revolve around his observations of her classroom work. She evaluated the relationship as hierarchical and largely ineffectual as in his feedback about her teaching, he “never talked about anything with students." Her first principal simply dispensed advice such as: "You can't be their buddy." Ultimately, Margaret felt she "didn't have much communication with him," which could have proved to be problematic in her development as a reflective practitioner, but she did not characterize this lack of communication as crucial to the development of her teaching practices and teacher identity. In fact, she indicated a low regard for administration overall across the interview series.

Based on Margaret's narratives of her early teaching experiences, it is evident she sought wisdom from multiple sources, including her colleagues and outside experts. However, she perceived that her support system within her school context was almost non-existent, which proved to be a source of frustration as she attempted to determine how she could improve her practice. Subsequently, it seemed Margaret determined that her prior experiences as a member of a large family may have influenced her teaching behaviors in the classroom. As she continued her review of the years prior to seeking NB Certification, she identified a number of ways in which she was able to engage in reflection, independently and collaboratively.

\section{The influence of autobiography on reflection and the development of reflective}

\section{practices.}

As Margaret oriented her early experiences with reflection-on-action (trying to "figure it out"), she shared, "I would talk to my mother sometimes.” It appears that Margaret's mother was her main source of support in her early years of teaching as the conversations Margaret had with her mother provided a space for her to describe and explore the complicating actions of her teaching; however, Margaret evaluated her mother's perspective as somewhat naïve and not 
Journeys toward Reflective Practice: How Engaging in National Board Certification Influences Teacher Identities and Practices

necessarily helpful for Margaret as she attempted to resolve the dilemmas she faced in her classroom. Margaret said,

But that was before she (her mother) was in the work world and she had a different view (complicating action)...I don't think her view of life changed until she became a social worker and then she saw a whole different side of life...(she thought) if you treat them with respect, you will get it back from them....and to a certain extent, this is true...but everybody isn't nice (complicating action)... You have trouble with parents sometimes (complicating action), and you know, you have kids who act up in class (complicating action). I think it went way beyond her imagination of what some kids were capable of doing...I don't think she had the understanding of what I was dealing with.

Thus when Margaret turned to her family support system, she often felt misunderstood and evaluated the solutions offered by her mother as ineffective or untenable. Although Margaret's resolution was to ignore the advice provided by her mother in these conversations, family experiences may have continued to play a role in her professional problem solving.

Margaret also used her experiences as a member of a fourteen person family as a context for understanding the students she taught. While her experiences may have been dissimilar to her students' home life experiences, family events in such a large household may have taken on classroom-like nuances. Her narratives, which described treating her students using strategies that simulated her treatment of siblings were pervasive in all three interviews and indicated she used her experiences with her siblings as models to make sense of the dilemmas she experienced in her classroom and to make decisions about how she would address these problems of practice. Gee (2011) maintains that language is used "to render certain things connected or relevant (or not) to other things" (p. 19); thus, I focused on the words Margaret used as she described the influence of her family on her teaching. Margaret often oriented her classroom experience to her prior family experiences. She said, 
Journeys toward Reflective Practice: How Engaging in National Board Certification Influences Teacher Identities and Practices

I could relate (the problems of teaching) to my younger siblings all the time. I was like a second mother at home, so I was like a mother at school too. But I also could be in your face ((laughter)). So, later I came back to mothering because it was a little more effective.

Margaret connected her early teaching experiences, and possibly her teacher identity to the ways she "mothered" younger siblings, which did not necessarily address how she might have attended to problems of learning. Margaret also frequently referenced the way things were with her family before she married, for example saying, "So, I ended up teaching them (students in my classroom) things we played as kids. And that was very successful and they enjoyed it a lot because I knew what I was talking about." It seems that Margaret's curriculum was also influenced by her experiences growing up in a large family. She seemed to be developing an understanding of the connection between expertise and student learning, as she attributed her students' successes to the fact that she knew what she was talking about. However, the nature of the expertise she was using to make instructional decisions was not described and was simply connected to student enjoyment, rather than learning. Her reflection on practice was unsophisticated as she did not explore how her practice influenced student learning. It is possible that her context valued keeping the students "busy" and "under control," which Margaret had learned how to do as part of a large family.

However, although Margaret used her familial experiences to inform her teaching, her inability to effectively frame, examine, and attempt to solve the dilemmas of her classroom practice (Zeichner \& Liston, 1996, 2014) led to stressors: “I worried so much (during) my first five years of school (teaching) about these kids. I took them home with me all the time. Just mentally took them home and worried about them constantly." She evaluated her own work by stating she "didn't know how to help my students" and her ultimate resolution was to address the problems of practice using strategies that had once worked with her younger siblings without 
Journeys toward Reflective Practice: How Engaging in National Board Certification Influences Teacher Identities and Practices

questioning the assumptions and values she was bringing to her teaching (Zeichner \& Liston, 1996, 2014).

Margaret's tendency to compare her students to her siblings and to make decisions about her pedagogy emerged as a reflective strategy. She shared,

I had a student who was extremely intelligent and I felt like I couldn't keep up with her (complicating action) almost. Like I needed to do something more to stay ahead of her...I wish I could go back and do it over... it took me to a while to place her and see she is not getting what she needs.

As Margaret made sense of this problem of practice, she compared this student's needs to those of her brothers and sisters. She said, “...especially my youngest brother who was very smart... So that is when I decided, I need to do something else for her. It's not fair." When she accelerated this child's curriculum as a resolution, Margaret remained unsatisfied when she reviewed the papers she assigned to this intellectually gifted child and evaluated the child's outcomes. In Margaret's evaluation, she said, "She could finish everything without having to think. I said this is not right. This is not right to make her sit through this." As Margaret discussed her early teaching experiences, she recognized this event illustrated her early reflective practices and was also representative of the frustrations she experienced during her years in fourth grade teacher.

Margaret also noted the influence of her prior experiences in school settings on her early experiences with teaching and reflection. As she reminisced about her college career she shared:

It's the way I learned and it was the way I was taught to do in college too. And I was pulling on prior experience. This is how my teachers did it and I am a pretty smart person so this must be how it works. And it was pretty much like filling in the blank...was it black or white. And that was the type of teaching I did then. 
Journeys toward Reflective Practice: How Engaging in National Board Certification Influences Teacher Identities and Practices

This is how I was taught became a repetitive phrase. Many times in sharing her resolutions for the dilemmas of her practice, Margaret indicated that teaching and learning behaviors were implicit. She depended on her experiences in a large family, her memories of being a student, as well as the models of teaching she observed to provide the "expertise" she needed to address the problems of practice she identified.

\section{The influence of sacred stories on reflection and the development of reflective}

\section{practices.}

Margaret, in orienting her teaching, asserted, "I was very traditional, you know...here is the question, they [the students] copy the question off the board, they answer the question." In reflecting on her early experiences, Margaret recognized, "And I really think looking back that was probably a control thing too. Because they would be busy copying from the board rather than busy thinking (complicating action), you know, just to keep them busy." She now realized she did not engage in reflection during her early career, but Margaret tempered this realization with, "I tried to do what was right (evaluation) ... I taught them the way I was taught (resolution)...I would say the ones (teachers) in my grade even were even more traditional, more inflexible than I was.” While Margaret assumed ownership of her instructional decisions by remaining a first person speaker throughout this lengthy passage and seemed to be moving toward problematizing her "traditional" practices, she also seemed to position herself as "better" than her colleagues, who were more traditional and inflexible. She closed with, "I was worried about being in control and afraid to be too flexible." Thus, while Margaret aligned her teaching practices with the "sacred stories" of her school, Clandinin and Connelly (2000), and used her autobiography to justify her traditional teaching (the way I was taught), she also seemed to acknowledge, as she reflected on her early teaching, that her resolution was not optimal. 
Journeys toward Reflective Practice: How Engaging in National Board Certification Influences Teacher Identities and Practices

Margaret may have believed that having control of her students took precedence over promoting their learning based on her understandings of the norms and traditions of the school. Indeed, pressure from colleagues and the ways in which they positioned teachers and students may have exerted an influence that Margaret did not openly question until many years later when she was immersed in an entirely different school setting. In the context of a traditional school setting of 1970 - 1980, Clandinin's and Connelly's theory of "sacred stories" (stories imposed upon teachers via the school, district office, or state and federal governments) emerged.

What teachers know depends on the school stories and stories of school that constitute their landscape..."how is teacher knowledge shaped by the professional knowledge landscape in which teachers work?' ...We believe we have shown that the professional landscape of schools is of such contextual complexity...that it is simply not possible to use this (research knowledge base)...to build with confidence, programs that lead to better teaching... We believe that teacher's practical knowledge, set in the context of teacher's professional knowledge landscapes...points in a different direction. (p. 29).

Margaret did not question her earliest professional landscape; she accepted without question the "sacred stories" of her apprenticeship of observation and her context (copying from the board) and their influence on student learning behaviors (keeping busy). In fact, Margaret perceived these practices to be appropriate in that setting at that time. However, as Olson and Craig (2005) assert:

Regardless of whether teachers personally approve of the communal story and whether it fits with the personal teaching narratives they are creating, compelling reasons exist to at least appear to be living the socially authorized story or stories (p. 163).

So while Margaret adopted this "”" as her own, her inability to create appropriate secret and cover stories led to frustration, which eventually contributed to Margaret's leaving teaching and pursuing other career options for a period of time. Furthermore Margaret expressed retrospective angst when she said, "I wish I could go back and do those early years all over. I would be so much better." As a veteran teacher, she recognized the internal conflicts that existed 
Journeys toward Reflective Practice: How Engaging in National Board Certification Influences Teacher Identities and Practices

within her first three teaching placements over eight years as tensions she was unable to problematize and resist.

\section{The influence of isolation and collegiality on reflection and the development of} reflective practices.

Referencing her first teaching position, Margaret shared her regret over the lack of tangible support from her colleagues, her principal, and the families of her students. Due to the reconstructive nature of our conversation, this appeared to be a result of an appreciation of her current supportive teaching context. She oriented her early circumstances when she stated, "I didn't have a mentor, and the only support would be when I would ask other $4^{\text {th }}$ grade teachers, like at lunch." These conversations with colleagues were casual, rather than collegial and Margaret was the one who approached her colleagues to share the complicating actions posed by

the behaviors and learning of specific students with questions such as, "How do you deal with so and so?" While her colleagues might have responded to her questions, Margaret felt profoundly isolated, which she shared in this evaluation of her interactions with colleagues: "But you were pretty much on your own I felt like a little island." Her fellow teachers were not unfriendly, but when asked about their role in welcoming her to the profession and engaging with her in collaborative efforts toward problem solving, Margaret recalled, "I don't remember much of any (support from my peers)." Margaret's resolution was to "just deal with it and figure it out." At this point in her career, any reflection Margaret engaged in was done independently.

Margaret continued her narrative related to advice seeking and related an experience that occurred in a subsequent position in a new teaching context. In this new position, Margaret was assigned a mentor who came to watch her teaching one time. This mentor told Margaret, "You don't need me," which proved to be a complicating action for Margaret as she sought mentoring. 
Journeys toward Reflective Practice: How Engaging in National Board Certification Influences Teacher Identities and Practices

Margaret "never saw her again," providing a resolution for this non-relationship and leading her to assert, "The mentor policy was completely ineffective." These experiences led Margaret to be dismissive of school based organizational structures and appeared to be a factor in her decision to seek National Board certification. In fact, Margaret's achievement of National Board Certification seemed to provide the validation and affirmation that Margaret often sought from mentors and colleagues.

Margaret continued to seek the expertise of others by asking informal questions of colleagues in various contexts: "At my school where I currently teach, but before I began the National Board process, we did not have collaborative teams at that point, so any conversations were held at lunch." As she evaluated this context, she said, "But I can remember, my lunch period was extremely supportive. And there were people with a lot of experience... that was very, very helpful to be able to go to lunch and talk about issues." Margaret felt comfortable sharing her problems of practice and she positioned colleagues as more knowledgeable than herself, who provided the expertise she needed to resolve the complicating actions she experienced in her classroom. Margaret said,

The experienced person would say... this is what I think... and try this... use discussion, use small groups to teach, use hands on materials, and things like that. So, I started to think about... well, how can I do this in a math class? You know, and that was very helpful to me.

Margaret acknowledged that this newer school context was supportive and she suggested that the team problem solving, which occurred in the lunchroom, played a major role in the development of her teaching strategies (resolution). The narrative Margaret's colleague shared about her practice, led to Margaret adopting similar practices, which expanded her teaching repertoire, but did not necessarily promote her development as a reflective practitioner. 
Journeys toward Reflective Practice: How Engaging in National Board Certification Influences Teacher Identities and Practices

Talk about teaching appears to have been a source of comfort for Margaret and this is potentially indicative of a propensity to accept without question the "sacred stories" of veteran teachers as a guide for less experienced practitioners. Margaret said, "I need to try something different, but I hadn't really thought about what does that mean." Margaret described her early attempts at using small group work and the dilemmas she encountered. Over time these struggles may have compelled her into problematizing her practices as an early form of reflection. According to Olson and Craig (2005) "these multiple stories [about a practice] give rise to tensions and entailments that emerge at the intersections where teacher's personal knowledge constructed and reconstructed from experience- meet the knowledge constructed by others" (p. 163).

Margaret responded to the complicating actions she experienced when implementing small group work in her classroom by seeking informal support. Once again, she sought an experienced colleague (a math teacher with 30 years of experience) and she evaluated his help in the following way: "He was extremely helpful...Um, he helped me pace my lesson plans... quizzes... set up my grade book... bell ringers. He taught me a lot of organizational skills that were very helpful in the classroom." Thus on a pragmatic, advice seeking level, she successfully connected with peers, while on a deeper reflective level, she maintained no support was readily available for collegial conversations. According to Schön (1983), "what teachers know becomes entangled with what they are supposed to know" (p. 165). It is possible Margaret believed she was "supposed to know" how to resolve her problems of practice, but she had not yet identified reflection on action as a strategy to address her dilemmas. Instead she employed her ability to "recognize and name the sacred stories," (Olson \& Craig, 2005) of this setting as a means for supporting her professional development, even if these pedagogies and the ways they were 
Journeys toward Reflective Practice: How Engaging in National Board Certification Influences Teacher Identities and Practices

enacted continued to promote traditional teacher centered practices. Margaret's decisions to remain in this school longer than the combined time spent in her previous teaching assignments may have been due to the fact that the "sacred stories" of this context aligned with her understandings of teaching and learning, and positioned her as a teacher who knew what she was supposed to know.

\section{The development of independent reflective practices.}

As Margaret gained more experience in the classroom, she discussed the development of her independent reflection strategies:

I started to think about it [problem solving in my classroom] not only as a surface thing, more in depth, I guess in thinking [about my students]... why do you think they are acting this way? What is going on at home?

In this way, Margaret was beginning to attend to the contexts in which she was situated, as well as the contexts in which her students lived and learned. The questions that emerged as a result of her reflection-on-action provoked a new way of responding to problems (getting to know students) rather than relying on what she knew about caring for her siblings. In a further complicating action, she said, "You know I found out about that boy and what he had to deal with every day when he went home, I became more compassionate." As she learned to evaluate her knowledge of students, she created different resolutions for her problems of practice. Margaret adopted more progressive, student centered practices, which were informed by her knowledge of her students and the relationships she developed with them. While race was not explicitly mentioned as a factor, Margaret acknowledged, when asked that the student to whom she referred was black and his home based values were quite different than her own. She gained a new perspective of this student and came to respect him when she acknowledged his struggles outside of school venue. As Margaret reflected on this experience, she recognized that 
Journeys toward Reflective Practice: How Engaging in National Board Certification Influences Teacher Identities and Practices

acquiring authentic knowledge of her students and caring about her students as people was essential for developing mutual respect and promoting student learning, which she shared this vignette:

What I would do to reach my students changed. I really think it was just doing those little personal things...like making sure they had cookies at Christmas and those kinds of things. That's when I finally started to reach them... that they knew I was genuine. You have to prove that you're genuine before they will accept anything from you...learning...help....anything. If they don't think you're genuine they are not accepting.

Margaret also questioned her disciplinary practices, connecting her newfound reflective practices with her autobiography (understanding of parenting): "I think I've learned if you raise your voice, they (a complicating action) tune you out. They completely turn you off." She evaluated this thinking when she stated, "And I have come to the conclusion they probably get screamed at while at home, so they learn not to hear you." She continued to stress her perspective as a relationship-builder and her resolution of this conflict with students and averred, "I became gentler...I became less...I think I was more aggressive when I was young because I was trying to prove I'm the boss and now I think you can do that a different way." She went on to affirm, "I found out what was more effective and it is more effective to come at it [teaching] from respect... a quiet respect... rather than I'm the boss here." It seems important to note that she now referred to respectful relationships with students as a factor in her reflections on her teaching.

While Margaret had previously relied on authoritarian strategies that positioned her as "the boss," she now believed these strategies were ineffective for ensuring her teaching engaged her students and promoted their learning. She said, 
Journeys toward Reflective Practice: How Engaging in National Board Certification Influences Teacher Identities and Practices

Rules. Here's the rules. I don't know what I expected to happen but I got what I deserved probably and you learn. I mean, you learn from experience. Okay that didn't work very well...what do I need to do to make this better?

Earlier she indicated that students' problems prevented them from learning, now she indicated it was she who needed to make a change. This revision in her narrative described how learning from experience led to a change in the ways she communicated with her students. This illustrated her evolution from her original uni-directional, teacher-centered conversation to a revised bidirectional communication style that included listening closely to her students to learn how to teach them effectively. She began to recognize student feedback as critical in helping her make adjustments in her teaching to ensure student success. The inception of this shift may indicate the use of the school context as a holding environment (Kegan, 1982), as a context for "fostering the person's psychological evolution" as Margaret began to evaluate, eventually make sense of, and subsequently altered her personal actions, which had formerly led to more conflict. She evaluated her previous responses to student behaviors as negative and adopted a more pro-active stance when she created a classroom context that was supportive of her students' need for social and emotional safety. Her former resolutions to the complicating actions she experienced in her classroom described student actions and their learning as being "in control." However, this initial tendency toward a control methodology segued into what she termed as "compassionate" care for her students, which she evaluated as a more positive resolution for her problems of practice. Her early attempts being reflective, albeit independently, may have contributed to her changing mindset as Margaret began to realize that creating a student centered climate might prove more effective in teaching her students. 
Journeys toward Reflective Practice: How Engaging in National Board Certification

Influences Teacher Identities and Practices

The influence of context and independent reflection on the development of pedagogy

content expertise, and identity.

Margaret reconstructed her level of expertise early in her career and shared:

Well, when I think back... I would just show them [the formula for a problem]... on the board and you know, here is how you do it. I never even thought about it. I do remember a college professor saying you have to teach it at least three different ways and they never taught us how to do it. They never said what they meant ((laughs)).

Although Margaret positioned her college professor as an expert and a mentor, she believed the professor failed her by not providing a step-by-step process Margaret seemed to need, at that point in time, in order to be an effective educator. Once again, it was evident that Margaret was "figuring it out on her own." Thus, in her first years teaching, Margaret relied on demonstrating the algorithms and providing independent practice sessions for her students, both in class and as homework.

At some point, she began to think of her students as independent learners with unique needs, and Margaret no longer simply taught using her preferences for teaching and learning and she related the following:

I didn't ... show them what it meant. Here's how you do it. Period. Because that is the way I was taught... and if it worked for me, well I wasn't thinking of those people who don't learn like me...so here's how I learned it so this is how I'm teaching it because this is what I'm comfortable with. And I never thought to go outside the box and go...well...how did these people learn... until later in my career.

Margaret's use of the phrase "how did these people learn" represented a turning point in her reflective on action, as she was able to frame the problems of her practice as located in her teaching, rather than in her students as problematic learners. Therefore, she was able to move away from the "sacred stories" she once accepted. 
Journeys toward Reflective Practice: How Engaging in National Board Certification Influences Teacher Identities and Practices

As Margaret reconstructed her transition from thinking about teaching from a subjectcentered action to a student-centered action, she spoke about the difficulty of teaching multiple subjects in an elementary school setting and said, "[I had] a lot more preps in elementary." She recognized teaching all core subjects as an extremely difficult complicating action for her work. Margaret felt she never truly resolved this dilemma and stated that in her work she "was all over the board" and did not connect the learning to the "larger world." Her transition to middle school level resulted in beginning to resolve the complicating action of her elementary experience as she began "looking at life all around you... and connecting it with math all the time... thinking of ways I can use it in my classroom." Thus, her change of venue resonated with her perspective and led to a resolution of her internal conflict, which she termed as a "lack of focus as a multisubject teacher."

Margaret's unresolved dilemmas with creating student-centered, multi-subject work and subsequent resolution occurred when she evaluated her mindset while teaching a single subject in the middle school environment. Margaret said,

It took me the first year (in middle school) I really didn't do it (reflect on my teaching)...And then I started seeing myself as a math person...not just a teacher... and that changed the way I look at everything... so I started to relate it (math) to their outside lives a little bit more...not in depth, but it was a beginning.

Margaret expressly changed her tone and demeanor while sharing this narrative and was emphatic in stating she considered herself to be a math teacher who connected mathematics to the real word for her students. Positioning herself in this way resulted in a change in her perceptions of teaching and learning. The complicating action at the middle school level took form in this statement "There were no manipulatives...there was nothing [no visible tools to help my students learn mathematical thinking]...there was nothing even out there" which was 
Journeys toward Reflective Practice: How Engaging in National Board Certification Influences Teacher Identities and Practices

revealing. This may have indicated that Margaret had not yet assumed responsibility for her own professional development (Zeichner \& Liston, 2014), as she had no prior knowledge of manipulatives and their effective use in math instruction at either the elementary or middle school level.

After becoming a middle school teacher, in another complicating action, Margaret realized she needed as she said, "something more in her teaching" and enrolled in a statewide course developed through WVDE and offered at the RESA level. The professional development was designed to increase student use of manipulative materials by instructional design based on National Council of Teacher of Mathematics standards. In this instance, it seemed that Margaret, through reflection, recognized she needed to learn more in order to meet the needs of her students and she took responsibility for beginning to gain additional knowledge and skills.

Margaret often refers to herself as a "math person" and her use of the word "I" at all times in this narrative demonstrated her alacrity with this professional identity. Moreover, Margaret stated she "views the world in black and white" terms, preferring to be extremely organized and believes this tendency is a personal strength. In a coda, she affirmed that she often takes on the role of record keeper and planner when working collaboratively with colleagues, especially those who have a tendency to be highly creative as she believes that "creativity is often (a trait) aligned with impulsivity" and low organizational skills. Margaret posited that she counterbalances these traits in her role "as a recorder of original thinking, rather than as a generator" of innovative ideas. While Margaret was very clear about the ways in which she positioned herself, it was not apparent that engaging in reflection led her to question the assumptions and values she brought to teaching and their effects on her teaching and student 
Journeys toward Reflective Practice: How Engaging in National Board Certification Influences Teacher Identities and Practices

learning. Becoming a "math person" had taken time and effort and Margaret had developed a very specific understanding of this identity.

Nearing closure during interview one, Margaret reflected on who she was as teacher prior to the NB process:

I mean at the time I thought I was a pretty good teacher when I was younger. And like I said, I taught the way I was taught. Um, I don't think I was as in depth with my thinking. I just followed the book from front to back. ... and I didn't really think about it... and I modified some... but I didn't really think about how effective is this? ...and what do you (students) really need out of this? I think that came to me later... I don't know if it was just because I matured.

The challenge for Margaret may have been an over reliance on textbooks and an under reliance on teaching that was informed by a teacher's knowledge of his/her students, which might include personal, academic, and socio-emotional knowledge. According to Kozulin (1986), knowledge of each student's “zone of proximal development" (ZPD) was a forerunner to effective instruction. Margaret began to embrace the concept of Zone of Proximal Development without using the term as she adopted the language of professional education proposed by the National Board in her portfolio work. The discourse threaded through NB portfolio work in turn was aligned with educational terminology and expected teaching practices influenced by $A$ Nation Prepared (1986). The vanguard exemplified by her question, "What do each of my students need out of this [instruction]?" may have indicated a professional turning point, which she attributed to her level of maturity. It is more likely that her teaching context, formerly fraught with self-doubt, allowed her to gain clarity as she connected with peers and engaged in professional growth opportunities tailored to her needs. Interestingly, once she engaged in learning practices in her own Zone of Proximal Development, she began to work toward being a teacher who designed instruction in her students' Zone of Proximal Development. 
Journeys toward Reflective Practice: How Engaging in National Board Certification Influences Teacher Identities and Practices

Margaret went off-topic to relate a story about her current teaching position in West Virginia and said:

When I came back into teaching, I had a different mindset. I wanted to be there. I am passionate about teaching and I remember saying that in my interview. I have to be a teacher. I was born to be a teacher... I started to deviate from what I had done before and looked more at the personal student and tried to be where they were instead of saying if you are going to be in my class, then you need to be at this level... and now how am I going to get them engaged to where they want to be at that level...And that is what I think changed for me.

Gee (2011) cautioned that "situated meanings" may reveal "ways of knowing" that are embedded in professional teaching contexts and that the interpretation of these meanings are often negotiated and built using "what is explicitly said and what we infer from context" ( $p$. 102). Margaret's candor during the opening interview was characterized by key words, phrases, and repetitions such as "the way I was taught...you learn... here is how you do it... on your own...island." Retrospectively she expressed frustration with feeling she was not fully effective in reaching her students, a sense of professional isolation, and the use of traditional teacher actions and values such as her dependency on the use of textbook and worksheet driven instruction. The high level of dissatisfaction she expressed was mitigated by verbally distancing herself from her early teaching contexts. Her repetitive use of "you" when discussing her actions during her early years in teaching occurred when she said things such as, "How many years do you have to teach before it gets there?" and "You have trouble... sometimes, and you know, you have kids who act up in class" when she referred to her conversations with her mother about her fourth grade students.

Her language was, conversely, highly personalized when she discussed her years in middle school and said, "When I came back into teaching, I had a different mindset. I wanted to be there" and "Then I started seeing myself as a math person...not just a teacher." The 
Journeys toward Reflective Practice: How Engaging in National Board Certification Influences Teacher Identities and Practices

establishment of her identity as a teaching specialist, a National Board term and a distinction, appears to have enabled a completely different underlying tone, affect, and situated meaning for Margaret. Her skills in content knowledge were highly specialized and accordingly, Margaret professed this certainty, by self-identification as a master of mathematic content, and by acknowledging her ability to ensure her students were able to know, understand, and do math successfully.

\section{Margaret's Reflective Practices during National Board Work}

Margaret was animated during this interview and described her experience as unique, as Margaret and her sister sought certification simultaneously and collaborated during the process, though the NB certification areas each has acquired are highly unrelated. She discussed their collaborative efforts to understand the portfolio requirements and their seeming difficulties in succinctly addressing the depth of the questions presented by the portfolio prompts. Ascertaining the manner in which her explanations were to be scored was an all-consuming process. The problem solving process presented by the portfolio prompts in effect mirrored the difficulties she experienced in her classroom including: what teaching strategies worked, what was ineffective, how was she learning about her students, and what were the highly specific impacts her teaching was exerting on their learning? The interview explored these concepts and was marked by pragmatic thinking, measured pauses, and reflective moments.

\section{The influence of the NB process on the development of reflective practice.}

Margaret sought change and in her evaluation of her teaching said:

I think I was beginning to evolve. (As a complicating action), I was changing my mindset about how I had to approach teaching and how to approach my students and their families, but I wasn't there yet. I still wasn't as reflective as the process encouraged me to 
Journeys toward Reflective Practice: How Engaging in National Board Certification Influences Teacher Identities and Practices

be. (Her eventual resolution emerged when she said,) I think that was the life changer for me. That's what made me the most effective teacher. It was probably the ingredient that was missing. I thought about them all the time. I thought about my students and their families. But, there was something...I don't know.

Margaret recognized she was beginning to reflect on her teaching and this selfexamination revealed the onset of her thinking about teaching reflectively. The questions asked within the portfolio entries were questions she had previously left unconsidered and provided complicating actions as she engaged in the NB process: "So, one of my entries I had to explain why...how did it impact my student learning... why was it important...how did it impact student learning. Nobody asked me to write like this before." The writing prompted Margaret's thinking and forced her to produce evidence she was interacting with her students in ways that had a demonstrable effect on student learning.

Somewhere in the writing process Margaret shared she was "forced to realize her thinking about students and about their families" was unfocused and ineffective. The "ingredient" she was missing was reframing her planning and instruction for student learning and making adjustments to her instructional design based on each student's instructional level.

Margaret affirmed her evolution as she shared,

[I used].... a new way to look at mathematics. Instead of being so traditional, now let's look at the elements of these problems...not let's do twenty problems and tomorrow we'll check them and talk about them. This was more hands on. This was how to reach those students that you missed. Which is why I was very interested because I realized...okay, this is not old school...like the way I was taught... These kids need more.

Her use of privileged educational language (reflective, process, impact, elements) indicated her movement from traditional teaching methods to more progressive student-centered work. 
Journeys toward Reflective Practice: How Engaging in National Board Certification Influences Teacher Identities and Practices

During the NB process, Margaret's professional practice and identity were in a state of flux. She wanted her students to examine how mathematics problems worked and how numbers were interconnected (a complicating action for her teaching) in order for her students to engage in deeper thinking about mathematics (her resolution). This stance was counter to how she experienced mathematics as a middle school student (her apprenticeship of observation). Thus, Margaret was no longer content to teach as she had been taught; instead her evaluation of her prior practices found them to be lacking. She grasped, "There is more to this [teaching] than just presenting the material. There has to be a way to reach these students and I wasn't. So I needed to find a way to help today's students learn." Margaret realized she needed to scaffold learning for her students so they would develop deeper understandings of mathematics, which were expectations of the NCTM standards.

Margaret continually made "I statements" as she spoke of her own transformation, first in thinking, then in action, while in the midst of the NB process. Gee (2011) posited that her use of "I" and the elements presented in her arguments depicted ownership of her work as a teacher of children as learners, not just a teacher of mathematics. This might have been especially notable in her statements: "There is more to being a teacher than just presenting the material." and " $I$ needed to find a way to help today's students learn." This change in pronoun may have been an indicator of Margaret's changing teacher identity as transformative to the work Margaret acknowledged as important. Dewey (1938) posited growth as a reflective practitioner was dependent upon responding to the problems of learning. Furthermore, Dewey asserted that effective teachers make decisions by recognizing the dilemmas inherent in teaching practice and suspending judgment on the course of action to resolve the dilemma until after a period of study of the problem itself, of potential solutions, of potential outcomes based on actions contemplated, 
Journeys toward Reflective Practice: How Engaging in National Board Certification Influences Teacher Identities and Practices

and finally commencing action as new teacher knowledge emerges. At this point in the interview process, it appeared that Margaret recognized her need to "reach" her students and "find a way to help today's students learn."

\section{The influence of critical reflection on the development of identity and practice.}

Early in her career, Margaret indicated her principal was not supportive in terms of professional development. She likewise indicated that the principal she worked with immediately prior to and during her NB process period had definite ideas about how a teacher should behave in the classroom. During her NB process, her principal negatively noted during an observation that she used too many open-ended questions; he preferred that she ask questions her students could answer on the spot. "I remember asking my principal about National Board Certification and asking other teachers and nobody had ever heard of it and didn't know what it was." This experience provided further support for the theme Margaret had recurrently expressed: her belief that the bureaucratic structure of her educational system was stultifying and her administrator interfered with her teaching and hindered her work. She believed that the educational bureaucracy and the administration of her school did not support her growth. Thus, she sought additional means to address her professional development needs.

Margaret later talked about her decision to establish NB candidacy, "Then I did some investigating [and watched videos of NB candidates]...And I saw...WOW! ...the video entry and it was impressive...teachers were so incredibly good and so engaging."

This response provided some insight into Margaret's new understanding of what teaching and learning might look like in a classroom rather than her traditional approach in which she demonstrated math procedure and assigned twenty problems for practice. Her viewing of the engaging videos provided Margaret with an opportunity to problematize her practice (a 
Journeys toward Reflective Practice: How Engaging in National Board Certification Influences Teacher Identities and Practices

complicating action). She noted how different the approaches she viewed in these teachers' practices were from her customary approach. Thus, Margaret decided to make a change in her teacher questioning behaviors (a resolution). After watching the videos of NB candidates, she noted that when students could not answer questions immediately due to the open-ended nature of the questions posed, the students assumed responsibility for learning and were deeply immersed in learning tasks involving conversations with peers. The "sacred story" Margaret had embraced (teacher-centered instruction) was challenged by a newer way of introducing material to students and promoting their acquisition of conceptual understandings and skills.

The language of NBCTs may be described as privileged (Gee, 2011) and the current propensity of West Virginia educators to use the word engaged when describing student learning behavior may be a result of the NB language pervasively stated in the West Virginia Teacher Evaluation System and subsequently in use throughout professional conversations in dyads, Professional Learning Communities (PLC), and other similar venues. Engage was defined as "to hold the attention of: engross" in the Miriam Webster Dictionary as the fifth entry, not perhaps the most common understanding shared by lay people (to pledge oneself: promise). As a privileged term, educators understand that student engagement in learning is a behavior that is planned for during the design of instruction and promoted by the pedagogies and learning tasks employed. Margaret's use of the word engaging is used to describe the teacher(s) she observed via video, not as the student response to the design. Again she distanced herself from the actions of teaching, saying, "Teachers were so incredibly good and so engaging." However, she qualified her thinking here by then becoming a NB candidate because she wanted to improve her practice and reach this level. 
Journeys toward Reflective Practice: How Engaging in National Board Certification Influences Teacher Identities and Practices

Margaret sought collegiality with teachers in her school district and joined a small group who met for the purpose of analyzing portfolio writing and critically viewing videos created for the portfolio entries with other teachers. This work served as the orientation for this the next passage:

The video scares a lot of people (potential candidates). They don't want to watch themselves teach (a complicating action)... But you get past all of that (another complicating action) and it becomes about you (evaluation of the scenario) and what you are teaching... what you are doing... and that's what National Boards is all about...you learn to step past and actually look at what's happening in your classroom (as a resolution). That's an eye-opener in itself.

In her reconstruction of her professional growth, she continued to make sense of the second person role of teacher as a leader in the classroom, but had not yet identified herself as a studentcentered or progressive teacher of children. She did note that her actions as an instructional leader had previously blurred her vision because she was focused on her statements and actions, rather than those of her students. This was shown in her statement, "[Y You] actually look at what's happening in your classroom" rather than her former pre-NB habit of thinking about student learning while grading student work. Margaret's prevalent use of second person as she created her narratives suggests a slight disaffection from the events described.

Margaret expressed that the actions of the teachers in the videos she viewed before she became a candidate in the NB process were significant to her. She said, “...video scares people...don't want to watch themselves...." by speaking in third person. Then she steps closer to ownership of teaching efficacy and reflective practice and said, "You learn to ... actually look at what's happening in your classroom." In stating, "what's happening in your classroom," Margaret was actually referred to observations of the whole child, not just the academic growth 
Journeys toward Reflective Practice: How Engaging in National Board Certification Influences Teacher Identities and Practices

of each student. She then moved into reconstructing her critical observations of students, first as learners, then as children.

Margaret went on to discuss a very personal reaction to her own experience when watching a videotaped sequence of her students after she declared candidacy. Her passion for the self-discovery was revealed and made the story salient as she reconstructed her thinking about use of recorded teaching for the purpose of self-analysis. She said:

What did you see about them (her own students)? They show you a side you don't see all the time. The camera caught things that my naked eye never caught. Which makes me think there is a lot value in videotaping. There are so many things you can learn from it... There is so much you can learn about your students from videotaping. It's a practice we should probably continue.

The ease in her transfer to first person collective when she posited, "[videotaping] it's a practice we should probably continue" was revealing of her mind shift toward self-awareness and to becoming a more discerning observer of student(s). First, her use of the first person pronoun indicated ownership of the idea and interestingly, she states that we should probably continue this (reflective) practice. The term should indicates an imperative state of mind, whereas probably is a synonym for maybe. This leads to questions about her feelings, as Margaret's use of term we indicates teachers as her "socially situated identity" (Gee, 2011, p. 207). She then slightly disclaims the practice due to her use of the ambiguously defined verbiage of should probably. "There are so many things you can learn from it (videotaped lessons)" is again slightly distanced from an ownership of this practice.

Margaret was then specific in her use of reflective strategies that she adopted during selfcritical video analysis, "Instead of being concerned about superficial things, you are objectively looking at...maybe body language. How did you respond to that student? What is your voice like? What are you giving to your students?” Her narrative indicated crucial growth factors in 
Journeys toward Reflective Practice: How Engaging in National Board Certification Influences Teacher Identities and Practices

observing her own teaching behaviors and asking herself reflective questions that defied easy answers. This concentrated thought about her teaching, over time and with peers, who asked themselves the same questions, led to this small group of candidates' improved learning about framing and reframing the teaching practices they viewed in their videos and analyzed in written passages.

Yet because Margaret shared an anecdote orienting her skills during this time frame, it seemed likely that this experience of analyzing and reflecting on videos of her own teaching resulted in a long-term change in her thinking about student cover stories. She described the surprisingly well-hidden flat affect that appeared fleetingly while viewing a female student's facial features. Margaret did not observe this fixed facial demeanor until she viewed a videotape of her teaching. Margaret believed the student kept her feelings hidden when she, the teacher, was looking, but the camera caught it when Margaret was not looking. After viewing this video, Margaret sought assistance from the school counseling team and the ensuing investigation by multiple colleagues revealed this particular student's precarious state of mind (depressive thoughts), which resulted in effective interventions. It seemed important to note this experience may have been a turning point in Margaret's perspective on students as more than learners of mathematics. Learning more about her students' lives beyond her classroom connected with NBPTS Core Proposition Knowledge of Students. Margaret's stunning realization was that a student, who Margaret thought she had assessed correctly as an emotionally stable child and a capable learner (a complicating action), was using a cover story in her classroom that was completely unnoticed until the camera caught her unadulterated expression. This incident prompted Margaret's resolve to develop her skills, and possibly, her identity, as an observer of her students. 
Journeys toward Reflective Practice: How Engaging in National Board Certification Influences Teacher Identities and Practices

Margaret's development as a reflective practitioner who questioned her practices, was influenced by the expectations of the NB process as illustrated in the following narrative:

When I watched (orientation) my early attempts at videotaping, I thought there is really something missing (complicating action) here. I thought what's wrong? You know, I think the activity was a good activity. What was missing? I didn't ask the right kinds of questions (evaluation) for them to talk about it [math reasoning]. They were more or less, here's the answer, no discussion required. So, my first question was... it was not about the students at all. It was about me (resolution).

In self-critically viewing her classroom activities, she realized, "There is no discussion. They are answering what they need to answer, but there is no discussion going on... That is when I decided it was my questioning. I wasn't asking the right things to encourage a discussion." When Margaret shared these reflections and realizations, she spoke in a calmly reflective and assertive manner as she went on to say:

In the beginning, I wasn't sure if my students were capable of doing what I thought they needed to do. I wasn't sure if it was because they were not academic all stars or because of my strategies. It was totally me.

This was a profound realization for Margaret, which compelled her to frame the problems of her practice in novel ways (Schön, 1983). Zeichner's and Liston's (2014) research recognized that wisdom was often derived from working to understand teaching based in reflective practice by examining the events in the classroom where the practices took place. Margaret's epiphany occurred when she studied what was effective and began to ask more open-ended questions of her students, while she engaged in teaching.

Watching her students in videotaped sequences without the stress of standing in the room with them allowed Margaret the space she needed to, in her words, " to figure it out." She started by focusing on herself, not her students and what they were doing. "Before, I would say, oh this is wrong. You do it this way." Margaret recognized the influence of her previous experiences 
Journeys toward Reflective Practice: How Engaging in National Board Certification Influences Teacher Identities and Practices

and practices on what was currently taking place in her classroom. In describing the complicating action, she realized, "If you can explain it, you are truly thinking it." Student learning actions were now the focus of her thinking and she connected their improved questions and statements about their thinking to the interactions she designed with them and for them. Thereafter she evaluated her questioning strategies and resolved to make changes saying:

I don't tell them now. My classroom became completely different. I think the biggest thing is the questioning. I started always walking around the room and talked to them. I was not doing that before. So I learned to know my students so much better than before.

Margaret came to understand that her knowledge of students was as valuable as knowledge of content. This was a basic tenet of achieving certification through the NB process and Margaret reiterated this thinking throughout the interview series.

Moreover, she became forceful and declared her current questioning techniques as more effective with:

Tell me what you were thinking when you did that. I don't tell them now... I don't tell them the answers. I say, tell me what you were thinking when you did this... Explain to me what was going on here. I make them come to the conclusion instead of me drawing the conclusion for them.

This passage was the first time during our interviews that she delved deeply into her classroom practices in a meaningful way using "I" as the teacher and "you" to define the learner, positioning me temporarily in the role of one of her students. She became absorbed in telling her story and shifted frequently from discussing her reflection on the videotapes of her teaching during the NB experience (when she was unsure of her practices) and seguing into describing her current beliefs that her questioning practices are highly effective.

Margaret was able to transport herself back into the context of reflecting on the videotapes of her teaching, as she has viewed these repeatedly and the prompt triggered this 
Journeys toward Reflective Practice: How Engaging in National Board Certification Influences Teacher Identities and Practices

memory as distinctive. Her confidence was noted as she built the connection between her skill with questioning, which encouraged her students to verbally share their heretofore hidden thinking, and the ways in which she planned subsequent instruction and learning tasks to match what her students knew, understood, and were able to do mathematically. She learned these strategies during her NCTM based coursework, made use of these strategies as she engaged with the NB process, and emerged confident that her instructional decision-making was informed not only by the content standards, but also by the NCTM process thinking standards.

Margaret's word choice when she recounted thoughts about her videotaping experiences and analyses revealed multi-level connections. First she used the pragmatic, “teachers don't like to see themselves," then the directive, "teachers can learn from the activity" and finally, the personal, as phrased, "I learned that I took my students at face value and I needed to look harder." Margaret's use of pronoun detachment (they, you) and attachment (we, I) varied throughout the interviews according to her level of frustration, acceptance, and ownership along a loosely structured continuum. This ultimately was aligned with her thoughts about presenting information in a manner that did not require the use of the textbook as a teaching guide and promoted student engagement in developing deeper understanding of the content. Recall of her statement, "I started to deviate from what I had done before and looked more at the personal student and tried to be where they were instead" indicated her shift from teacher-centered to more student-centered instruction. Her use of the first person pronoun, "I ...deviate (d), I...looked and (I) tried," potentially indicated she might have developed a level of ownership of her professional learning about how students learn as she reconstructed her experience.

Gee (2011) maintained that:

Context is an important notion for understanding language-in-use and for understanding the nature of discourse analysis (which is, after all, the study of language-in-use). When 
Journeys toward Reflective Practice: How Engaging in National Board Certification Influences Teacher Identities and Practices

we speak or write, we never speak or write all that we mean. Spelling everything out in words explicitly would take far too long. Speakers and writers rely on listeners and readers to use the context in which things are said and written to fill in the things that are unsaid, but assumed to be inferable from context" (p. 100).

Gee's understanding of D/discourse served to define the understated relationship between participant and researcher. This was assumed as we both experienced the NB process and held some openly shared, as well as veiled interpretations of portfolio entries, videotaping experiences and the reflective thinking required by the NB prompts. These multiple meanings were silent at times, defying verbalization perhaps due to the intensity of self-reflection and the realization we both held beliefs that thoughts were not fully known to self until written, rather than spoken. This was defined when Margaret said:

In the portfolio, the questions ask, why is this particularly effective with this child? Because I had to justify what I was thinking it made me reflect...well, why exactly do I do that? Some things you have done it for so many years you don't think about why you do it. And some things you probably just did it and it worked once and you continue, but why do you do that and why is this working. And so, when you have to explain your thinking it forces you to become more reflective, I think.

The act of writing is silently verbal, can be edited, and must stand up to deeper long-term scrutiny. Recording interviews and making verbal assertions available to critical assessment altered the context of the conversation and ultimately allowed for additional, possibly more insightful, inferences to emerge from Margaret's reconstructed experiences.

When Margaret recalled the story of the depressed student, her realization may have been an acknowledged or unacknowledged "AHA" moment that further strengthened her resolve to know her students beyond the act(s) of solely teaching content. Her previous statements implied that prior to this resolution, her relationships with students and families were superficial, mostly initiated by student behaviors she viewed as unacceptable and that she wanted to change. The 
Journeys toward Reflective Practice: How Engaging in National Board Certification Influences Teacher Identities and Practices

continuum of her reconstruction indicated various points in all three interviews when, in the struggle to manage a classroom, she sometimes chose to seek greater knowledge of students by eliciting support from peers, administration, and the parents of her students.

When she resumed a position in education, she continued to view students as passive recipients of her traditional teaching style expertise until she took ownership of her own professional learning by enrolling in standards based professional development and during the National Board Certification process. Then, according to Margaret, "I was changing my mindset about how I had to approach teaching" and she began to realize she need to design instruction based on student needs and preferences.

\section{Margaret's Reflective Practices after National Board Certification}

Margaret asserted numerous times that her questioning strategies were transformed by her NB process reflections, especially as related to working through the portfolio entries that delineated her work with students. She continued viewing her videotaping and this forced her to "see" student learning through a newly refined lens. Her highly interactive instructional design came under negative scrutiny by peers and her principal, although he has since left her setting. In fact, she has worked with three principals since earning NBCT status. Margaret also assumed a teacher leader role with her grade level PLC and subsequently a few teachers in her building have completed the NB process. These specific influences served to create opportunities for substantive collegial interaction at her school level, especially as related to solving student-based dilemmas.

\section{Choosing collegiality over isolation.}

In referring to her school principal, Margaret said: 
Journeys toward Reflective Practice: How Engaging in National Board Certification Influences Teacher Identities and Practices

It [our relationship] was negative and it was an uphill battle for three years. He wanted me to teach the way he had taught. He told me the examples and how he used them in his classroom, which [he thought] for me, would have worked. Years ago, too, I would have done the same thing. However, now I had changed and I wasn't willing to go back, you know, is it black or white? I wasn't willing to go back to that type of teaching anymore...And so, (new complicating action) I invited him in, I said, you need to come in and listen...to their mathematical discussions that are taking place and then we will talk (resolution). So he came in and he walked around and he listened to them and then he was a believer. After that he said, this is great.

She went on to describe the coda for this experience, and said:

He actually nominated me for the Presidential Award for Excellence in Mathematics Teaching (PAEMST) after that. I was the West Virginia mathematics winner for the PAEMST...That came from the guy who thought I was asking too many open-ended questions. So that was kind of nice that it [the nomination] came from him.

This nomination came from an administrator who did not respect her progressive approach to encouraging student learning and challenged Margaret's professional learning and beliefs as nonessential and possibly, even detrimental. "That came from the guy" makes it appear as though he held no higher status in the organization and situated her as maintaining her higher ground as a progressive teacher when she shared:

Which [he thought] for me would have worked. Years ago, too, I would have done the same thing. Now I had changed and I wasn't willing to go back, you know, is it black or white? I wasn't willing to go back to that type of teaching anymore.

Margaret's strong, repeated use of "I" statements suggested close identification with progressive student-centered teaching as a higher standard of practice against what she perceived as her former principal's traditional practices. While she believed that non-supportive administrators have been present her in professional landscape in more than one school context, she also acknowledged that this post NB scenario ended nicely because the coda was recognition of her teaching performance as exemplary. 
Journeys toward Reflective Practice: How Engaging in National Board Certification Influences Teacher Identities and Practices

Collaboration with peers has been a challenge over the years, and Margaret spoke of collegial relationships as emerging from practices designed to support student learning. She oriented opportunities for shared dialogue with "The special education teacher in my school has been through the [NB] process. We do a lot of reflection and discussion to compare what she is doing...to what I am doing." In a complicating action she continued, "We had a student who was severely autistic and couldn't be in the regular classroom. It was too overwhelming for him." When Margaret and the special educator jointly evaluated the circumstances, they determined that although "He was in her class because of the smaller setting... he was much too smart to be in that class so (evaluation) we worked out a way so he could Skype with my class" (resolution). Margret went to the smaller classroom to check on him and he became comfortable enough to talk about the math and explain what he was doing. This unique teaming enabled creation of a novel solution for this student with special needs and was something Margaret was pleased to relate, as this story not only provided evidence of increased collegiality, but also greater knowledge of a student in need. Margaret positively averred, "We worked very closely together."

Clandinin's and Connelly's (2000) understanding of the "professional knowledge landscape" was further clarified by (2013) "as composed of two fundamentally different places, the in-classroom place and the out-of-classroom place" (p.163). Margaret noted a smooth transition from classroom to school level for the first time when she discussed her relationship with her colleague, the special education teacher. At no other time during the interviews did she speak of school level collegiality with peers. It was interesting that she chose to create time and space to nurture this relationship during after school hours. The connection she highlighted involved common students and common teaching strategies with shared students and she closed 
Journeys toward Reflective Practice: How Engaging in National Board Certification Influences Teacher Identities and Practices

this strand of conversation saying, "I think showing support for one another... the new National Board Certified Teachers creates a different kind of community...I think it also give you credibility... It gives you that extra bit of credibility...I think it's a strong community."

This understanding potentially demonstrated Schön's (1987) focus on the contexts for professional learning and his assertion that the type of learning that took place in paired conversations was distinct from introspective reflection. Articulated and shared thought allowed these teachers to "consider and reconsider what it means to know or believe something, and then to examine and reinvent ways of teaching that are consistent with their knowledge and beliefs" (Cochran-Smith \& Lytle, 1999, p.272).

\section{Developing from reflexive to reflective.}

During our final interview, I asked Margaret to reflect on the concept of being a National Board Certified Teacher, and she responded with a meaningful monologue.

She said, "As I reflect on the national board certification experience, if anything, it helped it (my ability to reflect) to blossom. I became much more reflective with every little thing." Her stories were indicative that this was especially true in her classroom. She stated her reflection is something she uses in action and she now realizes she is using reflection when she problems solves with her students, especially with non-verbal student signals. She illustrated this orientation as she suggested:

Sometimes without...without...it was not intentional, but it was...oh, look at that look (complicating action) on MaryLu's face...means struggling with this...that is a reflection right there... okay, I need to back up here (evaluation) because I just lost MaryLu... if I continue... then I have lost her for the day...now what can I do...how can I approach (resolution) this differently? 
Journeys toward Reflective Practice: How Engaging in National Board Certification Influences Teacher Identities and Practices

Looking for and subsequently spotting student misunderstandings and misconceptions has become a highly salient feature of Margaret's identity. Consequently she related her propensity to make constant miniscule, minor, or major shifts in her instructional delivery.

The importance of her teacher identity was stressed when she affirmed, "So, I think it has definitely helped... it is who I am now, a reflective practitioner... it's not just something I learned to go through the process, it's what I have become." The very act of becoming implied transformation and Margaret referred to the work she had done to earn NB Certification in her discussion, with "Probably the biggest thing was when you had to explain your thinking. When you had to talk about why was this appropriate for these students at this time." Her use of the language of the National Board helped frame Margaret's reconstruction. The language of “explain your thinking” created a bridge to how she made decisions about her instructional strategies. National Board questioning prompts also used the phrase "appropriate for these students at this time," which could be translated into teaching students in their zone of proximal development (Vygotsky, 1986).

Margaret was explicit in her reflections on her early teaching and how it influenced student learning:

I knew my students were not understanding the way I was presenting. I was teaching traditional and my students didn't get it... I thought I need to change something here (as a complicating factor) because I am missing the boat (in her evaluation)...I am not reaching these students...they are not engaged in the process...(then she reached resolution) I need to look for something else.

In her quest "to look for something else" so that she was able to meet the needs of her students, she turned to the NB process. Margaret recognized how the NB portfolio requirements created spaces for her to grapple with her felt difficulties and problems of practice. She shared the influence of providing written responses on her previous and current reflective practice: 
Journeys toward Reflective Practice: How Engaging in National Board Certification Influences Teacher Identities and Practices

So, I had to explain all of this...I had to explain my writing...how did I know I didn't reach my students...how did I know that I needed to change something and how did I know if this was the route to go... and so by explaining it (complicating action) I had to reflect...well, I am continuing to do that (resolution)...what else do I need to do...where can I go from here.

Margaret struggled to write out her reasoning during the process of creating her portfolio, and did so successfully. Accordingly she has continued to embrace the struggle post NB process. She said:

You always have to go back and think...well, what was I thinking...how do I know these students need help with this particular thing... or how do I know that my students are successful in this area or not successful and you have to be able to put into words exactly what you are seeing, exactly what your criteria was, and how did you evaluate it. That's how I know how it did impact student learning.

\section{Conclusions}

Margaret maintained that she continues to use these thinking strategies and frames problems in words to determine a course of action. As a mathematics teacher, this talking aloud strategy was often used to demonstrate the steps in problem solving of multi-step equations, so her technique may span multiple venues, both as an instructional strategy and as a reflective habit of mind.

Margaret's statements in her second and third interviews were aligned with Schön’s theory (1983) that a practitioner had to develop an appreciation of phenomena, reframe them and take action(s) though interaction(s) with the learner. "The unique and uncertain situation comes to be understood through the attempt to change it, and changed (emphasis added) by the attempt to understand it" (p.132). These changes in her thinking seemed pervasive and she was frank in stating her beliefs about her transformation. As Margaret began her career, she considered 
Journeys toward Reflective Practice: How Engaging in National Board Certification Influences Teacher Identities and Practices

herself a textbook driven teacher; however, she grew to become a student needs based teacher. In her final statements, she called herself a reflective practitioner.

Margaret's musings were consistent in connection (Gee, 2005) to the language of communicating ideas (p.102) within the fields of mathematics and pedagogy. Her connection to visualization and verbalization, whether written or spoken, was clear when she stated, "how do I know these students need help with this particular thing" and "I mean you can't explain it until you have thought about it and then you have done [it]." While the phrases "how do I know that my students are successful in this area or not successful" appear on the surface to hold universal meaning, this terminology held a degree of privileged as the sign systems and knowledge needed to understand and make sense of "successful" within the Discourse of education may not be apparent to those outside this discursive community.

Content knowledge was highly specialized; something Margaret has professed a certainty with by identifying as a mathematics specialist, both an earned (PAEMST) and generally recognized term. Margaret furthered her level of accomplishments when she devised strategies and increased her knowledge of students. Thereafter she used her highly specific understandings of student needs and strengths in developing her abilities to design instruction using the modes in which her students might best benefit during the time spent under her tutelage. This professed identity has helped Margaret become more vocal at the school level and beyond.

She characterized her early teacher thinking as more reactive than reflective, and determined through reconstruction that she often relied on personal family experiences, as well as the traditional practices of her school site to solve the problems of her teaching. The insightful and unpretentious narratives Margaret constructed of her development as an educator demonstrated elements of consistency and change, tradition and progression, reflexivity and 
Journeys toward Reflective Practice: How Engaging in National Board Certification Influences Teacher Identities and Practices

reflection. The theme of consistency and change was noted when she referred to self-questioning and self-analysis, which is a skill she is still developing. Traditional practices driven by textbooks gave way to progressive student-centered teaching as exemplified by her discussions about her progress throughout the NB process. While there were silences in Margaret's narratives concerning student equity, access and fairness in school contexts, she acknowledged that she thought about creating pathways to learning for students informed by her understandings of the influences of race, socio-economic status, religious beliefs, and family values on student learning; however, as Margaret constructed narratives related to specific students, the stories focused on cognitive, rather than individual and contextual factors. Markedly, as a final resolution to her evolution as a professional, Margaret was passionate when she spoke of her transformation from being a rigid lesson planner who, as she said, "just put the problems on the board, showed them how to do it, had them copy from the board and then did examples and we checked them the next day" to becoming a reflective practitioner, who "became more deliberate about everything I do. It is more intentional. My instruction is, my questioning is, my evaluation of my student's accomplishments...it's all much more intentional than it was." In retrospect she felt she reacted too quickly and ineffectively in her dealings with students before experiencing the NB process and, while working on her NB portfolio, she learned to frame student problems from multiple perspectives as she determined the best fit strategy for individualized learning based on knowing what her students already knew and what they had yet to learn. Margaret affirmed that this last was the most important passage she experienced in her teaching career. 
Journeys toward Reflective Practice: How Engaging in National Board Certification Influences Teacher Identities and Practices

\section{Chapter 5}

\section{Ethan}

Ethan began his teaching career during the late-1980s in a middle school setting in West Virginia, and then moved to a high school setting in another school system. Our conversations focused on his experiences while employed in both school settings. The interview series, which took place during the summer school break over a period of weeks, was finalized well into the fall semester.

His first position was in a high poverty middle school with students who were seemingly unprepared for scientific exploration due to the disparities they faced in and outside of school. In his current position at the high school level, his classes were populated with a mix of low performing and high performing students: some of his students were placed in institutional settings, some of his students had deeply involved and supportive parents, while other students had families who were not able to be as deeply involved for a number of reasons.

Ethan and a colleague (from the science classroom next door) were the first members of their school community to enter and complete the NB process. Subsequently, several staff members at his location have completed the process. For much of his teaching career, university and college professionals placed pre-service teaching candidates in his classroom. Ethan characterized himself as resourceful and reported that his science classroom was well stocked with materials, as during his first decade as a teacher, he devoted much of his time and energy to becoming a highly successful grant writer. He also was a regular science conference presenter at 
Journeys toward Reflective Practice: How Engaging in National Board Certification Influences Teacher Identities and Practices

the local, state, and national level, and developed a strong network of contacts as he furthered his expertise both as an instructor and content specialist.

\section{Ethan's Reflective Practices prior to National Board Work}

In his early years of teaching middle and high school sciences, Ethan was motivated to design and organize his learning activities for his students with less reliance on textbooks and more reliance on the use of what he had assumed to be discovery based inquiry methods. Ethan learned about scientific processes as a college student and sought to make his high school level coursework as stimulating for his students as the discovery process had been for him.

During interview one, Ethan referred to his early experience through the lens of a student and teacher stating, "I never touched a beaker until I came to college, and so I had no idea what that was all about. So that was kind of different for me. So, that was a big thing about how I learned." He claimed to have spent the bulk of his college years with theoretical courses and credited his professors as instrumental in supporting his development of a strong foundation of knowledge and skills for teaching science. Then Ethan declared that “[coursework] isn't really the same as getting out there and actually being in a classroom and thrown to the wolves."

He recalled feeling confident in his early teaching days and said, "Everything I knew about teaching science came from my cooperative teacher. The way I learned to teach was from my cooperating teacher, and... just getting in front of them and having to do it."

According to Olson \& Craig, 2005, knowledge communities offered pre-service and inservice teachers an opportunity to "tentatively explore how they are making sense of situations, explain their own actions, and excavate their stories in concert with others" (p. 178). Ethan was a member of one knowledge community during his undergraduate days and he developed 
Journeys toward Reflective Practice: How Engaging in National Board Certification Influences Teacher Identities and Practices

theoretical stories of science. His student teaching experiences provided Ethan with a different knowledge community in which he was able to develop stories related to science in a particular context. Ethan described his student teaching placement as being "thrown to the wolves." He described how his mentor teacher "showed me how you could teach without a book... you just basically go in and give kids stuff and say alright... here are the problems you can figure out... Um, everything was, you know, lab based, for my experience.” In essence, his cooperating teacher gave students baseline scientific information with corresponding materials and expected the students to design limited inquiry lessons and arrive at conclusions consistent with scientific processes. In fact, he stated, "that was a big thing about how I learned" science could be taught using inquiry-based pedagogies. The dual presence of students who were figuring it out and a supportive cooperating teacher who spent time helping him figure it out by teaching "without the book" seemingly was effective for Ethan. He credited the underlying theory from his college level coursework as helpful, but stated that while student teaching he needed pragmatic knowledge to be successful. His reconstructed stories affirmed that his cooperating teacher offered him sufficient time (sixteen weeks in the same classroom setting) to develop a skill set that enabled him to begin his teaching career immediately post-graduation.

Ethan oriented his learning about teaching by re-enacting the two teacher models set before him; both his primary college professor and his cooperating teacher used strategies that were closely aligned. He remembered:

There was one thing that I did get, cause this is what actually got me started...it was my... university professor...she would show us something... wouldn't say anything about it and she would simply stop and then say, For what question or questions would you like an answer? And that's all she did. She wouldn't answer them [the questions]... we were frustrated at first, but then we figured out what she was doing. 
Journeys toward Reflective Practice: How Engaging in National Board Certification Influences Teacher Identities and Practices

Ethan clarified his interpretation of the professor's thinking when he said, "She was doing what she wanted us to do and that's how I started... For what question or questions would you like an answer?" Ethan went on to describe how his experiences as a student teacher informed his practices as a teacher; thus he prompted his own students to generate their own questions using:

In the continuum of more free inquiry...the teacher is not generating the problems. The students are generating questions and what keeps us from full inquiry was I provided them the situation. They generated questions from the situation, which I told them to do. And so, if they were able to generate their questions they were a lot more interested in it than if I would have generated it.

However, his students expressed frustration with the prompt (a complicating action), "For which questions would you like an answer?" which he believed to be important to the learning curve his students experienced. In his evaluation, he assuredly stated that "I have not had to shift to inquiry... when I came out of college, student led questions were in full swing." As he resolved this dilemma, Ethan reiterated that he did not need a textbook to teach. Instead, he could provide opportunities for his students to engage in productive struggles in order to discover and construct understandings of concepts and principles they needed to engage with science. Indeed, he believed that these practices ensured his students developed deep understandings of the science he taught.

Ethan continued to use the phrase "figure it out" as an underpinning of his teaching practices (Olson \& Craig, 2005). He asserted that he adopted the practices of his former laboratory professor in stopping short of full elaboration on the content and then supporting students as they constructed conceptual understandings. Furthermore, he expressed comfort with allowing his own students to experience and express frustration as a step in the learning sequence, as he believed these productive struggles promoted student learning. This was a 
Journeys toward Reflective Practice: How Engaging in National Board Certification Influences Teacher Identities and Practices

practice the discourse of the science community supported. As Darling-Hammond (2005) noted, teachers with strong science methods coursework were more likely to use the laboratory and post- laboratory discussion for instruction and less apt to use memorization strategies. Ethan's use of open-ended strategies (common to effective teaching of science) was supported in the community of practice he entered during and after his pre-service experience. This community promoted and facilitated the "sacred story" of figuring it out that Ethan personally authored in his ongoing narrative (Olson \& Craig, 2005).

Ethan reconstructed one of his most important philosophies developed while working with his cooperating teacher who "would see things and ask me stuff... The one thing I remember... [was] do you think that is going to take all period? ((laughter)). That was a great question. It's the one I remember most." Her advice led Ethan to ensure that his students worked "bell to bell." Furthermore, this was not busyness for its sake, students had to be engaged with genuine work tasks during scientific problem solving. Ethan believed he learned effective teaching strategies and techniques quickly and posited, "My motto has been always be prepared...I would rather have too much to do than not enough." Indeed, authentic student work projects and products would also be stressed and evaluated in the NB portfolio submitted for assessment.

Ethan was well aware that as a beginning teacher he needed materials for use in student generated inquiry processes (a complicating action). He addressed this need, saying, "[My cooperating teacher] was good in grant writing, and I kind of caught that from her. I didn't have a lot of materials." Thus he asserted that their conversations were more likely to be focused on pragmatic considerations, with little talk about student learning as he assumed classroom leadership. He knew that he would be required to have materials and that "Biotechnology was 
Journeys toward Reflective Practice: How Engaging in National Board Certification Influences Teacher Identities and Practices

very expensive and not in our budget (evaluation). So (as a resolution) I started writing these grants and I already knew what I wanted to do and that was the important thing." Ethan's evaluation averred that, even as a novice, he was effective in creating a learning environment. "[In my practice] I used understanding by design. I knew what I wanted to teach, so I had to go back and start building in... at that time it was actually physical things [teaching materials] needed for teaching." As a reflective practitioner, Ethan seemed to be embracing his role as a developer of the curriculum, but he was not framing his dilemma in terms of student learning of the personal, academic, and social/political consequences of his decisions (Dewey, 1933; Zeichner \& Liston, 1966).

It also appears that the understanding of theory that Ethan gained as a result of his undergraduate studies supported his early classroom teaching and the guided inquiry experiences he designed for his students. Bransford, et al., 2007, proposed a framework encompassing learning in learner centered classrooms in which engagement in tasks that were just manageable for the learner was an important tenet for teaching students who were gaining knowledge and skills via guided practice sessions. In Ethan's reconstruction of his early experience, he conveyed that his cooperating teacher stressed a strong level of preparation, use of proper materials and beginning with the end in mind as important teacher knowledge and skill sets. Ethan's recognized the strength of his origins in these particular pre-service and in-service knowledge communities and how they shaped his foundational narrative as a science teacher. The support offered by his professors and cooperating teacher, in the form of both advice and modeling, seems to have been effective in supporting the teacher identity he was beginning to shape as a reflective practitioner. Ethan often framed the dilemmas he faced in terms of engaging his students with science, and he repeatedly discussed using the "wow! factor" in engaging his 
Journeys toward Reflective Practice: How Engaging in National Board Certification Influences Teacher Identities and Practices

students in learning. It seems this was the knowledge he had constructed about teaching science form models provided by his professors and cooperating teacher for creating laboratory settings. His desire to expose students to the awe and wonder of scientific principles was, in his thinking, good technique, However, this strategy may not have provided the specific support his students needed to be effective in solving their self generated questions. His focus on self, rather than on students limited the influence of reflection on his practice.

Kozulin (1986) proposed that Vygotsky's social theories of learning suggest "growth is a continuous self-conditioning prospect" (p. 125) and this conceptualization of learning is evident as Ethan described is own development as a teacher. He often stated how he learned from engaging in "trial and error" as he explored how particular practices influenced his learning and teacher identity. Ethan offered:

Then through trial and error I learned... cause I didn't know how... And back then Internet wasn't that robust. You know, it was okay and I did find some things online... NSTA publications... I had plenty to do the classrooms. Those were kind of the steps so it was really a lot for my experience of my working in that first thing.

As he searched for information to design his lab work for his students (complicating action), Ethan also continued to search for science experiments, which could be staged for maximum effect much as he had done as a college student when he designed teacher workshops. He shared, in his evaluation, he was able to do this because of his experiences in college classes: "I would build the model and lab as a training, prepare all the samples, and show them.... it was pretty new... I knew the material. I knew from experience.” His statement, "I knew the concepts... from experience" which were trial and error based, was not reflective in nature. His teaching was routine, rather than reflective (Dewey, 1933). As an early career teacher, Ethan seemed focused on the pragmatic nature of his positions, finding material and activities. 
Journeys toward Reflective Practice: How Engaging in National Board Certification Influences Teacher Identities and Practices

Researching topics within his discipline, designing experiments, keeping students busy, and maintaining control (all complicating actions) while giving students some space to begin developing their questions were hallmarks of his novice years. It was also evident that Ethan was developing an identity as a competent science teacher, based on his understanding of teaching, and becoming a full-fledged member of the discursive community of science educators. Ethan evaluated his work as focused on content development and building his repertoire of learning tasks/experiments.

In becoming an expert presenter of baseline information to launch science lessons (orientation), he continued to use a strategy he developed as a pre-service teacher of stopping just short of giving students all of the answers. As Ethan made decisions about designing his lessons (complicating action), he researched the concepts and focused on presentation strategies (resolution) he thought to be important. Although he wanted to include a "wow" factor in his lessons, Ethan was adamant that he was never a Mr. Wizard type instructor (evaluation); in fact he was explicit in discussing his goals for science education as a novice teacher. He said:

You have to look at the objectives and make sure you addressing your objective with what you are teaching. There is neat stuff for every objective or for every discipline (evaluation) and everything like that. So, it was content standard based, but I would go out and look for the neatest things I could. I would sit in the library and actually go through old editions of the Science Teacher and look for activities and stuff.

In his early career as a teacher, Ethan viewed his construction of knowledge about teaching as dependent on his prior experiences. He believed that his youthful enthusiasm allowed him to gain credibility with his students and he expressed this thinking, saying:

I got to keep them engaged in cool and neat stuff because I love this science thing after discovering it in college (laughter) and being able to actually work with stuff and do lab work. So, I was still really excited about it and so, I guess, some of my enthusiasm would show through. So, it was natural. 
Journeys toward Reflective Practice: How Engaging in National Board Certification Influences Teacher Identities and Practices

The narratives he reconstructed revealed the complicating actions he experienced and his resolutions and evaluations in a successive series of events related to becoming a self-sufficient science teacher, thereby generating a story with a "coherent sense of being about something for a stretch of speech" (Gee, 2011, p. 141). The discourses he used to relay these narratives positioned him as a science teacher who professed to have a deep understanding of scientific concepts and who was also a good presenter of information related to these concepts. These perspectives indicate privileged ways of knowing the world. As Ethan reconstructed his stories, he paused more than once to ask for reassurance that I was able to understand the scientific concepts presented and very often used the word "stuff" to designate involved explorations that might alter the course of the conversation into scientific realms. Ethan learned to move beyond any initial frustration he experienced to embrace practices that empowered him as a science educator and in his coda to the first interview, he expressed his outlook on how these early experiences contributed strongly to his belief in his ability to continue to grow professionally. However, even in retrospect, Ethan did not seem aware that his development as a reflective practitioner was relatively limited.

\section{Developing identity as scientist and as science teacher.}

Prior to engaging in the National Board process, Ethan began to identify the tensions that existed between his identity as a scientist and his developing identity as a science teacher. This included grappling with the difficulty of measuring student time on task with inquiry while teaching multiple students at differing "ability" levels. He said, "When a science teacher defines inquiry it is actually a continuum of inquiry from guided discovery to full inquiry. Not many

people do full inquiry since the Dewey school...it's impossible for the time and materials...the preparation." His evaluation noted some conflict between scientific exploration and actual 
Journeys toward Reflective Practice: How Engaging in National Board Certification Influences Teacher Identities and Practices

teaching. He explained, "Preparation comes after the students say what they want, so the inquiry is completely open-ended...very...the students generate their own questions...they generate their own wonders... so very difficult. You can't teach unit wise, you know, with real full inquiry."

Ethan's framing of his disequilibrium between his identities as a scientist and a science teacher was couched in the privileged language of science teaching and technology: (a) a continuum of inquiry from guided discovery to full inquiry, (b) Dewey school, (c) (students) generate their own wonders, and finally, (d) you can't teach unit wise. Most of the narrative was in second person, providing personal distance from the tensions associated with scientist-science teacher identities. Ultimately, he seemed to leave the resolution of how to engage students in inquiry to the authority of others when he said, "people find it's [full inquiry] impossible." His use of third person (people and teachers) divested him of an opportunity to reflect and instead provided him with relatively prescribed understanding of engaging students in inquiry as a "sacred story" (Olson and Craig, 2005) in this school context and limited options for resolving the dilemmas that emerged with this kind of teaching. Ethan said,

Now, a lot of times when we say inquiry, a teacher will present a situation where some questions are obvious that they think students will ask and they allow students to explore those questions. That is what is going on the minds of inquiry up to the most rigid where the teacher gives a particular question and now you figure out how it works. All that stops short of cookbook follow the procedure labs. So many of them are good. It just depends how much time you actually want to have invested.

In the early years of his career, it appeared as though Ethan grappled with how his beliefs about science could be integrated into the identity he was constructing as a teacher of science. He believed his teaching style was authored by constraints, by the authority of others, including but not limited to, safety, policy, content standards, time, materials, student abilities and learning behaviors. However as Ethan worked to teach science within these constraints and constructed 
Journeys toward Reflective Practice: How Engaging in National Board Certification Influences Teacher Identities and Practices

narratives of his experience, it was obvious he was able to resolve some of the ongoing dilemmas (complicating actions) related to his pedagogical choices and to evaluate the positive outcomes for student learning that resulted from his instructional decisions. One such instance involved an inquiry about electrophoresis Ethan designed for a "really low level ninth grade class." He set up the electrophoresis bowl, turned it on, and let his students watch. He shared,

Of course, we had bubbles going now, and bubbles are coming from the electrode, the water separated, and we turned it off and poured purple cabbage juice in it. Then we turned it on, and we had a color continuum because you have acids and bases, based on the electrodes and the colors would mix and twirl and flip back and switch...they were mesmerized and they were actively involved [so] there was no trouble at all. So it made a big difference in how they were engaged.

This was followed by student generated authentic questions, "Why do they do it? Why does that happen?" He told them it was their responsibility to figure it out even as he recognized the limits of what his students would be able to pursue. "Now this is another place that inquiry can cause trouble for science teachers because of safety issues. They can't open the box and play around with it. It's an acid."

Although there were limits to how he could engage his students in inquiry, Ethan recognized that student engagement was crucial to their learning, their retention of concepts, and was in concert with his conception of teaching and classroom management.

Considering the multitude of hours he spent in searching for strategies that were aligned with the concepts he wanted to introduce, he spent just as many hours creating lesson plans that engaged his students in active learning. Ethan often made use of anticipatory reflection (Van Manen, 1991) as he thought about how his specific students might experience the lessons he designed: "What is the history of these people in here. Are they going to hurt each other? Are they gonna break stuff, you know, that kind of thing. So, I am reflecting on what their potential is 
Journeys toward Reflective Practice: How Engaging in National Board Certification Influences Teacher Identities and Practices

for bad things." As Ethan wrote extensive long-term plans, imagined scenarios of how those lessons might play out, and after teaching made comments on his notes about adjustments he might make to improve hos future teaching.

The following excerpt illustrates his reflection on action:

You know, you are thinking all the time. So, if I am going to start setting up material for a lab thing, I am reflecting at that... maybe I shouldn't do that one because the last time I used this material you know such and such didn't happen, so you are reflecting constantly.

His reflective practices, even when predominantly pragmatic, provided Ethan with opportunities to reconcile the tensions between his scientist-science teacher identities and to resolve and evaluate the complicating actions that arose in his classrooms in ways that benefitted his own, as well as his students' learning.

Ethan was well aware of the management problems that were prone to develop in his classes and said, "With 8 or 9 groups in a class, everybody could be doing a different thing, so they were all [researching] doing different questions and there became a kind of nightmare." This complicating action was recognized and his evaluation led to adjustments to lower his teacher stress and create manageable routines to benefit his students, keeping them engaged, but on track with the concepts he expected them to study. He also strove to provide more resources for his students (resolution) so they might become researchers when a question proved too challenging to be solved by lab work alone. Ethan's satisfaction with his teaching style was evident as he continued, "The teacher is not generating the problems...and so, if they were able to generate their own questions, they were a lot more interested in it than if I would have generated it." He believed he was able to sidestep issues that many first year teachers experience because he stated, 'I really didn't have a lot of problems... not a lot of issues came up. I did follow advice...don't smile until Christmas and it worked. It doesn't work for everybody. By the 
Journeys toward Reflective Practice: How Engaging in National Board Certification Influences Teacher Identities and Practices

end of the year, everything was great." His growing confidence in the teacher identity he was constructing may have been due to his perception that his content knowledge and learning tasks contributed to the fact that his students were on task and his students did not choose to engage in inappropriate behaviors.

This management conversation resumed with, "I mean, so when I was designing instruction, I'm thinking, I need to keep my groups small. I need to keep them visible." This was an immediately recognized resolution to the dilemma of multiple groups and was furthered when he said; "I used things where they can't hurt themselves or me ((laughter)). Those were definitely... in the back of my mind. In the front of my mind was designing things I knew could keep their interest, the WOW factor." This "WOW Factor" theme consumed much of the interview series as Ethan repeated stated, “I like to go, Oh that's neat!” In Ethan's view, his teaching promoted learning that had a lasting impact on student perceptions of how science works because the labs were memorable and illustrated key enduring concepts that were connected over time.

It was interesting to note that when Ethan spoke of his classroom management, he spoke largely in second or third person, saying, "you" and "the teacher" when discussing the problematic subject of managing small groups and maintaining on task behavior prior to developing expertise in this area. When he positioned himself as a designer of small group and student generated questions, his perspective on teaching changed as he used the word "I" 15 times, "me" twice, and "my" three times; thus Ethan seemed to be more confident as a designer of instruction, as opposed to being a facilitator/manager of learning in the classroom. He returned to second person when describing the managerial role he assumed during teaching, "There were five or ten minute lectures... a lot of explaining...there has to be whole group discussion...to 
Journeys toward Reflective Practice: How Engaging in National Board Certification Influences Teacher Identities and Practices

develop the concept...here they get the vocabulary...but if you are dealing with a 14-year-old kid, attention span is not at that [lecture] level."

However, when Ethan returned to his discussion of instructional design, he continued to outline what he believed worked and the ideas he discontinued and replaced with more effective methods of instructional delivery, he returned to using first person. As Ethan described his identity as an instructional designer, he said, "I spent a lot of time planning and actually looking for neat stuff so I could keep their attention based on the curriculum.” Once again, Ethan asserted his teaching was not just for show and he did more than employ a pseudo-wizard of science demonstration format.

The language Ethan used to further construct an identity as a teacher of science was privileged (Gee, 2011, p. 20). He spoke often of "understanding by design" (Wiggins \& McTighe, 1998), a method for unit and lesson design that is prominent in the educational community. Ethan described his "planning for lab periods" as a tool for managing and monitoring student learning. "You have to look at your objectives and make sure you are addressing your objective with what you are teaching." This remained a forefront element of his practice, and Ethan's thinking about worthy instructional design was tied closely to National Board precepts, with the teacher as the designer of highly intentional learning. Ethan professed that he felt the many hours spent in planning were crucial to his successes.

I knew I needed to keep those kids active, keep them engaged in cool and neat stuff because I love this science thing since I discovered it in college ((laughter)) and being able to work...do lab work, So I was really excited about it, and so, I guess, some of my enthusiasm would just show through. So, it was natural.

In his view, the enthusiasm he demonstrated for science contributed to high levels of student engagement and created the opportunities for student learning. It was interesting to note that at 
Journeys toward Reflective Practice: How Engaging in National Board Certification Influences Teacher Identities and Practices

no time during the first interview did Ethan speak of measuring and responding to student learning/understandings or misconceptions.

Ethan spoke slowly and thoughtfully of the school context, as he demonstrated his concern for the wellbeing of his students. "I knew these kids were going to be in there hungry. They were going to be in there abused. I knew they were going to be in there with all kinds of cognitive and mental challenges...emotional challenges." There were students that took all of the extra time and effort he could muster.

The teachers would talk about such things...because if somebody had just lost a parent or someone was placed in a home (complicating action), it would explain certain types of behaviors. You would react to that person a little bit differently.

His resolution was to meet with identified students during their study period to go over materials and procedures privately prior to the lab, as he hoped this would increase these students' likelihood for success with the specific content for the labs.

In positioning the school community and teaching staff as holding specialized insider knowledge about individual students, Ethan again reconstructed a scenario in which knowledge communities (Olson \& Craig, 2005) prevailed, albeit on a very different level. In this manner, teachers who were from the community and knew about the students' home experiences, or lack thereof, shared their knowledge about specific students. These conversations led Ethan to attribute their struggles with learning and/or behaviors to external factors. In fact, some of the students who performed below grade level often faced serious issues and pressures outside of school.

Ethan reached out to one student in particular whose parents were imprisoned, and he worked with this student during this student's study period (Ethan's planning period) and pretaught him the skills he would need to in order to be successful in the laboratory setting. 
Journeys toward Reflective Practice: How Engaging in National Board Certification Influences Teacher Identities and Practices

His rationale was, "I knew that some kids...some kids will respond to individuals that they believe are showing an interest in them...a vested interest...and care about them so I did." Knowing that some kids will respond when a person has a vested interest was the first personalized student statement expressed by Ethan. Heretofore, he had spoken only of managing behaviors by providing complex tasks to keep students busy. For instance he shared:

I like to keep problems from happening because it is hard for me to get back on track ((laughter)). I don't like conflict. I like to design things, keep conflict from happening, and when I wanted to keep him from causing a disruption and conflict, that is what I tried.

Ethan believed when his students were performing specific scientific tasks, they were less likely to be in conflict with one another, or with him. However, Ethan's narratives also began to provide evidence of how he understood his students as "whole" people with lives outside of his classroom, although as a novice teacher his goal in connecting with students in this way was to help the student maintain on task, non-disruptive behavior during his lessons. In the preceding paragraph, Ethan spoke of using strategies to control student behavior; but his narratives about teaching also included an aspect of his teacher identity that moved beyond teacher as designer and manager of instruction. His affect was more sensitive, but not overly so, when Ethan suggested this very different perspective on classroom interaction.

It made me realize that not everybody was like me. Well, when I was growing up, I wasn't like most of these kids [that I was teaching]...I learned a lot about how was their mentality built ...I got to see me, you know, in some of the kids. I learned a lot about them... a lot more about what was going on... with these kids who were not like me.

The conversation was still matter of fact, but he realized his students were not necessarily like him and need more than content knowledge. This recognition may have contributed to developing perspective in contemplation of elaborating his teacher responsibilities. 
Journeys toward Reflective Practice: How Engaging in National Board Certification Influences Teacher Identities and Practices

\section{Indications of Ethan's development as a reflective practitioner.}

The gentle and serious tone of Ethan's realization that his students' home-based supports were very different from his own indicated he was both startled and inspired by this revelation. Ethan believed this was when he began to think about his teaching in terms of ensuring all students do learn. "Equity means making everything available for the students... fairness with equity... just making it even. Making it fair. I didn't really grasp this until more recently because I thought if instruction is fair then everybody has the same shot." Ethan reconstructed his early teaching habits and his realization that some students were truly unprepared and therefore unable to access the learning he intended in his lessons.

He grasped, “These kids need a lot more help...they don't have a base to build on... just giving the same amount would be a disservice to those kids. They didn't have basic understanding... it isn't always equal... not the same." Based on this reflection, he began to design work that provided time for an exploratory phase at the outset of concept development. This enabled Ethan to interact with students verbally to ascertain prior knowledge and use his impressions as the starting point for laboratory work assignments. This realization that he, the teacher, was a gifted learner and many of his students were not became a pervasive complicating factor in his professional learning. Furthermore, his students were deeply lacking in background experience as a link to what he wanted his students to learn. This was reinforced by his own experiences as a learner college experience when he discovered lab-based learning in his college courses, a highly significant context for learning that had been denied him during high school.

In his evaluation of his practice, Ethan never stepped away from his belief that high engagement was his best management tool. He affirmed his perseverance and said,

I want the WOW! because it kept them doing what I wanted them to do. That kept them on task. It was challenging and, well see, I would rather have the mental challenge than in 
Journeys toward Reflective Practice: How Engaging in National Board Certification Influences Teacher Identities and Practices

class behavior problems. The physical challenge of planning...getting the materials...doing all that... I don't mind the hard labor.

His summary of this practice served as a coda for interview one, as Ethan referred to using this wow factor strategy as in every interview. He expressed a relationship between mentally taxing, but effective, planning with the accompanying labor-intensive acquisition of materials for laboratory experiences with the academic learning goals he held for his students. As a novice teacher, Ethan expressed confidence as he worked to capture student attention and in retrospect believed he was still learning how to tailor instruction to student abilities in order to maximize their academic achievement.

\section{Ethan's Reflective Practices during National Board Work}

Ethan did not credit his decision to enter the NB process to outside support; in fact he slightly discredited his school's and county's system of professional development prior to his NB experience. He said, “Administration was lacking in strength. Teacher leadership activities weren't what they are now. (As a complicating action), teacher-leaders were discouraged from doing anything. County/district levels discouraged teacher input. So, everything was pretty much top down at that point." He went on to discuss teacher leadership and its potential positive effect on learning by both teachers and their students. Then Ethan closed his narrative with the evaluation that prior to his NB experience, his school leadership team was of little influence.

"We never had bad leadership but I think it was a little lacking in strength or...how would you say it...um, the leadership ability or the leadership potential was not great in the school...for a few years." Ethan had been teaching for eight years in his content area, biology, and believed he had a "pretty good amount of experience" but by no means believed he was an accomplished 
Journeys toward Reflective Practice: How Engaging in National Board Certification Influences Teacher Identities and Practices

teacher. These statements indicated that Ethan felt the lack of collaborative support was problematic. The resolution to the lack of perceived support came when he recognized a potential partner who was "a colleague in the hall...we decided to do it at the same time."

Ethan shared an additional experience that contributed to his decision to pursue National Board Certification, "At the state science conference (orientation), we had gotten some information about it [NBPTS certification]... a teacher at the conference was talking (complicating action) about his experience ...we decided to go ahead and apply." After submitting his enrollment, Ethan became aware and evaluated his standing as uninformed, "Neither one of us knew what we were doing." He resolved that "We really couldn't support each other in ignorance, so we just encouraged each other I guess." Ethan described this relationship with a little more clarity when he claimed:

We would talk about things like the instructions...How are you supposed to do this part? (complicating action)... I remember it was just nice to have someone going through at the same time and (evaluation) trying to figure out what's going on because (a resolution he realized in retrospect) neither one of us had a clue.

Ethan began this process by writing ideas down on his own to "figure it out." He looked at his lesson plans, and the notes he had written about his lesson plans and said, "I looked at the content standards, too." According to Ethan, this was "barely a start." Pooling multiple sources of information to develop strategies for creating a National Board Portfolio was consistent with the descriptive, analytic, and reflective thinking required by this certification work. His work in creating his portfolio was focused on science content standards (NSTA) as well as the highly specific NB standards because these "were the ones you really had to focus on...they were required...to master those took more time, much more time and hard work." The time element stated by the National Board was generally recognized as 400 hours, or the equivalent of ten 
Journeys toward Reflective Practice: How Engaging in National Board Certification Influences Teacher Identities and Practices

fulltime weeks. In reality, Ethan believed this was a low time estimate as he was already in the habit of working many hours beyond the school day to develop instructional design prior to his NB candidacy. He was still functioning at the pragmatic level within this process, as was his traditional approach.

His first problem or complicating action was made apparent when Ethan began to consider his formerly low level of awareness of the importance of the environment outside the school on student achievement. He averred that the NB process made him contemplate things such as, "Family structure...having enough food to eat...having all those types of things...because I was very sheltered. When they come into the classroom and you don't know this kind of stuff, you might think they are a disciplinary problem." He began to think about the purposes behind inappropriate student behaviors and the reasons students were not understanding and retaining the concepts taught, possibly his own assumptions and beliefs (Dewey, 1933; Zeichner \& Liston, 1996). This stimulus of figuring out proved to be a predominant complicating factor that provoked this question, "What does the National Board want in my portfolio?" This was a pivotal moment for Ethan as he began to engage in new ways of thinking, both about his teaching and how students learn. With the onset of a revised perception of student dispositions and the needs of the whole child, his understandings about his role as an educator slowly began to change. It is likely that his previous experience in working to pre-teach the struggling student influenced his perception about how to go beyond practical instructional design and begin to focus on relationship building in a concerted effort to gain knowledge of his students.

Ethan shared some of his struggles to respond to NB portfolio prompts (an external context): "I taught the top kids in the school and the lowest kids in the school... what I had to say [when writing to create student context information] was night and day different between the two 
Journeys toward Reflective Practice: How Engaging in National Board Certification Influences Teacher Identities and Practices

groups." This was eye opening because, as he said repeatedly, he was interested in the wow factor, how was he going to make class exciting? All of his thinking was actually focused on himself, the teacher as a creator of the wow factor. Before entering the National Board process, Ethan had not considered how the wow factor did or did not actually meet student needs. This was illustrated when he made these statements about ways the National Board portfolio work influenced his perspective:

The prompts would really get me thinking about how they are thinking and what they are going through, there was a point when I got to thinking about...if they don't know where they are going to sleep...if they may have not been able to get sleep... then they are not going to worry about science...that kind of changes how you think about kids...it makes a big difference... having to look and think about, okay...this top class is getting this...this lower class isn't getting this. I think that context really promotes reflection because I had to figure out... and a lot of it comes down to knowledge of students, about knowing what their context is...where they are coming from.

Ethan's teacher identity was evolving, still slowly, but he began to consider himself a teacher of students who were learning about science, not solely as a teacher of science when he compared the learning experiences of his top versus his lower class. Although Ethan seemed to have begun to realize that the diversity of his students should inform his teaching, this evolution in his identity, as a teacher of students rather than a teacher of content, seemed to be heavily influenced by the external context of the NB standards. "The thing that was different in the National Board process was... before I never stopped to consider what kids were thinking actively. For me to take time to stop... try to analyze what kids were thinking was required." Thinking about how people learn, a theme addressed by Dewey (1910), was noted when Ethan discussed inquiry and said, "Not very many people really do full inquiry since the Dewey School." He seemed to be drawing a connection between Dewey's theory and his practice related to the notion that "the best thinking occurs when the easy and difficult are duly proportioned to 
Journeys toward Reflective Practice: How Engaging in National Board Certification Influences Teacher Identities and Practices

each other... Too much that is easy gives no ground for inquiry; too much of hard inquiry renders the inquiry hopeless" (Dewey, 1910, p. 222). Ethan also referred to his own theoretical underpinnings as an undergraduate student when he was faced with exploring the act of learning in scientific laboratory settings. These contributing factors may have influenced his responses to NB Portfolio questions. NB prompts expected Ethan to use his knowledge of content, easy for Ethan, and make instructional decisions that would make learning possible for his students. The prompts were open-ended and steeped in inquiry as he struggled to find resolutions; the work of answering these prompts. He was engaged in finding the balance between what he knew and what he was expected to demonstrate to be successful in achieving NB certification. Learning how to describe and analyze his work as he responded to the difference between his content knowledge and creating access to this knowledge for his students was still out of reach. NB portfolio prompts asked him questions that he had not considered prior to the NB process. Ethan evaluated his revised assessment of his teaching acumen and said:

The activity was the same, but the level of actually evaluating not only what they were doing, but how I was learning about my students while they were doing it changed because you were required to learn from your teaching.

For the first time, he started to ask himself intense reflective questions about student academic growth. Ethan looked for evidence that his teaching practices worked to build his students' repertoire of skills and content knowledge. The NB prompts included questions such as:

Describe the relevant characteristics of this class that influenced your instructional planning, format, and strategies for this lesson (e.g., ethnic, cultural, and linguistic diversity; the range of abilities of the students; the cognitive, social/behavioral, attentional, sensory, and/or physical challenges of students with exceptional needs; the personality of the class).

How did you use detailed knowledge of your students' backgrounds, needs, abilities, and interest and your knowledge of biology in your planning and choice of strategies?

What are the instructional challenges represented by your students?

How did the social and physical context you described influence your planning? 
Journeys toward Reflective Practice: How Engaging in National Board Certification Influences Teacher Identities and Practices

What is your rationale for choosing the instructional format that you used to meet the goals of this lesson?

How did you monitor and assess student progress during the lesson and how did this influence your decision making during instruction?

How was student feedback provided and what was your rationale for providing it in this manner?

When he asked himself these questions, his thinking slowly evolved and he began to take responsibility for his decisions and actions (Dewey, 1933). However, he seemed certain that prior to NB work, this thinking was implied, just never explicit. Ethan believed his focus had always been on his presentation and the ensuing learning tasks assigned to students prior to NB work. During this process he began learning from his students so he began to design differentiated instruction.

Completion of the National Board process yielded a positive effect on his ability to deal with his own intellectual functions. Ethan valued NB tenets and credited the process thusly,

Reflection was a requirement of the National Board process. That was the really... the first time I had really stopped to reflect and think on what the kids are thinking. So far as meta-cognition goes...that's what made my teaching change.

He was taken to task in his written response to the NB prompts to collect work samples from all of his students, and then he "followed those students and tried to think about what they were thinking...how they were putting misconceptions" into their lab reports. He asserted he was becoming a lot more interpretive as he mulled over the work samples while trying to look deeper into what they were actually doing to figure out why they were writing and recording ideas, which may have been close, but were somewhat off the mark. Ethan said, "I reflected...trying to look deeper into what they were doing, whereas before I would write wrong or put a comment on it and hand it back. That was the difference." Ethan began to look at student thinking, inasmuch as it was observable, and responded to student thinking by making use of what he learned to 
Journeys toward Reflective Practice: How Engaging in National Board Certification Influences Teacher Identities and Practices

create more student -teacher dialogue. He used these interactions to dispel misconceptions, ask questions that might solidify thinking, or redirect students' learning actions. Formerly, he said he would have assigned a grade and moved on to the next topic. He concluded with "The activity was the same, but my level of evaluating, not only what they were doing, but how I was doing it changed...because you were required to [by the NB process].” In thinking about the consequences of teaching, Ethan looked deeper at what students could understand, know, and do, and what they did not yet understand, did not yet know, and could not yet do. Furthermore, his students were charged with self-evaluation of their own thinking and actions.

In learning how to frame the dilemmas of his practice, the NB prompts became a catalyst to stimulate Ethan's thinking. Ethan ascertained that: "While I was writing, I had to think through the reflection. I had to reflect on my work. I hadn't done anything like that before." When he realized the value of reflection and metacognition, he tried to emulate similar prompts in the work he asked his students to perform. Ethan was internalizing the NB precepts. He continued to write after completing the portfolio prompts: "I keep a notebook, which has worked out pretty good. It is important to me... I see changes that happened in my instruction...now I know why I did it." Thus, writing became a tool for reflection and inquiry for Ethan to collect his thoughts, review his work, and evaluate his teaching practices as effective, or as lacking, over time. A crucial phrase in this passage is "why I did it." This might be an indicator that the method of writing itself organized Ethan's thoughts and provided a stimulus for reflection when he rebuilt or revised instruction for his students.

Ethan, the scientist, who evolved into Ethan, the wow! factor teacher, had to slow down his own thinking so he could grasp and understand how his students were learning. He needed self-monitoring strategies to make that happen. Ethan sensed that reflection was crucial and with 
Journeys toward Reflective Practice: How Engaging in National Board Certification Influences Teacher Identities and Practices

what he recognized as his own analytical mindset, he was making progress. "I know exactly how it happened," he said, "The reflection was while I was writing. What happened... what I did and what I still always do now...just write it down in a notebook.” He kept his own notes, and stated that these were not lesson plans, about what worked well, what needs adjusted, and what is no longer going to be included in his repertoire. He started this practice as a candidate and claimed, "I would write down what worked well and what didn't ... while I was in the National Board process... and now it's what I do everyday." The process of penning words was an excellent meta-cognitive strategy for Ethan and gave him access to his own privileged language for self-reflection. He went forward in time and explained,

The notebook is significant because I am in them everyday that I work because I look back over the years...it gives me ideas...it gives me a pacing plan...I can look back five or six years and see change that happened...things that moved around...how my students learned. It has been really important...it saved me a lot of time now... using that from the past and knowing why it works. So, that is why I kept them [the daily notebooks].

Ethan was certain that his candidacy in the NB process exerted the greatest force for change in his teaching practice. Prior to being an NBCT, Ethan recalled obtaining materials so he could lead exciting labs and present information to students in an inquiry format. He felt that his teaching style in his earlier days was presentation based. He used small blocks of time in direct instruction and provided minimal feedback to students. Completion of he NB process changed his teaching style. He was resolved as he stated, "It started me down a road to look at critical thinking, teaching study skills, teaching development of obtaining knowledge, actually actively teaching that...where before I didn't do that." Once again, and genuinely so, Ethan credited the act of being absorbed in his writing, recording his thinking, and generating reflective portfolio entries with becoming a reflective practitioner. Perhaps the most revealing statement made was, "but I had never really thought to look into teaching them how to think because before [NB] I 
Journeys toward Reflective Practice: How Engaging in National Board Certification Influences Teacher Identities and Practices

never really thought that much.” The process of writing about his work for his portfolio submission, in his opinion, made him a better learner, and therefore a better teacher for his students. Ethan embraced the notion of wholeheartedness Dewey (1933) and this newfound intensity of reflection contributed significantly to his work as a teaching practitioner.

Ethan discussed the changes he made to become a more effective teacher when returned to his realization that his students' problem solving capacity was not as developed as might be required to complete the tasks he assigned. The science specific vocabulary was impeding their learning and Ethan began teaching the process of balancing equations with redesigned strategies. One strategy, a very basic chemical reaction labeling procedure came about because he now understood his students could not recognize the basic structure of an equation. Ethan said, "At the beginning, they weren't getting the connection because these were different words and to use unknown words in a context when you are not familiar with the words is pretty difficult to do." He came to the realization his students did not recognize $\mathrm{NaCl}$ as salt, so they were unable to connect the use of reactants in yielding a reaction with by products (a complicating action). He learned to simplify the actual events in the experiment and used words such as salt, baking soda, vinegar, water, and baking powder instead of using the chemical symbols (resolution). This he redesigned the work based on his newly acquired knowledge of students, "Yeah, the smaller parts of it...pieces of it...putting that together to get bigger parts and then you can get concepts and overall summation and big ideas." After Ethan simplified the reactant process, his students were able to relate it to the real world substances they were using to the scientific vocabulary through his scaffolding of their learning, eventually adopting the scientific terminology.

In Ethan's reconstruction of events, he noted that he was forced by the act of trying to answer the questions in his portfolio to recognize the chunks of information he expected his 
Journeys toward Reflective Practice: How Engaging in National Board Certification Influences Teacher Identities and Practices

students to use did not make sense to the students. One critical factor he recognized in this "reflection on action" was that it took the work involved in the NB process for him to evaluate his work and come to the conclusion that he was using vocabulary his students could not understand.

In beginning to frame the problems of his teaching practice, he imparted some important thoughts about his teaching style and the subsequent growth he believed was generated by his NB work:

What the process made me do... for all the topics that were covered in the process is that it made me think about how the kids were thinking which is what I didn't do before. I mean that really is the big thing about how it impacted me as a teacher is it got me to think how are they thinking. It started me down a road to look at critical thinking, teaching study skills, teaching development of obtaining knowledge, actually actively teaching that... where before I didn't do that I would just get the stuff and say get this, you know, here is the information, here is how... not so much as a direct instruction...I would still teach inquiry based ... lab based before, but I never really thought to look into teaching them how to think because I never really thought about that much.

This passage demonstrated the evolving nature of Ethan's taking responsibility for his teaching and the multiple consequences of his decisions and actions on student learning. This indicated a distinct difference in how Ethan positioned himself as a teacher of students who were learning science, rather than as a scientist who presented information and expected his students to be responsible and take it upon themselves to continue learning when his instruction concluded. It seems that following the pedagogical model provided by his college instructor, who worked with students who possessed the background knowledge to become self-directed, Ethan was just realizing that this strategy was unproductive, and perhaps unsuitable for high school level learner. If Ethan wanted his students to develop critical thinking and study skills in addition to constructing understanding of science, it was up to him to remedy this situation.

Then he discussed the importance of deepening his knowledge of students while 
Journeys toward Reflective Practice: How Engaging in National Board Certification Influences Teacher Identities and Practices

he experienced NB candidacy:

At that point, I hadn't really talked to the students ...more than just checking for recall. Some of the questions they (the National Board) were asking in the reflective process you actually had to interview the students. I mean you had to really get the answers from them to show your knowledge of students. You had to get to know what was going on in the heads of those students and as a result of me just seeing the concept that knowledge of students is the core... an integral part of the architecture of my teaching, it made me get to know my students better...the context of their lives, you know, outside events...some of that came from questionings and the questionings would go a lot deeper than... what did you get here? What was your answer? So, it became why did you design it this way? ... What was your objective? ... Justify your support...those types of questions.

Ethan demonstrated altering his language of teaching from that of the privileged language of scientific perspective $(\mathrm{NaCl})$ to more universally accepted terms (salt) and this action provided opportunities for his students to access the content. He realized it was his responsibility as the teacher to support his students as they made those language connections (Gee, 2011, p. 19) While Ethan may have needed to use lay terms when he introduced the lesson, he was also responsible for ensuring his students learned the science discourse, which would enable to enable and promote their learning; this was a novel view for Ethan at that point in time. He described his early classroom climate as one that supported a certain level of restricted student inquiry with low teacher support levels. In describing the complicating action, Ethan believed a communication gap existed and the unsophisticated feedback loop he offered at that time hindered student progress. The turning point took place when he attempted to respond to difficult NB portfolio prompts and could not. He then turned directly to his students. According to Ethan, what he learned astounded him:

It got them to thinking about the structure of the equation then you could put some bicarbonate and () acid, all these other formulas...eventually when they were ready for it, but they weren't ready for that until they knew the basic structure of the equation. So, they had to work with that stuff, because me telling them reactants in the beginning products at the end, it wasn't registering. They just weren't getting the connection 
Journeys toward Reflective Practice: How Engaging in National Board Certification Influences Teacher Identities and Practices

because these were different words and to use words in a context was too difficult for them.

What his students told him led him to believe that science vocabulary was a barrier, impeding deeper concept development by his students. He made modifications in word choice and engaged in feedback when he listened to his students as each articulated his/her experimental design and results. Ethan said, "They had to work with me and tell me about it, because me telling them wasn't working." To resolve the dilemma, he asked himself why his students were thinking in particular patterns.

He then reconstructed how he solved the NB questions in the reflection piece of all entries:

You are going back and you are looking at ...What did you do? ...How did that? ... I had to work more in the reflection aspect cause there is a reflective part in all of the entries and in the reflection parts, they would be asking questions and giving you prompts about... How do you know that you met your objective? ... How do you know that this happened? ... So you actually had to ask students questions. So, I had to ask concept questions ...explain to me this... Why did this happen? ... So that I could know they were actually really getting it (the concept) and then I could go and answer the questions about my reflective process. I know...this happened for my students because I asked them X and this was the type of response.

As a coda, he reiterated that this revised feedback loop asking students to explain their thinking was essential to developing his ability to identify progress each student made toward accomplishing the goals he had for their learning. This realization occurred as a result of his engagement in NB portfolio work. The use of the teacher/student feedback loop reappeared as we continued the interviews.

Ethan shared another narrative of his experiences assessing student learning before entering the NB process in which he talked with students but not at the level of questioning (complicating action) that he learned to use during and afterwards. He once believed if students 
Journeys toward Reflective Practice: How Engaging in National Board Certification Influences Teacher Identities and Practices

scored well on tests they were mastering the material. Conversely he said, "If they didn't have a good score, I thought they were not getting it. But, I found out ... sometimes good scores are by luck and bad scores... were not always accurate." Therefore, it was during the NB process that Ethan evaluated his own assumptions about teaching, learning, and assessment, and learned objective, multiple-choice tests did not necessarily provide the most accurate evaluation of student learning.

Ethan's believed that learning to reflect definitely informed his instruction "whether it be for the next period or the next year" because he concluded he had learned how to reflect in action (Schön, 1983). Ethan stated:

The kinds of questions that I have asked have certainly gotten better as far as me beginning to know the underlying concepts that the kids have or not. I think that the National Board process... going through the initial certification, but also the renewal, kind of reawakened that too. When I tried to answer their (NB) questioning techniques and basically NB asked me, how do you evaluate? ...How do you know that the students are getting what they are getting? And how did you know that this happened? What is your evidence? And some of the (student learning) objectives may not have been met and assessed from multiple-choice questions or something like that so you actually had to ask them (students) the questions... Explain to me this... Why did this happen?... So that I could know that they were actually really getting and then I could go and answer the reflective process questions in my portfolio.

By reflecting in action due to his attempts to respond to NB portfolio prompts, Ethan became adept at listening to students as they explained their thinking, observing student actions and reactions during instruction, and evaluating whether his lesson design was successful or required modifications as he taught.

In conclusion, Ethan discussed how he was becoming reflective. He asserted, "The NB process made it pretty evident how being able to reflect and evaluate as a teacher impacts what a student can learn." Before becoming an NBCT, he now believes he was unschooled in reflection 
Journeys toward Reflective Practice: How Engaging in National Board Certification Influences Teacher Identities and Practices

(a complicating action), "because I didn't know what it meant to reflect until being forced to go through the reflective process." His background as a scientist developed his strength as an observer; yet he repeatedly averred he had never been forced to reflect. This may be an indicator the context of being a NB candidate exerted influence on his teaching practices and teacher identity. While working through the process, he resolved this dilemma when his efforts to be reflective became intentional: he developed his thinking through recording everything and by writing about what he had noticed. He credited the time he spent writing about his ideas as time invested in learning how to be reflective. "I think that when you look at how you write, how you struggle to find the correct word to describe your thinking...really helps to give you some hints on how you reacted at the time." Over time he believed he learned to examine how his students were learning and he eventually evaluated his own thinking processes as sharper. Ethan believed the NB question and response process required him to be more intentional in using reflection to solve problems.

During the process, it gives you specific questions to help you in the reflective process, and for me, I am pretty much a black and white kind of guy. I really don't like a lot of gray and that pretty much sums me up. The entries asked questions that would stimulate reflection. I wasn't really a reflective person because, you know, we (teachers) are busy.

Over time and with practice (his coda), reflection became an ingrained teacher trait. Ethan believed reflective thinking continued to guide his decision-making after he was recognized as a National Board Certified Teacher.

When Ethan thought about an assessor reading the reflection sections of his portfolio entries, he had fears about being told he was wrong. This sense of disequilibrium experienced when the self-questioning about decision-making in one's teaching practice process commenced. Dewey (1910) deemed this insecurity to be suitable when he said, "reflective thinking is always 
Journeys toward Reflective Practice: How Engaging in National Board Certification Influences Teacher Identities and Practices

more or less troublesome because it involves overcoming the inertia that inclines one to accept suggestions at their face value; it involves willingness to endure a condition of mental unrest or disturbance" (p. 13). However, it soon became clear to Ethan he was learning to be a better teacher while he was writing. He clarified his reasoning when he said, "What they [NB] have works. The National Board way of reflection is not phony. It's well done. It is a good way of learning reflection." He revealed that, in his way of thinking, it was an advantage to educational systems to have a tool, such as the NB process, that makes people reflect. It was a concrete set of introspective practices combined with an examination of the candidate's teaching behavior that created the model of "how to reflect" through written responses to very specific demanding prompts and the production of evidence that teaching practices met the standards supported by NBPTS.

His final statement during interview two provided a bridge into interview three when he said he ultimately believed that the work of reflecting "does become faster and you never, at least I never, completely stop reflecting.” Therefore, Ethan maintained that his time spent writing during the process made him a believer in the reflective process and in his opinion, years later he now functions well as a reflective practitioner because "It [NB process] changed me...by getting me to think about what are they thinking and that was the biggest of all the processes. Now I think about how my students think all the time." Dewey outlined reflective strategies as (1938):

It involves (1) observation of surrounding conditions; (2) knowledge of what has happened in the past, a knowledge obtained partly by recollection and partly from the information, advice, and warning of those who have had a wider experience; and (3) judgment which puts together what is observed and recalled to see what they signify (pp. 68-69).

Ethan mentioned his studies of Dewey during the interview process, and was able to summarize his thinking about his work as a teacher as aligned with these theories. He said: 
The smaller parts...pieces of it...putting that together to get bigger parts...then you can get to concepts and overall summation and big ideas. Because essentially in researching my student learning problems, I am actually trying to look at how they try to solve problems, you know, learning more of the parts ... so that when I reflect... my thinking is about each example... and can provide a piece of the big puzzle.

The teacher was anticipated to continue his own learning according to Dewey, and to use contemplative skills, critical thinking, and decision-making skills in the context of meaningful learning, thereby doing improved work in serving his students.

From Ethan's perspective, reflection in action (Schön, 1983) was a powerful tool for improving his knowledge base. He was able to integrate knowledge of content with knowledge of students and thereby improving the learning of students under his tutelage. Ethan asserted that through reflective thinking, he became more knowledgeable in applying the content knowledge he possessed to the knowledge, skills, and dispositions he expected his students to develop as a result of learning tasks he designed. This aligned with the assertion of Schön that reflection played an important role in the ongoing professional development of teachers and enabled adaptive learning by teachers through metacognition and/or reflection.

\section{Ethan's Reflective Practices after National Board Certification}

Ethan was still committed to continuing his work with colleagues and he spoke about this idea at length during our third session. Becoming an NBCT appears to have caused him to struggle with his models of presentation at the local, state, and national in a complicating action. He said:

Now after you are certified...when you have that realization it gets you evaluating...thinking about what you present [at conferences]... Okay... I want to go and do this presentation... How is it going to impact the student learning? It may not be your students, but the students of the people that are in the room. 
Journeys toward Reflective Practice: How Engaging in National Board Certification Influences Teacher Identities and Practices

Subsequently he evaluated his work and determined that he needed to revise his approach to leading professional development sessions. Prior to NB Certification, Ethan supposed his presentation style was likely to increase the content knowledge of teachers in his audience and he was satisfied with this outcome. After certifying he revised presentations with the intent of supporting teachers as they learned how to align their deep knowledge of content with their knowledge of students. He now believed what he offered needed to ensure that the teachers in attendance would, in turn, be able to use the information they gained to positively impact the learning of their students. In rethinking his work, he began to reflect as he asked himself, "When I present, what are teachers going to be able to take back to their students?" He felt that his work as a presenter was of little "trickle down" value to participants unless each made a connection to student learning as a result. This was an important transition for Ethan because his intent in exposing others to the awe and wonder of scientific phenomena shifted to making learning accessible to others, a major precept of the NB process. It was salient also that this portion of the interview was also the first time that he explicitly indicated his work with others, colleagues in particular, positively impacted his thinking about how people learn on a broader scale.

Ethan also explored his student-teacher interactions, which were notably altered after certification. He commented on the high percentage of the school day (approximately three hours due to block scheduling) he shared with his students. As an NBCT, he had learned to use this time with students to listen to them express their thinking, the ways in which they constructed understandings of the content. As he walked from table to table, he allowed students significant stretches of uninterrupted time to engage in research defined by content objectives, questioning, and interactive learning with peers. This instructional design also allowed for one on one questioning of student learning strategies, which Ethan termed "informative feedback." 
Journeys toward Reflective Practice: How Engaging in National Board Certification Influences Teacher Identities and Practices

Informative feedback was described as asking questions, and using specific vocabulary at times to provide scaffolds, until the students themselves began to draw scientifically correct conclusions, generally via deductive reasoning. He also encouraged the use of reference materials, with "I asked if they looked it up yet and they said no they hadn't looked it up yet... so I knew they would eventually get it." He termed his use of body language in the feedback mode as instrumental to this approach. Ethan related:

They [my students] were designing a lab and they wanted to know what was copper sulphate going to do. I had read the article [from their research work] and I knew where the [research] material was... so I gave them the shrug... because I knew they would figure it out. But if they had needed more guidance I would use more facial expressions to direct them in either a positive or negative and I do it intentionally. I remembered the way that group responded, so I knew they understood the chemical process.

In fact, his students even named his gestures that "pushed" their thinking and thereby creating a positive classroom climate in which they became more self-directed and responsible. Ethan also related his emerging non-verbal behaviors, "I just started doing it... the kids named it not me... I didn't pick up on it right away... what it is not to lead them... now the grimace leads them... the bright eye maybe...but the shrug doesn't lead them." At times when students began to make conjectures along a pathway that might lead to unsuitable conclusions, Ethan suggested they consult written sources to verify their thinking. On other occasions he might be specific in his redirection. Thus Ethan learned through his own inquiry into his practice that his students were capable of taking on more responsibility for their learning than he had ever imagined. Because he created structures in his classroom that allowed for students to use large blocks of time for uninterrupted small group work, they were able to engage in student initiated (student to student and student to teacher) interactions that supported their learning. Ethan, the scientist, wanted to allow students the space to conduct inquiries and work as independently as possible, while Ethan, the teacher, realized that his educator identity needed to fulfill certain responsibilities in 
Journeys toward Reflective Practice: How Engaging in National Board Certification Influences Teacher Identities and Practices

the classroom beyond his early supposition of being a class manager/monitor. According to Gee, 2011, "the way we tell the stories of our lives - and what we have to say about who we are - to others and to ourselves ... can change in different contexts at different times" (p. 112). By the third interview, Ethan moved beyond his collegiate identity as a nouveau scientist and reconciled his original open-ended personal learning style with the constraints of teaching in a public high school. The stages of this evolution were outlined with a fair amount of reconstructive reflection on Ethan's part as he verbally shared his thinking about his journey thus far.

Ethan reflected:

Well, the conceptual framework... the products of the reflection and development of the framework...thinking about why I am doing things not just getting it done for an assignment... the National Board really made me focus on the professional teaching standards and... to reflect from the angle of student achievement and student development and not always be more teacher centered. But, over time I look at the reflection as...there isn't time to do justice for it... but it has to be pretty focused.

Prior to be an NBCT, Ethan designed teacher centered instruction. He realized academic freedom was a likely outcome of becoming a NB Certified, because he learned student learning really does determine the pace for an accomplished teacher.

Ethan closed the final interview with his lengthiest speaking passage of our series when he said:

I didn't understand reflection... fully... I didn't fully understand it... I did better than when I started... with National Board Certification I was going through... just answer the questions... the questions are pretty guided even for reflection... but after that there was a little bit more to reflection... I figured out that there is a little bit more to reflection... it's like poetry... you don't go in as a student of poetry and say well, I am going to write this way ...... but after you had written 20 volumes then you can go off on your own and do it and that is what I think reflection is... well it is the way teaching is... but I may do the same thing because I know I have been at it long enough that I know what I would be doing....in reflection right now I think I can do it much faster because I have gotten more used to looking at well... what are the kids thinking...I narrowed my thinking and observation to think now why are they thinking this... why are they putting these things together? 
Journeys toward Reflective Practice: How Engaging in National Board Certification Influences Teacher Identities and Practices

It was noticeable that Ethan built this entire section of the third interview in first person and this was different from some of his earlier characterizations. He discussed how the process itself asked questions of him as a teacher that he took personally and the resulting answers he constructed challenged his assumptions about teaching and learning. Eventually upon successful NB process completion, he recognized his transformation to a student-centered stance as a result of being asked to verbalize his thinking as he responded to the highly specific NB prompts about his work.

Ethan launched into an explanatory passage describing how NB work prompted his current teacher identity, when he stated, "The kinds of questions I have asked have certainly gotten better as far as getting to underlying concepts that the kids have." Here Ethan strongly asserted that he learned how to ask good questions by being asked good questions. This took place during his NB writing, first during initial certification and again during the renewal process, as he answered prompts that entailed reasoning, justification, and meta-cognition. Furthermore, Ethan was adamant in his reiteration that the process of becoming NB Certified influenced and strengthened his classroom practices in a) instructional design (because he provided "more support during laboratory sessions"), b) student-student, teacher-student, and student-teacher interaction (because most of his "student work sessions were interactive" and small group based), c) formative evaluation technique ("use of observation and question techniques with students"), and d) summative evaluation strategies (no longer reliant on “multiple choice tests"). These conclusions were prompted by his own learning and related back to his earlier discovery that students were not able to think using the same level of skills and vocabulary that he, the teacher, possessed. Ethan asserted, "If you are thinking about, what are they (the students') thinking? You have to ask them." It took effective questioning on his part so 
Journeys toward Reflective Practice: How Engaging in National Board Certification Influences Teacher Identities and Practices

he could "figure out" what the students he taught did, and did not, understand at the time, which he then addressed in his long-term planning. He claimed that the NB process transformed his thinking about how to ensure that students under his tutelage experienced equity and access to learning, which included better questioning strategies. Ethan justified his thinking by asserting that he learned some students required more support than others and he intentionally created this space for their academic growth because he was a teacher of students who were learning science.

\section{Conclusions}

In reviewing the transcripts of conversations with Ethan, it appeared that his passion for scientific process and love of the reasoning involved in constructing understandings of science were driving forces in his decision to become a teacher of science. Early on he seemed to believe it was his role to construct the environment and students would naturally learn with the tools he provided. Having learned science process skills and science content knowledge as a college student proved to be both an advantage and a hindrance to his early teaching career. The discovery process that Ethan embraced was an advantage, as it fueled his passion to write grants that provided the funds for the materials he used for teaching and learning. This research he did related to materials and methods for presenting his lessons kept him learning about science content and methodology, including how technology could be meaningfully integrated into his teaching and learning tasks. Factors such as the time spent thinking about gaining materials and the work of searching for grants by reading paper journal articles prior to Internet access were burdens. These tasks slowed his ability to step back from his students and take the time required to become reflective. In one interview, he spoke of building a life-sized version of a blue whale, and in another a scale model of the solar system that involved the entire community. While he 
Journeys toward Reflective Practice: How Engaging in National Board Certification Influences Teacher Identities and Practices

felt these were successful attempts to engage students, as a veteran teacher he now believes that the major impact on student learning had more to do with measurement and scale, ostensibly math concepts and not necessarily scientific research or content knowledge. It was interesting to note that interviews centered on Ethan's early years seemed to have more dialogue couched in the constraints that influenced his teaching, including student behaviors that impeded learning and lack of materials to conduct the kinds of labs he wanted to present. These concerns disappeared from the conversation after Ethan certified, giving way to his concerns about the learning experiences he was designing and how they might best benefit his students, as well as ensuring that these tasks were designed to meet the needs of all students.

When Ethan reflected on his career, he stated emphatically that he had evolved from being a constructor of the environment to serving as the primary guide during actual classroom experiences.

I would show something [a presentation]... stop and then say and for what question or questions would you like an answer...At that point [when I started NB work], I hadn't really talked to the students...more than just for checking content recall. When I saw that...basically asking how do you evaluate... how do you know that the students are getting what they are getting. I [had to] make that jump to...oh, this is knowledge of students... with questioning which I wouldn't have known not having gone through the process...It was something that I have been doing ever since...If you are thinking about what are they thinking, you have to ask them and you can't really get that from just observing.

Thus, he characterized his reflection as being "in action." In fact he saw his role as a supporter of investigation, whose questioning strategies motivated his students into deeper reasoning and thought processes and prompted justifications for their responses during both laboratory and, as needed, lecture based tasks. Time for reflection "on action" emerged as a major constraint. Ethan noted he thinks about the events of his daily classes while driving to and from school, which he assumed to be a common practice. 
Journeys toward Reflective Practice: How Engaging in National Board Certification Influences Teacher Identities and Practices

Perhaps when I am driving home? Yeah, now, honestly, I have worked very hard to leave school at school... but I can't... I don't know of a teacher that has been successful at that... but, I think about things all the time... you see stuff... things just click, you know, when I am not even thinking about it...things just click.

However, he believed that his current thinking is less about the "how to" design and more about the "how did," meaning he is focused on the nature of correct student response patterns or lack thereof. Ethan said:

I don't think I have to devote as much effort to the how to planning part so I can devote more to thinking about what to do and I am pretty comfortable with what I'm doing... when I'm doing it...so I can focus more...on how did these students work on this and I am edging off a misconception right when it happens.

Ethan continued to mull over what each student said individually and relied on notes he continued to keep daily as he created classroom experiences that kept his students engaged. He based student academic growth on the experiential learning he observed and then on their retention of ideas over time that he measured via summative assessment. Ethan seemingly grew to identify himself as a teacher of students when he said:

The level of questioning that I used taught me about my students during and afterwards [NB work] because before, if they had the right score [on a test], I thought they were getting it...I think getting to talk with my students and finding out that... oh, well, you are right...you had the concept exactly right...what is the meaning of this or why did you put this and then they would explain why they put something in...then I knew... you were right, you were correct.

His instructional design as an NBCT enabled student acquisition of tools including critical thinking, analysis, communication, collaboration, and research skills for understanding scientific content. Ethan also expressed that his teaching practices were based on his knowledge of his students as they learned to grasp and use process based thinking skills and reasoning as a reflective practitioner. However, during interviews, Ethan did not acknowledge his concerns 
Journeys toward Reflective Practice: How Engaging in National Board Certification Influences Teacher Identities and Practices

about student equity, access and fairness in school contexts based on his understandings of race, socio-economic status, and religious beliefs on student learning. This was a silence of note, in part, because he teaches in a context with students of multiple races, social class backgrounds, and ethnicities. He discussed at length designing his teaching in the students' zones of proximal development, (Vygotsky, 1983) and it may be that in the absence of specific prompts concerning demographics, his focus remained on his students' cognition rather than their disparate backgrounds and funds of knowledge. Over the course of his career, Ethan began to recognize, define, and provide support for student learning during their classroom interactions as he "reflected in action" and developed better questioning strategies. This learning then became integral to his long-term instructional design as Ethan used his knowledge of students to "reflect on action" and rebuilt future labs to reflect what he now knew about student learning. Ethan's teaching practices may have been influenced by multiple contexts; including his engagement in the NB process, school level PLCs, and the wider educational community. 
Journeys toward Reflective Practice: How Engaging in National Board Certification Influences Teacher Identities and Practices

\section{Chapter 6}

\section{Gretchen}

Reconstructive interviews with high school teacher, Gretchen, focused on her initial years in the classroom in an award winning Performing Arts Department as a hybrid English and Speech and Theater teacher. She also reconstructed her work from a more recent time period as a teacher of English and special topics. Gretchen launched the interview series by stating that in her onset as a teacher, she was a "man without a country" and in fact, her classroom was a school auditorium with seats bolted to the floor in rigid rows. In this atypical classroom setting, she faced challenges with proximity to her students (stage to audience) and in creating interactive experiences for her literature based classes. Her early memories of mentors and administration were precise and dismissive and Gretchen described how she relied on interactions with students to determine her course of action in her teaching practices.

Gretchen was thoughtful in her responses, stating, "I am a pauser," and there were often breaks of 15- 25 seconds in her verbal responses. She used few verbal holds such as "um" but did use repetitions and vocal stress to provide emphasis. While she seldom overtly referred to teaching colleagues, administrators, and mentors during the interview series, there appeared to be evidence that interactions with students validated her work. She self identified as an outlier, in part she said, due to the fact she earned her teaching certification at the age of forty-seven after a successful career as a banker and time spent as a full-time mother. She earned National Board Certification after teaching for five years and openly talked about her teaching practices before, during, and after the NB experience. 
Journeys toward Reflective Practice: How Engaging in National Board Certification Influences Teacher Identities and Practices

\section{Gretchen's Reflective Practices prior to National Board Work}

Gretchen approached the interview series with gentle truthfulness and repeatedly stated she enjoyed talking about her work. She liked tracing her career in education to this point in time, and was especially proud of her achievements. Now she is regarded by peers, locally and beyond, as a teacher-leader due to her recent work which, if included in this document would make her identity known. She confided, "I am a vastly different teacher than I was eleven years ago when I first started. I feel like I came out of college not knowing how to teach.” In the beginning, she used a "textbook approach" and she repeated this termed frequently because she didn't 'know her strengths as a teacher and I didn't know my weaknesses ((laughs)). No, I did know my weaknesses.” As she shared her journey, Gretchen often paused and, at times, revised her narratives, as she slowly reconstructed her experiences.

Gretchen accepted a dual teaching position as a hybrid Speech and Theater/ English Language Arts position in what she termed as a "white bread" consolidated high school in August 2004. In setting the orientation of early teaching circumstances, Gretchen characterized her Performing Arts students as very hard working, committed, competitive, and emotionally stressed. She said, "I had to learn in a hurry how to coach [the speech team]. You wanted to maintain the excellence." Because the teachers and students in this school had developed a reputation for bringing home trophies in recognition of their prowess, Gretchen was concerned that the focus of this department in particular was on "winning versus learning." The stress on the students, which was probably an outcome of the years of winning awards as well as the perhaps unrealistic expectations of the local school community that this trend continue influenced Gretchen' teaching and her interactions with her students. Gretchen's children performed in this department before she became a teacher, and she knew, from her children's 
Journeys toward Reflective Practice: How Engaging in National Board Certification Influences Teacher Identities and Practices

experiences, that the stress of competition was sometimes a positive motivator, but could also become a negative influence as students exhibited varying degrees of exhilaration or tension depending on the particular circumstances. Gretchen explained: "I think that having the perception of being a parent of a student on this high pressured team made me more cognizant of the stress those children feel... Um, and it didn't cause me to go any easier on them because we still had that streak to keep alive and the excellence." She taught the Introduction to Speech and Theater classes and, in a complicating action, described her role as that of a filter, someone who identified student strengths and encouraged selected students to "try out for" the next level. She went on to aver that her role, as a mature coach, was more nurturing, although she still identified candidates for the competition team. She also quietly culled, from the department, those students perceived as non-competition material. In describing her resolution, it was apparent she acquiesced to the ways she had been positioned by her department and school, as she described herself as a "Harry Potter-type sorting hat," an evaluator of students' skill sets. Gretchen qualified this with, "We worked... I worked in such close proximity with those students that the relationship piece of it was very, very important. To get children to perform at that high level consistently requires a shared investment in each other." While the relationships she developed with her students during her early years of teaching may have been to ensure the school's standing in subsequent competitions, it is also possible that Gretchen's early teaching context exerted a long-term effect on her perceptions of the teacher role and the subsequent teacher identity she constructed (Gee, 2014). This early focus on student strengths and deficits and in building strong relationships with students reappeared as a coda across the entire interview series. 
Journeys toward Reflective Practice: How Engaging in National Board Certification Influences Teacher Identities and Practices

Gretchen also reconstructed her early days as an English 10 teacher and said, "When we had department meetings I would go with English because I thought that was more important than an elective department." Gretchen spoke of getting "bogged down" with grading student writing in her English 10 classes and presenting lessons to help the students improve. She thought her students would learn if she could "show them how to fix their writing errors." Gretchen said, "hopefully they recognized" that I was presenting lessons to them that helped them make those corrections. "Presenting" seems to indicate that her early teacher identity positioned the teacher as "an expert," "a fixer of student deficits." This early reliance on lecturing, Gretchen felt, was related to her lack of experience, her unconventional classroom context, which was an auditorium, as well as input from her teaching peers. However, it might also have been influenced by the ways in which her institution positioned her as a teacher of theater, who was expected to identify student strengths and deficits and then ensure that the strong students won competitions.

\section{Influence of sacred stories on reflection and the development of reflective practices.}

She shared that her English 10 teaching strategies, which were probably the "sacred story" of this context, included taking a week or less to read a story with her students, followed by asking her students to answer the questions at the end of the story and then taking a quiz. As a hybrid teacher, she believed she devoted significantly more time to her Performing Arts Department work due to its visibility in the school context and spent what she termed "an inadequate amount of time" wrestling with her problems of practice in the traditional English classroom. 
Journeys toward Reflective Practice: How Engaging in National Board Certification Influences Teacher Identities and Practices

Gretchen felt her service in a dual teaching position left her little time to reflect and barely enough time to plan her lessons. These self-talk statements revealed some of her consternation regarding her early years of teaching:

Well, coming to the profession so late and not really being a fulltime English teacher...You're doing a fine job, so don't keep second guessing yourself...oh, so and so is a better teacher than I am... hey, I'm a good teacher too, I'm just different.

Reflectively, she now recognized she felt intimidated by the methods used by colleagues, as they were likely to teach six or more short stories per term. This rapid transitioning from one literature format to another was complicated by the need "to produce grades for student work," and grading student essays proved to be "a very time consuming endeavor." Her colleagues also placed a high level of emphasis on vocabulary, which was regularly taught in isolation and, for Gretchen, served as a complicating action. She termed this as "getting a lot of the same stuff." She evaluated this situation naming the use of short stories and answering the questions at the end of the chapter as a standardization of the curriculum. Even as Gretchen realized the dangers of the traditional practices she encountered, she found herself, in these first few years, asking literal questions of her students and assigning lower level work that did not require students to justify their thinking or provide text based evidence to support their views. Her resolution was to adopt these practices, rather than to create a secret story and in telling her story recognized that she did not truly know how to teach a novel and was unable to make changes to her practice during this time because she was not reflective, nor did she deeply analyze students' responses to learning tasks and assignments.

This early context influenced the teacher identity Gretchen constructed that was situated in a school where the school's focus was on "[bringing] home trophies" (Speech/Theater) and students' focus in English 10 Honors was on "wanting good grades" (Gee, 2011). It appeared 
Journeys toward Reflective Practice: How Engaging in National Board Certification Influences Teacher Identities and Practices

these outcomes were more important to Gretchen's thinking at that time, than was the "process of learning and becoming" a teacher of her own making. The "sacred stories" of this school exerted strong pressures on Gretchen to believe it was her role to ensure these desired outcomes (trophies and good grades). Gretchen acquiesced to this positioning, rather than resisting it and constructing an identity as a facilitator of student learning, which might have been informed by her strong feelings about the necessity of relationships with her students. Over the course of the first interview, Gretchen recognized that she slowly gained self-confidence as a teacher (coda) when she said:

Truthfully I think once I got out of the theater and into the classroom I started to feel like a teacher because I could...do group work. So, I think back in those days I was more like just (long pause) teaching English. But, then along the way... and it happened before I left that department because I could feel myself growing and needing more as an English teacher.

She also expressed a robust current identity as an innovator and instructional leader. As Gretchen fast-forwarded to her present day teaching, she was adamant in her belief that students benefit more from immersion in classic literature because novels "apply to their lives...great pieces of literature have remained germane to society because they reflect human nature...they need to know that these behaviors still exist in the world." This strong emphasis on ensuring her teaching and choice of learning tasks and resources are relevant and meaningful for her students was pervasive and she regards it as a personal strength.

\section{The influence of isolation and collegiality on reflection and the development of}

\section{reflective practices.}

In her early years, Gretchen oriented herself as isolated in her classroom and she did not acknowledge any positive influences related to the wider context in which she was situated, including her teaching team, school staff in various disciplines, or administration. Indeed, 
Journeys toward Reflective Practice: How Engaging in National Board Certification Influences Teacher Identities and Practices

Gretchen related that she perceived a complete lack of administrative support (a complicating action) for transforming the educational status quo, the sacred stories of the teachers and administrators in her first teaching placement.

I think also the fact that, I think a lot of teaching at that time was... this is the way we've always done it... and so, there wasn't a need to question... well, this is the way we've always been doing it and now I think even though I was older... I was 47 when I started teaching... there's a maturity that comes as you grow as a teacher and you start to realize that it's almost like a childhood progression that when you are young... your parents say to do it this and that's the way you do it and then you start to question when you get older... well, why do we always do it this way... why can't we do it this way. So, I think you can probably apply that same kind of time line to a teacher. Teachers come out of school doing what you think is what's been done according to your administration and then you start to find your own voice by looking at what you have been doing.

Her resolute stance positioned her as an outlier and it may be averred that her context influenced the decisions she made about her teaching, her interactions with students, as well as the ways in which she pursued professional development (Seidman, 2006). It seems likely she actually sought advanced certification as external validation of her teaching practice due to her perceived isolation. Moreover, Gretchen acknowledged that the ways in which she initially positioned her students, in terms of their deficits, did not persuade her to take responsibility for the personal, academic, social, or political consequences of her teaching (Dewey, 1933) as she located her problems of practice in her students or external factors.

Gretchen confronted conflicting memories as she reconstructed narratives of early years as a teacher. She said, "I did not think enough about my teaching in my early years." She indicated that (in her English classes) "the clientele was not [well prepared]...I didn't (long pause) ...I don't think I gave them much of a chance.” Time, and the lack thereof, was expressed as a complicating action in her thinking about teaching on several occasions and was never actually resolved as she reflected on her experiences. Gretchen acknowledged she devoted a great amount of time and energy to her Performing Arts classes and her role in the Speech and 
Journeys toward Reflective Practice: How Engaging in National Board Certification Influences Teacher Identities and Practices

Theater Department. Her evaluative statements indicated there may have been a lack of contextual support. She said:

Let's go back to the very beginning. I was kind of doing things... well here is what everybody else is doing. Then, when I started to grow as a teacher and attend some workshops or some professional developments outside of the school I started to get some ideas...oh, I can do this or I can try this... once you open your creativity and you realize you don't have to do it the way that everybody else is doing it.

As a novice teacher, Gretchen worked long hours to support the students in the Performing Arts Department. While honing that highly visible level of craft and expertise, Gretchen reflected that her daily work with her general education students was not a priority during the time she served in this hybrid-teaching role.

Gretchen often compared herself with her fellow teachers, and these evaluative thoughts provided an opportunity for her to reflect on the breadth and depth of her practice. She indicated that "I think, probably, compared to some others, I probably was a darn good teacher but just because I know myself... I could have done more.” The dichotomy in her characterization of her Performing Arts student groups as driven and her planning as energetic and focused, versus the students in her general English 10 classes, who she described as unmotivated and where she felt she was less prepared, was evident as a complicating action. The main co-teacher served only the Performing Arts students, so Gretchen felt she had no other teacher she respected or trusted with whom to discuss the needs of her English 10 students. At that time, Gretchen did not realize this lack of collegial conversations made teaching more difficult; however she did experience frustration as a result of her inability to learn from and with her peers. She said, "The team meetings early on... we didn't have them as often as we do now. When we did it was primarily just to plan... okay what are we going to teach this year... when are we going to teach it." As a high school teacher, she met regularly with the English Department and evaluated these sessions 
Journeys toward Reflective Practice: How Engaging in National Board Certification Influences Teacher Identities and Practices

as pragmatic, congenial conversations, which she dismissed as not supporting reflection.

Gretchen stated, "They [department team meetings] were pretty generic really.” Describing her first department chair as "cut and dried" and "the team was not collaborative," as "we all had to have the same ideas back then" and no one chose to problematize or question those ideas (sacred stories). However Gretchen was firm in her resolution: "I'm not going to let them tell me what to say." When queried about who "they" were, Gretchen provided no response. It was unclear whether or not Gretchen created a "secret story," but if she did, her story did not align with her team's view of effective practice, nor did it support her growth as a reflective practitioner. She may have felt powerless to voice her questions; instead, the sacred story became her story (Olson \& Craig, 2005) as she dutifully followed the pacing guide of her peers and taught the prescribed six short stories when what she really longed to do was teach novels that were meaningful for her students and to explore ways to engage her students in learning through analyzing texts.

When pressed to describe her early mentoring experiences, Gretchen said she never actually met with her assigned mentor. "I know that the school assigned a mentor my first year like for opening day... um, and that person never showed up so I never felt that I had somebody I could go to officially." Later in the interview, she referred to two informal teacher guides (one from each department) with whom she was able to pose her questions about teaching and learning. The aforementioned Speech and Theater instructor, an informal role model, was instrumental in her developing perceptions of teacher behaviors. As she evaluated this experience, she believed the reason she considered him a mentor was due to the public nature of his Speech and Theater position and the fact that she was able to repeatedly observe this instruction in action as his performances of teaching and interactions with his students were often visible. Gretchen also described how she eventually sought a senior member of the English 
Journeys toward Reflective Practice: How Engaging in National Board Certification Influences Teacher Identities and Practices

Department to discuss classroom management issues (complicating action), but she recalled no specific conversations related to teaching strategies, nor any reflective conversations focused on student needs and academic growth. As a further complicating action, Gretchen spoke, in a roundabout way, of her speech and theater role partner and model many times throughout the interview series. Though she did not recognize him as mentor at that time, she attributed learning about some elements of practice in her conversations with him.

I think that I did rely on Mr. C a lot because he had been an English teacher. Mr. C., being the head coach of the speech team, he was totally fine with performing arts, but I would go to him... like about teaching "The Catcher In the Rye"... um, he could help me become better at my teaching... well, look at this... what about this... and so, I did have him as a mentor I would say without realizing I was using him as such.

In fact, as she shared these narratives of her mentoring experiences, Gretchen realized she depended on Mr. C more frequently than on her teacher education coursework or any learning that took place during what she termed, "the strong guidance and supervision" of her student teaching experience. Because Gretchen spent much time observing Mr. C teach, she also recognized how the teacher identity she began to construct during her early career included aspects of his teaching persona, such as his holding high expectations of his students, his strong interpersonal skills, and precise language during interactions with students. She said:

My foundation in this position...working with him...I think that that really helped me to see the importance of developing that strong foundation quickly with students because if you want them to work hard for you, they have to care about you and want to do well.

\section{The development of independent reflective practices.}

Near closure to this interview, Gretchen shared some of her insights related to student/teacher relationships. First, Gretchen stated, "I mistakenly thought I was just teaching Speech and English, then along the way... [I grew into] a teacher of human beings who need to 
Journeys toward Reflective Practice: How Engaging in National Board Certification Influences Teacher Identities and Practices

learn how to use their brains and stretch and take on new things without fear." She recalled a time when she gave a speech about teaching and said:

People will forget what you said and forget what you did, but they will never forget how you made them feel... I thought I was being, like, groundbreaking ((laughter)). In time, with teaching, and the more research I do, I realize, no, that's ... well everybody realizes this... If you are a teacher of merit, you have to have a bond and you'd better work to establish a relationship with your students within that classroom...because you have to have an atmosphere of trust.

It was evident she valued relationships as an important aspect of her teaching. This vein continued when Gretchen revealed this story:

[Early in my teaching] I pondered over a young man who sometimes fell asleep in class. I noticed that when he had a headphone in, listening to music, not two, just one, that he would pay attention to what was going on in class and he said to me (pause)...if you let me wear a headphone, I promise you, I will pay attention to everything that is going on in class. So, I said okay, deal. And sure enough, he did and he got [read and understood] that book and he participated in the class discussions.

Gretchen believed this story indicated the origin of her eventual recognition that she wanted to move away from textbook (English) or formulaic driven (speech/theater) work to design student centered learning. She was very animated when she declared, "That was one of my first AHA! moments." After a long pause she said, "I will never forget that day."

The fact that she fondly recalled this episode may be illustrative of the beginning of a transformation in her philosophical stance. Gretchen recognized a student who often appeared disinterested and was fully disengaged (a complicating action) and she decided to resolve this problem by seeking the student's input in framing the problem. He offered a simple solution that Gretchen was willing to try. Ultimately the strategy they agreed upon led to his attention during class and his contributions to discussions with peers. Gretchen noted engaging this student in problem-solving led to a decision that not only addressed the issues raised by Gretchen and this student, but also created a classroom climate that positively influenced student learning and was 
Journeys toward Reflective Practice: How Engaging in National Board Certification Influences Teacher Identities and Practices

a strong impetus for her future decision-making. While Gretchen did not mention race or socioeconomic class when she related this vignette, she later acknowledged the student came from a less supportive non-white home environment and she felt this background knowledge caused her to reframe her thinking about what student behaviors she could accede to in order to keep students engaged while in her class. Gretchen averred, "These are not cookie cutter students; they each have something very special about them that I get to need to know so I can reach them best." In evaluating her growing knowledge of students, she expressed that her desire to cultivate mutually respectful relationships with students was all encompassing. First Gretchen built caring relationships through individual conversational interactions with her students and then she learned to listen closely as students of multiple races, social class backgrounds, and ethnicities came into this mix in her classes, although she mentioned more than once the lack of student diversity in her school. She felt the lack of diversity was a detriment to student growth, and was perplexed by how few students of color enrolled in her classwork after she later began teaching Advanced Placement courses. Gretchen established relationships with all of her students, therefore using interpersonal skills; she was able to engage them in content-based work to prepare them for a future in which each of them will be tasked with making his/her own way in the world.

The teacher identity she was constructing acknowledged this much deeper agenda for her work. When reconstructing her early days in teaching, she realized she was not reflective. She matured and began to situate herself differently as a teacher. She remembered:

Um, the early years of teaching...I was so busy with the fine and performing arts component that I didn't take the time necessary to reflect... I think a lot of teaching at that time was...this is the way we've always done it... and so, there wasn't a need to question ...there's a maturity that comes as you grow as a teacher...then you start to find your own voice. So, for me, the biggest part of teaching is relationships. If students trust me, then they can experiment and try out new ideas and speak their mind. 
Journeys toward Reflective Practice: How Engaging in National Board Certification Influences Teacher Identities and Practices

Her consciousness of this richer purpose for teaching was earned through wrestling with her problems of practice and engaging her students in this problem-solving and learning to cite the reasoning behind their thinking, and to communicate their thinking to others. Gretchen ultimately resolved her dilemma with a newfound desire to create a climate in her classroom, which purportedly enabled each student to strive for a stronger sense of self that might provide fortification in facing the unknowns of the future. Gretchen subsequently worked to fulfill her intentions for a classroom climate based on trust and interdependence.

Gretchen closed the first interview with this insight, "I just think that [trust and caring] is the foundation for learning... They [students] can experiment and try out new ideas and speak their mind [because] this person [my teacher] cares about me. I care about this person [my teacher]... Therefore we are invested in each other." This realization likely indicated Gretchen had begun to rely less on her interest in the subject matter as a focus of her teaching and more on her responsiveness to her students' needs including their social and emotional needs, as well as their academic needs.

\section{Gretchen's Reflective Practices during National Board Work}

Gretchen opened interview two by averring, "I am not the same teacher now that I was when I went through National Boards.” She was no longer teaching speech and theater; instead she was in a standard classroom with moveable furniture and increased time for planning. Thus, she began to concentrate her efforts on developing her English teacher repertoire. Evolving as teacher/learner was oft reiterated in the narratives she shared about her teaching as she engaged in national board certification. She reflected that in her first four years teaching, she didn't "even know how" she taught and in retrospect didn't think her "work quality was very good" saying, "I 
Journeys toward Reflective Practice: How Engaging in National Board Certification Influences Teacher Identities and Practices

must have been okay, but I just think that how I have evolved over the years, my teaching is 180 degrees different than it was." Eleven years ago, she lectured, requiring her students to recall facts with a "little bit of interpretation" and that was just "talking in class... now that method of teaching is gone and I think learning is much deeper." Gretchen moved from literal questioning techniques, in which the discussion was more teacher-centered (sharing what she believed to be the appropriate interpretations of literature). She asked her students to recall stories as sequences and to reiterate the symbolism she shared during lectures. Gretchen cited one of her former assessment questions as, "it all depends on what I am asking... cause like say I was teaching the "Mask of the Red Death"... maybe 11 years ago a test question would have been... the seven rooms ran from what to what?" She realized her early teaching stimulated students to memorize and recall what she said and did not encourage her students to develop their thinking and reasoning abilities.

Gretchen enthusiastically described her emotional and intellectual response to the actual production of her NB portfolio as a process that "really made me think more about my teaching and what I was going to do... with my students that would facilitate deeper thinking on their part." She recognized the portfolio work was transformative to her instructional design and to her students' learning as she enabled her students to:

Substantiate their thinking, share opinions and insights and help in teaching the students around them... that was really fun to see and be a part of ... this is when I began getting more excited about letting the students do both teaching and learning.

Gretchen realized she was effective in supporting student learning when the students took a more dynamic role, discussed ideas actively, and were charged with creating evidence to support their claims. Designing this active discussion took intense preparation on her part. In describing her personal growth as a teacher, Gretchen shared a complicating action that emerged immediately 
Journeys toward Reflective Practice: How Engaging in National Board Certification Influences Teacher Identities and Practices

for her. The NB process required the use of multiple teaching strategies, including small group work, which for Gretchen, was an untried technique at this stage in her career. She was tasked with learning new ways to teach and creating different class norms that embraced student-tostudent discourse than teacher as a lecturer. Developing her ability to facilitate student-centered discourse was a slow and laborious process for Gretchen, yet she persevered as student-tostudent dialogues were required to earn NB Certification.

\section{The influence of context and independent reflection on the development of}

\section{pedagogy, content expertise, and identity.}

Gretchen evaluated her learning during this process of creating opportunities for dialogue that positioned herself and her students in ways that shared power as, "I don't have to be the one with all of the answers." Gretchen engaged in reflection on action as she watched the videos of her students at work and evaluated her efforts and their influence on student learning. She characterized her first discussions as a "massive failure," stating it "was not a discussion at all." Gretchen eventually resolved her dilemma with revised and reinvigorated instructional design. She began to employ focused questioning strategies that encouraged her students to take ownership of their learning and the understandings they constructed of the content. The reflection required by the NB process provided her with moments to evaluate the efficacy of these for her students: "There was a lot of questioning their own thinking (pause)...where did we go wrong...how can we get to the answer... and recognizing that [their misconceptions] ...the next time...those adolescent minds were stating to mature.” She became more effective in recognizing the problems of her practice, "where did we go wrong?" and was able to reframe her thinking using iterative and adaptive processes which enable her to design opportunities for learning that were responsive to her students' needs (Schön, 1983). She exemplified how she was 
Journeys toward Reflective Practice: How Engaging in National Board Certification Influences Teacher Identities and Practices

working to solve her felt difficulties by transforming her thinking about student learning and planning for responsive teaching. Gretchen said:

I was beginning to incorporate those standards into our lessons. Like, for example, like on my small group entry... no it was my whole group discussion and we were talking about the Catcher in the Rye and trying to relate it to modern day life and I think... um, where before, you know, I don't think that I ever focused so much on making books relate to my students' lives and I think it is really a great way to make literature relevant because I tried to bring in that outside stuff. So, that was emerging then.

In her early teaching, Gretchen had recognized that her teaching was not necessarily meaningful for her students, but she was unable to resist the sacred stories of her context and the traditional teaching they valued. During the NB process, Gretchen was able to question her teaching and envision possibilities for her future practice that met the specific needs of her students.

Moreover, Gretchen discussed the benefits of repeatedly watching her videos and then transcribing excerpts when she said,

I had to transcribe what I heard and that was a great thing to do because you really, really listen and you watch it so many times that you ... I think you get a much clearer understanding of your students and of yourself because you are watching yourself and how you respond and what kind of questions do I ask and am I asking the right kind of questions so they will go where they need to in thinking?

This led to deep reflection on her part as she analyzed her practices and their effects on her students' learning, which she averred, she had never considered prior to engaging in the NB process. Gretchen revealed:

It used to be that I would read a story, we would answer questions and take a quiz. Now, it is read the story and now let's go back and reread the story and annotate and now let's go back and really look at the things that we brought out... maybe look at one thing in particular... the use of imaginary... what is the purpose of those colors... and it's just... it used to be maybe it took me three to four days to do a story and now it may take three weeks. So, that is how my teaching has evolved through I think national board certification and the standards.

Gretchen realized that analyzed the connections between her teaching and student learning prior to her engaging in creating a NB portfolio she came to understand that learning to teach involved 
Journeys toward Reflective Practice: How Engaging in National Board Certification Influences Teacher Identities and Practices

ensuring that all students learn. Gretchen said, "I learned a lot about myself ...that I talked too much ... I didn't wait long enough for students to answer" as the complicating actions her students experienced as a result of her teaching. She expressed that repeatedly watching the many NB process videos of her own teaching resulted in her being able to critically reflect on and evaluate her own teaching:

When you step back from yourself and watch as an observer, you see things that you normally would not see...including focusing my attention too much on some students and not being equitable with my attention...it was hard to watch yourself, but [she evaluated the scrutiny with] the benefit is good because you learn about yourself as a teacher.

In her coda, she discussed how this self-scrutiny led to growth as a learner and teacher who was able to make better instructional decisions as a result of reflecting on her practice. The NB process was designed to stimulate teacher thinking and teachers' development as reflective practitioners and, in the passage, Gretchen eloquently described her changing ideas about her work and the ways in which she reflected on her design, practices, and the student learning outcomes she observed.

Gretchen recognized how this self-awareness eventually segued into her belief she was "getting better and better every year and that was wonderful because my students were the ones who benefitted." She began assigning small group work:

Based on the students reading passages and then applying what they knew to questions they were asked and the questions were very difficult ones, so what I did, was have them work in small groups to come up with the answers that they had to discuss... and then I um, would have them let me know when they had come up with and be able to substantiate why you have selected that answer.

She evolved as a teacher who became increasingly innovative in the design of her instruction and classroom culture. Gretchen shared how her reflection on action and the reframing of her dilemmas informed her decisions. She began to see the results of her improved design when: 
Journeys toward Reflective Practice: How Engaging in National Board Certification Influences Teacher Identities and Practices

They were working together to come up [with ideas]... somebody might have a better grasp of the author's purpose... so they were able to share their opinions and insights and help to teach the people around them and the that was good. That was really fun to see. That is when I started getting more excited about letting the kids do the teaching and learning.

She cited evidence of increased student access to learning and providing more equitable lessons and learning tasks for those who learn differently. Gretchen said, "So when I see those kind of results, I know I am doing good things." She also cited her own heightened knowledge and skills in terms of learning the NB Standards that evoked making thinking visible through student-tostudent discourse as primary mode of learning and she internalized this thinking as a part of building her NB portfolio.

\section{Choosing collegiality over isolation.}

This internalization of the NB standards led to an interesting move, on Gretchen's part, when West Virginia adopted the Common Core Standards, also known as the NextGen (NG) Standards four years ago. Gretchen approached her teaching team and suggested the team examine the NG Standards together and collaborate to become early adopters of these innovative strategies. She said:

So we took it upon ourselves to try to incorporate those standards into our lessons [immediately] to be ahead of the curve...we have really enhanced our teaching by making ourselves researchers. We got together and shared ideas and would get excited about the things we would be presenting to our students. They [our students] saw we are putting as much [work] into learning as they were... I really feel that there was no learning taking place without investment of students to teacher and teacher to students.

Gretchen's evolving identity as a teacher, who was a member of a teaching team, possibly a professional learning community, was greatly altered from her former statements of not letting them (her peers) "tell her what to say." She credited her team with supporting her construction of a teacher identity that represented her beliefs and vision. Gretchen stated, "But now our team 
Journeys toward Reflective Practice: How Engaging in National Board Certification Influences Teacher Identities and Practices

meetings are quite different because we aren't doing cookie cutter anymore...I think that helps

you grow." She mentioned her current teaching team with respect and affirmed that these conversations with peers functioned to stimulate her reflective thinking. Gretchen believed her team was innovative and their heightened ability to work together led to shared ideas and she began to view herself as an innovator when she began relying on media tools to generate discussion topics for her classes which were current and engaging for her students. Working as a team, they became online researchers to make connections between the novels she taught and the social and cultural climate her students now experience. Gretchen again was emphatic about the change in her ability to design instruction saying:

You know, I want them to see that there is an inter-connectedness of things...like in that unit where we are doing the story Robot Dreams we explore an MIT Professor who developed this robot and we have an article from $2000 \ldots$ that was updated in 2005 ...but then because of the wonderful internet I have been able to find more current stuff on her and we followed this woman's progress... here is where she is now... here is what she is doing... and it's fascinating for the students to see the tie in with their literature about robots maybe taking over...becoming more human.

She spoke without pausing to outline multiple methods her team developed through sharing current web based information. They began expecting their students to make associations between the novels and informational texts they read with multiple contemporary sources including, but not limited to, works of art, movies, posters, brochures, articles, blogs, and current research posted online with her students. The students were then tasked with analyzing and verifying the information and rendering both personal and plausible connections to their reading assignments.

This newfound researcher identity (Gee, 2011) was noticeable in Gretchen's selfassessment of her work. She believed the NB process of analyzing videos of her teaching, students' written work, and examining her work with colleagues, families, and her community 
Journeys toward Reflective Practice: How Engaging in National Board Certification Influences Teacher Identities and Practices

challenged her in multiple ways. She sought answers to the questions posed by the National Board portfolio when she engaged with colleagues in self-questioning, read teacher blogs online, viewed videos of other teachers' work, and then tried to determine how these ideas might support and inform her understandings of teaching and learning. Gretchen, in her efforts to certify, became a "member of a larger teaching community" beyond her classroom walls and used what she learned from others, even very distant colleagues, to develop practices that were more effective in reaching her students.

\section{The influence of the NB process on the development of reflective practice.}

Reconstructing her thinking as a coda to the NB process period, Gretchen was explicit when she said, "The self-reflection piece is very important and I think the National Board process ... where you are forced to look at yourself and your teaching much more intensely...is a great step in helping the person grow professionally because then that [deep self-reflection] is never turned off." She continues to self-examine her teaching with thoughts such as, "How do I do that better next time and what am I going to do better next year?" As she processed and reflected on student feedback, she made changes to her teaching that she said resulted in the "betterment" of her students. Specifically she discussed the improvement of her students' writing techniques, the well-constructed sentences in their essays, and their heightened self-expression. Gretchen noted:

When I see that first writing sample from my students, um, generally I can tell... okay, I pretty much need to be focusing on writing complete sentences... writing the four different types of sentences...they do not have sentence variety in their writing. So, it's a combination of historic data as well as taking a little snapshot of where they are right now when they come into my class. Then by the end of the term they use variation and create whole new thoughts in their written work... They have a personal stake in this and maybe... they learned something even on a deeper level. 
Journeys toward Reflective Practice: How Engaging in National Board Certification Influences Teacher Identities and Practices

As a result of note taking during her candidacy, she now keeps a little spreadsheet of common mistakes" so that she can tailor lessons to help strengthen students' skills.

Gretchen spoke convincingly in her evaluation of the NB process as one that:

Commands your attention toward the student as a learner, as a citizen of the community...Y You can't do the national boards [process] without developing a greater awareness of students and their learning...Y You are required to create an environment where they can learn and where there is fairness... equity... access. It is going to be a safe place for people to learn. Learning is not going to take place if it is not there.

She repeated this thinking at multiple points during the interview series and spoke dynamically, using her "teacher voice." Thoughts about equity, access, and fairness emerged when she realized that as a lecturer, she had a tendency to engage the students in her classroom who enjoyed verbal repartee and never noticed the many students who remained silent unless specifically called on. When viewing videos of her teaching, she noted that she favored and responded to students with non-verbal and verbal cues, which in retrospect, she felt may have been inequitable. This disturbed Gretchen and she said, "But just watching and seeing...things like not noticing a child that might have something to say and thinking...darn it I missed that opportunity...or focusing too much on some students and not being equitable with my attention." As a result, she created multiple conversations between students so more students were provided with opportunities to participate in the discussion and to develop the skills for self-expression.

This strong emphasis on the value of the NB process was reiterated when she, very slowly and with much intonation, said:

I think that before the National Board process...you just don't know those things. It's not instinctive...There is a new presence of mind...It's not just that you go through the process; it is that the national board process transforms you into a different type of teacher. Even if you were a great teacher coming into it, you are going to be even better when you come out because (pause and hold) you are never going to think the same way again about your teaching. 
Journeys toward Reflective Practice: How Engaging in National Board Certification Influences Teacher Identities and Practices

This new intellectual presence might be termed mindful (Dweck, 2007). Gretchen's passage about her level of mindfulness indicated her deliberate work to understand her own work by framing and reframing her practices (Schön, 1983; Zeichner \& Liston, 2014) to seek better ways to facilitate student learning. She was aware that she needed to frame learning one student at a time (NB Entry 2), and this stance informed by the work done in her NB portfolio. Creating this portfolio to represent her teaching changed her philosophy about the presentation of material versus engaging students in thinking. Subsequently she used lecture as a primary teaching strategy less often after she became aware she was responsible for knowledge of students (KOS) and, according the NB processes, needed to use KOS in her instructional design so each student was able to access and retain the content.

\section{Gretchen's Reflective Practices after National Board Certification}

According to Gretchen, completion of the National Board process and earning "those four letters after my name" elevated her teaching. "It refined me...it molded me into somebody different." She credited learning about reflection on action (Schön, 1983) as crucial to developing her sense of consciousness and mindfulness. She said, "I have to be in the moment the entire time I am doing it [teaching] so that heightened my awareness of what I was doing and why I was doing it and how I was doing it." Gretchen averred that reflection on her actions, when she was a NB candidate, supported her growth as a teacher and prevented her from becoming complacent after she certified. It seemingly aided her abilities to continually "refine and define" what and how she actually wanted to be teaching. "I think that had I not done it [become board certified]... I would still be teaching differently than I did ten years ago...but I think my forward movement would have been at a much slower pace. I accelerated [my learning 
Journeys toward Reflective Practice: How Engaging in National Board Certification Influences Teacher Identities and Practices

about teaching]... I lit a fire." In her school system, passion is often used to describe effective teaching and learning in the classroom and Gretchen embraced this idea. When working with her team to develop new themes integrating the Arts and literature, they worked hours during the summer and implemented new units the following semester. When Gretchen reconstructed how the students engaged in this learning, she smiled when she said, "I just remember feeling really good about the excitement level of the kids."

Learning about teaching itself metamorphosed Gretchen's thinking about teaching cycles. She no longer repeats lessons verbatim from year to year, semester to semester, or even from period to period. She said, "The way I feel about teaching now is that every single thing I teach is up for reflection...that I have to...that I don't have a choice...it's just a part of me now." It may be significant to note the phrase "every single thing I teach" falls under reflective scrutiny. This might be connected to her earlier statements about being a vastly different teacher and characterizing the evolution of her identity as being framed by active reflection across all aspects of her professional life. At the onset of her career, Gretchen positioned herself as an "unknowing novice" and while she may have been attempting to examine and reflect on her practices, she felt her attempts were ineffective. After taking the time to experiment with her teaching strategies and then repeatedly watching and analyzing videotaped segments of her teaching, she began to critically view her students at work without the normal temporal constraints of performing teaching duties simultaneously. Gretchen said, "from watching the videos I learned a lot about myself...that I talked too much...that I didn't do enough wait time for students to answer. My students were letting me do all the work, but it was me, not them." She realized that her design of learning tasks had to change and after the NB process, she continued to create classroom 
Journeys toward Reflective Practice: How Engaging in National Board Certification Influences Teacher Identities and Practices

routines and assignments that heightened student thinking and engaged them in discourse. Then she went said:

I would watch them [videos] and when you step back from yourself and watch as an observer you notice things about yourself that you would not normally see...you can't see yourself without a mirror and it was like teaching in front of a mirror. I remembered how it was hard to watch myself...but the benefit was life changing because I learned about myself as a teacher. So I had to continue to change to get better... and I still do change to get better.

Gretchen posited she learned when she was able to repeatedly watch her students working in small groups on video, and this analysis supported her in becoming a better observer of her students during class time and learning from listening to them express their ideas. She thought this was, in part, because she no longer had to constantly think about what she needed to say. Sometimes she was able to just listen and when she listened she could reflect in action (Schön, 1983) and perhaps determine how these student exchanges demonstrated their understandings and/or needed to be challenged or supported.

According to Gretchen, "National Board Certification is not an ending, it is a beginning." It was not the recognition of being certified that most influenced Gretchen's affinity for reflective practice. In her earlier interviews, she admitted to entering the process for the status and compensation afforded to NBCTs in West Virginia. Ultimately, it was her sense that being a NBCT promoted her discernment of how her students learned and how she might support their learning, as well as her own professional development over the course of her professional lifetime. Gretchen was adamant in her assertions saying, "The National Board certification process created a new teacher."

This new teacher identity was elaborated upon in her vision for student achievement, not as measured by mandate, but as a tool for self-fulfillment. Gretchen asserted: 
Journeys toward Reflective Practice: How Engaging in National Board Certification Influences Teacher Identities and Practices

In everything I have them do, I always tell them it is strength training for their brain. That I want to just keep building on what is already there... strengthening, strengthening, strengthening. So when I look for new things, this is what is going through my mind. It has to be relevant for their lives in order for them to invest in it.

Speaking of her classes this year, she reminded herself that being a "National Board certified teacher gives her an edge." She believes she has better tools to reach learners of all abilities and from all walks of life because she considers each student's needs in developing the questioning techniques she employs during her work with small groups that provide all students with the opportunities they need to learn. Her thinking about questioning was challenged when she began to teach both AP and regular (non-Honors) English this year. Placement in these courses was determined by student summative testing, and the tracking system confirmed lowered expectations by administration for the achievement of these students. Gretchen determined:

I really, really liked working with kids that need more... more than just a good grade to get into college... you can have those little moments when you see that they are learning and you know you may be able to help them in the long run.

Gretchen evaluated her former teaching methods as traditional because she was "trying to teach all students the same way" and believed that "learning should not be hard." Her resolution has led to teaching practices that value patience in her interactions and she strives to make the learning interesting. "If I can facilitate learning without them realizing they are learning, then it is pretty cool because they hate to work ((laughter)). They will tell you, I hate school." Gretchen's evaluation of her teaching is based on the responses of her students to the methods and learning tasks she designs: "Some of them will make the comment...it is easy to learn in your class and they don't realize that even though I am not giving them a test every week that I am gauging their learning in other ways.” In analyzing her observations of student learning during small groups, she noted that when students engaged in the work of finding text evidence to support their comments and interacted with their peers, they did well in her class. 
Journeys toward Reflective Practice: How Engaging in National Board Certification Influences Teacher Identities and Practices

\section{Developing from reflexive to reflective.}

Her less motivated students required reflection in action frequently and this was exemplified when Gretchen evaluated their attention during instruction. Gretchen explored the complicating actions for this lack of attention as factors that included boredom, tiredness, disinterest, and illness. She resolved this dilemma using adaptive questioning techniques to get at the root of her students' disengagement and recognized a growth in her ability to identify and adapt to student verbal and non-verbal signals. She attributed this increased awareness to the NB process, especially with regard to assessing her teaching practices and student task behaviors during the video entries. She referenced this reflection on action when she said:

I taught a real bright kid [but he was] in a bad home situation, but I was able to give him that little space and time so he could contribute to the class and that made me feel good that I hadn't overlooked that, but I think that two years earlier I might not have noticed that...I just would of maybe thought that he was antsy or something, but when you watch your students and you watch yourself, you learn a lot more about what is going on in your classroom.

Gretchen attributed this enhanced teacher skill set to her accomplished practice in watching and interpreting student learning and body language, which was essential for the self-reporting required for her NB portfolio analysis and reflection sections.

Gretchen also connected her work as a reflective practitioner with a responsibility to teach her students to employ self-reflection. Thus, she assigned student work with multiple and varied ways to display citations of textual evidence and required her students to self-evaluate their work. She evaluated her instructional design and teaching as successful:

So they had to think about it and decide which piece of work is my homerun? It is really valuable for them to be successful and assess their own work. I taught them something and they used meta-cognition. You've got to think about your own thinking.

Her use of "I" in "I taught them something" demonstrated a high level of ownership of her teacher identity as a student-centered teacher who successfully provided opportunities for her 
Journeys toward Reflective Practice: How Engaging in National Board Certification Influences Teacher Identities and Practices

students to develop self-direction in learning. The sentence "You've got to think about your own thinking" refers to both her students and herself with a slightly removed stance. She attributes the National Board process, where you are forced to look at yourself and your teaching much more intensely as a formative factor, although she distanced herself somewhat due to her second person word choice. This might indicate that her meta-cognitive skills played a role in her embryonic, and then cultivated, reflection on her classroom practices. Gretchen stated she changed and continued to grow as a teacher because, "I have this knowledge... I have to go back and rethink everything...you know, it's just much richer because I know more." Reflection on her practices made her persist in reconsidering and redesigning instructional strategies as she developed a student-centered teacher identity. Much of this took place while she participated in the NB process, but according to Gretchen continues daily.

Gretchen's strategies for reflection may be viewed in the abstract as proactive and anticipatory as noted when she related, "How are my students going to be impacted by this?" which was her most frequent evaluative thought when designing instruction. She actively seeks continued professional learning as she "constantly searches for new information" to be brought in, integrated into her instructional design, in order to keep the student learning tasks current. Use of technology has been a complicating factor since she became a teacher. Gretchen stated it has changed the way her students act and react:

It is really hard to get them to settle down and think about those things, so, like this year, I have changed my method of teaching like four times with these kids because things aren't working and I have to find something that is going to work. It is very frightening when you think that these kids are so social media dependent that they don't really want to read anything longer than a tweet, so, trying selling a novel, that's difficult. So, I am seeing a progression of that and so, therefore, I am constantly having to rethink... how am I going to teach these things that they need a totally new way because their world is completely different than the world five years ago? 
Journeys toward Reflective Practice: How Engaging in National Board Certification Influences Teacher Identities and Practices

Accordingly she noted she has made choices to counterbalance what were perceived as students' tendencies toward the use of technology for entertainment, rather than engagement in critical thought processes. Gretchen said:

I use a variety of strategies to reflect on the ways I use technology. It can be simple things like looking at my students for engagement or no engagement. It can be reading their written responses to various media sources and seeing if they have grasped a concept that I have tried to teach... to see who needs a little more work on it.

These reflection strategies, as modest as watching student body language in the moment, and as multi-faceted as conducting a close read on student written pieces for deeper analysis and critical reflection enabled her to build long term goals for learning using her continually deepening knowledge of students. She has also redesigned lessons using just in time reflection (Schön, 1983) between class periods when she noted "it's doing a lesson one period and thinking... I have to do something before I have the next period come in so that that doesn't happen again." Gretchen often capitalized on discoveries she termed "aha moments!" Such adjustments might include a change in teaching or learning task, especially when students seemingly were unable to grasp concepts or skills based on how she had planned to teach.

Gretchen was specific in relating one strategy for reflection as a notebook review of her formerly compiled plans at the end of each (story) unit. She wanted to use the most current information so she could relate novels to the trends in students' lives, if applicable, and to use techniques she learned from her research and associations with other teachers. She stated, "I will go though and just clean house. Then what else can I bring in?” Her realization, as an accomplished teacher, that there is a brief window of time (one semester to one year) to enable student growth weighed heavily and was also a source of joy. "As a result of National Board," she said, "you just work harder and you have this inner compass that keeps you on the right track." According to Gretchen, the world was changing and she was changing with it to keep up 
Journeys toward Reflective Practice: How Engaging in National Board Certification Influences Teacher Identities and Practices

with her students. "If I am going to be teaching a 400 year old piece of literature, I'd better tie it into today." Hence, she constantly scrutinized her instructional design and updated it. This belief resulted in a "clean house" practice and was reinforced by her insistence that her instructional design needed to be based in her knowledge of students, who changed every semester, or her students were not going to benefit. Before she was an NBCT, she believed her teaching was "blah" and fragmented, embroiled mainly in her content presentations. After certifying, Gretchen wanted to learn more about her students' lives outside of school because she believed this knowledge of students to be "crucial to reaching them...It is always my best effort to create lessons that are going to be meaningful to them...and sometimes the kids will say...well, you know that wasn't bad ((laughter)) and there is the homerun." The homerun metaphor returned to the idea that content-based work, specifically designed for these students at this time, was in their zone of proximal development (Vygotsky, 1983). Under these teaching and learning conditions, students could and did achieve.

\section{Conclusions}

She may have felt powerless to use her own voice in her early teacher career and she certainly did not position herself as a teacher leader. Instead, it seemed she adopted the sacred story of traditional methods, which was valued, (Olson \& Craig, 2005) at that time, but this context eventually gave way to a much more collaborative team of teachers with whom she practices today. Her former thinking was highly revealing because she went on to mention current department practices as moving toward collegiality: "collaborating with teachers where you share your toys, you share your successes, and you share your failures." Furthermore she was animated in stating, "Reflection in isolation is fine for your practice, but when you get 
Journeys toward Reflective Practice: How Engaging in National Board Certification Influences Teacher Identities and Practices

together with your group, and you see what others are doing, I think it helps you grow." This statement took place during the first interview, but represented her presently developed positive feelings about staff interaction and support. Danielson (2009) made observations that reinforced Dewey's (1938) notion that responding to the problems of learning were inherent to growth as a reflective teaching practitioner and interaction with colleagues fostered this development.

It seems possible that Gretchen's evolving identity (Gee, 2014) and self-confidence as an NBCT contributed to her willingness to be open in conversation with her peer group. This mutual respect may have contributed to the development of her collegial interactions with peers. Additionally, she is now a more senior teacher, the original team leader is no longer in her school, and the teacher who replaced the original team leader tends to facilitate, not dominate, conversation. All of these factors may have had a positive influence on the nature of the professional learning community in her context.

In conclusion, it may be construed that Gretchen now views herself as an accomplished teacher and she attributes her student-centered teacher identity and innovative teaching practices, in part, to the reflective processes she experienced and internalized when she pursued National Board candidacy and successfully completed the process. She illustrated her thinking with this:

I will give you an analogy... my teaching prior to being a national board certified teacher was like a navy blue bedspread... you know it does what you need it to do... it covers the bed... keeps you warm... but now it is a quilt and it's got more patches than you can count on it or squares or whatever it's made up of... and that they are all really interesting and as you look at it... you want to keep looking and look for more because it always changes.

This evolving identity as a teacher researcher who continually reinvents her work and searches for new material to implement in her instructional design stimulates her ongoing professional growth. This need for transformation was seemingly informed by Gretchen's determination to maintain a student centered teaching style because as she said, "We live in an ever changing 
Journeys toward Reflective Practice: How Engaging in National Board Certification Influences Teacher Identities and Practices

world permeated by technology" and she is fully intended to embrace these changes in order to meet the learning needs of all her students.

Also of note is the "homerun" metaphor that appeared multiple times in the stories she told about her practice. When asked to define this, she said,

For me, hitting a homerun is when a student is able to do more than parrot information back to you...that they can recall and use it later...it's the sort of thing where they can make connections with things they learned previously. To me, it is success, not just learning something for the sake of the test...but so they can express themselves in $a$ different way.

Then Gretchen qualified her response with these comments:

So, I think the NB process really just causes you... no, compels you to expand on the ways you let your students learn and makes you try to find as many ways as you can to get them to engage...you are not going to hit a homerun every time, but boy, you'd better hit a homerun with each of those children a couple of times during the semester.

The NBPTS Five Core Propositions established the premise of coalescing knowledge of students with knowledge of content, then managing and monitoring the student growth process.

Gretchen's term, “homerun,” provided a graphic visual representation of her meta-cognitive processes of self-reflection as she pondered her classroom practices. Indeed, she aspired to prepare students for the unknown future of college or career readiness.

Although Gretchen believed she used traditional methodology throughout her early teaching years, it appeared that in recent years she has been more likely to collaborate and reflect with fellow teachers. After certifying, she was less likely to engage in "the textbook approach" to teaching and more likely to find ways to make learning "relate" to historical literature contexts, the canon, and contemporary events in order to reach every student of all persuasions. Student race, gender, and social class were not the main focus of her interview response pattern and this may be due, in part, to her description of the "white bread" students in her teaching context. However, Gretchen maintained she was deeply concerned with issues of equity and believed she 
Journeys toward Reflective Practice: How Engaging in National Board Certification Influences Teacher Identities and Practices

made a strong attempt to connect classic literature, including but not limited to, To Kill a Mockingbird (Lee, 1960) and The Catcher in the Rye (Salinger, 1951), to the present time by stimulating debate concerning prejudicial behaviors and human conflict to explore societal issues. Gretchen also believed her thinking about providing a safe, high tech, high touch classroom climate promoted and encouraged her students to take responsibility for their learning. She presented evidence that her students were brave enough to take the risks associated with self-expression and self-evaluation related to literacy. Gretchen believed the work she assigned, "gives my students the chance to feel and think about their own learning and what did they really do well... to feel successful and to be able to assess their own work is really valuable." It appeared that Gretchen's teaching stimulated and provided for significant student growth in selfexpression and ensured they were prepared for their next steps beyond the sheltered, yet on many levels challenging, high school environment. 
Journeys toward Reflective Practice: How Engaging in National Board Certification Influences Teacher Identities and Practices

\section{Chapter 7}

\section{Reflections of NBCTs Initiated Via Video Experiences, Journals, and the West Virginia Teacher Evaluation System}

Several artifacts connected to the NB process provided additional elements for analysis that were aligned with the participants' narratives elicited during the series of three interviews. Interview four provided a coda to our shared reconstruction of the teaching and learning experiences of these participants. Interview themes prompted discussion of their current thinking about teaching, reflection in/on action related to present time personal decision-making, instructional design, and practices. Participant journals offered written verification of the practices each believed facilitated the education of "these students at this time."

During the NB process, each participant was required to submit two entries featuring videotaped segments of his/her teaching practices with the teacher appearing at regular intervals during the videotaped segment, complete scripts of the events taking place during the videotaped lessons, and succinctly analyze the classroom practices in use. The NB candidate was expected to focus on student response patterns, note developing concepts and/or skill patterns, and provide interventions as needed to ameliorate student misconceptions as assessed by the teacher. Students were expected to be interacting with one another as a primary mode of learning. Three types of discourse were required: student-student, student-teacher, and teacher-student in descending order of priority. Hence, analysis of a more current video served as a tool to stimulate conversation with participants about their evolved capacity to analyze and reflect on videotaped teaching segments and their current identity as a reflective practitioner. 
Journeys toward Reflective Practice: How Engaging in National Board Certification Influences Teacher Identities and Practices

Moreover, teacher journaling was also integral to the NB process for two different entries. These entries analyzed the development of student work over prescribed time periods in one entry, while the other entry contained a detailed log of the candidate's work with parents, families, colleagues, and the community. Both of these entries required candidate analysis of his/her abilities to create and maintain a positive impact on student learning. Recording one's thoughts about teaching was claimed to be the determining factor in developing reflective skills by each participant and these notes took various forms as recorded in the addendum.

Finally, the revised West Virginia Teacher Evaluation System, fully launched in 2012, was explicitly aligned with National Board for Professional Teaching Standards. As these teachers each achieved National Board Certification prior to its inception, each was well aware of and involved in goal setting processes involving student growth. A segment of questioning related to goal setting was included in the interview series and elicited a wide range of participant sentiment.

\section{Margaret}

In viewing a video of her sixth grade students engaged in a more recent math lesson, Margaret shared that this lesson provided a review for the bulk of her class and was designed to provide peer guided practice for three new students under her tutelage. The students were collecting data from literary sources, tallying the results, then converting the ratios of information acquired into part to whole relationships using both fractions and decimals. Margaret assigned her students to groups of three and circulated between the tables in the video. As we viewed her video, she noted that one student was non-participatory and asked him a basic skills question to draw his attention into the work assigned. As Margaret probed a bit further, she said 
Journeys toward Reflective Practice: How Engaging in National Board Certification Influences Teacher Identities and Practices

she learned that her students sometimes did not know how to ask for help. In the video, she stopped, reviewed two basic algorithm patterns with him by saying, "First you look at turning the mixed number to a mixed fraction. (Student performs action that cannot be discerned.) Then you multiple the numbers on the top straight across. (Student performs action that cannot be discerned.) Now what?" and she stepped back to observe. This would indicate that Margaret used reflection in action and when asked about her decision, she stated she organized some further one to one sessions with this student to work with the skills repetitively, indicating reflection on action as well. At one point, she questioned a student to determine his present level of understanding by saying, "Is there any chance you were off in your thinking at this stage?" She noticed this and determined that in the future she would prompt the student to locate the step in the problem solving exercise where the calculation was slightly inaccurate rather that pointing it out directly. She said, "I would ask him to explain all the steps after he chose the formula aloud, that way he would be able to locate his own errors." It seems Margaret was reflecting on action as she determined use of an altered questioning technique might be more effective. The actual exercise was scheduled in her mind to last about 20 minutes. However when Margaret saw the debates between students related to using formulas appropriately or inappropriately, she paused and allowed extended time for the students to create workable decisions. This she declared was "more valuable than rattling off an answer that might happen to be correct." She went on to say that when her students are struggling, it is hard for her to remain quiet and she has to remind herself that she won't always be there to give them clear directives. She felt it was better to listen while her students tried to talk it out during her "best lessons" and to remind herself, "What is the real goal here?" Margaret knew she wanted her students to make good decisions about the strategies they chose when solving authentic math problems and to accurately complete their 
Journeys toward Reflective Practice: How Engaging in National Board Certification Influences Teacher Identities and Practices

work. She began using the term stamina to describe her students' work ethic and to place value on eliciting and responding to student thinking that was made transparent in their discussions.

While watching the video, she paid particular attention to questions her students began creating to encourage participation by the less verbal members of the class. She said this aspect of their discussion exceeded her expectations. Margaret also noticed one group who she said, "were not relying on past knowledge" and therefore kept failing. When their end result did not meet expectations, she asked them, "How will you make this accurate?" The students were not frustrated, but stayed on task and little by little located the minor errors in their earlier estimation and/or calculations. As each error was corrected, the train of thinking of this team improved and the guided practice was likely to aid development of their strengths in problem solving behaviors.

At the closure of this video viewing session, Margaret talked about learning from watching her own teaching. She averred, "I thought about teaching a lot more after I videotaped. Seeing myself teaching made me very conscious of the questions I asked and I think about this when I compose the questions I still ask.” Margaret took a great deal of pride in designing work that kept her students on task while they are having fun while learning. She believed these lessons were successful with middle school students because they really enjoy working with peers and the challenge provided by the tasks she chose provided opportunities for students to engage in discussion of their problem-solving. Most importantly, she cited time as a complication, because the students needed to have enough tasks per class to allow her adequate time as she circulated and heard justifications for processes chosen by each group member on a daily basis. The time factor was also important for optimal strategic thinking by students, to create the spaces for each student to use and develop skills in mathematical reasoning. 
Journeys toward Reflective Practice: How Engaging in National Board Certification Influences Teacher Identities and Practices

The journals Margaret shared distinctly resembled lesson plans and actually were from a piece of student-centered work she was continually redesigning. She based the work on finding the surface area of six sided rectangular prisms as an activity, which provided a distinct model for student use (see Appendix A). Margaret then moved students to solving the surface area of a cylinder. These activities were relatively straightforward and students moved toward applying the needed mathematical formulas with relative success and developing their adaptive thinking to problem solve. The next two tasks, finding the volume of a rectangular prism and volume of a cylinder were not nearly as clear-cut for her eighth graders. As she logged the activity and reviewed her student responses, she said, "I thought they would immediately go to their knowledge of formulas for area of a circle but they did not." In her journal, she recorded that her students took much longer than she had planned for the discovery process, which she felt to be of crucial importance to their operational thinking. Ultimately she provided more support than she had originally planned as well. She looked back and wrote, "It was not until I asked some guided questions on day 2 that some students began to find the diameter of the circle, converted to radius and then found the area of the circle." With this stimulus, they now were able work forward and apply the correct formulas to the tasks at hand. This writing may have been quite similar to her NB reflections as she concluded, "The understanding they developed would allow us to advance to more abstract thinking in future lessons." She ultimately determined that teacher patience and the use of the right tools, including extended thinking time enabled her to reach her overarching goals for student learning. Margaret expected her students to "demonstrate an improved understanding of mathematics, participate in mathematical discussions, and improve performance on formative and summative assessments." Her teacher thinking in her journals bore a strong resemblance to statements she made earlier as we viewed videotapes ("they were 
Journeys toward Reflective Practice: How Engaging in National Board Certification Influences Teacher Identities and Practices

not relying on prior knowledge" and "I had to ask questions that cued thinking") when she offered opportunities for students to work with peers as they attempted mathematical problem solving.

Margaret recognized WVTES as directly affiliated with National Board Professional Teaching Standards and. at this point in time, she felt that the impact of WVTES was minimal in her school setting due, in part; to changes in administration. While her former administrator took the work seriously and piloted the program, the current leader of her school is less invested.

Currently, the science and math teams create shared goals as did the social studies and language arts team. In Margaret's view, “this doesn't work because our goals for students are based on incremental growth on summative assessments and that doesn't help me measure or reflect quickly enough to make adjustments to the work my students do." She closed by saying these shared goals were not open to genuine discussion and therefore held little meaning because she did not embrace the concept.

\section{Ethan}

Ethan chose to share a video exemplifying how his students learned to construct a model of the human heart as they explored the blood flow pathways in an advance placement (AP) course. His students were assigned to small groups of three/four students, with an intentional mixture of abilities and prior experience, mostly high achievers, including a few who had previously taken human anatomy and some currently enrolled in anatomy. Ethan focused on what he viewed as the greatest obstacle to success for these students at this time. His talented students were used to "not having to study" and making straight As. "So I have to teach them strategies... to slow down and think while they read and think about how they are thinking." 
Journeys toward Reflective Practice: How Engaging in National Board Certification Influences Teacher Identities and Practices

Ethan reflected on his students' skills and strengths and knew that for future success his goal was to help students grapple with disequilibrium during the process of learning, as well as learning how to focus, concentrate, and self-evaluate their own learning as they constructed understandings of the content. He commented, in several instances, on the level and nature of student-student interaction, citing places where he noted students who were struggling, especially with perspective during their production of the clay model. He was pleased to see them struggle because, he said, "They have to fight with it because if it comes easy, they won't retain it. If somebody gives it to you, you are not going to keep it." This intentional level of slowing down student thinking and assigning work products that make their thinking visible was consistent with how Ethan described his progress through the NB process. During the interviews, he said, "The activity was the same [as prior to becoming a NBCT], but my level of actually evaluating [grew because]... not only what they were doing, but how I was learning about my students while they were doing it." He also discussed knowing how and when to intervene so the work was just in reach for students, rather than composed of insurmountable challenges.

Ethan also learned, by observing himself on video, and discussed the strategies he used including: teacher observation only, teacher hints in various forms, teacher to student questioning, and student to teacher questioning. He noted the places where he stopped to watch students, saying nothing and remaining neutral. Another hint strategy was ensconced in nonverbal teacher behavior when Ethan said, "[I know] what it is not to lead them... now the grimace leads them... or the bright eye maybe... but the shrug doesn't lead them." His intention was to make his students figure out solutions to solve the lab based problems posed as long as what the students proposed to do was within safety guidelines. Ethan went on to say that his students named his non-verbal cue for his neutral stance was the "Teacher name shrug." It has 
Journeys toward Reflective Practice: How Engaging in National Board Certification Influences Teacher Identities and Practices

since become an icon, and a very effective one, in his classroom. In the video, when the shrug appeared students were given the message that their teacher had confidence in them to figure it out.

In his teaching video, questions posed by a student to Ethan led to the following responses: 1) Ethan used his knowledge of the student to direct the student to the text for very specific information that might provide effective guidance needed at that very moment, 2.) Ethan drew an instructive partial diagram as an intervention when a student's idea demonstrated a misconception. When asked if these diagrams became a part of the student notes, he said, "No, I draw on pieces of paper towel and at the end of class I pick up my drawings all the time."

In the following passage he described his actions and those of his students on the videotape:

So, they are working from pretty low knowledge base at first. By the time they are done with this, they should be able to name everything and describe the entire path [of blood flow through the human heart]. Now if this was a different level class I wouldn't be able to do that. But I know they are capable of actually getting to that level. Now they will start going into the model construction... a lot of that movement a minute ago was just getting the materials. So, at this point I go around to each group, pause, and just check. Sometimes I give little hints... maybe to make a point. When the time is right, they will be released to open their books.

These responses may have provided "just in time" information sharing (Bransford, 2000) to scaffold student thinking just enough to alleviate a block, but not enough to solve the entire dilemma for students.

Ethan took some time to reconstruct how he began using non-verbal signals in his work as discipline and management techniques. He related he learned, through watching videos during the NB process, that his students read him well, so he learned to control his reactions to maintain neutrality when he was placing students in charge of their work in laboratory situations. He also used video segments to learn to control his use of verbal spacers in his directed teaching 
Journeys toward Reflective Practice: How Engaging in National Board Certification Influences Teacher Identities and Practices

eliminating, to the extent possible, his use of the word "okay." Ethan also cited watching prior videos as instrumental in teaching himself to cover the classroom equitably in moving from group to group. He also noted working with other teachers in his school context as they watched themselves on videotape and became more cognizant of how they reacted to, favored, or overlooked students, especially minority students. When we videotaped across many classes in our school as a learning project teachers said, "Wow, that really opened my eyes and that's true it does." He then went on and discussed the constraints with this professional learning collaborative project:

So, that's where the context first started and I think soon after that is when I started... the videoing at my school... we were the first ones here certified and so we started... Carol and myself and somebody else... and we started because we wanted other folks to learn, but as I said eventually it dropped because we didn't have the time to do it, but it was very valuable... In Japan... they would have one model where everybody collaboratively designed and then they would take that lesson and analyze that lesson to that model which would be very valuable but then again it comes down to the time... that was the context.

He also lamented the limitation on collaborative time, at several other points in the interview series, particularly with team meeting time frames as planned by his administrative staff.

When the conversation progressed to a review of Ethan's journal entries (see Appendix B), he stated he was convinced of the value of recording his thoughts using key words such as: “exceptions to Mendel's law, hormone questions, protein synthesis conclusion, operon and gene control, colon cancer case study," and he has maintained this practice diligently. Ethan stated, "These are actually more valuable than lesson plans...I keep them to go back and write things in and mark out. This has helped me so much. I have 12 or 13 years so I can go back and look." His journals were not actually written in sentences, nor were they lesson plans. Ethan actually termed these as a "dynamic notebook" and said that this work was "evolutionary" for him. The written notes were records of curriculum pacing for Ethan. He adjusted his pacing yearly based on 
Journeys toward Reflective Practice: How Engaging in National Board Certification Influences Teacher Identities and Practices

whether or not he assessed his students' understanding as acceptable or as demonstrating a need to continue working with difficult material. Ethan created a constantly updated frame of topical matter comprised of sequences with sidebars, cross outs, diagrams, highlights and circles depending upon the time the updates were inserted. These notes in Ethan's estimation were “probably the most valuable tool I have for reflection... this is really dynamic." Ethan's notes helped him visualize the strategies in place that worked in prior years and recall the pacing that enabled student growth over time. He stressed that no two classes will ever be in the same place at the same time, but as a reminder for his recollection, these notes were instrumental in maintaining his teacher confidence that learning was unfolding as it should.

The evolution of Ethan's understanding of teaching was further illustrated in comments he made about a colleague and pacing of student learning. According to Ethan, restrictions on teacher work come from many sources including, but not limited to, parent expectations, student abilities and prior experience, peers, administrators, and the teacher's content and pedagogical knowledge and skills. He opened the door to discussion about teacher academic freedom, espousing the idea that it is the teacher's responsibility to move student learning from the onset of the school year to its closure saying:

I have to make things click for my students... that is why we do it that way... I don't think my need for change for me right now is as big as it was ten or eleven years ago. As of right now, I feel pretty comfortable in what I do and it's not because of test scores... it's that I am at a point right now where I have had enough kids get finished... Kent, a dentist, is one of my students... a pediatrician assistant is one of my former students and they have made it. Many of my kids are doing cancer research... They graduated and they come back to me and say I am here because of what you did. I am pretty comfortable now with what I do... whereas ten years ago I wouldn't have... I would be saying am I doing the right thing... so I am more comfortable now saying I am okay with this... but still the individuals are different from year to year...like these kids right there on that screen... they are different than the ones who graduated... I know what they need and I use standards to get them there... it is reflecting on how to get them individually get it. 
Journeys toward Reflective Practice: How Engaging in National Board Certification Influences Teacher Identities and Practices

Ethan's learning about teaching was based on student needs and he used WVDE and NSTA learning outcomes as the standards. It appeared that, in Ethan's view, academic freedom matters because student needs determine the pace of learning in the classroom. He seemed to believe constraints, including but not limited to, imposed artificial assessment practices to meet government mandates are overwhelming the education of our students.

In discussion about the West Virginia Teacher Evaluation System (WVTES), Ethan recognized that this work is rooted in National Board Professional Teaching Standards and therefore influences his thinking when he engages in the yearly goal setting. He shared that his administration imposed some level of control on the goal setting process as he and peers were instructed to use a combination of PLC goals and personal goals. This was yet another statement of his concern that his administration either was not equipped to, or was unwilling to, allow teacher freedom in his school context.

However, he did feel that the goal setting was to some extent beneficial because it compelled teachers to use professional language to self-rate progress, and he recognized the value of stressing data collection as a subsection of knowledge of students. Ethan also noted the alignment of his work with the families of students as emphasized significantly during the NB process. He defined these influences on his goal setting thinking process as:

You have to know your kids... I mean you have to be able to work with parents and faculty... I mean you self-rate yourself based on things that we dealt with the national board certification. So, you self-rate yourself and then you come up with goals to address ... you collect your data... you show that either that progress was made or not. But they are rooted on... do you know your content... do you know your student... do you work with your families and these are the same topics that we worked with in the national board certification.

He closed his reflection on the WVTES by diminishing its usefulness for him personally when he asserted, "The level and the value of reflection (in WVTES) is not as high as the self- 
Journeys toward Reflective Practice: How Engaging in National Board Certification Influences Teacher Identities and Practices

assessment I gained from the NB reflective process and is not as valuable as the day to day reflection I do.” He went on to elaborate:

[My reflection is] not as deliberate... [not as] goal oriented as during the process of national board certification. It was a part of the entries. Now it is thinking about...okay, how do I take what I am doing now and get better. So, there isn't a product... a reflective product that I can show... but there has been improvement on how things have progressed as far as what I do in a classroom.

These themes in dealing with the problems of his practice were consistent across his entire interview series.

\section{Gretchen}

As a very enthusiastic supporter of videotaping, Gretchen was eager to review her student work during the videotaping process. She believed these to be the most difficult entries during the process and. at more than one point, said she learned more about herself as a teacher from watching herself in action than from any other entry. She became acutely and painfully aware of not interacting equitably with every student in her class during candidacy and uses tally strategies on a daily basis to assure she "never falls into that trap again." Gretchen learned how to design and implement small group work during the NB process and she seemed confident in saying, "That was when I started getting excited about letting the kids do the teaching and learning."

In her current video, Gretchen assigned a variety of passages to students from a classic literature piece. Her students were to rewrite brief sections using modern linguistic patterns to represent the character's viewpoint and voice. This led to debate on the accuracy of specific characterizations, a lively and at times, controversial discussion which was what Gretchen had hoped for as it placed her in facilitator's role and required students to support their written 
Journeys toward Reflective Practice: How Engaging in National Board Certification Influences Teacher Identities and Practices

passages with justification(s) from the text. As she watched the video image of her students engaged in discourse and she moved from group to group, she often simply paused and waited.

She commented she was extremely conscious of "wait time" with her students because often her students' body language, which she was learning to understand, signaled deep thought and a potential verbal contribution. One male student was, as she termed it, "particularly antsy," so she stood near him, made eye contact, and waited. She went on to say that the opening her presence created in conversation led to his being able to, "come out with this great insight." She believed her experiences analyzing videos of her teaching, which she watched over and over again, provided her the "time and space to become observant" while she was teaching, not just after the fact. From a distance, she noticed the body language exhibited by a pair of students and determined they were possibly being antagonistic, rather than engaging in honest debate. She moved in that direction, redirected their conversation, and held a private conversation with one of the students to remind him of protocols. While watching this, she referred to a circumstance prior to becoming NB certified when she might not have had the insight to intervene. She ruefully related, "These two students totally hijacked group discussion. They went into performance mode [they were members of the debate team] and I was so mad at them and so mad at myself for not stopping them." She attributed the situation to a lack of self-control on the part of her students and held herself responsible for allowing them to move into the same group in an effort at "one up man ship." Gretchen believed this might "have happened because these students were wiseacres," but this behavior had no place in the classroom climate she sought to promote.

As Gretchen watched her video, she recalled why she is now on the alert for students who seem to be on the verge of speaking as she is very much "in tune with" trying to maintain equity 
Journeys toward Reflective Practice: How Engaging in National Board Certification Influences Teacher Identities and Practices

and promote student voice because her students "believe what they say." She believes that student voice is one of the most important outcomes of learning and that vocalizing the understandings one constructs, with a justifiable rationale, solidifies the thinking process for her students. Gretchen also contends that for a high school student, "speaking to peers end expressing your opinions takes bravery" and she encourages this. When a student opened her book to show another student a passage and went on to explain why this section was tied to her lyrical voice, the second student nodded, and Gretchen asked the second student, "What if the phrase went further, what are two opposing ideas that might be said next?” Advocating for deeper thinking seemed to be a priority for Gretchen, and she was patient in order to ensure that the dialogue was open-ended. She endeavored to allow for expression of a variety of student perspectives as she tried to create openings for multiple speaker contributions. In her analysis of this video scene, she was definitive in her intent when she asserted, "I get a much clearer understanding of my students and of my teaching because I watch myself to see how I respond, what kinds of questions do I ask, and am I asking the right kinds of questions?" As a postscript, and with no prompting she added, "Being reflective for me is asking myself, do I ask the right questions? I never did that before (the NB process). Then I became aware, but now I do it because it works for me." Gretchen was candid in reviewing what she saw on tape, she was not pleased with everything her students were doing, and overall she was able to say that, based on earlier videos of the learning and interactions of these same students, much progress was shown. She also averred strongly all teachers should have to videotape and watch what is really happening in their classrooms.

The journaling process was a strategy that was familiar to Gretchen, which, interestingly enough, she found difficult to maintain at this point in time. She does write on her lesson plans 
Journeys toward Reflective Practice: How Engaging in National Board Certification Influences Teacher Identities and Practices

phrases such as “ this didn't work... next year do this...next year do not do this...so I have a running history of what I have done and what has been successful." In reality though, she said she is much more likely to go out and find new materials than to re-use materials she felt were marginal at the time. She stated she is extremely likely to tweak lessons between periods and much of her material this year is brand new. In an interesting move, she chose to teach "lower level" students and in doing so decided not to use her two favorite novels this school year. It would appear that journaling might be more important than ever for her work as she teaches new courses. With her history as an English major, Gretchen used "writing to clarify my thoughts and loved every minute of it" during her college years. She was unsure why she abandoned this tool though she did cite a series of constraints that she asked not be shared in this document. However, she did share she is engaging "in thinking about the sum total of her own practice." This would seem to be a lofty undertaking given the time constraints she recognized, as Gretchen has been teaching for about ten years and serves in many capacities beyond her classroom. Gretchen goes to school every Saturday morning and many Sundays and said she "cherishes this time to build" her teaching repertoire.

Gretchen was indignant when the topic of the revised WVTES was broached; she said flatly, "I have nothing good to say about it." She talked for several minutes about the injustice she experienced when she articulated, “that principal told me to come by sometime, he didn't even tell me to make an appointment and then he rated me lower because I was busy ([with legitimate educational work for the state department] and did not make an appointment." Gretchen believed that the system had no effect or respect for her position, respect for her dedication, and was "furious that student test scores could be tied to her evaluation." She also stated that WVTES does not have an effect on her salary and the teacher in the room beside her 
Journeys toward Reflective Practice: How Engaging in National Board Certification Influences Teacher Identities and Practices

classroom works twenty hours less per week and there is no substantial difference in the evaluation of the two. Her displeasure continued as she described the administrator in charge of reviewing her work and what she felt to be "his trivializing attitude." After she confronted the administrator, he changed the particular rating to distinguished. She sensed that the evidence she gathered was not reviewed carefully and his ratings were subjective at best. She then said, "I am distinguished, so, so, I will go the extra mile for myself, but it still doesn't change anything. Who reads it?" Her recounting of the evaluation process she experienced was enlightening and she, in nearing closure on this topic, did agree that WVTES does make sense because the standards concur with NBPTS. But she didn't feel it was important to her "because as a NBCT, she is already reflecting 24 hours a day." As an epilogue, she said the WVTES helped her review all of her accomplishments over the course of each school year. However it would appear she remains unconvinced about its personal value in light of her recent experience.

\section{Conclusions}

Each participant remained convinced of the value of videotaping his/her work in the classroom and all three have done further videotaping post-certification. The consensus was that time constraints were prohibitive in making this a regular tool for engaging in reflection. Were it available through a systematic coaching system, each would be inclined to participate. Time constraints also included finding a videographer, the collection of signed student permission slips, finding uninterrupted stretches of time (fire drills, assemblies, students in and out of the room, etc.), and searching for a working video tool with an adequate sound system. Newer technology tools have improved sound systems and accessibility to audio recording is essential in the analysis of a videotaped lesson. Finally scripting was required for effective analysis and 
Journeys toward Reflective Practice: How Engaging in National Board Certification Influences Teacher Identities and Practices

scripting a 40-minute taping easily took upwards of 10 hours of watching, writing, and review. So while committed to the idea, each participant agreed that their time constraints made this a commitment they were unable to maintain. Ethan suggested he would be more effective in continuing to develop his teaching skills if his daily schedule permitted one hour of planning allotted to each hour of teaching. His reasoning suggested he had given much thought to this ratio and researched it by studying educators from international locations.

Not one participant could immediately find formal daily journals to share. Each kept some type of notation system, on lesson plans or in another format. Margaret reconstructed her journal from lesson plan notes, while Ethan and Gretchen each chose to share annotated work that held deep meaning for each, but using these notes was extremely difficult for my unseasoned eye. I needed their expertise to discern how the notes would trigger memories over time that might prove important to student learning in future years. Their pacing of the introduction of concepts leading to student work and time spent ensuring high quality student work products seemed to be a primary concern as all three reiterated these as important.

Every participant earned NB Certification prior to the inception of WVTES. Each gave little time to the WVTES process, felt they had mastered its tenets, and held more teaching credentials than this revised system recognized. Not one expressed that the school level introduction to WVTES contributed to potential positive effects on teacher efficacy or student learning. Throughout all of the interview series, participants repeatedly expressed views that fell just short of censure for many, but not all, of their school administrators. Interestingly, considering the NB emphasis on supportive two-way relationships at all levels in school systems, there was a perceived lack of overt support directed toward these three highly professional teachers by their administrators. This may be one of the strongest disconnects revealed through 
Journeys toward Reflective Practice: How Engaging in National Board Certification Influences Teacher Identities and Practices

these interviews and this perception may impede these situated school communities from optimal functioning. 
Journeys toward Reflective Practice: How Engaging in National Board Certification Influences Teacher Identities and Practices

\section{Chapter 8}

\section{Discussion}

In chapters $4,5,6$, and 7 , I presented my findings related to the research questions I proposed from working with three participants and recording their responses during three in depth interviews, review of one video of an interactive class learning activity, and a sample teacher journal. Interviewing in depth has its strengths and its limitations according to Seidman (2006) and mainly functioned as a tool for describing my teacher participants' experiences from their perspectives. Seidman noted that the "individual experience interacts" powerfully with the social and organizational structures of one's life experience. As we explored questions related to the overarching research question "How do teachers learn to teach over the course of their teaching careers?" evidence arose to support the notion my participants' teaching contexts exerted a powerful influence on teacher learning. The process of engaging in the National Board Certification was a common context for these participants and appeared to have influenced each in developing personal abilities to use reflection on teaching practices supported by their analysis of videotapes of their practice, in which they framed and reframed their problems of practice, as well as their written journal reflections related to student learning and growth.

The experiences of each of my participants included entering the world of professional education through traditional means: an undergraduate education, student teaching, and employment in public schools. While they were able to create narratives related to their early career, they struggled to recall their novice teacher identities as we explored and discussed how the early years of teaching created a mindset that eventually led each participant to take on the challenge of achieving National Board Certification. The central interviews, when participants were requested to reconstruct the actual work and meta-cognitive thinking required by the NB 
Journeys toward Reflective Practice: How Engaging in National Board Certification Influences Teacher Identities and Practices

process and to share stories of how engaging in this process influenced their current teaching and identities, elicited narratives that indicated their understandings of how pursuing and achieving NB certification influenced not only their teaching, but also their identities as reflective practitioners. The final meeting involved analyzing video excerpts of their teaching and a journaling piece, which were current, and allowed for active reflection during the interview, which provided further evidence of the teacher identities my participants had constructed. In this chapter, I discuss how these teachers learned to teach over the courses of their careers, the ways in which the context(s) in which they were situated and the experiences they encountered influenced their development as reflective practitioners, as well as how the contexts in which they positioned themselves and were positioned by others influenced their identities and practices. I will end this chapter with a discussion of the implications of my study for professional educators at multiple levels of influence who are dedicated to serving students well.

Seidman (2006) posited that stories emerge from narrative inquiry and these stories were a major method used by my interviewees to "make sense of themselves and their social world... and link(ed) the individual's experience to the social and organizational context within where he or she operate(d)" (p.120). The contexts in which they were situated were an external factor that influenced how each teacher developed his/her practices and identities. However, there were times during the interviews when each of my participants appeared either wary or unable to recognize and acknowledge these influences. Unless pressed, no participant reconstructed information related to administrative support; moreover administrators were not presented in a positive manner at any point when they reconstructed their teaching contexts or histories. It was noted that no participant remained in a stable or singular position throughout his or her teaching career. Although this factor was not explored in my inquiry about the NB 
Journeys toward Reflective Practice: How Engaging in National Board Certification Influences Teacher Identities and Practices

process, changing teaching contexts within the school system or across multiple school systems did allow participants multiple perspectives, which none acknowledged as personally formative, of the wider school environment. The ways in which each participant understood and developed their teaching practices and identities were not a "simple reflection of what is there, but is a set of social artifacts of what we make of what is there" (Schwandt, 1997, p. 20).

Thus, it seemed that my participants' thinking about the evolution of their teaching practices and identities was influenced by the context(s) in which they were situated including, but not limited to, collegial teaching relationships, administration guided by applicable policy, and most importantly perhaps, the opportunities for professional educators to study how people learn via interaction with students, who were diverse learners, and, to some extent, their families and the school community. Limitations, such as the curriculum pacing Gretchen experienced which did not support her teaching style nor her students' learning, or supports, such as the mentor who provided Margaret with pragmatic tools, influenced their professional development and they eventually engaged in introspective scrutiny using focused reflection.

\section{Reflection on Practices and Identities prior to National Board Work}

References to the participants' perspectives on their early years in teaching indicated high levels of self-reliance born of great frustration with the rigors of serving the needs of students. Each wanted to learn more about how to teach; however during their early days of practice, my participants did not know how to problematize their teaching practices. The concepts of "reflection on action" and "reflection in action" (Schön, 1983) to frame, reframe, and solve problems were not present in their repertoires as pre-service and novice teachers. Thus, the 
Journeys toward Reflective Practice: How Engaging in National Board Certification Influences Teacher Identities and Practices

corresponding desire to improve one's own professional acumen may have been a factor in each participant's initial decision to seek advanced certification.

This stance was exemplified when Margaret stated, "I knew I needed adjust my teaching when I saw that I wasn't quite meeting the needs of my students. I was inspired by the quality of work from other teachers going through the (NB) process." The wider school community was composed of some teachers, who like Margaret, were struggling "to figure it out," while others seemingly demonstrated exemplary practice. In discussion, Margaret's thinking appeared to ascribe to what Drago-Severson (2004) described as "the instrumental way of knowing” (p.25). Instrumental knowing was concrete and was manifested with an exchange level perspective in interaction with others. Margaret's thinking was characterized by trying to find "answers" to her problems in teaching, rather than going deep to figure out what was going on. As a novice, she experienced professional development sessions after which she developed more questions about what she "should be doing" as a teacher. Thus Margaret subsequently experienced heightened levels of frustration when her teaching practices seemed ineffective. Margaret knew she wanted to rise to the level of exemplary practice, therefore this influenced her decision to seek certification and during the process she sought support from like-minded peers. Then, much later in her career, she also referenced maintaining a level of collegiality with NBCTs from the wider school community as reassuring to her and a source of satisfaction and she acknowledged her interactions with trusted adults continued to play an important role in her development as a teacher. As Seidman (2006) noted that the "individual experience interacts" powerfully with the social and organizational structures of one's life experience. 
Journeys toward Reflective Practice: How Engaging in National Board Certification Influences Teacher Identities and Practices

Ethan focused his time and efforts during his early years on developing his repertoire of science experiments that could be completed with his students and he spoke at length about writing grants to obtain the materials to do so. His "way of knowing" may have been "selfauthored" (Drago-Severson, 2004, p. 25). Self-authoring involved capacity for heightened responsibility and a sense of internal authority. Combined with regulation of relationships, selfauthoring had a tendency to limit one's perspective according to Drago-Severson. This limiting of perspective became an asset for Ethan to some extent when he established his parameters on relationships with students (teacher designed/controlled experiments, busy students, teacher leading student thinking, but expecting students to ask questions), but this according to DragoSeverson, ruled out his ability to take on their perspectives. Ethan was confident as a designer of instruction and in his early identity (Gee, 2011) thought himself to be a scientist and manager. He also believed the enthusiasm he demonstrated for science contributed to high levels of student engagement, which he believed, provided evidence of their learning.

After teaching for almost a decade, Ethan began developing new "ways of knowing" when he reflected on student work and realized his students were deeply lacking in the background experiences that would serve as a link to what he wanted his students to learn. This newfound perspective that he, the teacher, was a gifted learner of science concepts while many of his students were not became a factor in his growth as a reflective practitioner. Ethan's growth involved a gradual renegotiation of defining his identity as a teacher within his teaching context (Gee, 2014) and the way he filtered his experiences (e.g., teaching, his interactions with students) dictated "how learning experiences will be taken in, managed, handled, used, and understood" (Drago-Severson, 2004, p. 24). Ethan, the scientist, wished to provide his students with spaces to conduct inquiries and to work as independently as possible, while Ethan, the more experienced 
Journeys toward Reflective Practice: How Engaging in National Board Certification Influences Teacher Identities and Practices

teacher, realized that, simply providing these spaces was not enough; he had other responsibilities he needed to fulfill in order to meet the needs of his students. Therefore, he sought NB Certification.

Gretchen's early memories of mentors and administration were precise and dismissive. Her reconstruction of events described how she relied on interactions with students to determine her course of action during her early career. Drago-Severson's (2004) social constructivist theory framework explored the use of reflective practice in education and how the school setting may become the holding environment and have the potential to illuminate how teachers "make sense of their internal and external experiences" (p. 23). Gretchen seemed to be engaged in informational learning during her early career as she felt constrained by her limited knowledge of content and pedagogy and characterized her colleagues as dictatorial and traditional. Her situation as further complicated because she did not embrace the "sacred stories" of her context even though these rigid practices seemed to be accepted as norms among her first teaching team. Clandinin's and Connelly's (2000) understanding of the "professional knowledge landscape" was further clarified by Clandinin (2013) "as composed of two fundamentally different places, the in-classroom place and the out-of-classroom place" (p.163). Gretchen felt caught between these two landscapes and eventually sought NB certification for personal reasons.

Furthermore, in her novice days, Gretchen determined she was able to connect with her students because she focused on building strong relationships with students even as a novice teacher. Drago-Severson (2004) defined this "socializing way of knowing” as dominated by more abstract thinking, the ability to generalize ideas, and the use of reflection on personal actions and the actions of others. Thusly during her first interview, Gretchen discussed at length how she built caring relationships with her students and listened closely to learn as students 
Journeys toward Reflective Practice: How Engaging in National Board Certification Influences Teacher Identities and Practices

revealed their strengths. Once Gretchen had established relationships with her students, she then felt able to engage them in content-based work. The theme of student-teacher connection was reiterated in all of her interviews.

\section{Development of Reflective Practice during the National Board Process}

The five core propositions of NBPTS were entrenched in teacher reflection on the precepts of fairness, equity, and access to learning for students. Margaret was adamant that her portfolio writing about the student learning she engineered led her to formal conclusions about what was not working for certain students and subsequently she engaged in self inquiry about what might lead to deeper student engagement in learning. Margaret, while trying to create a portfolio that would meet the rigorous NB certification process standard, experienced conditions that compelled her into reflective self-examination (Dewey, 1910) and allowed her the space she needed to initiate progressive student centered practices. She learned the language of connection (Gee, 2011) as she reflected during her work to her personalize NB mathematics standards.

We can use language to make certain sign systems and certain forms of knowledge and belief relevant or privileged, or not, in given situations, that is, to build privilege or prestige for one sign system or way of knowing over another (p.18).

As she accessed this emerging self-expression, she began positioning herself as a "mathematics specialist" (Gee, 2011). Margaret's ownership and authentic use of the language of NB standards included personalizing the standards such as: "I demonstrate flexibility, insight, and responsiveness in dealing with the flow of the classroom by recognizing and responding to the mathematical potential of student questions, and I pursue ideas of interest that emerge during classroom discussion." Owning these personalized self-statements led her to create ways to ensure these standards were evident in her practices. This built her confidence and led her to 
Journeys toward Reflective Practice: How Engaging in National Board Certification Influences Teacher Identities and Practices

construct a teacher identity that included problematizing her practices and the use of reflection on action.

Ethan knew he was not engaged in reflective work prior to entering the NB process. In his struggles to answer the portfolio prompts, he had to become deliberate in his thinking to articulate the reasons he chose to allow his students to struggle with problem solving in his lab design. While these lab based learning strategies were effective for him as a college level student, Ethan had not yet reflected on the effectiveness, or lack thereof, of an open-ended setting for less mature students. When Ethan realized his students used different learning strategies than his own, he began to reflect when writing his NB portfolio on his ability to create an environment that supported their learning (Kozulin, 1986). He had to slow down to reflect. Only after the experience of self-examination was he able to commence making student-centered adaptations in his instructional design.

Ethan's intentional level of slowing down student thinking and assigning work products that made student thinking visible (Ritchhart, Church, Morrison, 2011) was consistent with how he described his progress through the NB process. During the interviews, he said, "The activity was the same (as prior to becoming a NBCT), but my level of actually evaluating (grew because I was learning) not only what they were doing, but how I was learning about my students while they were doing it." His "reflection in action" (Schön, 1983) was eventually described as knowing how and when to intervene so the work was just in reach for students, no longer presented to students at an insurmountable difficulty level. Ethan was now using the scientific method to examine, analyze, and reflectively dissect student learning (Dewey, 1938) and to connect their successes or failures with his professional acumen in providing access and equity to learning for his students. 
Journeys toward Reflective Practice: How Engaging in National Board Certification Influences Teacher Identities and Practices

These stages resulted in an evolving identity (Gee, 2011) for Ethan that repositioned him both in his work with his students and in his view of his work with the wider education community. Ethan self-identified as a scientist prior to engaging in the NB process, and after its completion he asked important questions about his students as he sought knowledge of their educational and personal histories. As Ethan began framing the problems he observed in his practices, he thought deeply about what he observed to refine practices (Zeichner \& Liston, 2014) and create access to learning for his students. Furthermore, in his work as a presenter at science conferences, his intent segued from attempting to expose teachers to the awe and wonder of scientific phenomena into teaching instructional design principles to those in attendance so they would be able to make learning accessible for their students, a major precept of the NB process. Ethan's teacher identity developed when he began to consider himself a teacher of students who were learning about science, not solely as a teacher of science, and as a member of the discursive community of science educators (Gee, 2014).

Gretchen believed she transformed her teacher identity (Gee, 2011) in ways that included becoming a researcher and innovator of relevant instructional strategies. She was challenged in multiple ways by the NB process, which included analyzing the videos of her work with students, as well as their written work, and examining her work with colleagues, families, and her community. In response to the self-reflective questions, she worked with colleagues (outside of her school context) and began self-questioning, read teacher blogs online, viewed videos of other teachers' work, and then determined how these ideas might increase her repertoire of teaching strategies. She eventually rejected the "sacred stories" (Olson and Craig, 2005) that caused her to self-position as an outlier when she was a novice teacher. Thus, Gretchen sought 
Journeys toward Reflective Practice: How Engaging in National Board Certification Influences Teacher Identities and Practices

membership in "a larger teaching community beyond her classroom walls" and used what she learned from others to develop practices that were more effective in reaching her students.

\section{The Development of Reflective Practices after the National Board Process}

"Being reflective for me is asking myself, do I ask the right questions? I never did that before the National Board process." While this was a response provided by Gretchen, all three participants reiterated this thinking at several points during the interview series. Text recorded and analyzed in narrative form yielded participant stories that asserted they improved their questioning practices based on knowledge of their students, which each of them identified as the most important outcome of engaging in the NB process. Therefore, the most prevalent outcome of NB certification for each was in the newfound use of open-ended questioning strategies employed with teacher-student, student-student, student-teacher exchanges. Queries that invited inquiries by students were also highly evident in the work (student-generated learning projects and problem based learning) these NBCTs designed.

Movement from reflexive teaching toward reflective practice evolved for each participant before, during, and after engaging in the National Board process. Consenting to participate in this research provided each of my participants the time and space to re-articulate, validate, and redefine the relationship between reflection and practice. Each verbal prompt became a dilemma as the participant paused, framed the question, and created a response using the prominent reflection strategies developed over their teaching careers. This narrative inquiry took place at the boundaries between my own narrative history and the inquiry I chose to conduct, examining the teaching lives of my participants before, during, and after NBC (Clandinin \& Connelly, 2000, p. 46). The boundaries that existed were explored safely due to our differences in specialization, 
Journeys toward Reflective Practice: How Engaging in National Board Certification Influences Teacher Identities and Practices

and the fact that the examination of practices was limited to particular teaching contexts.

However, learning to articulate one's thinking and to communicate complex thoughts were at the heart of this research, and narrative inquiry provided a space for my participants to tell stories of how they engaged in "reflection on action" (Schön, 1983) and developed as reflective practitioners. These spaces are important in learning to teach as according to Zeichner \& Liston (2014), "Without these conversations among and dialog between practitioners...our reflection will be severely limited" (p. 20).

Margaret continued using the reflective thinking strategies she learned during the NB process and after completion, framed her teaching problems in order to determine her course of action. As a mathematics teacher, she practiced talking students through the sequence of steps in problem solving. She continually asked her students to justify their mathematical reasoning, to explain why selected formulas applied to problem solving, and to communicate their mathematical evaluations to their peers. Margaret transferred this strategy to her own reflective work when she began thinking aloud to "reflect on action" (Schön, 1983). Her journal (Appendix C) was lengthy and somewhat difficult to decipher because it represented her thinking process and described her students' actions, some of which were logical and others which provided evidence that some students needed more support to help them successfully understanding/apply the mathematics concepts/strategies. Her journal made it apparent that she used open-ended questions and provided opportunities for her students to make choices about their work and that she continued to problematize her practices as her students responded to her teaching and learning tasks.

Margaret worked closely with her sister during their simultaneous periods of NB candidacy and the conversations in which they problematized their practices were important to 
Journeys toward Reflective Practice: How Engaging in National Board Certification Influences Teacher Identities and Practices

her growth. In using the plan to implement, reflect, and redesign the model without realizing they were doing so, they attempted to connect their practices to the evidence of student learning they collected. In making her thinking discernable to others, Margaret developed a habit of using the structure of language to articulate her cognitive process and when she talked about her work with students. This strategy was one method she used in framing her problems of practice. She would state, "step 1," then verbally talk students through the sequenced steps in problem solving, being verbose and explicit with many repetitions. This articulation helped her learn to describe procedures to her students, and perhaps more importantly it helped her categorize and label her thought patterns as she created the running dialogue. Margaret and her sister (NBCT) still meet regularly to talk about teaching. In this NBCT sister partnership, they frame, examine, and attempt to solve the dilemmas of their classroom practices (Zeichner \& Liston, 1996, 2014). Furthermore, Margaret's use “direct speech acts” to demonstrate significance, practices, identities, relationships, politics, connections, and sign systems and knowledge (Gee, 2011), and her use of connections and relationships appeared to guide her teaching/learning partnership with her sister as Margaret continued to use her familial experiences and connections to inform her teaching.

In Ethan's assessment, his reflective capacity developed when he had to write answers to NB portfolio prompts and this task was initially extremely difficult. During the NB process, he adopted the habit of framing problems when he tried to determine why his students were not successful. Reflection on action (Schön, 1983) became his mode for solving his problems of practice. This took time and he was willing to devote many after school hours to framing problems, attempting solutions, and analyzing the results. Ethan believed that reflection on action evolved into his ability to use reflection in action. He characterized this as slowing down 
Journeys toward Reflective Practice: How Engaging in National Board Certification Influences Teacher Identities and Practices

his class periods and asking open-ended questions to support student problem solving while providing effective resources to support their inquiries. Ethan has now adopted practices in which his goal is to make student thinking visible (Ritchhart, Church, \& Morrison, 2011). His dynamic role as facilitator of learning and in promoting the active engagement of his students in learning were apparent when we co-viewed video of current practices.

Gretchen's current level of intellectual presence is closely aligned with her identity and might be termed mindful (Dweck, 2007). Gretchen indicated that she deliberately worked to understand her own work by framing and reframing her practices (Schön, 1983) to seek better ways to facilitate student learning. As she provided a coda for her discussion about framing learning problems, she expressed that she developed this strategy using individualized analysis of each student when she produced Entry 1 in her NB portfolio. She purposively provided herself the space to experiment with her teaching strategies with one individual student (Entry 1), repeatedly watched and analyzed the videotaped segments (Entries 2 and 3), and then began to critically view her students at work. She was able to reflect on action (Schön, 1983) and developed skill using intentional consciousness and mindfulness. As Gretchen learned to focus intently "in the moment" while teaching, this ability heightened her awareness of how to facilitate student learning. Gretchen averred that reflection on her actions, when she was a NB candidate, supported her growth so she could eventually "reflect in action" (Schön, 1983); thus she continued to develop as a reflective practitioner and this prevented her from becoming complacent after she certified. Gretchen positioned herself as an NBCT with proactive tendencies, as a researcher seeking novel ways to connect information, and as an adaptive student-centered teacher who collaborates with colleagues to design innovative instruction. In her ultimate outcome, she moved from believing she was an outlier in her English department to 
Journeys toward Reflective Practice: How Engaging in National Board Certification Influences Teacher Identities and Practices

a role of teacher-leader. Gretchen's later interviews described her transformational learning, which according to Drago-Severson, (2004) alters "how a person knows... adults undergo a development and profound change in the way they construct or make sense of experience. Her development from "informational learner" to "transformational learner" (p.25) indicated that Gretchen's teaching and learning contexts exerted a long-term effect on the ways she positioned herself as a teacher and teacher identity she was constructing (Gee, 2014).

Each participant struggled with the production of NB portfolio Entry 1, which required in depth analysis of the causes and effects of personalized instruction on academic achievement toward personalized learning goals with individual students. The design of the West Virginia Teacher Evaluation System (WVTES) adopted this profile of assessing student learning using the student's zone of proximal development (Vygotsky, 1983) and embedded this concept as a subsection of teacher self-evaluation. In analysis of her responses, it appeared that Gretchen was uninformed and did not realize the similarity between her NB work of assessing an individual students and designing instruction and that met his/her learning needs to her teacher role as defined by WVTES process work. In the WVTES roll out, administrators were positioned as partial evaluators for WVTES, while the NB process was couched in self-reflective evaluation. It seemed neither administrators nor teachers in her school understood the high expectations, which when combined with identification of evidence, outlined novice, emergent, accomplished, or distinguished practices embedded in the WVTES design. Nor did personnel in her school embrace the self-fulfilling prophecy aspects of the stages of expected teacher growth when the WVTES teacher self-rating scale was implemented. WVTES was explicit in moving the teacher from novice, toward emerging, to accomplished, with distinguished as its highest rating. It was designed to provide exemplars of practice so that a teacher might gradually grow to produce 
Journeys toward Reflective Practice: How Engaging in National Board Certification Influences Teacher Identities and Practices

work similar to the practices modeled by its rubric. This also to enabled teachers to adopt its language in much the same way as NBPTS expected candidates to take responsibility for their own beliefs when personalizing NB standards.

Conversely, Margaret and Ethan both held deeper understandings of WVTES and recognized its alignment with NBPTS. In their self-evaluation each year, both felt they had achieved and maintained distinguished status and were able to provide evidence of such. In their PLC relationships with colleagues, it seemed important to center their conversations on knowledge of students first and then to align their pedagogy with this knowledge. This focus appeared to be much more connected to being a NBCT than to the private conversation between teacher and principal in determining the validity of the teacher evidence of his/her rating in WVTES, as the rating system had no outward or visible benefits in their view.

Each participant was clear in stating how his/her professional growth over the course of his or her teaching career was related to many forces. Furthermore, they all connected their current reflective practice to PLC work (DuFour, DuFour, Eaker, \& Karanek, 2004). Verbalizing their reflective practice processes with colleagues compelled each to maintain a private self-analysis, which was articulated as appropriate, during PLC meetings. This tendency was universal to all participants as was their concern that not enough time was allotted by school administrators to achieve the goals of PLC work (Zeichner \& Liston, 2014). Interestingly, not one noted colleagues in the school context as important to his or her professional growth until after the NB process experience was completed. Participants expressed the collegial conversations and collaboration during Professional Learning Community (PLC) meetings were of importance in their continued development of classroom expertise after the process. It may be that teaching within a specific discipline may foster higher levels of teacher collaboration, as teachers share 
Journeys toward Reflective Practice: How Engaging in National Board Certification Influences Teacher Identities and Practices

specific content and pedagogical knowledge. Gretchen felt highly supported by her PLC and was enthusiastic in her assessment of their collaborative work. Both Ethan and Margaret are now Department Chair/Team Leaders in their school PLC work.

Time constraints were stressed and proved to be confounding at many levels. Margaret, Ethan, and Gretchen suggested that school structures did not allow suitable blocks of time to reflect on student learning, design instruction, implement, and reflect on action to determine next steps for student learning. All three teachers asserted they were required to be on school sites for forty hours per week, yet each averaged fifty-sixty hours of "on task teacher time" each week. The implications for school structures may indicate that these teachers felt the educational bureaucracy, school budgets, and subsequently their administrators did not respect their needs for time to reflect both in solitude and with colleagues, design instruction after analyzing and reflecting on their practices, provide personalized professional development, and position themselves as teacher-leaders who could effectively lead customized professional development entrenched in knowledge of students and context with their colleagues.

Context was a consistent influencing factor as their traditional teacher driven methods evolved into student-centered practices. It was an important factor for each to realize that knowledge of students was considered by NBPTS to be the driving determinant of teaching strategies and each was silent about the potential KOS barriers that may have included consideration of student race, social class background, and ethnicity. NBPTS makes it clear that these factors are to be considered if, and only if, teaching strategies are altered due to these factors. Participant silences on the potential issues of these influences may have been related to their understandings (emphasis added) of the NBPTS precepts of knowledge of students. Each participant believed context was an inhibiting factor, yet each overcame these influences in order 
Journeys toward Reflective Practice: How Engaging in National Board Certification Influences Teacher Identities and Practices

to learn teaching techniques through collaboration with colleagues or learning from their students, their families, and their communities. Through this "collective generation [and transmission] of meaning” (Crotty, 2010, p. 58) Margaret's, Ethan's, and Gretchen's understanding of the significance of their teaching experience(s) in their respective school contexts, and the ways in which they would make use of those understandings to become 'better' teachers for their students, was always evolving.

Teachers appeared to learn during their teaching careers by becoming more fully engaged in the teaching and learning process as evidenced by the questions they asked about practice. Novice teachers wondered, "What should I do?" However, as these teachers became more reflective they began to ask: "What can I design to help my students learn?" "What are my students doing while they learn?' and "How do my students think and make their learning known to others?" The answers my participants discovered to these questions guided their thinking about supporting the growing academic needs of the students they served. These questions came about while each struggled to answer the prompts embedded in the NB process. This might be exemplified by Ethan's realization that his students approached thinking and learning tasks in ways that were highly dissimilar to his own thinking and learning methods. "Ways of knowing" (Drago-Severson, 2004) were unique to the individual and acknowledging and addressing this concept was enlightening for each participant.

The contexts in which these teachers practiced influenced their thinking about the evolution of their teaching practices and identities. These influences included, but were not limited to, their collegial teaching relationships, administrative influence, policy, and their study of how diverse students learn. The process of engaging in NB Certification provided no assurance that the strategies teachers used to reflect, as required by NB work, would became 
Journeys toward Reflective Practice: How Engaging in National Board Certification Influences Teacher Identities and Practices

embedded in their work. However, each participant claimed he/she maintained self-questioning practices. Margaret's, Ethan's, and Gretchen's continued reflection was evident in their responses to interview prompts, albeit they felt reflection functioned for them at a different level during the interviews than when students were present. Each believed including open-ended queries and problem based learning had a positive impact on the learning of their students and felt this was the most powerful influence that developed as a result of becoming NB certified.

\section{Present Influences of the National Board Process on the Continuous Learning Cycle}

While the NB context each of my participants experienced as candidates challenged their thinking about teaching as they struggled to produce evidence of NB Standards in their work with students, it also supported their growth as reflective practitioners and contributed to the transformation of their teacher identities. In this instance, "support," which is derived from Latin, "supportare" which means "to transport," might be defined as to "advocate," or to "provide a foundation for." In fact, as my participants shared narratives of their lived experiences, each asserted that the process of engaging in NBC transported him/her from one phase of teaching and learning to another, and each believed this new phase was marked by increased use or attempts to use reflective practice as a means to inform all aspects of their teaching.

There is no assurance the strategies teachers used to reflect when they were required to write about their reflective thinking during NB process work became embedded in their work. However, it seemed that these three participants maintained self-questioning practices and continued to reflect when designing student work because they believed including open-ended queries and problem based learning had a positive impact on the learning of their students. Each reiterated their intention to continually assess and understand student learning by asking students 
Journeys toward Reflective Practice: How Engaging in National Board Certification Influences Teacher Identities and Practices

to describe their own thinking through ongoing interactive dialogue and by assigning a menu of student work products.

Furthermore, each participant expressed frustration with reaching students, especially early in their teaching careers. Their adherence to the "sacred stories" (Olson \& Craig, 2005) of their schools during their early days in the classroom faded when the pragmatic questions they asked about their practice commingled with deeper thinking about teaching. In time, deeper thinking about how children learn became their priority. It seemed that a focus on noticing how some students blossomed while others withdrew from learning processes, either subtly or overtly, caused each of my participants to take responsibility for the consequences of his/her teaching actions and to question how he/she designed and carried out instruction and how their teaching and learning tasks might be changed to better meet the needs of his/her specific students. In working to understand human learning behavior, these teachers came to learn that "the unique and uncertain situation comes to be understood through the attempt to change it, and changed (emphasis added) by the attempt to understand it" (Schön, 1983, p.132). As my participants attempted to solve these problems of practice they reached out to peers, principals, the families of the students, and sought information via books, websites, videos, teacher blogs, and multiple other print sources. Their implementation of new pedagogies, learning tasks, and informal assessments became a series of orientations for problematizing their circumstances and resolving the complicating actions that needed to be addressed. As they evaluated the resolutions they adopted in their teaching, their reflection on/in action continued to dominate their thinking and the professional conversations in which they engaged as they problematized the difficulties that arose daily. 
Journeys toward Reflective Practice: How Engaging in National Board Certification Influences Teacher Identities and Practices

As each of these teachers framed and reframed their dilemmas of practice and understood what was happening in their classrooms through multiple perspectives, they came to realize that students work harder for teachers with whom they have positive relationships. This understanding of how students value learning differently than adults and of their variance in levels of impulse and reasoning led to their use of more authentic questions and a variety of options for learning tasks and formative and summative assessments, as well as methods for learning. All of my participants learned to teach by teaching as they dealt with constructing situated understandings of teaching and learning in their classrooms and schools, removing the barriers that complicated learning processes, and evaluating what worked or failed in order to ensure that all students met their high expectations for learning. The consensus was learning about teaching could never cease. Each participant was positive that his/her teaching practices will continue to improve and professional growth was "always a work in progress."

\section{Implications for School Leadership and Future Research}

Over a period of less than two decades, two dissimilar forces were at work in the US educational system. First, the former No Child Left Behind Act (2001) undermined the education of our students by imposing artificial frequent assessments to meet government mandates. Secondly, the initiation of the National Board for Professional Teaching Standards (1987) was largely due to the widening achievement gap evidenced during longitudinal studies conducted by the Carnegie Foundation and published in 1986. The mission of the National Board provided specific suggestions for professionalizing the teaching workforce by creating standards in teaching, which in turn were presumed to lead to improved student learning outcomes. As the number of NBCTs grew on a national level, more teachers were exposed to or adopted reflective 
Journeys toward Reflective Practice: How Engaging in National Board Certification Influences Teacher Identities and Practices

practices and many successfully built instructional practices with the plan, implement, reflect and redesign model embedded in the NB process (Darling-Hammond, Wei, Andree, Richardson \& Orphanos, 2009). Thus the NB intention for providing authentic student learning in individual classrooms was aligned with an attempt to close the achievement gap (Coleman, 1990;

Goldhaber \& Anthony, 2004).

NBPTS intertwined depth of content knowledge (DOK) with knowledge of students (KOS) as the standard to be attained when achieving NB Certification. While the implication that a single teacher can be the expert content tutor for every child in his/her classroom was misleading; the idea that reflection enabled teachers to mitigate problems by framing and reframing practices held promise. These two premises were intertwined in the work required by the NB process.

Educational systems were also facing new challenges over these two decades in West Virginia and nationally, as the demographic representation of our student body (49\% non-white) and our teachers (82\% white) (National Center for Educational Statistics, 2014) was not aligned. There was little likelihood that this distorted ratio might be brought into line in the future (Deruy, 2016). While teachers sought knowledge of students, the KOS they sought to ascertain was often unavailable because students and their families refused to make their lives transparent or what students and families chose to share might have been misunderstood. Teachers (whose backgrounds were shaped by life circumstances) may not be able to fully embrace the knowledge of a single student (who may have had a highly dissimilar life experience) and use this knowledge to support the student's academic, social, and emotional growth. This was a compelling reason the work of all teachers must be tempered with the concerns for equity, access, and fairness for students of all races, social class backgrounds, and ethnicities. In the 
Journeys toward Reflective Practice: How Engaging in National Board Certification Influences Teacher Identities and Practices

future, school leaders might consider how the disparate cultural history of teachers and students impacts the teaching practices and values in these contexts and work to ameliorate the ways this disparity may diminish the likelihood of equity, access, and fairness for learning by all students. Emphasis on creating pathways for culturally diverse future educators will continue to be of concern as our knowledge of the growing diversity of our students depends on constructing understandings of their actual, not perceived or externally measured, educational needs. This is necessarily an area for further consideration and research.

Throughout all of the interview series, participants repeatedly expressed views that fell just short of censure for many, but not all, of their school administrators. Interestingly, considering the NB emphasis on supportive two-way relationships at all levels in school systems, there was a perceived lack of overt support directed toward these three national board certified teachers by their administrators. This may be one of the strongest disconnects revealed through these interviews and this perception may impede these situated school communities from optimal functioning. Schön (1983) noted that individuals in a bureaucratic system generally operated within the accepted behavioral norms of the system. The organization systems tended to be social which in turn "determine(s) the boundaries and directions of organizational inquiry, they are learning systems... (and) may severely constrain organizational learning” (p. 328). This was highly relevant to the larger context of education and the ways in which these participants situated themselves in their educational organizations. It may be teacher learning, independence, and innovations posed a threat to the continued acceptance of the "sacred stories" of some school environments (Clandidin \& Connelly, 2000). There was evidence that each participant believed others within the system constrained, resisted, were slow as they initially embraced, and then finally grew to respect the participant's innovative teaching practices after the NB process. All 
Journeys toward Reflective Practice: How Engaging in National Board Certification Influences Teacher Identities and Practices

three expressed, after being recognized and respected as an NBCT, this status allowed for the likelihood of access to academic freedom in their classroom practices. This freedom then provided them with opportunities to design instruction based on worthy student learning goals and also positioned them as leaders at the PLC level.

Creating time and space for all teachers to construct and engage in reflective strategies that are focused on "the learning needs of these students at this time" (NBPTS) may be the most salient implication noted. The challenge and resolution may lie in establishing teaching conditions that support teacher reflection and time for developing understandings of the unique student so each student may be supported to flourish and grow. Educators at all levels may do well to pause, reflect, and reconsider the how the structures of public school might be changed so that teachers have the spaces they need to learn to teach in ways that ensure all students receive an equitable education.

Given the teaching conditions of this time period, each participant looked back and considered whether educational systems functioned in support of teacher quality development over his/her career. NCLB (2001) was eradicated and the Every Student Succeeds Act (2015) will unfold and influence the acquisition of learning for both students and their teachers in ways as yet unknown. The West Virginia educational system, according to these research participants, did not support their professional learning at the outset of their careers so each participant went outside the educational system to seek personalized professional learning by declaring candidacy in the context of National Board Certification. Dr. Martirano (2016), Superintendent of WVDE, recently revised the structure and focus of teacher professional development in West Virginia School systems and authorized teacher professional learning to be site chosen and developed, rather than using the top down model that has often driven teacher professional development. 
Journeys toward Reflective Practice: How Engaging in National Board Certification Influences Teacher Identities and Practices

Therefore, further studies of teachers as learners and their evolution from novice to distinguished practitioners across all teaching disciplines may be indicated and connected with research specifically designed to define and build innovative system-based supports for teacher learning. 
Journeys toward Reflective Practice: How Engaging in National Board Certification Influences Teacher Identities and Practices

\section{References}

Allen, J. (2007). Creating welcoming schools. New York: Teachers College Press.

Argyris, C. \& Schön, D. (1974) Theory in practice: increasing professional effectiveness. San Francisco: Jossey-Bass.

Auerbach, C., \& Silverstein, L. (2003). Qualitative data: an introduction to coding and analysis. New York: New York University Press.

Berliner, D. \& Biddle, B. (1995) The manufactured crisis: myths, fraud, and the attack on america's public schools. Teachers College Record. http://www.tcrecord.org ID Number 1714

Boleman, L. \& Deal, T. (1997). Reframing organizations: artistry, choice, and leadership. (2 ${ }^{\text {nd }}$ Ed.). San Francisco: Jossey-Bass.

Boleman, L. \& Deal, T. (2006). The wizard and the warrior: leading with passion and power. San Francisco: Jossey-Bass.

Bransford, J., Brown, A., Anderson, J., Gelman, R., Glaser, R., Greenough, W., Ladson-Billings, G., Means, B., Mestre, J., Nathan, L., Pea, R., Peterson, P., Rogoff, B., Romberg, T., \& Wineburg, S. (2000). How people learn: brain, mind, experience, and school. Washington: National Academy Press.

Bransford, J., \& Darling-Hammond, L. (2005). Preparing teachers for a changing world: what teachers should learn and be able to do. San Francisco: Jossey-Bass.

Brookfield, S. (1995). Becoming a critically reflective teacher. San Francisco: Jossey-Bass.

Bryk, A., \& Schneider, B. (2002). Trust in schools: a core resource for improvement. New York: Russell Sage.

Bryk, A., Sebring, P., Allensworth, E., Luppescu, S., \& Easton, J. (2010). Organizing schools for improvement: lessons from Chicago. Chicago: University of Chicago Press.

Bush, G. (2001). The no child left behind act. Retrieved June 2, 2014 from http://www2.ed.gov/nclb/overview/intro/execsumm.html

Bybee, R. (1997). The sputnik era: why is this educational reform different from all other reforms? Retrieved June 2, 2014, from National Academy of Sciences Web Site: http://www.nas.edu/sputnik/bybee2.htm.

Cantrell, S., Fullerton, J., Kane, T., \& Staiger, D. (2008). National board certification and teacher effectiveness: evidence from a random assignment experiment, retrieved February 
Journeys toward Reflective Practice: How Engaging in National Board Certification Influences Teacher Identities and Practices

26, 2015 from http://cepr.harvard .edu/cepr-resources/files/news-events/ncte-nationalboard-certification--cantrell-fullerton-kane-staiger.pdf.

Carey, B. (2014). How we learn. New York: Random House.

Carnegie Forum on Education and the Economy's Task Force on Teaching as a Profession, (1986, May). A nation prepared: teachers for the 21st century: the report of the task force on teaching as a profession. New York, NY.

IES Cited: ED359220.

Clandinin, D. (2013). Engaging in narrative inquiry. Walnut Creek: Left Coast Press.

Clandinin, D. \& Connelly, F. (2000). Narrative inquiry: experience and story in qualitative research. San Francisco: Jossey-Bass.

Cochran-Smith, M. \& Lytle, S. (2010). Relationships of knowledge in practice: teacher learning communities. Research and Review in Education, 24 (1999), 249-305.

Coles, R. (1989). The call of stories: teaching and moral imagination. Boston: Houghton Mifflin.

Collins, A., Bybee, R., Worth, K., Champayne, A., \& Pratt, H. National science education standards. Washington: National Academy Press.

Collins, J. (2001). Good to great. New York: HarperCollins.

Costa, A. \& Garmston, R. (2002). Cognitive coaching: a foundation for renaissance schools. Norwood: Christopher Gordon.

Craig, C. \& Olson, M. (2005). Uncovering cover stories: tensions and entailments in the development of teacher knowledge. Ontario Institute for Studies in Education, 35 (2), 161-182.

Crotty, M. (2010). The foundations of social research: meaning and perspective in the research process. Thousand Oaks: Sage.

Creswell, J. (1998). Qualitative inquiry and research design: choosing among the five traditions. Thousand Oaks: Sage.

Czikszentmihalyi, M. (1990). Flow: the psychology of optimal experience. New York: HarperCollins.

Danielson, C. (2007). Enhancing professional practice: a framework for teaching. Alexandria: Association for Supervision and Curriculum Development. 
Journeys toward Reflective Practice: How Engaging in National Board Certification Influences Teacher Identities and Practices

Danielson, L. (2009). How teachers learn. Association for Curriculum and Development, Volume 66, Issue 5, pp. 1-5.

Darling-Hammond, L. (1998). Strengthening the teaching profession. Education Leadership, Volume 55, Issue 5, pp. 6-11.

Darling-Hammond, L, Bransford, J., LePage, P., Hammerness, K., \& Duffy, H. (2005). Preparing teachers for a changing world: what teachers should know, understand, and be able to do. San Francisco: Jossey-Bass.

Darling-Hammond, L. (2010). The flat world and education: how America's commitment to equity will determine our future. New York: Teachers College Press.

Darling-Hammond, L., Wei, R., Andree, A., Richardson, N., \& Orphanos, S. (2009, February). Professional learning in the learning profession: a status report on teacher development in the United States and abroad, National Staff Development Council and The School Redesign Network at Stanford University.

Deci, E. (1995). Why we do what we do. New York: Penguin.

Deruy, E., Student Diversity is Up, But Teachers are Mostly White, American Association College Teachers in Education. https://aacte.org/news-room/aacte-in-the-news/347student-diversity-is-up-but-teachers-are-mostly-white 18 March 2016

Dewey, J. (1910). How we think. Boston: D.C. Heath \& Co.

Dewey, J. (1925). Experience and nature. Peru: Open Court.

Dewey, J. (1938). Experience and education. New York: Simon \& Shuster.

Diaz-Maggioloi. G. (2004). Teacher-centered professional development. Alexandria: Association for Supervision and Curriculum Development.

Drago-Severson, E. (2004). Helping teachers learn: principal leadership for adult growth and development. Thousand Oaks: Sage.

DuFour, R., DuFour, R., Eaker, R., \& Karanek, G. (2004). Whatever it takes: How professional learning communities respond when kids don't learn. Bloomington: Solution Tree.

Dweck, C. (2006). Mindset: the new psychology of success. New York: Random House.

Ermeling, B. (2012). Improving teaching through continuous learning: the inquiry process john wooden used to become coach of the century. National Association for Kinesiology in Higher Education Quest, 64, 197-208. 
Journeys toward Reflective Practice: How Engaging in National Board Certification Influences Teacher Identities and Practices

Etschidt, S., Curran, C., \& Sawyer, C. (2011). Promoting reflection in teacher preparation programs: a multilevel model. Teacher Education and Special Education: The Journal of the Teacher Education Division for the Council for Exceptional Children, Volume 35, Issue 7, p.7-26, DOI 10.1177/088840641120887.

Fairclough, N. (2003). Analyzing discourse: textual analysis for social research. New York: Routledge.

Feiman-Nemser, S. (2001). From preparation to practice: designing a continuum to strengthen and sustain teaching. Teachers College Record, 103 (6) 1013-1055.

Feire, P. (1972a). Pedagogy of the oppressed. Harmondsworth: Penguin Press.

Fox, J. (2008). Your child's strengths. New York: Penguin.

Fox, M. (1993). Radical reflections. Orlando: Harcourt Brace.

Fullan, M. (2001). Leading in a culture of change. San Francisco: Jossey-Bass.

Garber, S. (2007). Sputnik and the dawn of the space age. Retrieved June 2, 2014 from National Aeronautics Space Association History Homepage: http://history.nasa.gov/sputnik/.

Gardner, H. (2008). Five minds for the future. Boston: Harvard Press.

Gardner, J., Raffi,R., Robinson, K., Breithecker, D., Sarate, L., Suzuki, D., Cooper, A., Calegari. N., \& Dyson, J. (2010). The third teacher. New York: Abrams.

Gay, G. (2000). Culturally responsive teaching: theory, research, and practice. New York: Teachers College Press.

Gay,L., Mills, G., \& Airasian, P. (2009). Educational research: competencies for analysis and applications. London: Pearson.

Gee, J. (1999). An introduction to discourse analysis: theory and method (2 ${ }^{\text {nd }}$ Ed.). Cornwall: MPG Books, Ltd.

Gee, J. (2001). Identity as an analytic lens for research in education. American Education Research Association, v25 p 99-125.

Gee, J. (2011). How to do discourse analysis: theory and method ( $3^{\text {rd }}$ Ed.). New York: Routledge.

Gee, J. (2014). How to do discourse analysis: a toolkit (2 ${ }^{\text {nd }}$ Ed.). New York: Routledge.

Glesne, C. (2003). Becoming qualitative researchers. New York: New York University Press. 
Journeys toward Reflective Practice: How Engaging in National Board Certification Influences Teacher Identities and Practices

Gramling, M. (2015). The great disconnect. St. Paul: Redleaf.

Greenwald, R., Hedges, L., \& Haine, R. (1996). The effect of school resources on student achievement, Review of Educational Research, v66 n3 p361-96 Fall 1996, ISSN-00346543.

Grushka, K., Hinde McLeod, J., \& Reynolds, R. (2005). Reflecting upon reflection: theory and practice in one Australian University teacher education program. Reflective Practice, 6 (2), 239-246.

Hatton, N., \& Smith, D. (1995). Reflection in teacher education: towards definition and implementation, Teaching \& Teacher Education, 11(1), 33-49.

Hickman, L., \& Alexander, T. (1998). The essential Dewey: volume 1 pragmatism, education, democracy. Bloomington: Indiana University Press.

Holstein, J., \& Gubrium, J. (2012). Varieties of narrative analysis. Thousand Oaks: Sage.

Hoy, W., \& Miskel, C. (2005). Educational administration: theory, research, and practice. New York: McGraw Hill.

Hunzicker, J. (2006). The leverage of national board candidacy. Boca Raton: Universal.

Hsieh, H., \& Shannon, S. (2011). Three approaches to qualitative content analysis. Sage, 2005(15), 1277-1288. Doi: 10.1177/1049732305276687

Ingersoll, R. (2003). Who controls teachers' work: power and accountability in America's schools. Cambridge: Harvard University Press.

Jensen, E. (2013). Engaging students with poverty in mind: practical strategies for raising achievement. Alexandria: Association for Supervision and Curriculum Development.

Kozulin, A. (1987). Thought and language. Cambridge: MIT Press.

Krathwohl, D. (2009). Methods of educational and social science research. ( $3^{\text {rd }}$ Ed.). Long Grove: Waveland.

Kleinhenz, E., \& Ingvarson, L. (2007). Standards for teaching: theoretical underpinnings and applications. Retrieved December 3, 2014 from Australian Council for Educational Research Homepage: http://reseach.acer.edu.au/teaching_standards/1.

Kouzes, J. \& Pozner, B. (2002). The leadership challenge. ( ${ }^{\text {rd }}$ Ed.) San Francisco: Jossey-Bass.

Kouzes, J., \& Posner, B. (2010). The truth about leadership. San Francisco: Jossey-Bass. 
Journeys toward Reflective Practice: How Engaging in National Board Certification Influences Teacher Identities and Practices

Kvale, S., \& Brinkman, S. (2009). Interviews: learning the craft of qualitative research interviewing. Thousand Oaks: Sage.

Lake, R. (2012) Vygotsky on education. New York: Peter Lang.

Lawrence-Lightfoot, S. (2003). The essential conversation: what parents and teachers can learn from each other. Toronto: Ballentine.

Lichtman, M. (2010). Understanding and evaluating qualitative educational research. Thousand Oaks: Sage.

Litky, D, \& Grabelle, S. (2004) The big picture: education is everyone's business. Alexandria: Association for Supervision and Curriculum Development.

Love, P., \& Guthrie, V. (2002). Kegan's orders of consciousness, New Directions for Student Services, Volume 1999, Issue 88, pp. 65-76, DOI 10.10021ss.8806.

Margolis, J. (2004). A response to "the national board hoax." Teachers College Record, http://www.tcrecord.org ID Number:11277

Marshall, C. \& Rossman, G. (1995). Designing qualitative research ( $2^{\text {nd }}$ Ed.). Thousand Oaks: Sage.

Martirano, M. "The Learning School Initiative" West Virginia Department of Education. http://static.k12.wv.us/superintendent/doc/learninginitiative.pdf Web. 20 November 2015

Marzano, R. (2003). What works in schools: translating research into action. Alexandria: Association for Supervision and Curriculum Development.

Marzano,R., Waters, T., \& McNulty, B. (2005). School leadership that works: from research to results. Alexandria: Association for Supervision and Curriculum Development.

Maxwell, J. (1998). The 21 irrefutable laws of leadership: follow them and people will follow you. Nashville: Thomas Nelson.

Miles, M., \& Huberman, A. (1994). Qualitative data analysis: an expanded sourcebook. Thousand Oaks: Sage.

Miles, M., Huberman, A., \& Saldana, J. (2014). Qualitative data analysis: a methods sourcebook (3rd Ed.). Thousand Oaks: Sage.

Milken Foundation. (n.d.) Milken educator awards. Retrieved from http://milkeneducator awards.org/connections.

Merriam-Webster's collegiate dictionary. (11 ${ }^{\text {th }}$ ed.). (2014). Springfield, MA: Merriam-Webster 
Journeys toward Reflective Practice: How Engaging in National Board Certification Influences Teacher Identities and Practices

Mitra, D. \& Halabi, S. (2012). Paradoxes in policy practice: signaling postsecondary pathways in the rust belt. Teachers College Record. 114 (1) 1-34, http://www.tcrecord. Org ID Number 16210

Mooney, C. (2000). Theories of childhood: an introduction to Dewey, Montessori, Erikson, Piaget, \& Vygotsky. St. Paul: Redleaf.

Murphy, J. (2005). Connecting teacher leadership and school improvement. Thousand Oaks: Sage.

National Center for Educational Statistics. Teacher trends. http://nces.ed.gov/fastfacts/display.asp?id=28 2014 Web. 18 March 2016

National Council of Teachers of Mathematics. (2000). Principles and standards for school mathematics. Reston: The National Council for Teachers of Mathematics.

National Science Foundation. (2003, July). Scientific foundations of qualitative research. Retrieved from http://www.nsf.gov/pubs/2004/nsf04219/nsf04219.pdf.

Oner, D., \& Adadan, E. (2011). Use of web based portfolios as tools for reflection in pre-service teacher education. Journal of Teacher Education, Volume 62, Issue 5, 477-492, DOI: 10.1177/0022487111416123.

Patton, M. (1990). Qualitative education evaluation and research methods ( $2^{\text {nd }}$ Ed.). Newbury Park, CA: Sage.

Patton, M. (2001). Qualitative research and evaluation methods. Thousand Oaks: Sage.

Patton, M. (2002). Qualitative education evaluation and research methods $\left(3^{\text {rd }}\right.$ Ed.). Thousand Oaks: Sage.

Peterson, K., \& Deal, T. (2009). The shaping school culture fieldbook. (2 ${ }^{\text {nd }}$ Ed.). San Francisco: Jossey-Bass.

Phillips, D. (1992). Lincoln on leadership. New York: Warner.

Pink, D. (2009). Drive: the surprising truth about what motivates us. New York: Penguin Group.

Pintrich, P., de Groot, E. (1990). Motivational and self-regulated learning components of classroom academic performance. Journal of Educational Psychology, Volume 82, Issue 1, pp. 33-40, DOI 10.1037/0022-0663.82.1.33.

Pitsoe, V.J., \& Maila, W. (2012) Towards constructivist teacher professional development. Journal of Social Sciences, 8(3), 318-324. Naham: Rowman \& Littlefield. 
Journeys toward Reflective Practice: How Engaging in National Board Certification Influences Teacher Identities and Practices

Pollock, J. (2007). Improving student learning one teacher at a time. Alexandria: Association for Supervision and Curriculum Development.

Pultorak, E. (2010). The purposes, practices, and professionalism of teacher reflectivity: insights fro twenty-first-century teachers and students.

Ravitch, D. (2010). The death and life of the great American school system. New York: Basic.

Ravitch, D. (2013). Reign of error. New York: Random House.

Reagan, T., Case, C., \& Brubacher, J. (2000). Becoming a reflective educator: how to build a culture of inquiry in the schools $\left(2^{\text {nd }}\right.$ Ed.). Thousand Oaks: Sage.

Ritchhart, R., Church, M., \& Morrison, K. (2011). Making thinking visible. San Francisco: Jossey-Bass.

Rodriguez, V., \& Fitzpatrick, M. (2014). The teaching brain. New York: The New Press.

Roenthal, R, \& Jacobson, L. (1992). Pygmalion in the classroom: teacher expectations and pupils' intellectual development. Bethel: Crown House.

Saldana, J. (2012). The coding manual for qualitative researchers. ( $2^{\text {nd }}$ Ed.). Thousand Oaks: Sage.

Scales, P. (2013). Teaching in the lifelong learning sector. ( $2^{\text {nd }}$ Ed.). Berkshire, England: Oxford University Press.

Schein, E. (2004). Organizational culture and leadership. ( ${ }^{\text {rd }}$ Ed.). San Francisco: Jossey-Bass.

Schein, E. (2009). Helping. San Francisco: Berrett-Koehler.

Schön, D. (1983). The reflective practitioner: how professionals think in action. New York: Basic.

Schön, D. (1987). Educating the reflective practitioner: toward a new design for teaching and learning in the professions. San Francisco: Jossey-Bass.

Schön, D., \& Rein, M. (1994). Frame reflection: toward a resolution of intractable policy controversies. New York: Basic.

Schneider, D., Adler, S., Beery, R., Ladson-Billings, G., Fernekes, W., Hartoonian, M., McFarland, M., Marker, G., Montgomery, M., Nickell, P., \& Tevis, C. (2002). Curriculum standards for social studies: national council for the social studies. ( $5^{\text {th }} \mathrm{Ed}$.). Silver Springs: National Council of Social Studies.

Schwandt, T. (2014). The sage dictionary of qualitative inquiry. Thousand Oaks: Sage. 
Journeys toward Reflective Practice: How Engaging in National Board Certification Influences Teacher Identities and Practices

Seban, D. (2009). Researching reflective practices of elementary pre-service teacher: twodimensional analysis of teacher narratives. Reflective Practice, 10(5), 669-681.

Seidman, I. (2006). Interviewing as qualitative research. ( $3^{\text {rd }}$ Ed.). New York: Teachers College Press.

Seidman, I. (2013). Interviewing as qualitative research. ( $4^{\text {th }}$ Ed.). New York: Teachers College Press.

Seligman, M. (2011). Flourish. New York: Simon and Schuster.

Sergiovanni, T. (1994). Building community in schools. San Francisco: Jossey-Bass.

Sergiovanni, T. (2005). Strengthening the heartbeat. San Francisco: Jossey-Bass.

Shafritz, J., Ott, S., \& Jang, Y. (2005). Classics of organizational theory. Belmont: Wadsworth.

Smith, L. (2008). Schools that change: evidence based-improvement and effective change leadership. Thousand Oaks: Corwin Press.

Sprenger, M. (1999). Learning and memory: the brain in action. Alexandria: Association for Supervision and Curriculum Development.

Soltis, J. (1984). On the nature of educational research. Educational Researcher. 13 (10), 6-7.

Sowell, T. (1996). Knowledge and decisions. New York: Basic.

Standards for the English Language Arts. (1996). Urbana: National Council for Teachers of English.

Szpara, M. \& Wylie, C. (2005). National board for professional teaching standards assessor training: impact of bias reduction exercises. Teachers College Record. 107 (4), 803-841.

Tallmadge, J. (1997). Meeting the tree of life: a teacher's path. Salt Lake City: University of Utah Press.

Thirunarayan, M. (2004). National board certification for teachers: a billion dollar hoax. Teachers College Record. http://www.tcrecord.org ID Number : 11266

Tough, P. (2013). How children succeed. New York: First Mariner Books.

United States Department of Education. (2015). Every student succeeds act. Retrieved 16 March 2016 from http://www.ed.gov/essa? src=rn

Vilson, J. (2014). This is not a test. Chicago: Haymarket. 
Journeys toward Reflective Practice: How Engaging in National Board Certification Influences Teacher Identities and Practices

Vygotskii, L., (1934). Myshlenie i rech. [Thought and language]. MIT: Halliday.

Walsh, J., \& Sattes, B. (2011). Thinking through quality questioning: deepening student engagement. Thousand Oaks: Sage.

Webster, L. \& Mertova, P. (2007). Using narrative inquiry as a research method. New York: Routledge.

Weinstein, R. (2002). Reaching higher: the power of expectations in schooling. Cambridge: Harvard University Press.

Wessler, S. (2003). The respectful school. Alexandria: Association for Supervision and Curriculum Development.

Wirt, F., \& Kirst, M. (2005). The political dynamics of American education. Richmond: McCutchan.

Wood, A. (2001). Basic writings of Kant. New York: Random House.

Zeichner, K. \& Liston, D. (1987). Teaching student teachers to reflect. Harvard Educational Review, 57 (1) 23-48.

Zeichner, K., \& Liston, D. (2014). Reflective teaching: an introduction. (2 ${ }^{\text {nd }}$ Ed.) New York: Routledge. 
Journeys toward Reflective Practice: How Engaging in National Board Certification

Influences Teacher Identities and Practices

\section{Appendix A}

Interview Sequence: Teacher Practices in Reflective Thinking

Interview 1: Exploring my participants' reflective practices before National Board Certification:

1. I'd like to begin by asking you some questions that provide an overview of your early years as a teacher... before you began the National Board Certification process.

a. Where did you teach?

b. What did you teach (what ages/grades, content)?

c. What was your school context like? Describe your administrator, colleagues, and professional development initiatives.

d. Who were your students? If possible, provide some general demographic information (race/ethnicity, SES, gender, etc.)

e. How would you describe your teaching in your first year?

f. How would you describe your teaching in the years before National Board Certification?

2. Now I'd like for you to think about your practice before you began the National Board Certification process. Please discuss those early years of teaching in terms of your own reflective practices. If you taught in more than one school, please reference the specific school (context) as you share your experiences.

Possible probing questions:

a. How did you identify the dilemmas you needed to reflect on and explore further?

b. How did you engage in identifying and exploring practices that might "resolve" your dilemmas? I will suggest that it may be helpful to select 2 or 3 dilemmas/students and reconstruct these experiences.

c. What supported or constrained your reflective practice?

3. Please describe how you were supported/mentored as you began your career in teaching. Possible probing questions:

a. Please describe some of your mentors and how your interactions with these mentors influenced your teaching and reflective practices.

b. Please describe how you collaborated with other teachers (to engage in reflection, improve your practice, understand your context... if teachers have worked in more than one context, ask them to specify the context that is relevant for their specific answer/stories).

4. Please describe some of the ways in which your particular context influenced your teaching, the ways in which you engaged in reflection, and/or the mentoring you received. 
Journeys toward Reflective Practice: How Engaging in National Board Certification Influences Teacher Identities and Practices

Possible probing questions: Depending on how the participant responds to the initial question, the probing questions will follow up on particular aspects of the context that are relevant to the experiences shared or that might not have been mentioned.

a. How did the [administrative structures, mentoring policies, workload, professional development (offered/required), diversity in the school, race/age/gender issues, family/personal issues] influence your teaching, the ways you engaged in reflection, and/or the mentoring you received?

5. What else do you think is important to share so that I understand your reflective practices prior to obtaining National Board Certification?

Interview 2: Exploring my participants' reflective practices during their National Board Certification process:

1. Please tell me a little about your school/classroom in which you were placed when you decided to begin the NBC process.

Possible probing questions:

a. Describe your school/classroom setting.

b. Describe your administrator and colleagues.

c. Describe the professional development offerings/initiatives/policies.

2. How/why did you make the decision to engage in the National Board Certification process?

Possible probing questions:

a. What were pivotal moments/people who influenced your decision to seek National Board Certification?

b. How did the contexts in which you were situated influence your decision to engage in the NBC process? (Refer specifically to contexts mentioned in interview \#1 as well as the contexts mentioned in the first warm up question suggested for Interview \#2)

Please provide me with a brief timeline of your experiences with the National Board Certification process. Please discuss the order in which you did the entries and why;

3. How did engaging in the National Board Certification process influence your teaching and your reflective practices? Participants should/might refer to their journal entries. Possible probing questions:

a. How did you identify, define, and resolve the problems of your practice?

b. In what ways did specific entries describe the nature of your reflective practice as you engaged in the NBC process?

c. In what ways did writing these entries influence your teaching?

d. In what ways did writing these entries influence your development as a reflective practitioner?

e. In what ways did writing these entries influence the perspective you used when considering your students and their families?

f. In what ways did writing these entries influence the perspective you used when considering your school wide community?

g. What other entries illustrate your experience of engaging in the National Board Certification process? 
Journeys toward Reflective Practice: How Engaging in National Board Certification Influences Teacher Identities and Practices

4. Please describe some of the ways in which the context(s) in which you were teaching and learning influenced (supported/constrained) your reflective practices, especially the ways in which reflection is defined by the NBC process.

5. What else might you share/do you think it's important to share so that I understand your reflective practices as you were engaged in the National Board Certification process?

Interview 3: Exploring my participants' reflective practices after obtaining National Board Certification:

1. What does National Board Certification mean to you?

2. Now I'd like for us to explore your experiences with teaching and reflective practice after you received National Board Certification. I'd like to begin by asking you some questions that provide an overview of your context(s) after you were certified.

a. Where did you teach?

b. What did you teach (what ages/grades, content)?

c. What was your school context like? Describe your administrator, colleagues, and professional development initiatives.

d. Who were your students? If possible, provide some general demographic information (race/ethnicity, SES, gender, etc.)

3. Please describe your reflective practices immediately after receiving National Board Certification. Please think in terms of your first year of teaching after receiving National Board Certification. Were you still teaching in the same school? Were there any external changes to the school context?

Possible probing questions:

a. Why did you decide to engage (or not engage) in particular reflective practices?

b. How did the context(s) in which you were situated influence your reflective practices? After participant responds, be sure to probe for contextual factors that were identified in Interviews 1 \& 2 for each participant.

c. How has your understanding of reflection and your reflective practices changed since National Board Certification? What has influenced/led to these changes (in understanding and/or practice)?

4. Please describe your current reflective practices.

Possible probing questions:

a. In what ways have you maintained, developed or transformed your reflective practices? Why has this occurred? Please describe how you engage in reflection independently and in collaboration with others.

b. How do your context(s) influence the ways in which you reflect?

5. Please discuss the goal setting process that is part of your teacher evaluation.

Possible probing questions:

a. How is engaging in this teacher evaluation process influenced by what you learned during your National Board Certification process?

b. How does engaging in this teacher evaluation process influence your reflective practices?

c. How does engaging in this teacher evaluation process influence your teaching? 
Journeys toward Reflective Practice: How Engaging in National Board Certification Influences Teacher Identities and Practices

d. How does engaging in this teacher evaluation process influence your students' learning?

6. What else do you think it's important to share so that I understand your reflective practices after you engaged in the National Board Certification process?

7. As you reflect on your National Board Certification experience, how does your context support/constrain your access to this process, as well as your experience in the process?

8. As you reflect on your National Board Certification experience, how does this NB process support/constrain your particular teaching practices?

9. As you reflect on your National Board Certification experience, how does this NB process support/constrain your particular reflective practices?

10. As you reflect on your National Board Certification experience, how does this NB process support/constrain your decision making practices? After participant responds, be sure to probe for contextual factors that were identified in Interviews $1 \& 2$ for each participant.

11. Please share any other insights you have related to your reflection and the National Board Certification process that might inform my study.

Questions for Video Exploration

1. Please tell me a little about the video clip we are going to view.

2. As we watch the video clip, please stop it at critical points you'd like to discuss further, when you can share what you were thinking and how your thinking was/is informed by your reflection in and on action.

3. In what ways did using video influence your reflective practices and therefore your teaching?

4. How did the context(s) in which you were situated influence your use of video for reflection, for learning to teach?

5. How do you currently use video for reflection?

You certified. Then what?

Now what?

How have you maintained and/or developed your reflective thinking strategies?

Let's watch your video.

Please describe exactly what you are thinking as you view this segment.

Tell me more.

Is there anything you would change if you retaught this segment today? Why or why not?

Please tell me about your journals.

Please tell me more.

What else might you choose to share? 
Journeys toward Reflective Practice: How Engaging in National Board Certification Influences Teacher Identities and Practices

\section{Appendix B}

Invitation Letter 
WestVirginiaUniversity.

COLLEGE OF EDUCATION AND HUMAN SERVICES

June 6,2015

Dear Participant,

This letter is a request for you to take part in a research project that explores the strategies used by National Board Certified Teachers as they examine and resolve problems of professional teaching practices related to student learning. This project is being conducted by MaryLu Hutchins, a doctoral candidate, as partial fulfillment of requirements for an Ed.D. in Educational Leadership. She will be supervised by Dr. Sharon Hayes (sharon.hayes@mail.wvu.edu), an associate professor in the College of Education and Human Services. Your participation in this project is greatly appreciated and will entail three interviews. I will also collect samples of your journals and goals related to teaching, selected lesson plan samples, and writing samples (not submissions) related to your National Board work.

Each of the interviews will be audio-recorded. The audio recording device will be kept in a locked box after each session and I will deliver it to a transcriptionist, who will transcribe the interviews verbatim. The transcriptionist will notify me via email when the transcriptions are complete and I will retrieve the audio recording device from the transcriptionist. The electronic transcripts will be sent to me via email and will be stored on a password-protected computer. All identifiers related to the participants will be removed from the transcripts. Any hard copies I make of the transcripts will be stored in a locked box, in a locked office. These hard copies will be shredded once my dissertation is complete. In addition, all identifiers from your journals, lesson plans, and writing samples will be removed.

As a participating teacher, your information and any information about your students will not be identified in any reports of this research. Further, in reporting any data, no students, teachers, or schools will be identified. All documents and audiotapes will be stored in a locked area and destroyed as soon as is possible after research is completed and finalized. In any publications that result from this research, neither your name nor any information from which you might be identified will be published without your specific consent.

Participation in this study is voluntary. You are free to withdraw your consent to participate in this study at any time. Refusal to participate or your withdrawal from the project will have no negative impact or penalty. In the event new information becomes available that may affect your willingness to participate in this study, you will be given this information so you can make an informed decision about whether or not to continue your participation. You may ask questions about the research and interviews and expect clear answers concerning any areas you did not understand. You may choose to be non-responsive to any question posed at any time. West Virginia University's Institutional Review Board acknowledgement of this project is on file.

I hope that you will participate in this research project, as it could be beneficial in understanding how teachers develop as reflective practitioners who can learn from studying their teaching. 
Journeys toward Reflective Practice: How Engaging in National Board Certification Influences Teacher Identities and Practices

Should you have any questions about this letter or the research project, please feel free to contact MaryLu Hutchins at (304) 280-2043 or by email at mlhutchi@k12.wv.us.

Thank you for your time and help with this project.

Most sincerely yours,

MaryLu Hutchins 
Journeys toward Reflective Practice: How Engaging in National Board Certification

Influences Teacher Identities and Practices

\section{Appendix C}

Margaret Journal

April, 2015

\section{Surface area of rectangular prisms}

I understand that many of my Math 8 students are progressing towards being abstract thinkers, they are still very concrete in their learning. I began the year with Hands On Equations, where students used a balance beam (balanced equation) with dice and pawns representing numerals and variables respectively. Using this system, students must physically remove a variable or number from both sides of an equation.

When we began the study of surface area, I divided the students into groups of two or three, gave them 3-D shapes representing rectangular prisms that unfold and lay flat and $\mathrm{cm}$ cubes. They had to answer the following questions:

1. What shapes do you see?

2. How many of each shape do you see?

3. How would you find the area of these shapes?

4. What would you need to do to find total surface area?

They found this to be fairly easy to determine and had a good understanding of the process. The next day, we discussed a mathematical and systematic way to determine surface area of a rectangular prism. They had a good understanding of the process because of their previous hands on experience.

\section{Surface area of cylinders}

Using the same type of 3-D shapes and the same cubes, students now had to answer the same questions but they now also need to know how to find the area of a circle. They did well with this because they could physically touch the shapes or visualize what they looked like.

May, 2015

\section{Volume of rectangular prisms}

Using the 3-D shapes and cm cubes, students had to answer the following questions:

1. What shapes do you see?

2. If you had to fill the rectangular prism with cubes, how would you begin? (cover the bottom layer)

3. If you don't have enough cubes to fill the rectangular prism, how can you calculate how many cubes it will take to fill this shape?

4. Can you calculate the number of cubes it will take to fill this shape?

Eli kept repeating, "You just find the volume." He is very bright and knows the formula for volume of a rectangular prism but is unable to tell me how to prove it. He was very frustrated with this process because he just wanted to regurgitate the formula. Given their prior experience, I thought the process of finding volume of a rectangular prism would be evident to them but it was not. They can all say the formula for volume but they use the same formula for every shape because they don't understand the process. 
Journeys toward Reflective Practice: How Engaging in National Board Certification

Influences Teacher Identities and Practices

\section{Volume of cylinders}

This was the most difficult for them to put into words and actions. Using the same questions as above, and drawing on prior experience, students knew that the first step was to cover the circle shape of the cylinder. Several students told me that you just need length times width times height to find volume. When I asked them to show me the length and width of the cylinder, they were stumped. They struggled with this whole process and then said the straight edges of the cubes were keeping them from determining the accurate measurement of the circular shape. I thought they would immediately go to their knowledge of formulas for area of a circle but they did not. I also thought this would take less than one class period. Watching them debate and try various means of making the cubes fit into the cylinder, convinced me that this was worth extending the lesson. It was not until I asked some guided questions on day 2 that some students began to find the diameter of the circle, converted to radius and then found the area of the circle. After some discussions with me, they had decided it was difficult to accurately determine radius (where is the middle of the circle, how do you know this is exactly right, etc.) so they decided to find the diameter and cut that in half. Once they determined they could calculate the area of the circle, they were able to draw on previous knowledge about how the number of layers in the shape determined the height and they multiplied the area of the circle by the height of the cylinder. This was much more difficult than I had envisioned and part of me wanted to hurry them through the process because we had so much more to do. However, I'm glad I didn't do that. I listened to their discussions and watched their interactions and decided that this was a much more valuable way to spend their time. Reflecting back on the Hands On Equations at the beginning of the year, I knew that these students would benefit from the extra time and the discussions that occurred. The understanding they developed would allow us to advance to more abstract thinking in future lessons. This would have been very frustrating for all of us and a waste of time if I had begun with the abstract or rushed them through this process. 
Journeys toward Reflective Practice: How Engaging in National Board Certification Influences Teacher Identities and Practices

\section{Appendix D}

Margaret

Draft of Professional Growth Experience National Board Recertification Document PGE 2-Promoting the study of mathematics

\section{Need}

Response to identified need

Remain current

Interacting with colleagues

Pedagogical skills

Content knowledge

I have been active in promoting the study of mathematics on many levels. Several years ago I

became aware that my students were not as engaged in the learning process as they could have been, and the traditional approach I had been using was no longer effective. In order to provide engaging and meaningful instruction for my students, I needed to refresh my pedagogical skills and the delivery of the instructional content. About that same time, I was introduced to Standards-based mathematics instruction and after researching its impact on student learning, I elected to become involved in a two year training program. This training included collaborating with colleagues in developing and critiquing grade level appropriate lessons. Integrating standards-based instruction into my classroom was a big change for me and required a concentrated effort on my part to evaluate the effectiveness of my instruction, modify my planning and instruction, and adjust my questioning techniques. My experience with standardsbased instruction concurred with the research I had read. My students showed a better understanding of mathematics, were able to have appropriate mathematical discussions, and improved their performance on formative and summative assessments. Based on this 
Journeys toward Reflective Practice: How Engaging in National Board Certification Influences Teacher Identities and Practices

information, I volunteered to pilot standards-based instruction in my school district. During that time I was frequently asked to defend my practice because this was an unfamiliar approach to instruction. Backed by research and student performance, I volunteered to open my classroom to observers and allowed them to witness the effectiveness of this instruction first hand. While seventy percent of the families in my school fall below federal poverty guidelines why does poverty matter? and we usually average one gifted student per year, my students consistently performed very well using standards-based instruction. After three years of proven success and several discussions about the research behind this, the assistant superintendent mandated that all schools adopt standards-based textbooks. I volunteered to serve on the textbook adoption committee as a means of presenting and defending this type of instruction. In order to assist with the transition, I was asked to conduct workshops for elementary school teachers to demonstrate how standards-based lessons could be taught and to allay the teachers' fears of the unknown. I was also asked to present at the Principal's Institute which was attended by all principals in the school system as well as central office administrators. I taught a mathematics lesson to my audience of administrators and showed them a video of my classroom. I demonstrated the classroom climate they should find when they visit standards-based classrooms and an approach to instruction that doesn't only include the silent completion of worksheets. Due to the transient nature of my school's population, several of the administrators recognized former students who had previously experienced difficulty in the classroom. It spoke volumes for them to see these students actively engaged and conducting appropriate mathematical discussions.

As part of my ongoing commitment to the promotion of the study of mathematics, I also volunteered to participate in several professional learning communities. I was a participant and a facilitator for The Advanced Placement (AP) Math Study Group. The purpose of this group was 
Journeys toward Reflective Practice: How Engaging in National Board Certification Influences Teacher Identities and Practices

to encourage students to take more advanced mathematics classes at the high school level and to discuss and implement changes at the middle school level which would assist students in meeting this goal. I was a participant and facilitator for Articulation and Collaboration for Math Teachers Grades 6-12 which was a follow-up to the AP Study Group. We took the many reoccurring topics that spiraled from middle school to high school and establish the connections.

demonstrated how a topic was introduced and taught in middle school and this was followed up

by a high school teacher who showed the next steps at their instructional level. Establishing these academic and professional connections was invaluable to all involved. It gave the high school teachers a chance to see the foundation of their students' instruction and it demonstrated to me what our students needed to learn and understand in order to be successful at the next level. I am currently facilitating a year-long series of workshops entitled Next Generation CSO's (Content Standards and Objectives) for Middle School Math Teachers.careful using CSO and COmmon COre...there may be a bias Our goal is to prepare for the Common Core standards and to share successful teaching strategies within our classrooms.

On another level, I have had the opportunity to influence the study and instruction of mathematics with pre-service teachers. After achieving National Board Certification I served as an adjunct professor for a local university for five years where I taught Diagnostics and Corrections in Mathematics. The main focus of this course was the different learning styles of students and how to best incorporate that information into instruction by using a variety of instructional strategies. I incorporated the use of manipulatives, literature and technology into mathematics instruction. I have been asked to teach a similar course at another local university.

The first year I arrived at my current school, I realized that all the other middle schools were involved in mathematics competitions with their students. I wanted our students to have this 
Journeys toward Reflective Practice: How Engaging in National Board Certification Influences Teacher Identities and Practices

same opportunity and quickly volunteered to be the coach. This involves giving up my time for thirty minutes daily in order to teach another class for grades six through eight and attending meetings and competitions after school hours. I have been doing this for twelve years and I am delighted that so many students are involved. Their eagerness to participate is directly related to their experiences in my math classes and is a testament to its success.

The most important thing that I do to promote mathematics involves my students. The classroom climate is relaxed but controlled and students learn they can always ask questions and openly discuss their mathematical thinking. The climate demands respect across the board and encourages students to think independently and to work collaboratively. I encourage my students to have mathematical discussions and to be prepared to defend their thinking. This prepares them for mathematical success at the next level as well as future work environments. 
Journeys toward Reflective Practice: How Engaging in National Board Certification Influences Teacher Identities and Practices

\section{Appendix E}

Ethan Notes Document 1 
)

$12 / 5$ and $12 / 8$ Friday and Mondby

Ap Biology

- Journol Entry 36

- Chpt. 14

complete priblenas

- Catechol- cenetrylust-sime as

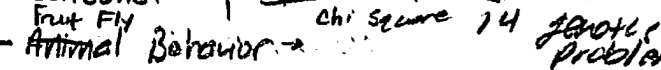

- Just Stress.

HW: Reit of 14 RC- Jurt E ESobsoy if

Biology

- Dourvel Entry 36

- Test Corrections

- Intro to kendalion Gexetics.

Hw: P. 283-284 1-5, 12, 13, 18, 24-2

$12 / 9$ and 12/10 Tuesday and wedhescky

(2) Jourral Entry $37 /$ why were the tolltall - Journd Entry 37

Q Catechol / Fruit Fly

(5) Humen Pedigree Geneties

(3) Exceptions to Mendel'slaws.

- Punnett Square Practice

- Ree bup Geneties fert 1

HW: Read/stirely 11.3

0 - Just Stress

(4) Molecular Inhantence of Bloodyraps

Hw: Study: Chpt. 14 Quiz. Next Cless

complete itssertsment ap.

Catechol of Fuit Fly

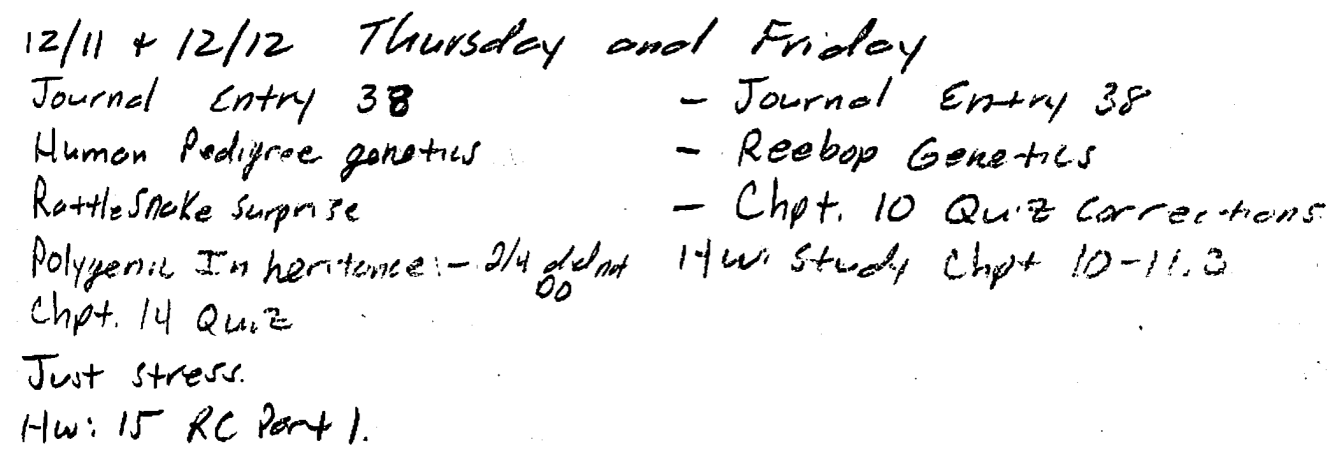


Journeys toward Reflective Practice: How Engaging in National Board Certification Influences Teacher Identities and Practices

\section{Appendix F}

Ethan Notes 2 
Journeys toward Reflective Practice: How Engaging in National Board Certification Influences Teacher Identities and Practices

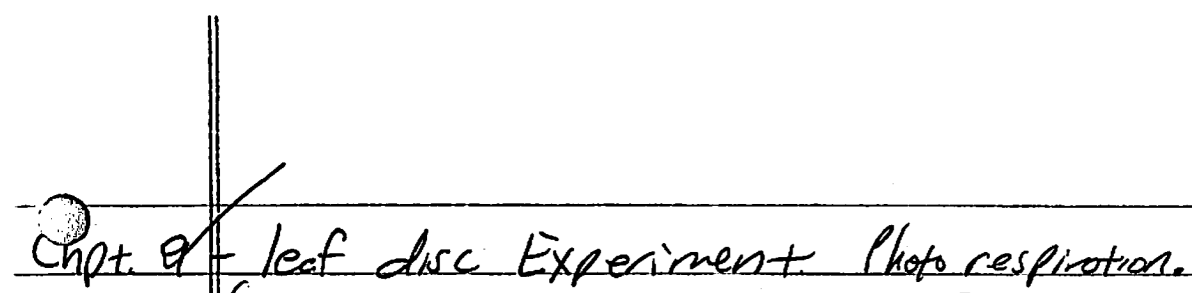

(took for Respereaton Stu fE)

chat loft limits of cell size-

Lnitoris phase ID -Biology Project, online.

chat Ill Reebops:- Make Bebops Higher w/ Calculations

- Inherited Traits lab from manual.-chpt.ll

1 Poo Bead lab- with pictures " Narrated P pt.

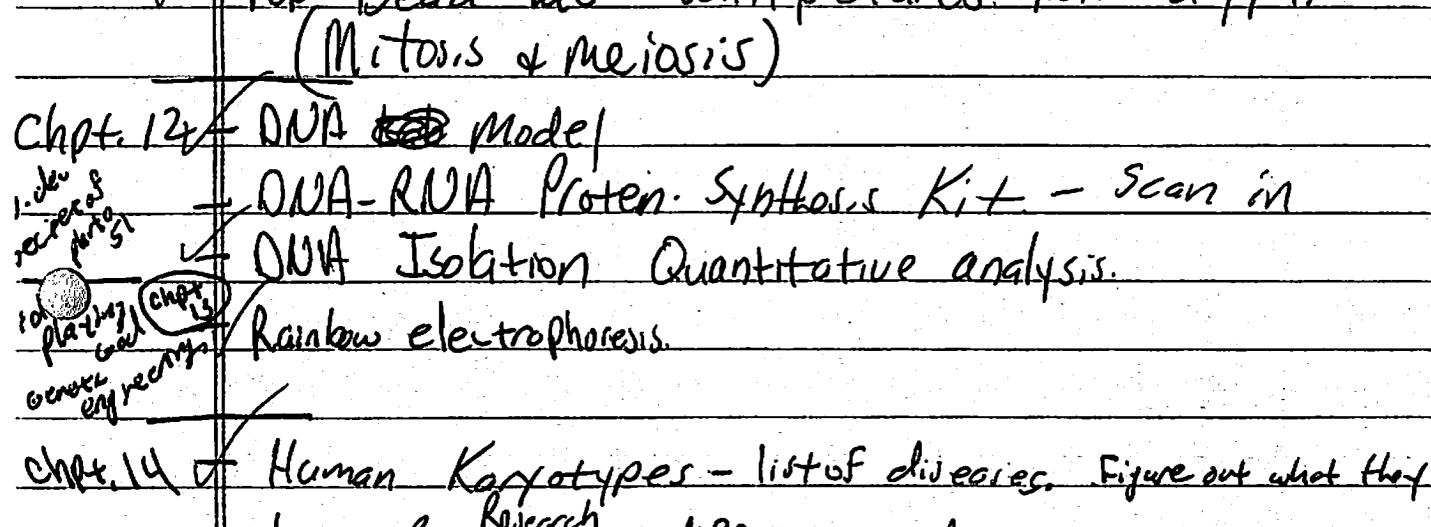
have, frowerecten different diseases.

* Pedigree Tech Steps.

- Comas (Pros a cons)

that 154 Dacwinv/s Lamarck

- Lab manual - Bob has activity bose for this.

- Adaptation lab-based on p. 131 Man al A Better mops

- Natural selection Simulation - Polkas lotas

Shpt, 16 - Modeling Not. Selection From manual B p. 123

tonetic Drift

- Modeling a Gere loot Manual AP. 137 -Reduce \#s Making graphs etc

290 
Journeys toward Reflective Practice: How Engaging in National Board Certification Influences Teacher Identities and Practices

\title{
Appendix G
}

\author{
Gretchen Reflection Document
}




\section{Journeys toward Reflective Practice: How Engaging in National Board Certification Influences Teacher Identities and Practices}

\section{Weekly Lesson Plan for}

\section{Adams, English 10, Dec. 7 - Dec. 11, 2015, Week 17 First Semester}

English / Language Arts

1. Students will be given 15 minutes to complete the questions from the "New Colossus: Emma Lazarus and the New Immigrant Experience." We will construct good responses together on the board using their त) writings. 2. Students will

T) read "Coming to America: Ellis Island and New York City." Learning Goal: Cite evidence in the text that o reveals conflicting attitudes toward American immigration in the late 1800 s and early 1900 s. Students $\Sigma$ will have four questions to answer in writing. What they do not complete in class will be assigned as homework for Wednesday.

\section{English / Language Arts}

Technology: Students will access NewsELA to read and respond to "U.S. resistance to Syrian refugees sparks comparisons

to WWII Jews' plight." They will read and respond at the 1010 lexile level. This will take the entire period.

If time is available, finish reading "Coming to America." article and give time to do questions.

\section{English / Language Arts}

Students will be given 10 minutes to finish their homework from Monday. We will construct best practice answers in class. Assignments will be efllected for a completion grade.

Students will read "A Farewell to Manzanar." This will take two days to read.

Did not do. Instead, read and analyzed 3 President Obama's address to the nation on Dec. F. 2015

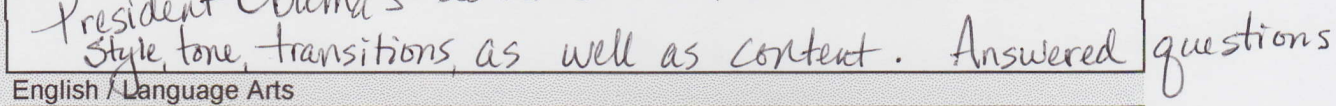

Students will finish reading "A Farewell to Manizangr." If we complete it before the class ends, the students will begin responding to the questions axthe end of the memoir. there hefcalls for of ban

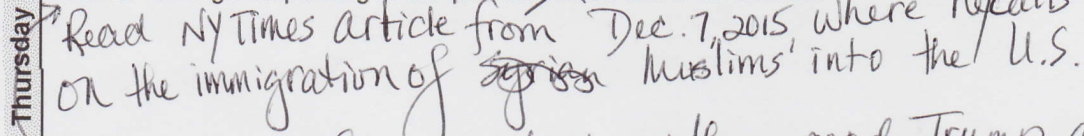
Continued from yesterday then read Trump article Compared writing purpose, style, audience.

\section{English / Language Alts}

Students will complete the activities associated with "A Farewell to Manzanar." Whole group: students will construct responses for the summaning questions.

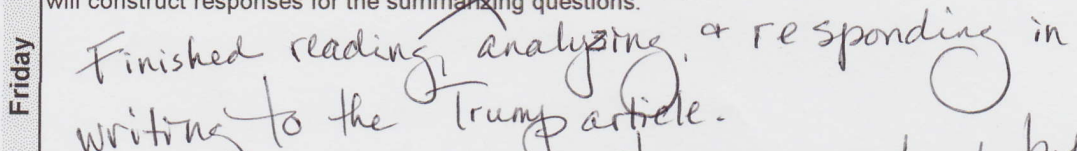
writing to the Irump artiele. cllad a whole sroup Cliscussion about both irchase licenses use only by one teacher - httpX/TeachersPayTeachers/Store/Janets-Tools-for-Schools @ Janet Beninco Compared the concepts to the "Coming to American article.

Interesting mini-unit. Good Class involvement. 